\title{
TRANSPORT PROPERTIES OF FISSION PRODUCT VAPORS
}

by

K. H. Im and R. K. Ahluwalia

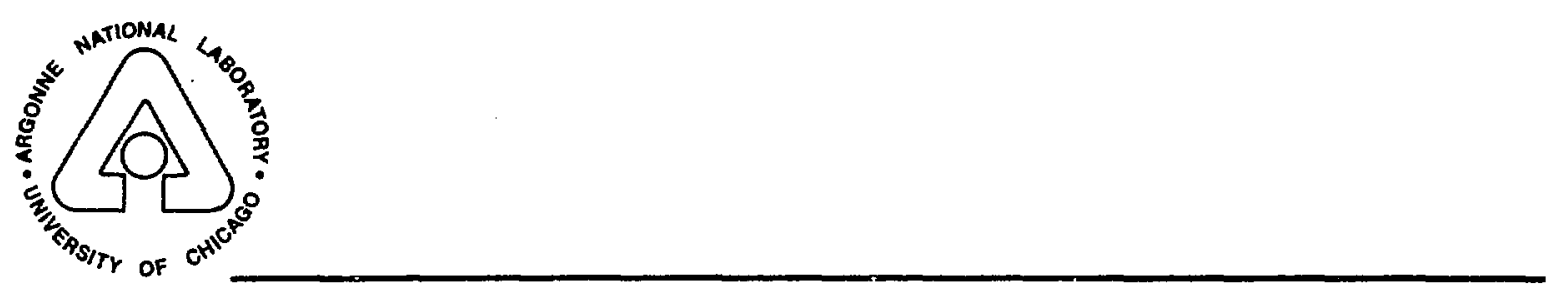

ARGONNE NATIONAL LABORATORY, ARGONNE, ILLINO'S

Operated by THE UNIVERSITY OF CHICAGO for the U. S. DEPARTMENT OF ENERGY under Contract W-31-109-Eng-38 
ANL/ENG/TM-01

TRANSPORT PROPERTIES OF FISSION PRODUCT VAPORS

by

K. H. Im and R. K. Ahluwalia

Engineering Division

Argonne National Laboratory

9700 South Cass Avenue

Argonne, Illinois 60439

July 1983

DISCLAIMER

This report was prepared as an account of work sponsored by an agency of the United States Government. Neither the United Siates Government nor any agency thereof, nor any of their employees, makes any warranty, express or implied, or assumes any legal liability or responsibility for the accuracy, completeness, or usefulness of any information, apparatus, product, or process disclosed, or represet is that its use would not infringe privately owned rights. Reference herein to any specific commercial product, process, or service by trade name, trademark, manufacturer, or otherwise does not necessarily constitute or imply its endorsement, recommendation, or favoring by the United States Government or any agency thereof. The views and opinions of authors expressed herein do not necessarily state or reflect those of the United States Government or any agency thereof.

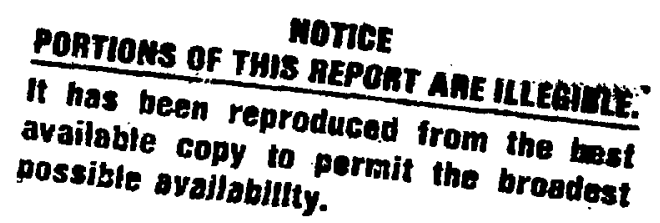


TABLE OF CONTENTS

Page No.

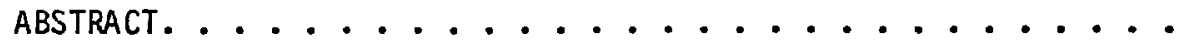

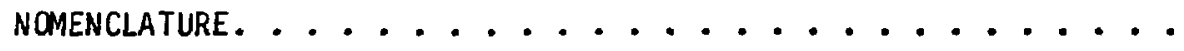

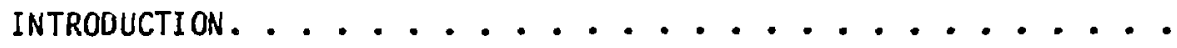

KINETIC THEORY FORMULATION OF TRANSPORT COEFFICIENTS. . . . .

1. Viscosity of Gaseous Mixture..............

2. Thermal Conductivity of Gaseous Mixture .........

3. Diffusivity of Steam and Hydrogen ...........

4. Diffusivity of Fission Product Vapors ..........

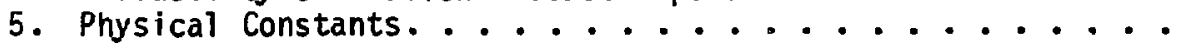

RESULTS AND DISCUSSION. ........................... 10

CONCLUUING REMARKS.................................. 14

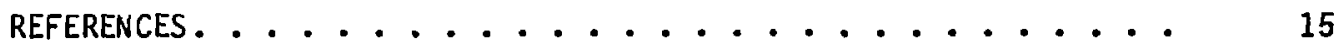

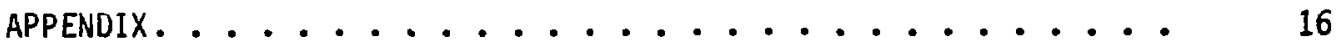




\section{LIST OF TABLES}

Table 1 Reduced Collision Integrals $\Omega^{*}$ for Calculating the Transport Coefficients for the Lennard-Jones (6-12) Potential

Table 2 Boiling Points and Densities

Table 3 Lennard-Jones Parameters

Table 4 Viscosity and Conductivity of Hydrogen

Table 5 Viscosity and Conductivity of Steam

Table 6 Coefficient of Diffusion for $\mathrm{H}_{2} / \mathrm{H}_{2} \mathrm{O}$ Mixture 


\title{
TRANSPORT PROPERTIES OF FISSION PRODUCT VAPORS
}

\author{
K. H. Im and R. K. Ahluwalia \\ Engineering Division, Argonne National Laboratory
}

\section{ABSTRACT}

Kinetic theory of gases is used to calculate the transport properties of fission product vapors in a steam and hydrogen environment. Provided in Labular form is diffusivity of steam and hydrogen, viscosity and thermal conductivity of the gaseous mixture, and diffusivity of cesium iodide, cesium hydroxide, diatomic tellurium and tellurium dioxide. These transport properties are required in determining the thermal-hydraulics of and fission product transport in light water reactors.

\section{NOMENCLATURE}

$C_{v} \quad$ specific heat at constant volume

D diffusivity

$k \quad$ Boltzmann constant

$M \quad$ molecular weight

$\mathrm{N}_{\mathrm{A}} \quad$ Avogadros number

$P \quad$ pressure

$R \quad$ gas constant

$T$ gas temperature

$T_{b}$ boiling point

$x \quad$ mole fraction

$\rho_{\text {sol density of solid }}$

$\lambda$ thermal conductivity

$\mu \quad$ viscosity

$\sigma \quad$ molecular size parameter

$\varepsilon \quad$ potential energy parameter

$\phi \quad$ potential energy 
INTRODUCTION.

Under severe accident conditions in light water reactors, superheated steam can react with zircaloy cladding of the fuel to produce hydrogen, and the fuel may be breached to release fission product vapors. Recently, considerable interest has arisen on the issues of recease and transport of fission products in the environment (probably reducing) of the primary system. The fission products of intermediate volatility belonging to cesium, iodine and tellurium families are of particular interest. At issue are what fraction of the released fission products can condense to form aerosols in the primary system, what fraction can condense on the cooled reactor walls, and what fraction of the aerosols formed is retained in the primary system. In order to address these issues, some knowledge of the transport properties of the fission products is required. The transport properties that play a role in determining the disposition of the fission product vapors and the thermalhydraulic conditions of the reactor are the thermal conductivity and viscosity of the gaseous mixture, diffusivity of steam and hydrogen, and the diffusivity of the fission product vapors.

Depending on whether the reactor environment is oxidizing or reducing, cesium, iodine and tellurium vapors can be present as different species, and condense out as $\mathrm{Cs}, \mathrm{CsOH}, \mathrm{Te}_{2}$ or $\mathrm{TeO}_{2}$ upon the gas being cooled below the dew point temperatures of these species. Under most accident conditions, the fission product vapors, on a molar basis, are present in trace amounts. Therefore, for the purpose of calculating the transport properties, it suffices to treat the gaseous mixture as being only composed of steam, hydrogen, $\mathrm{CsI}, \mathrm{CsOH}, \mathrm{Te}_{2}$ and $\mathrm{Te}_{2}$ and ignore other trace species whose transport behavior is not of any particular interest.

\section{KINETIC THEORY FORMULATION OF TRANSPORT COEFFICIENTS}

As shown in the textbook by Hirschfelder, Curtiss and Bird [1], the transport coefficients may be calculated from the kinetic theory of gases and expressed in terms of a set of reduced integrals $\Omega(\ell, s)^{*}$, the molecular weights $M_{i}$ and the mole fractions $x_{i}$. For all practical purposes, the first approximation to the transport coefficients is sufficiently accurate. For 
generality the Lennard-Jones (6-12) potential may be used to specify the intermolecular potential energy function:

$$
\phi(r)=4 \varepsilon\left[(\sigma / r)^{12}-(\sigma / r)^{6}\right]
$$

For polar molecules, an additional term should be added to the Lennard-Jones energy function to account for the electrostatic interaction of the dipoles.

For the Lennard-Jones potential, Table 1 gives the collision integrals

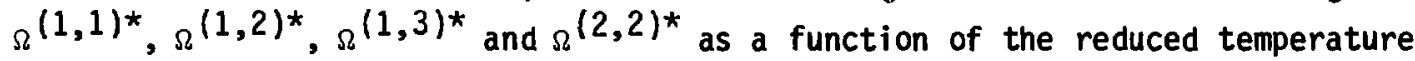
$\left(T^{*}=k T / \varepsilon\right)$. In the transport coefficient formulas given below, three combinations of the integrals occur frequently and have been given special symbols.

Table I

Reduced Collision Integrals $\Omega(l, s)^{*}$ for Calculating the Transport Coefficients for the Lennard-Jones (6-12) Potential

\begin{tabular}{lllll}
\hline$T^{*}$ & $\Omega(1,1)^{*}$ & $s i(1,2)^{*}$ & $\Omega(1,3) *$ & $(2,2)^{*}$ \\
\hline 0.30 & 2.662 & 2.256 & 1.962 & 2.785 \\
0.40 & 2.318 & 1.931 & 1.663 & 2.492 \\
0.50 & 2.066 & 1.705 & 1.468 & 2.257 \\
0.60 & 1.877 & 1.543 & 1.336 & 2.065 \\
0.70 & 1.729 & 1.423 & 1.242 & 1.908 \\
0.80 & 1.612 & 1.332 & 1.172 & 1.780 \\
0.90 & 1.517 & 1.261 & 1.119 & 1.675 \\
1.00 & 1.439 & 1.204 & 1.076 & 1.587 \\
1.10 & 1.375 & 1.157 & 1.041 & 1.514 \\
1.20 & 1.320 & 1.119 & 1.013 & 1.452 \\
1.30 & 1.273 & 1.086 & 0.9887 & 1.399 \\
1.40 & 1.233 & 1.059 & 0.9680 & 1.353 \\
1.50 & 1.198 & 1.034 & 0.9502 & 1.314 \\
1.60 & 1.167 & 1.013 & 0.9345 & 1.279 \\
1.70 & 1.140 & 0.9947 & 0.9205 & 1.248 \\
1.80 & 1.116 & 0.9780 & 0.9082 & 1.221 \\
1.90 & 1.094 & 0.9633 & 0.8968 & 1.197 \\
2.00 & 1.075 & 0.9500 & 0.8867 & 1.175 \\
2.10 & 1.057 & 0.9380 & 0.8775 & 1.156 \\
2.20 & 1.041 & 0.9267 & 0.8688 & 1.138 \\
2.30 & 1.026 & 0.9167 & 0.8612 & 1.122 \\
2.40 & 1.012 & 0.9073 & 0.8538 & 1.107 \\
2.50 & 0.9996 & 0.8987 & 0.8470 & 1.093 \\
2.60 & 0.9878 & 0.8907 & 0.8407 & 1.081 \\
& & & &
\end{tabular}




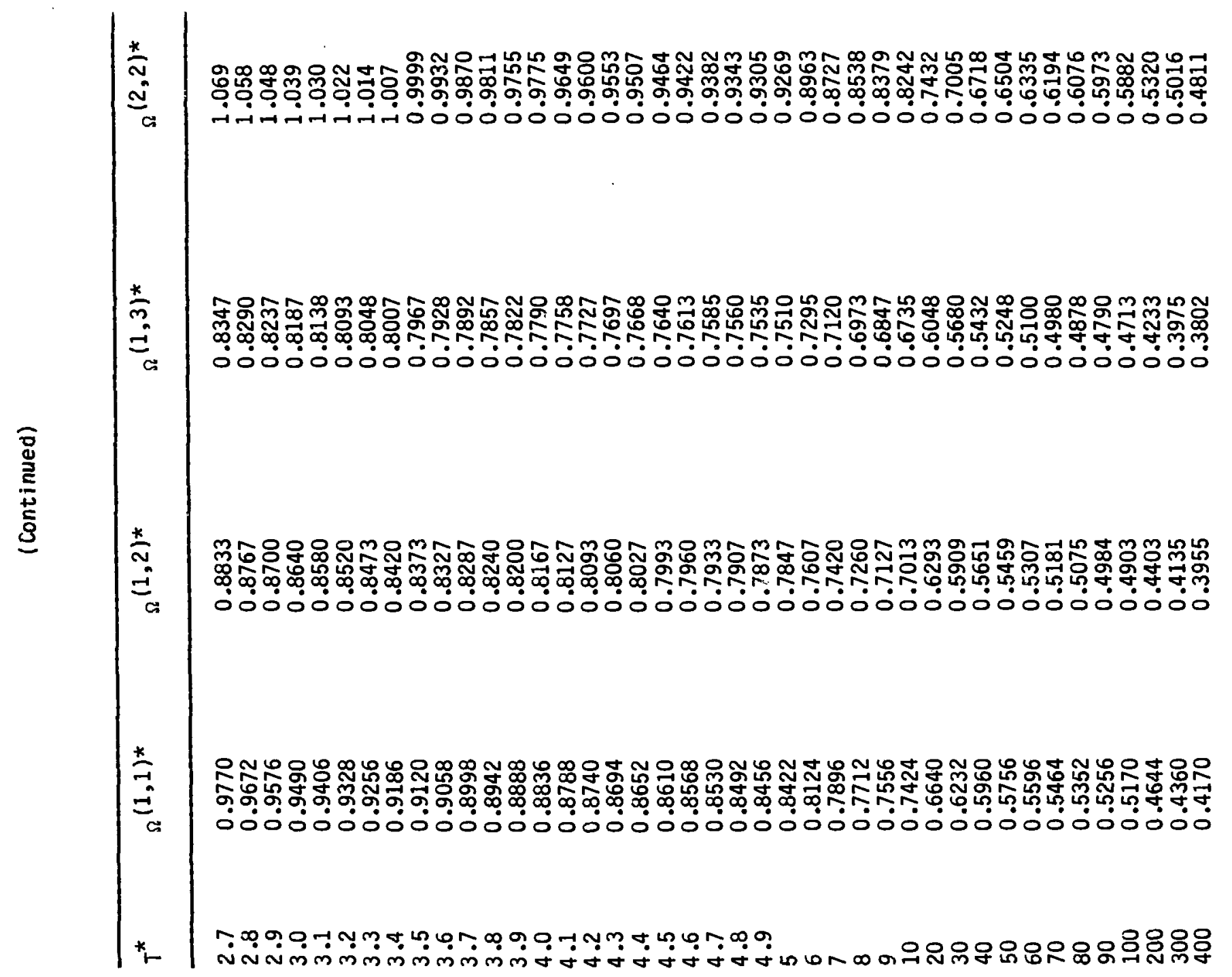




$$
\begin{aligned}
& A^{*}=\Omega_{\Omega}(2,2)^{\star / \Omega}(1,1)^{\star} \\
& B^{\star}=\left(5 \Omega(1,2)^{\star}-4 \Omega(1,3)^{\star}\right) / \Omega(1,1)^{\star} \\
& C^{\star}=\Omega_{\Omega}(1,2)^{\star} / \Omega(1,1)^{\star}
\end{aligned}
$$

Viscosity of Gaseous Mixture

The calculation of the viscosity of the gaseous mixture can be simplified by recognizing that for most accident conditions, the fission product vapors, on a molar basis, constitute trace species. Therefore, the gaseous mixture can be regarded as a binary mixture of $\mathrm{H}_{2} \mathrm{O}$ and $\mathrm{H}_{2}$. For a binary mixture of species 1 and 2 , to a first approximation, the mixture viscosity is given by the following set of equations.

$$
\begin{aligned}
& \frac{1}{\mu}=\frac{x_{\mu}+Y_{\mu}}{1+Z_{\mu}} \\
& x_{\mu}=\frac{x_{1}^{2}}{\mu_{1}}+\frac{2 x_{1} x_{2}}{\mu_{12}}+\frac{x_{2}^{2}}{\mu_{2}} \\
& y_{\mu}=\frac{3}{5} A_{12}^{*}\left\{\frac{x_{1}^{2}}{\mu_{1}}\left(\frac{M_{1}}{\mu_{2}}\right)+\frac{2 x_{1} x_{2}}{\mu_{12}}\left(\frac{\left(M_{1}+M_{2}\right)^{2}}{4 M_{1} M_{2}}\right)\left(\frac{\mu_{12}^{2}}{\mu_{1} \mu_{2}}\right)+\frac{x_{2}^{2}}{\mu_{2}}\left(\frac{M_{2}}{M_{1}}\right)\right\} \\
& Z_{\mu}=\frac{3}{5} A_{12}^{*}\left\{x_{1}^{2}\left(\frac{M_{1}}{M_{2}}\right)+2 x_{1} x_{2}\left[\left(\frac{\left(M_{1}+M_{2}\right)^{2}}{4 M_{1} M_{2}}\right)\left(\frac{\mu_{12}}{\mu_{1}}+\frac{\mu_{12}}{\mu_{2}}\right)-?\right]+x_{2}^{2}\left(\frac{M_{2}}{M_{1}}\right)\right\}
\end{aligned}
$$

In the foregoing equations, $\mu_{1}$ ar. $\mu_{2}$ are the viscosities of the pure gaseous species 1 and 2 , and $\mu_{12}$ is the viscosity of a hypot'igtical pure substance, the molecules of which have a molecular weight $2 M_{1} M_{2} /\left(M_{1}+M_{2}\right)$ and interact according to a potential curve specified by the interaction paraineters $\sigma_{12}$ and $\varepsilon_{12}$.

$$
u_{12}=\frac{5}{16 N_{A}}\left(\frac{\sqrt{2 \pi M_{1} M_{2} R T / 7 M_{1}+M_{2} T}}{\pi \sigma_{12}^{2} \Omega_{12}^{(2,2)^{\star}}\left(T_{12}^{\star}\right)}\right)
$$




$$
\begin{aligned}
& \sigma_{12}=\frac{1}{2}\left(\sigma_{1}+\sigma_{2}\right) \\
& \varepsilon_{12}=\left(\varepsilon_{1} \varepsilon_{2}\right)^{1 / 2}
\end{aligned}
$$

Thermal Conductivity of Gaseous Mixture

For reasons given in the last section, the coefficient of thermal conductivity of the gaseous mixture can be calculated by regarding the gas to be a binary mixture of $\mathrm{H}_{2} \mathrm{O}$ and $\mathrm{H}_{2}$. The method of calculating the conductivity of a mixture of polyatomic gases recommended in Ref. 1 and adopted here is an empirical one. The first step of the method consists of calculating the conductivity by treating the molecules as effectively monatomic. The conductivity of a binary mixture of monatomic gases is given by the following set of equations.

$$
\begin{aligned}
& \frac{1}{\lambda_{\text {mon }}}=\frac{x_{\lambda}+y_{\lambda}}{1+\sum_{\lambda}} \\
& x_{\lambda}=\frac{x_{1}^{2}}{\lambda_{1}}+\frac{2 x_{1} x_{2}}{\lambda_{12}}+\frac{x_{2}^{2}}{\lambda_{2}} \\
& y_{\lambda}=\frac{x_{1}^{2}}{\lambda_{1}} u^{(1)}+\frac{2 x_{1} x_{2}}{\lambda_{12}} u^{(Y)}+\frac{x_{2}^{2}}{\lambda_{2}} u^{(2)} \\
& z_{\lambda}=x_{1}^{2} u^{(1)}+2 x_{1} x_{2} u^{(2)}+x_{2}^{2} u^{(2)} \\
& u^{(1)}=\frac{4}{15} A_{12}^{*}-\frac{1}{12}\left(\frac{12}{5} B_{12}^{*}+1\right) \frac{M_{1}}{M_{2}}+\frac{1}{2} \frac{\left(M_{1}-M_{2}\right)^{2}}{M_{1} M_{2}} \\
& u^{(2)}=\frac{4}{15} A_{12}^{*}-\frac{1}{12}\left(\frac{12}{5} B_{12}^{*}+1\right) \frac{M_{2}}{M_{1}}+\frac{1}{2} \frac{\left(M_{2}-M_{1}\right)^{2}}{M_{1} M_{2}} \\
& u^{(Y)}=\frac{4}{15} A_{12}^{*}\left(\frac{\left(M_{1}+M_{2}\right)^{2}}{4 M_{1} M_{2}} \frac{\lambda_{12}^{2}}{\lambda_{1} \lambda_{2}}-\frac{1}{12}\left(\frac{12}{5} B_{12}^{*}+1\right)\right.
\end{aligned}
$$




$$
\begin{gathered}
-\frac{5}{32 A_{12}^{*}}\left(\frac{12}{5} B_{12}^{*}-5\right) \frac{\left(M_{1}-M_{2}\right)^{2}}{M_{1} M_{2}} \\
u^{(Z)}=\frac{4}{15} A_{12}^{*}\left[\left(\frac{\left(M_{1}+M_{2}\right)^{2}}{4 M_{1} M_{2}}\right)\left(\frac{\lambda_{12}}{\lambda_{1}}+\frac{\lambda_{12}}{\lambda_{2}}\right)-1\right]-\frac{1}{12}\left(\frac{12}{5} B_{12}^{*}+1\right)
\end{gathered}
$$

In the foregoing equations, the quantity $\lambda_{12}$ is defined in a manner analogous to ${ }^{\mu} 12 \cdot$

$$
\lambda_{12}=\frac{75}{64} k\left(\frac{\sqrt{\left(M_{1}+M_{2}\right) \pi R T / 2 M_{1} M_{2}}}{\pi \sigma_{12}^{2} \Omega_{12}^{(2,2)^{\star}}\left(T_{12}^{*}\right)}\right)
$$

The formulas for $\lambda_{1}$ and $\lambda_{2}$ are obtained from the above equation by replacing the subscript 2 by 1 , and 1 by 2 respectively.

The second step of the calculation consists of correcting Eq. (9) to account approximately the transfer of energy between the translational and internal degrees of freedom. If the experimental value of thermal conductivity is known for each of the molecules, then one can compute the ratio

$$
E_{i}=\frac{\left(\lambda_{i}\right) \operatorname{expt}}{\left(\lambda_{i}\right)_{\text {mon }}}
$$

and apply the following empirical correction to the thermal conductivity $\lambda_{\text {mon }}$.

$$
\lambda=\lambda_{\operatorname{mon}}\left(x_{1} E_{1}+x_{2} E_{2}\right)
$$

If the experimental measurements of the pure-gas thermal conductivity are not available, then the correction factor can be estimated from Eucken's formula [1].

$$
E_{i}=\frac{4}{15} \frac{C_{v}}{R}+\frac{3}{5}
$$

Diffusivity of Steam and Hydrogen

For reason given earlier, when calculating the diffusivity of $\mathrm{H}_{2} \mathrm{O}$ or $\mathrm{H}_{2}$, it suffices to treat the system as a binary mixture. Then, to a first approximation, the binary diffusivity is given as 


$$
\hat{D}_{i j}=\frac{3}{8} k\left(\frac{\sqrt{\left(M_{i}+M_{j}\right) \pi R T^{3} / 2 M_{i} M_{j}}}{\pi p \sigma_{i j}^{2} \cdot \Omega(1,1)^{\star}\left(T_{i j}^{*}\right)}\right)
$$

Diffusivity of Fission Product Vapors

In the gas mixture, $\mathrm{H}_{2}$ and $\mathrm{H}_{2} \mathrm{O}$ are the most abundant species and the fission product vapors are present in trace amounts only. Thorefore, in calculating the diffusivity of a trace species, it is reasonable to discount the presence of all other trace species. In other words, for calculating the diffusivity of CsI one need only consider the three component system $\mathrm{CSI}_{\mathrm{I}} \mathrm{H}_{2}$ $\mathrm{H}_{2} \mathrm{O}$ : Similarly, $\mathrm{CsOH}-\mathrm{H}_{2}-\mathrm{H}_{2} \mathrm{O}$ system is considered for determining the diffusivity of $\mathrm{CsOH}_{3}, \mathrm{Te}_{2}-\mathrm{H}_{2}-\mathrm{H}_{2} \mathrm{O}$ system for the diffusivity of $\mathrm{Te}_{2}$, and $\mathrm{TeO}_{2}-$ $\mathrm{H}_{2}-\mathrm{H}_{2} \mathrm{O}$ system for the diffusivity of $\mathrm{TeO}_{2}$.

The diffusivity of a species (denoted by subscript 1) in a three component system (the species denoted by subscripts 1,2 and 3 ) is determined by the following procedure. First, the coefficient of diffusion of a binary mixture is calculated by using Eq. (14); there are three binary diffusion coefficients, $\hat{D}_{12}, \hat{D}_{13}, \hat{D}_{23}$, to be calculated. Next, from these binary diffusion coefficients, one can use the following formulae for calculating the binary diffusion coefficients, $D_{12}, D_{13}$ and $D_{23}$, in a multicomponent mixture.

$$
\begin{aligned}
& D_{12}=\hat{D}_{12}\left\{1+\frac{x_{3}\left(\frac{M_{3}}{M_{2}} \hat{D}_{13}-\hat{D}_{12}\right)}{x_{1} \hat{D}_{23}+x_{2} \hat{D}_{13}+x_{3} \hat{D}_{12}}\right\} \\
& D_{13}=\hat{D}_{13}\left\{1+\frac{x_{2}\left(\frac{M_{2}}{M_{3}} \hat{D}_{12}-\hat{D}_{13}\right)}{x_{1} \hat{D}_{23}+x_{2} \hat{D}_{13}+x_{3} \hat{D}_{12}}\right\} \\
& D_{23}=\hat{D}_{23}\left\{1+\frac{x_{1}\left(\frac{M_{1}}{M_{3}} \hat{D}_{12}-\hat{D}_{23}\right)}{x_{1} \hat{D}_{23}+x_{2} \hat{D}_{13}+x_{3} \hat{D}_{12}}\right\}
\end{aligned}
$$


Finally, the effective diffusion coefficients $D_{1 m}$ for use in the mass transfer formula is calculated from the following relationship.

$$
D_{1 m}=\frac{M_{2}}{M} D_{12}+\frac{M_{3}}{M} D_{13}-\frac{M_{2} M_{3}}{M_{1} M} D_{23}
$$

where $M$ is the molecular weight of the mixture. In practical terms, the species 1 can be $\mathrm{CsI}, \mathrm{CsOH}, \mathrm{Te}_{2}$ or $\mathrm{TeO}_{2}$ whereas $\mathrm{H}_{2}$ and $\mathrm{H}_{2} \mathrm{O}$ are represented by the subscripts 2 and 3 .

\section{Physical Constants}

Other than the molecular weights, the physical constants required in the computation of the transport coefficients are the Lennard-Jones potential parameters $\sigma$ and $\varepsilon$ for the various species in the gas mixture. For $\mathrm{H}_{2} \mathrm{O}$ and $\mathrm{H}_{2}$, these parameters are readily available. However, for the fission product vapors, $\sigma$ and $\varepsilon$ are not presently available. One of the many ways of estimating $\sigma$ and $\varepsilon$ is through the boiling point and the density of solid at the melting point[2].

$$
\begin{aligned}
& \sigma=\left[\frac{3.45}{\pi N_{A}}\left(\frac{M}{\rho_{\text {sol }}}\right)\right]^{1 / 3} \\
& \frac{\varepsilon}{\bar{k}}=1.15 \mathrm{~T}_{\mathrm{b}}
\end{aligned}
$$

A compilation of the boiling points and densitities of $\mathrm{CsI}, \mathrm{CsOH}, \mathrm{Te}_{2}$ and $\mathrm{TeO}_{2}$ is given in Table 2. The tabulated boiling points have been extracted from the following sources: Barin and Knackle [4], for CSI, 1974 supplement of JANAF [5] for $\mathrm{CsOH}$, Stull and Sinke [6] for $\mathrm{Te}_{2}$, and the vapor pressure data given by Mills [7] for $\mathrm{Te}_{2}$. The tabulated densities have been extracted from the Handbook of Chemistry and Physics [8], except that the quoted value for $\mathrm{Te}_{2}$ is actually that of $\mathrm{Te}$ and the density listed for $\mathrm{TeO}_{2}$ is obtained by averaging the densities of $\mathrm{TeO}$ and $\mathrm{TeO}_{3}$. Table 3 summarizes the estimated Lennard-Jones parameters for the fission products and the known parameters for the carrier gases $\mathrm{H}_{2} \mathrm{O}$ and $\mathrm{H}_{2}$. 
Table 2 Boiling Points and Densities

$\begin{array}{lcc}\begin{array}{l}\text { Species } \\ \text { Boiling Point } \\ (\mathrm{K})\end{array} & \begin{array}{c}\text { Solid Density } \\ \mathrm{kg} / \mathrm{m}^{3}\end{array} \\ \mathrm{CsI} & -\vdots & 4510 \\ \mathrm{CsOH} & 1<63 & 3675 \\ \mathrm{Te}_{2} & 1260 & 6250 \\ \mathrm{TeO}_{2} & 1535 & 5200\end{array}$

Table 3 Lennard-Jones Parameters

\begin{tabular}{|c|c|c|}
\hline Species & $\begin{array}{c}\sigma \\
\left(A^{\circ}\right)\end{array}$ & $\begin{array}{l}\varepsilon / k \\
(K)\end{array}$ \\
\hline $\mathrm{H}_{2} \mathrm{O}$ & 2.641 & 809.1 \\
\hline $\mathrm{H}_{2}$ & 2.827 & 59.7 \\
\hline Cs I & 4.12 & 1785.9 \\
\hline $\mathrm{CsOH}$ & 3.67 & 1452.5 \\
\hline $\mathrm{Te}_{2}$ & 3.67 & 1449.0 \\
\hline $\mathrm{TeO}_{2}$ & 4.06 & 1765.3 \\
\hline
\end{tabular}

RESULTS AND DISCUSSION

Table 4 shows an excellent agreement at all temperatures between the calculated viscosity and conductivity of hydrogen and the values quoted in Ref. (3). As expected, the agreement is not so good for conductivity, the maximum disparity being nearly $20 \%$. The kinetic theory being used here is strictly applicable to monatomic gases. When applied to polyatomic gases, it 
is more accurate for the transport coefficients such as diffusion and viscosity that are not very much affected by the internal degrees of freeciom. On the other hand, thermal conductivity is quite dependent on the interchange of energy between translational and internal degrees of freedom. The Eucken's correction factor was applied in Eq. (12) to correct for this deficiency.

Table 5 shows the comparison between the calculated and quoted values of viscosity and conductivity of steam. The previous comments pertaining to the rather good agreement for viscosity and the disparity for conductivity apply here as well. The large disparity for conductivity at low temperatures is not a serious limitation in that such low temperatures are not encountered in reactor accidents.

There is only limited data available for the transport coefficients of the $\mathrm{H}_{2}-\mathrm{H}_{2} \mathrm{O}$ mixture. The comparison between the calculated and experimental values of the coefficient of diffusion is shown in Table 6 . Hirschfelder, Curtiss, and Bird [1] were able to obtain a somewhat better agreement by modifying the Lennard-Jones parameter to specifically account for the interaction between polar and non-polar molecules.

We have not found any experimental data to compare with the calculated transport coefficients of the fission product vapors. However, we have no reason to suspect that the accuracy of the results should be any poorer than seen in earlier comparisons for hydrogen, steam and $\mathrm{H}_{2}-\mathrm{H}_{2} \mathrm{O}$ mixture. The only reservation is that the Lennard-Jones parameters of the fission product vapors are not available and consequently had to be deduced from approximate density and the boiling point.

To aid in making heat and mass transfer calculations in reactor accident situations, we have tabulated the following transport coefficients: 
Table 4 Viscosity and Conductivity of Hydrogen

\begin{tabular}{|c|c|c|c|c|}
\hline \multicolumn{2}{|c|}{ Viscosity } & & \multirow{2}{*}{\multicolumn{2}{|c|}{$\begin{array}{l}\text { Conductivity } \\
\qquad \mathrm{W} / \mathrm{m}=\mathrm{K}\end{array}$}} \\
\hline \multirow{2}{*}{$\begin{array}{l}\text { Temperature } \\
\text { (K) }\end{array}$} & \multicolumn{2}{|c|}{ Pa.s } & & \\
\hline & Calculated & Quoted ${ }^{3}$ & Calculated & Quoted ${ }^{3}$ \\
\hline 273.15 & $8.697 \times 10^{-6}$ & $8.40010^{-6}$ & $1.745 \times 10^{-1}$ & $1.660 \times 10^{-1}$ \\
\hline 373.15 & $1.092 \times 10^{-5}$ & $1.030 \times 10^{-5}$ & $2.163 \times 10^{-1}$ & $2.143 \times 10^{-1}$ \\
\hline 473.15 & $1.285 \times 10^{-5}$ & $1.210 \times 10^{-5}$ & $2.582 \times 10^{-1}$ & $2.524 \times 10^{-1}$ \\
\hline 573.15 & $1.458 \times 10^{-5}$ & $1.390 \times 10^{-5}$ & $3.000 \times 10^{-1}$ & $2.864 \times 10^{-1}$ \\
\hline 673.15 & $1.616 \times 10^{-5}$ & $1.540 \times 10^{-5}$ & $3.419 \times 10^{-1}$ & $3.183 \times 10^{-1}$ \\
\hline 773.15 & $1.761 \times 10^{-5}$ & $1.690 \times 10^{-5}$ & $3.838 \times 10^{-1}$ & $3.489 \times 10^{-1}$ \\
\hline 873.15 & $1.896 \times 10^{-5}$ & $1.830 \times 10^{-5}$ & $4.257 \times 10^{-1}$ & $3.787 \times 10^{-1}$ \\
\hline 973.15 & $2.023 \times 10^{-5}$ & $1.960 \times 10^{-5}$ & $4.675 \times 10^{-1}$ & $4.076 \times 10^{-1}$ \\
\hline 1073.15 & $2.144 \times 10^{-5}$ & $2.100 \times 10^{-5}$ & $5.094 \times 10^{-1}$ & $4.350 \times 10^{-1}$ \\
\hline 1173.15 & $2.258 \times 10^{-5}$ & & $5.513 \times 10^{-1}$ & $4.637 \times 10^{-1}$ \\
\hline 1273.15 & $2.367 \times 10^{-5}$ & & $5.931 \times 10^{-1}$ & $4.909 \times 10^{-1}$ \\
\hline 1373.15 & $2.472 \times 10^{-5}$ & & $6.350 \times 10^{-1}$ & $5.176 \times 10^{-1}$ \\
\hline 1473.15 & $2.572 \times 10^{-5}$ & & $6.769 \times 10^{-1}$ & $5.438 \times 10^{-1}$ \\
\hline
\end{tabular}


Table 5 Viscosity and Conductivity of Steam

\section{Viscosity}

Temperature

(K)
Pa.s

Calculated
Quoted[3]

\section{Conducitivity}

$\mathrm{W} / \mathrm{m} \cdot \mathrm{K}$

Calculated Quoted[3]

\begin{tabular}{|c|c|c|c|c|}
\hline 273.15 & $1.002 \times 10^{-5}$ & & $2.457 \times 10^{-2}$ & $1.615 \times 10^{-2}$ \\
\hline 373.15 & $1.352 \times 10^{-5}$ & $1.255 \times 10^{-5}$ & $3.334 \times 10^{-2}$ & $2.464 \times 10^{-2}$ \\
\hline 473.15 & $1.707 \times 10^{-5}$ & $1.635 \times 10^{-5}$ & $4.289 \times 10^{-2}$ & $3.366 \times 10^{-2}$ \\
\hline 573.15 & $2.063 \times 10^{-5}$ & $2.024 \times 10^{-5}$ & $5.311 \times 10^{-2}$ & $4.564 \times 10^{-2}$ \\
\hline 673.15 & $2.418 \times 10^{-5}$ & $2.412 \times 10^{-5}$ & $6.391 \times 10^{-2}$ & $5.706 \times 10^{-2}$ \\
\hline 773.15 & $2.770 \times 10^{-5}$ & $2.677 \times 10^{-5}$ & $7.518 \times 10^{-2}$ & $6.997 \times 10^{-2}$ \\
\hline 873.15 & $3.118 \times 10^{-5}$ & & $8.684 \times 10^{-2}$ & $8.385 \times 10^{-2}$ \\
\hline 973.15 & $3.461 \times 10^{-5}$ & & $9.882 \times 10^{-2}$ & $9.848 \times 10^{-2}$ \\
\hline 1073.15 & $3.800 \times 10^{-5}$ & & $1.111 \times 10^{-1}$ & $1.114 \times 10^{-1}$ \\
\hline 1173.15 & $4.133 \times 10^{-5}$ & & $1.235 \times 10^{-1}$ & $1.301 \times 10^{-1}$ \\
\hline 1273.15 & $4.461 \times 10^{-5}$ & & $1.360 \times 10^{-1}$ & $1.467 \times 10^{-1}$ \\
\hline 1373.15 & $4.783 \times 10^{-5}$ & & $1.487 \times 10^{-1}$ & $1.634 \times 10^{-1}$ \\
\hline 1473.15 & $5.099 \times 10^{-5}$ & & $1.614 \times 10^{-1}$ & $1.803 \times 10^{-1}$ \\
\hline
\end{tabular}

Table 6 Coefficient of Diffusion for $\mathrm{H}_{2} / \mathrm{H}_{2} \mathrm{O}$ Mixture

Temperature

(K)

307.4

328.5

325.2
Binary

Expt1[1]

1.02

1.12

1.20
Diffusion

$\left(\mathrm{cm}^{2} / \mathrm{s}\right)$

Expt1[1]
Coefficient

calcd[1] calcd

0.95

0.80

0.99

1.07

0.91

1.10 

a) Diffusivity of steam and hydrogen $\left(\mathrm{m}^{2} / \mathrm{s}\right)$
b) Viscosity (Pa:s) and conduci, vity $(\mathrm{H} / \mathrm{m} \cdot \mathrm{K})$ of the mixture
c) Diffusivity of $\operatorname{csI}\left(\mathrm{m}^{2} / \mathrm{s}\right)$
d) Diffusivity of $\mathrm{CsOH}\left(\mathrm{m}^{2} / \mathrm{s}\right)$
e) Diffusivity of $\mathrm{Te}_{2}\left(\mathrm{~m}^{2} / \mathrm{s}\right)$
f) Diffusivity of $\mathrm{TeO}_{2}\left(\mathrm{~m}^{2} / \mathrm{s}\right)$

The tabulated values of the binary diffusion coefficient of the $\mathrm{H}_{2}-\mathrm{H}_{2} \mathrm{O}$ mixture is independent of the mole fractions of $\mathrm{H}_{2}$ and $\mathrm{H}_{2} \mathrm{O}$ and is given for atmospheric pressure. In order to calculate the diffusivity at pressures other than atmospheric, the following correction should be used.

$$
D(p)=D(p=1 \mathrm{~atm}) / p(a t m)
$$

The viscosity and conductivity of the $\mathrm{H}_{2}-\mathrm{H}_{2} \mathrm{O}$ mixture are independent of the system pressure and are tabulated as a function of temperature and the mole fractions of $\mathrm{H}_{2}$ and $\mathrm{H}_{2} \mathrm{O}$.

The diffusivity of the fission product vapors $\mathrm{CsI}, \mathrm{CsOH}, \mathrm{Te}_{2}$ and $\mathrm{Te}_{2}$ has been tabulated as a function of temperature and mole fractions of $\mathrm{H}_{2}, \mathrm{H}_{2} \mathrm{O}$ and the fission product vapors, at atmospheric pressure. The pressure correction, Eq. (21), should be applied to calculate diffusivity at pressures other than atmospheric.

\section{CONCLUDING REMARKS}

A kinetic theory formulation of transport coefficients has been used to calculate the viscosity, thermal conductivity, and diffusivity of a steamhydrogen mixture containing $\mathrm{Cs}, \mathrm{CsOH}, \mathrm{Te}_{2}$ and $\mathrm{TeO}_{2}$ in trace amounts. The required Lennard-Jones potential parameters of the fission product vapors are not available in the literature and consequently had to be estimated from the 
density and the boiling points of related species. Improved calculational results may be obtained with updated physical data by following the procedure formulated in this report.

\section{REFERENCES}

i. Hirschfelder, J. O., Curtiss, C. F., and Bird, R. B., Molecular Theory of Gases and Liquids, John Wiley \& Sons, Inc., New York, 1967.

2. Reid, R. C. and Sherwood, P. K., The Properties of Gases and Liquids, McGraw-Hil1, Inc., New York, 1966.

3. Raznjevic, K., Handbook of Thermodynamic Tables and Charts, Hemisphere Publishing Corporation, Washington, 1976.

4. Barin, I. and Knackle, U., Thermochemical Properties of Inorganic Substances, Springer-Verlag, New York, 1973.

5. Chase, M. W. et at., JANAF Thermochemical Tables: 1974 Supplement, The Dow Chemical Company, Michigan, 1974.

6. Stul1, D. R. and Sinke, G. C., Thermochemical Properties of the Elements, American Chemical Society, Washington, D. C., 1956.

7. Mills, K. C., Thermodynamic Data for Inorganic Sulphides, Selenides and Telluorides, London Butterworths, London.

8. Weast, P. C. (Editor), Handbook of Chemistry and Physics, CRC Press, Cleveland, 1974 . 


\section{APPENDIX: TABULATION OF TRANSPGP ${ }^{-}$COEFFICIENTS}

The following symbols have been used in the tables.

$\begin{array}{ll}\text { DCSI } & \text { diffusivity of } \mathrm{CsI}, \mathrm{m}^{2} / \mathrm{s} \\ \text { DCSOH } & \text { diffusivity of } \mathrm{CsOH}, \mathrm{m}^{2} / \mathrm{s} \\ \text { DG } & \text { binary diffusivity of } \mathrm{H}_{2} \text { and } \mathrm{H}_{2} \mathrm{O}, \mathrm{m}^{2} / \mathrm{s} \\ \text { DTE2 } & \text { diffusivity of } \mathrm{Te}_{2}, \mathrm{~m}^{2} / \mathrm{s} \\ \text { DTEO2 } & \text { diffusivity of } \mathrm{TeO}_{2}, \mathrm{~m}^{2} / \mathrm{s} \\ \text { KG } & \text { thermal conductivity of the mixture, } \mathrm{W} / \mathrm{m} \cdot \mathrm{K} \\ \text { MUG } & \text { viscosity of the gas, } \mathrm{N} \cdot \mathrm{s} / \mathrm{m}^{2} \\ \text { T } & \text { temperature, } \mathrm{K} \\ \text { XCSI } & \text { mole fraction of } \mathrm{CsI} \\ \text { XCSOH } & \text { mole fraction of } \mathrm{CsOH} \\ \text { XH2 } & \text { mole fraction of } \mathrm{H}_{2} \\ \text { XH2O } & \text { mole fraction of } \mathrm{H}_{2} \mathrm{O} \\ \text { XCSI } & \text { mole fraction of } \mathrm{CsI}^{2} \\ \text { XCSOH } & \text { mole fraction of } \mathrm{CsOH}^{\circ} \\ \text { XTE2 } & \text { mole fraction of } \mathrm{Te}_{2} \\ \text { XTE02 } & \text { mole fraction of } \mathrm{TeO}_{2}\end{array}$


BINARY DIFFUSIVITY OF $\mathrm{H}_{2}$ AND $\mathrm{H}_{2} \mathrm{O}$

T

DG

300

7.657E-05

400

1.336E-04

500

$2.038 \mathrm{E}-04$

600

$2.861 \mathrm{E}-04$

700

3.792E-04

800

4.824E-04

900

$5.949 \mathrm{E}-04$

1000

$7.162 \mathrm{E}-04$

1130

$8.458 \mathrm{E}-04$

1200

9.831E-04

1300

1.128E-03

1400

1.280E-03

1500

$1.438 \mathrm{E}-03$

1600

$1.604 \mathrm{E}-03$

1700

$1.775 \mathrm{E}-03$

1800

$1.953 \mathrm{E}-03$

1900

$2.136 \mathrm{E}-03$

2000

2.325E-03

2100

2.520E-03

2200

2.720E-03

2300

$2.925 \mathrm{E}-\mathrm{2} 3$

2400

$3.136 \mathrm{E}-03$

2500

3.351E-03

2600

3.571E-03

2700

3.796E-03

2800

$4.026 \mathrm{E}-03$

2900

$4.261 E-03$

3000

4.499E-03 


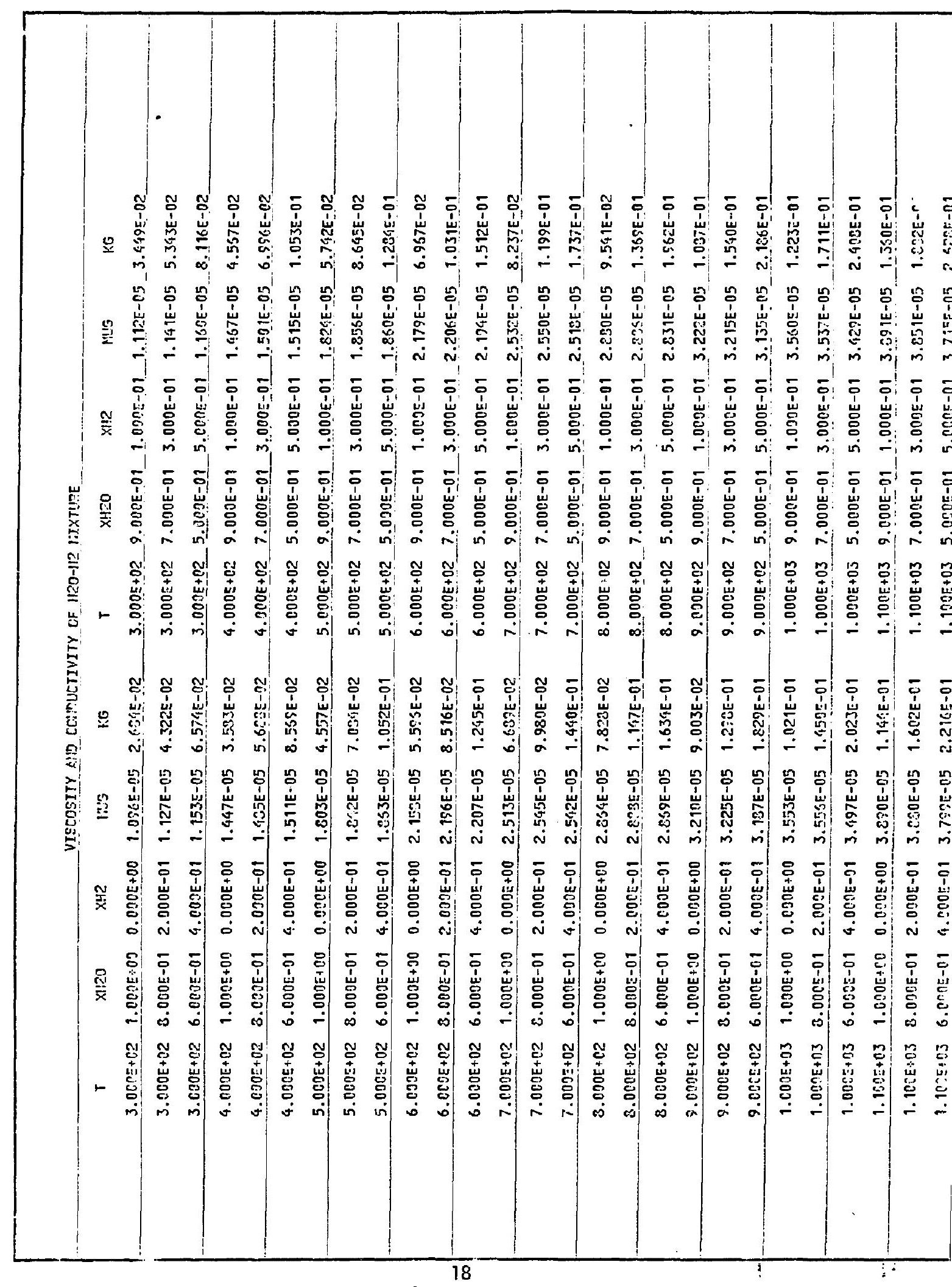




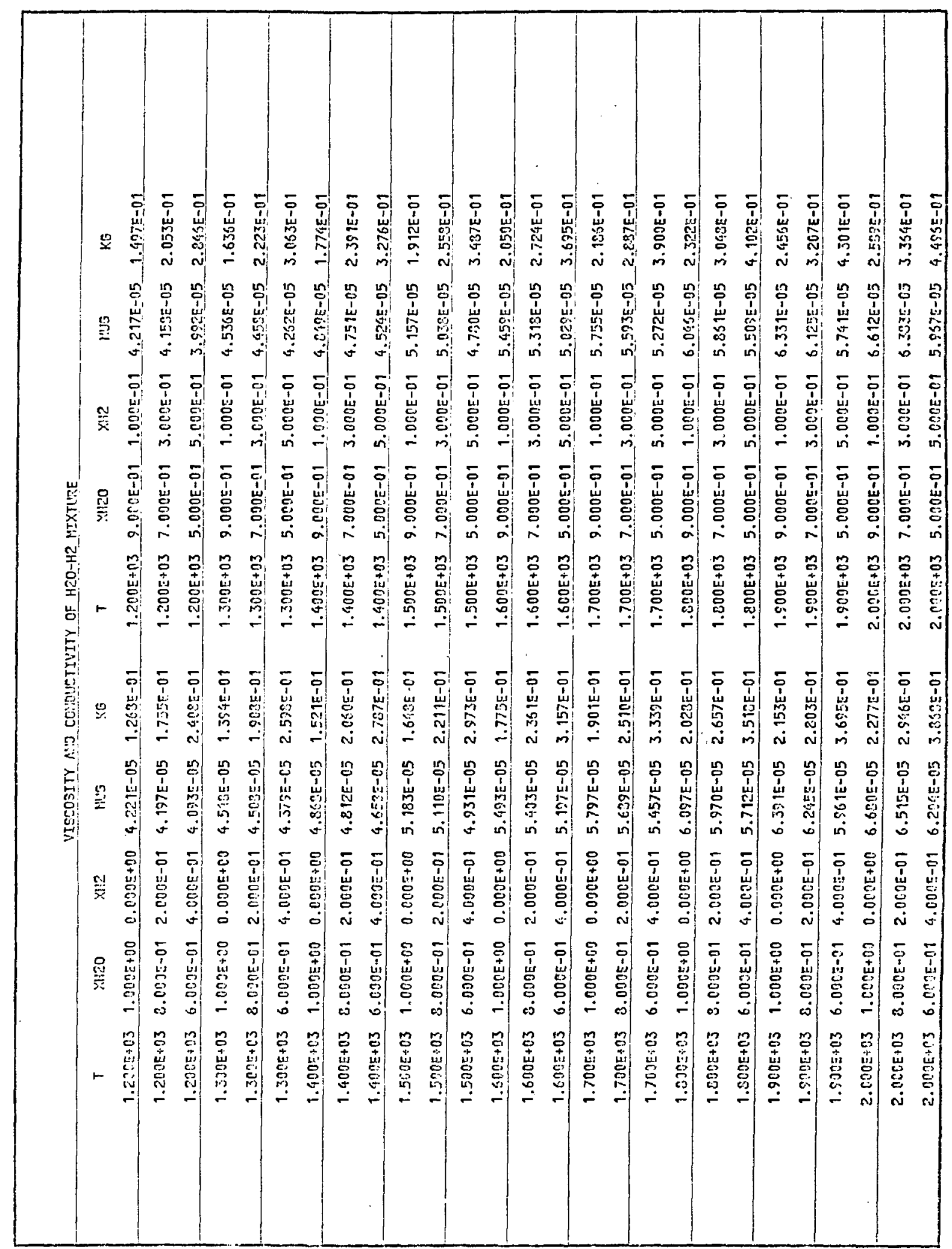




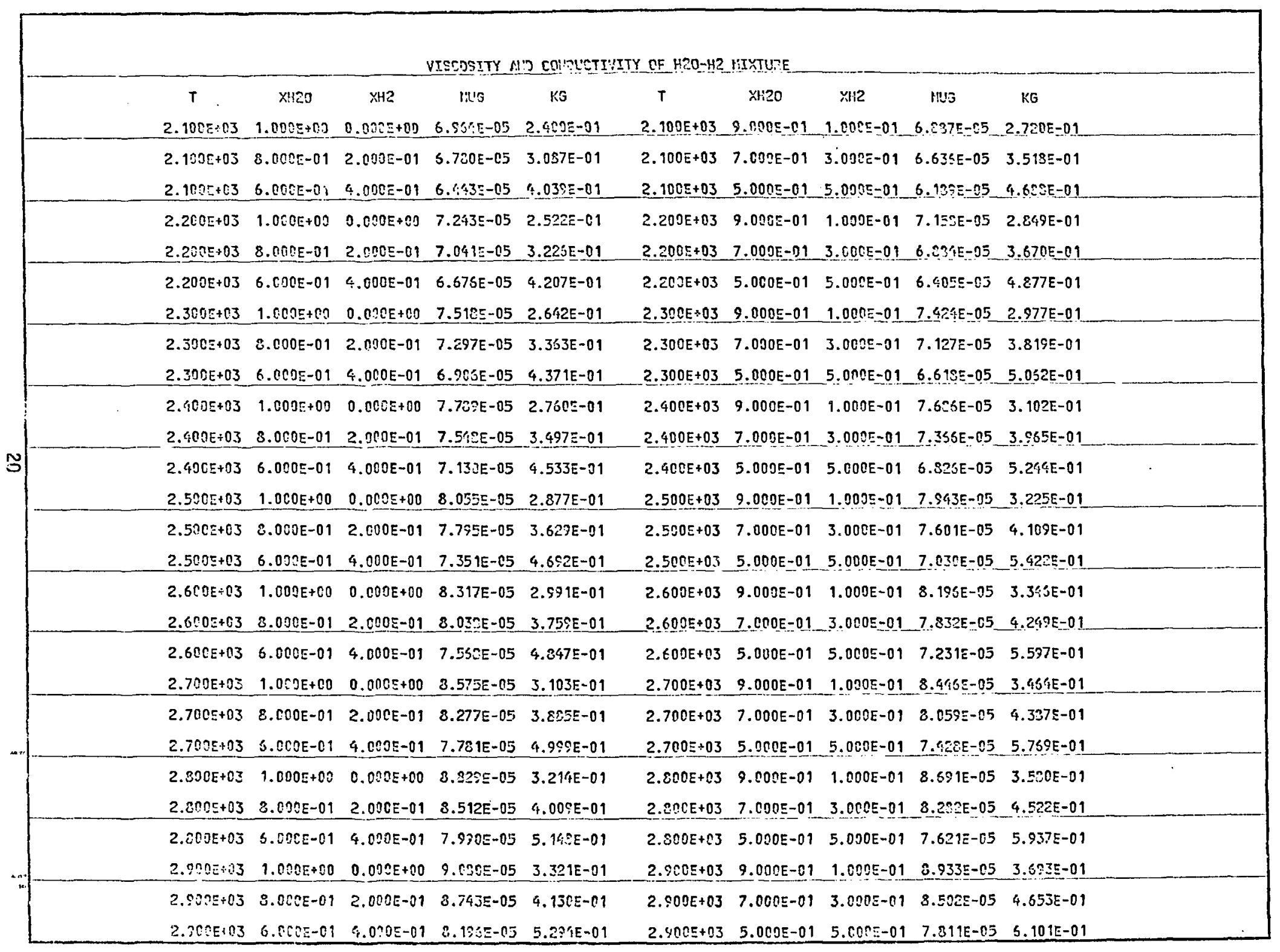




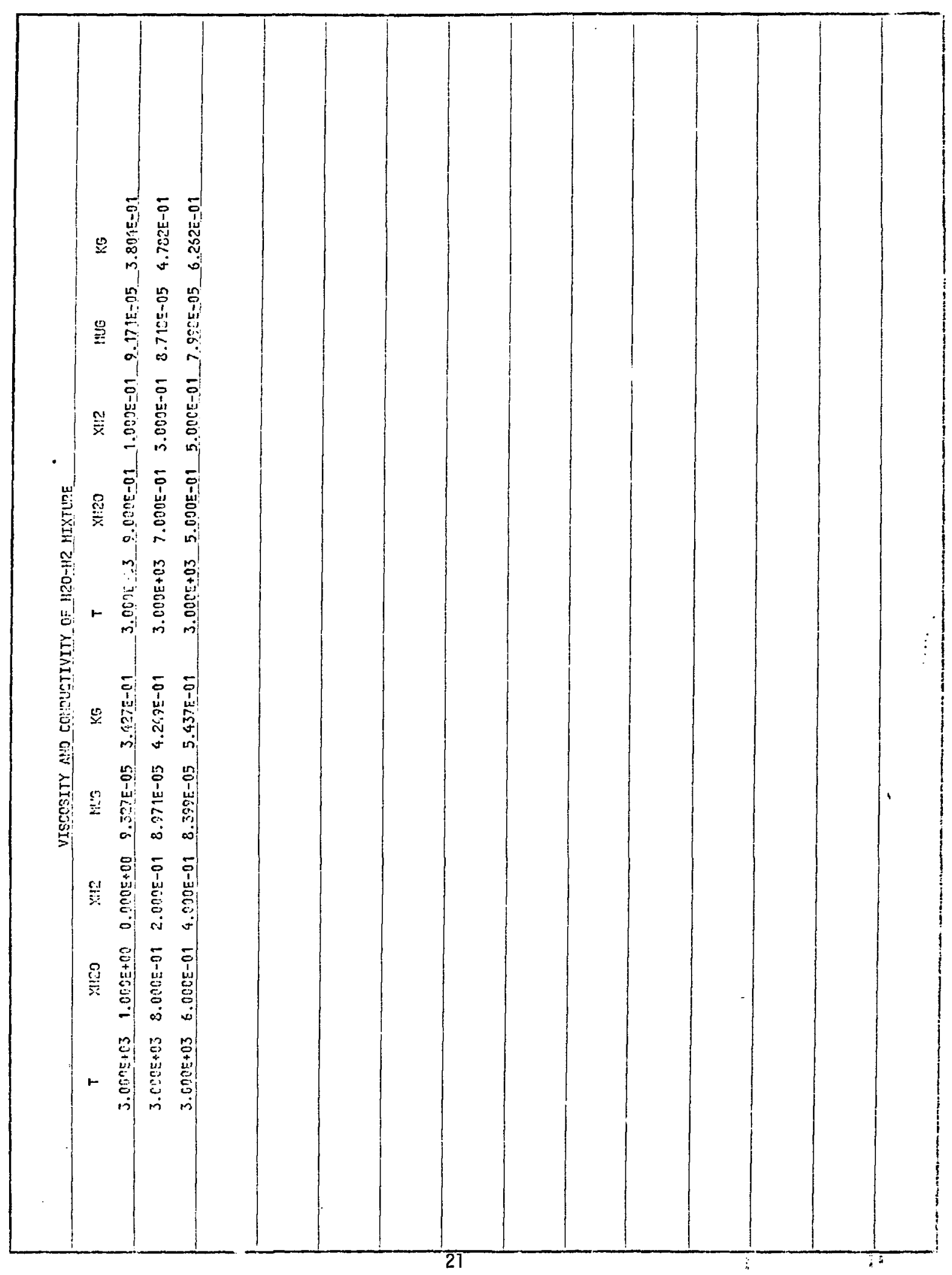




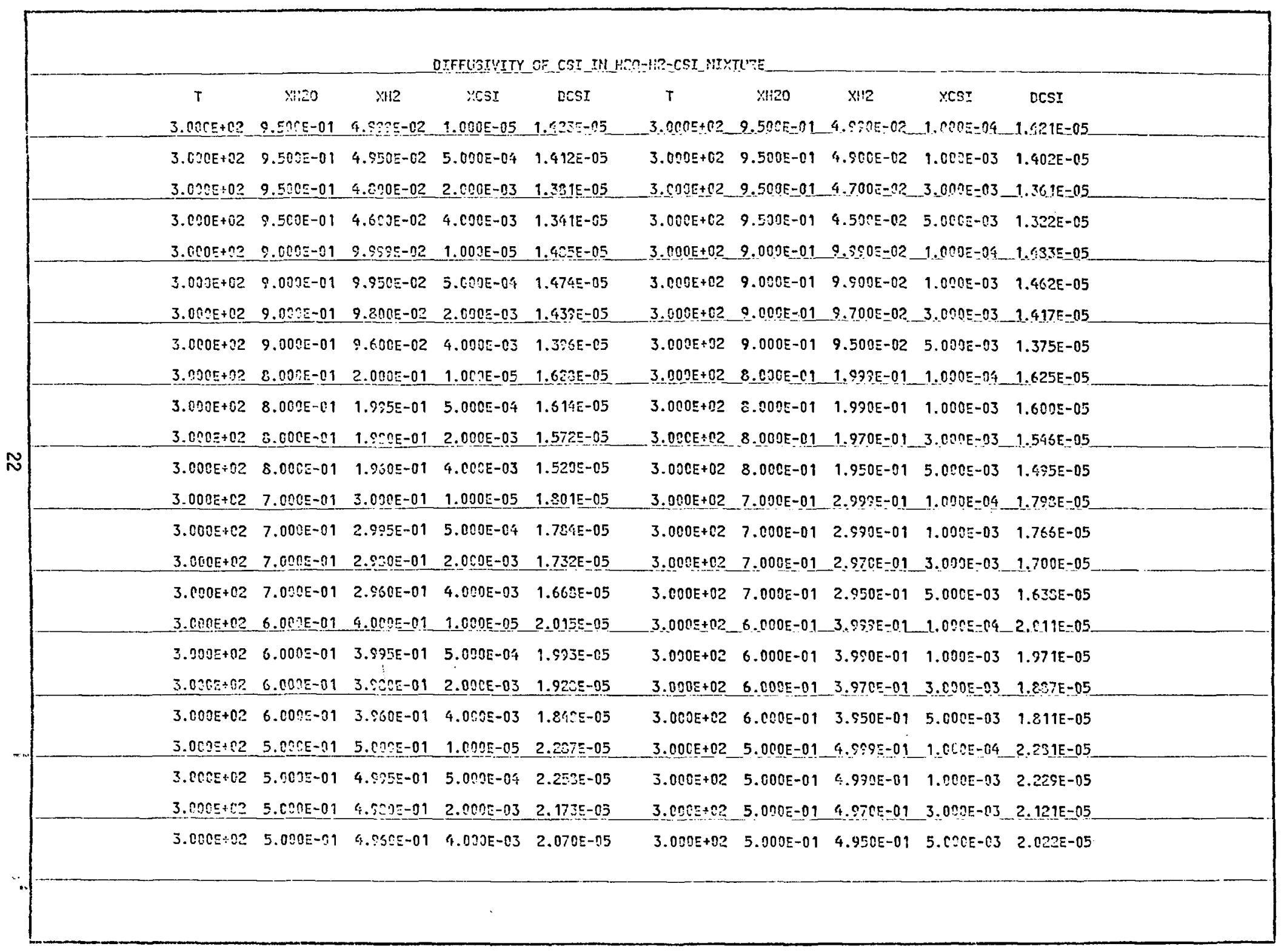




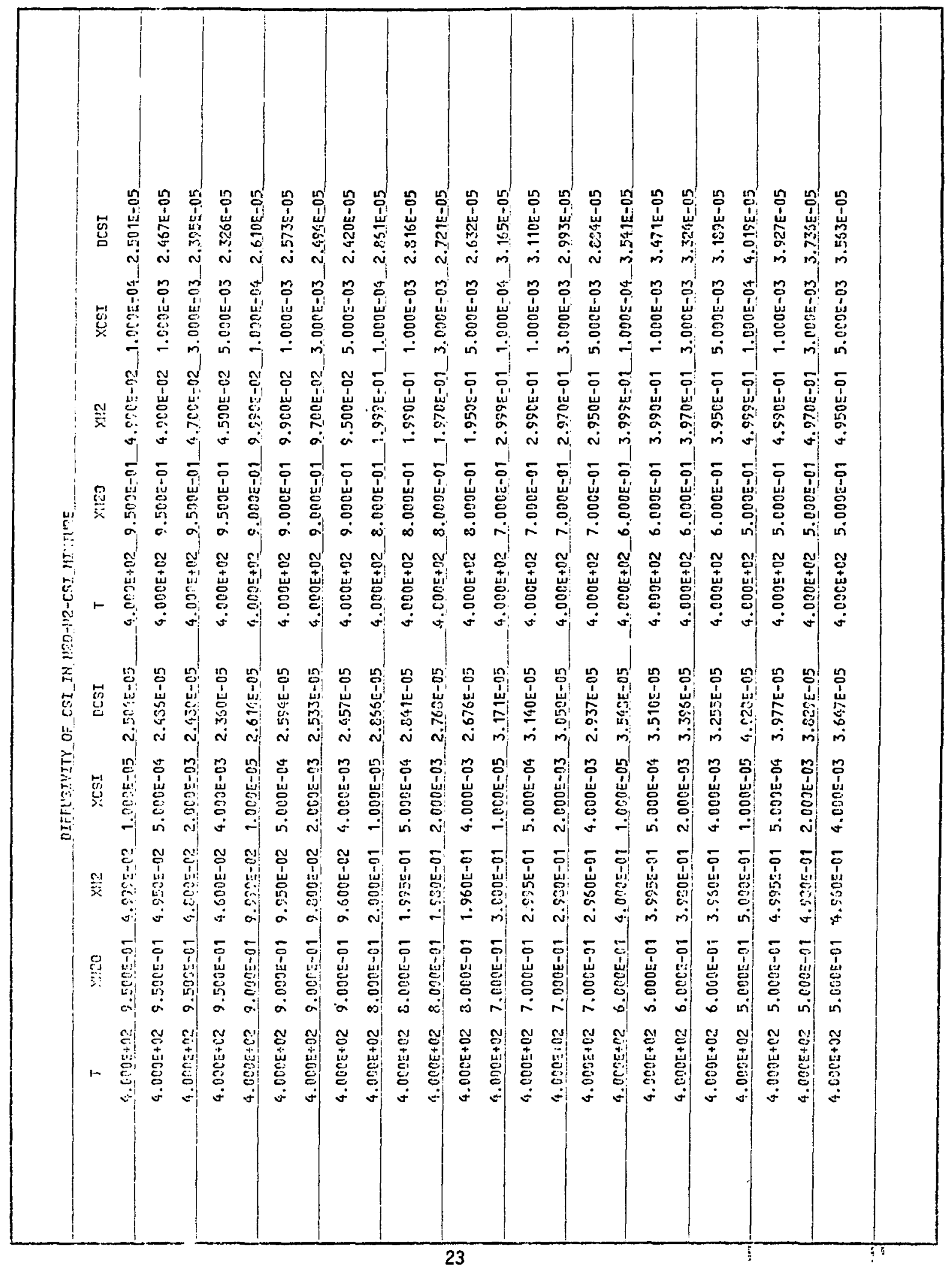




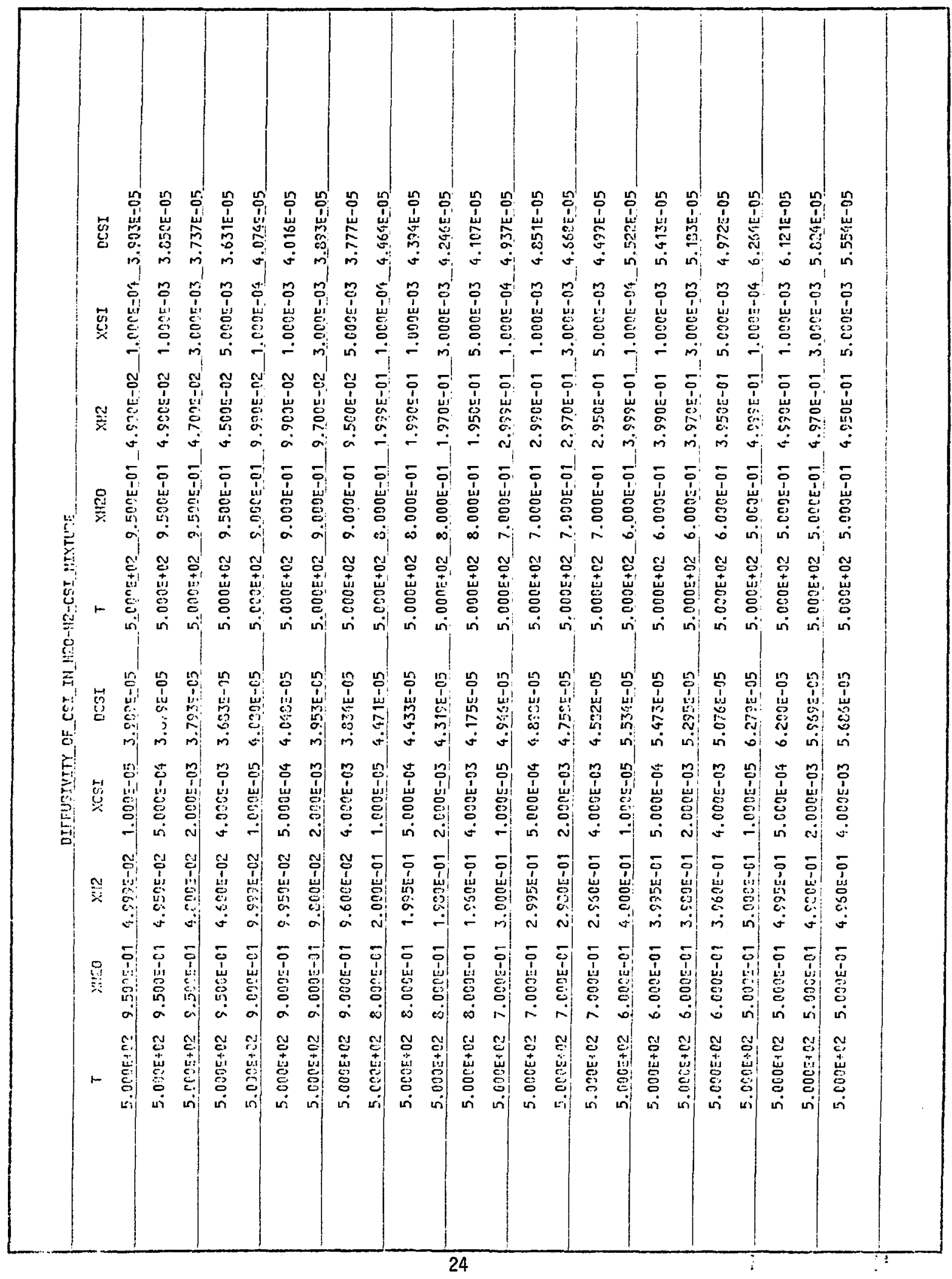




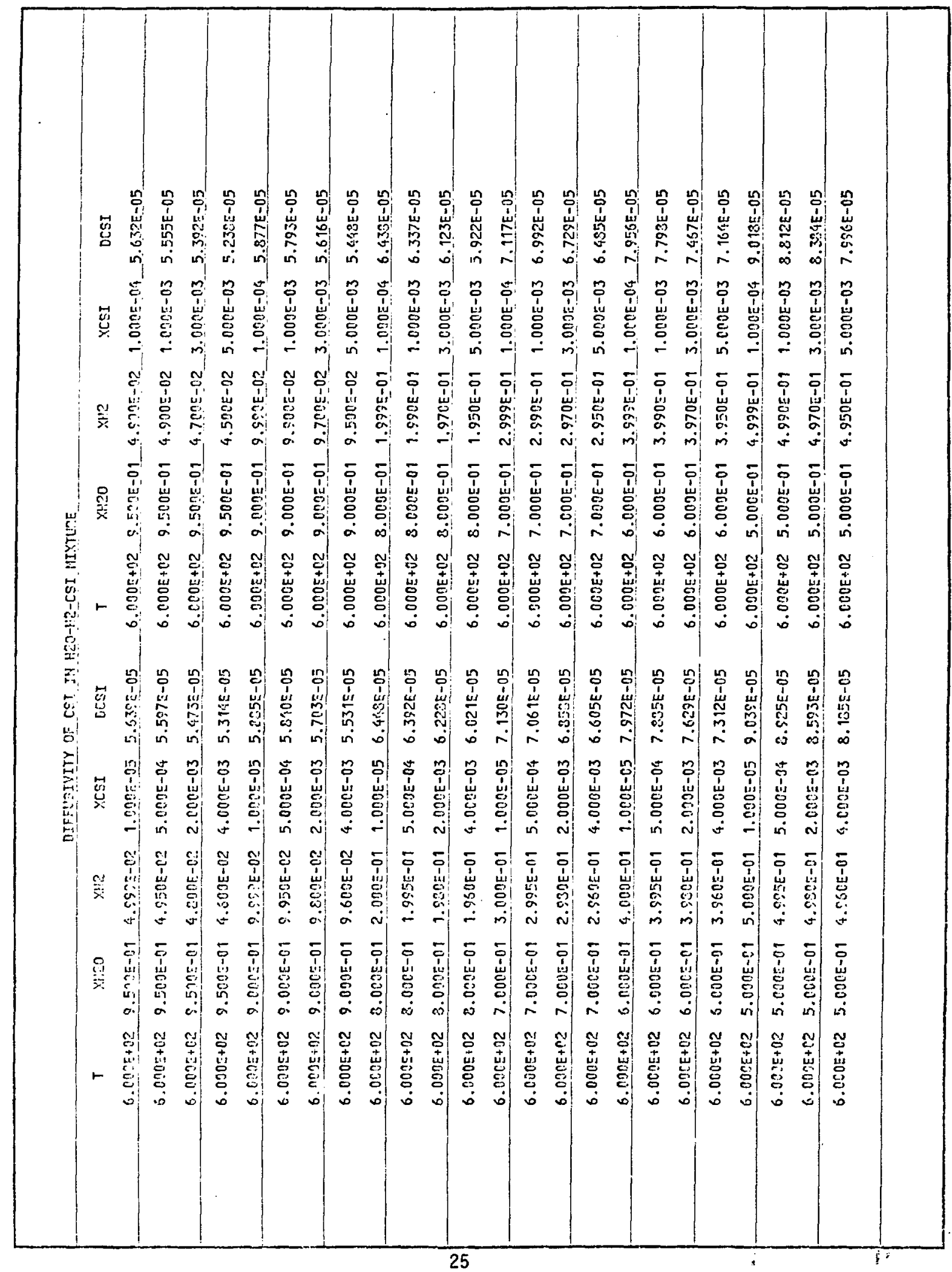




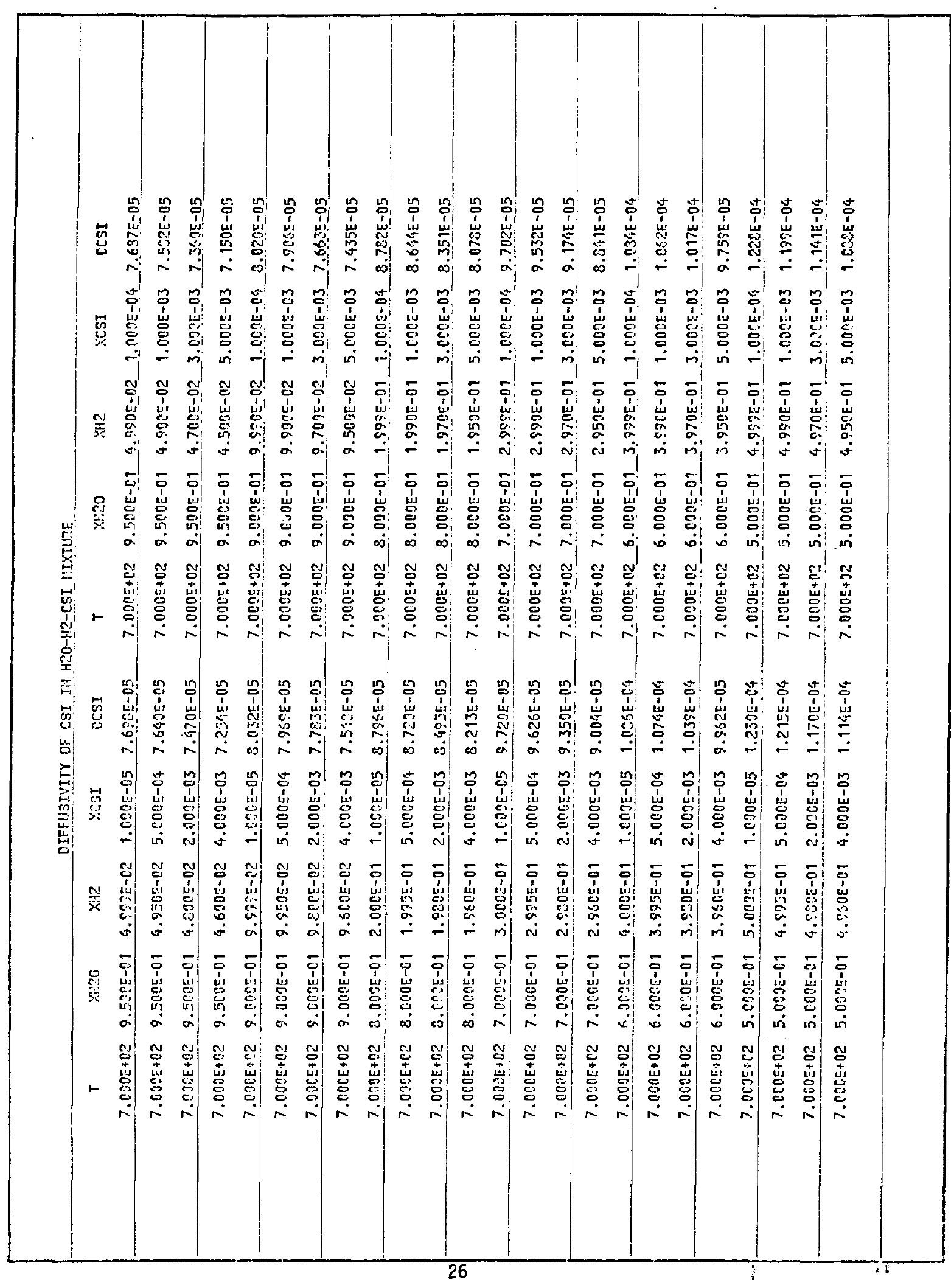




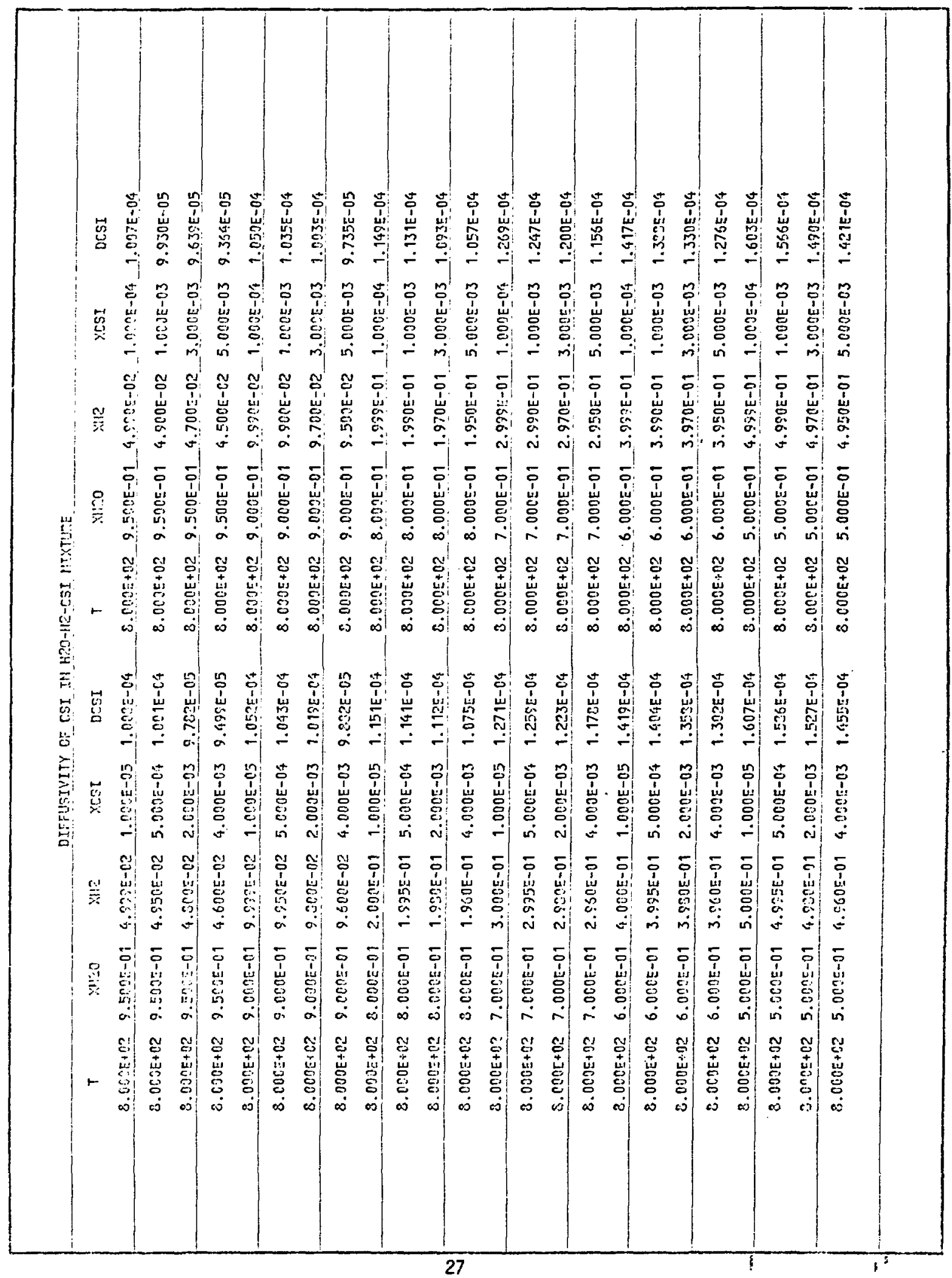




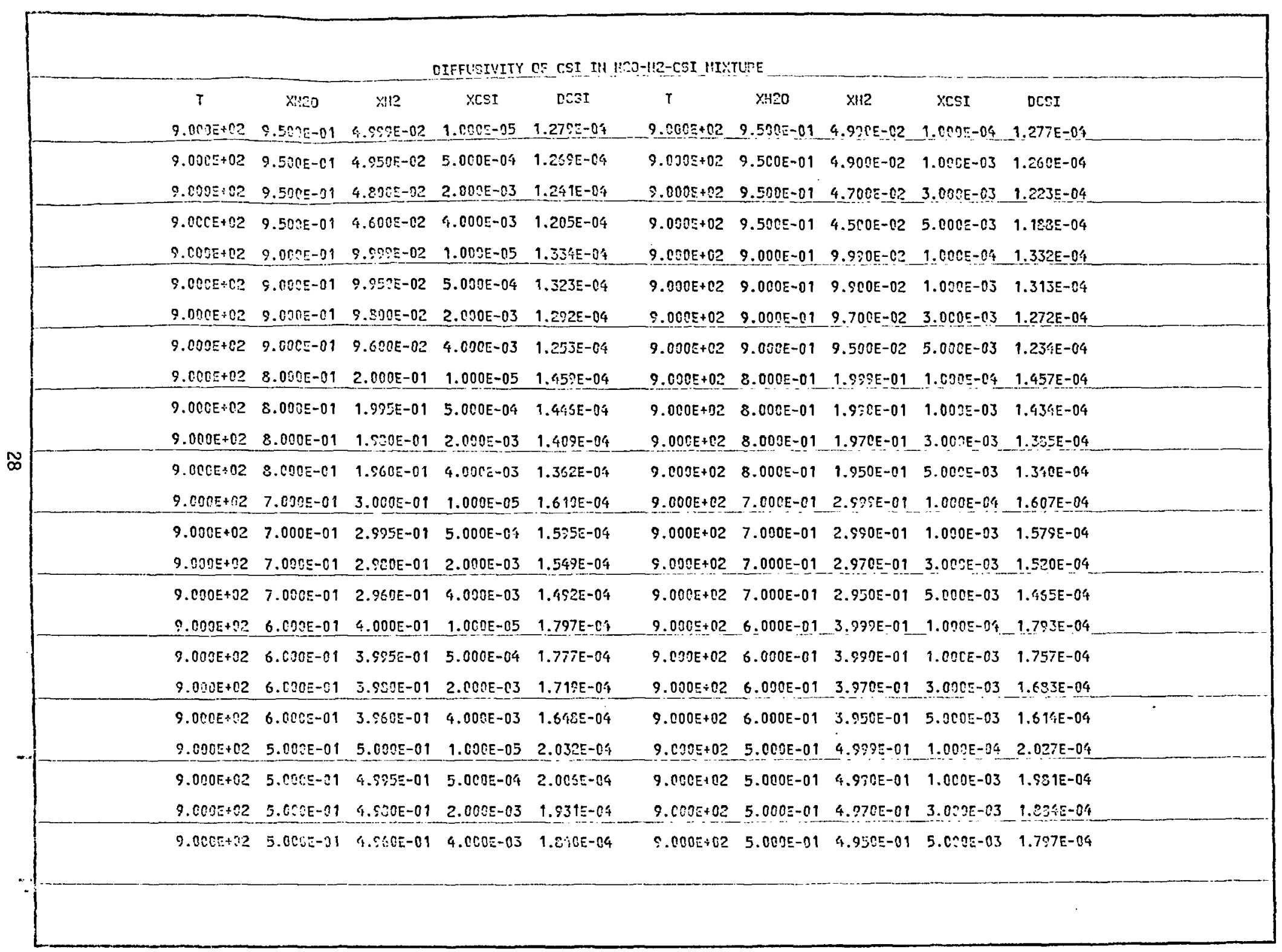




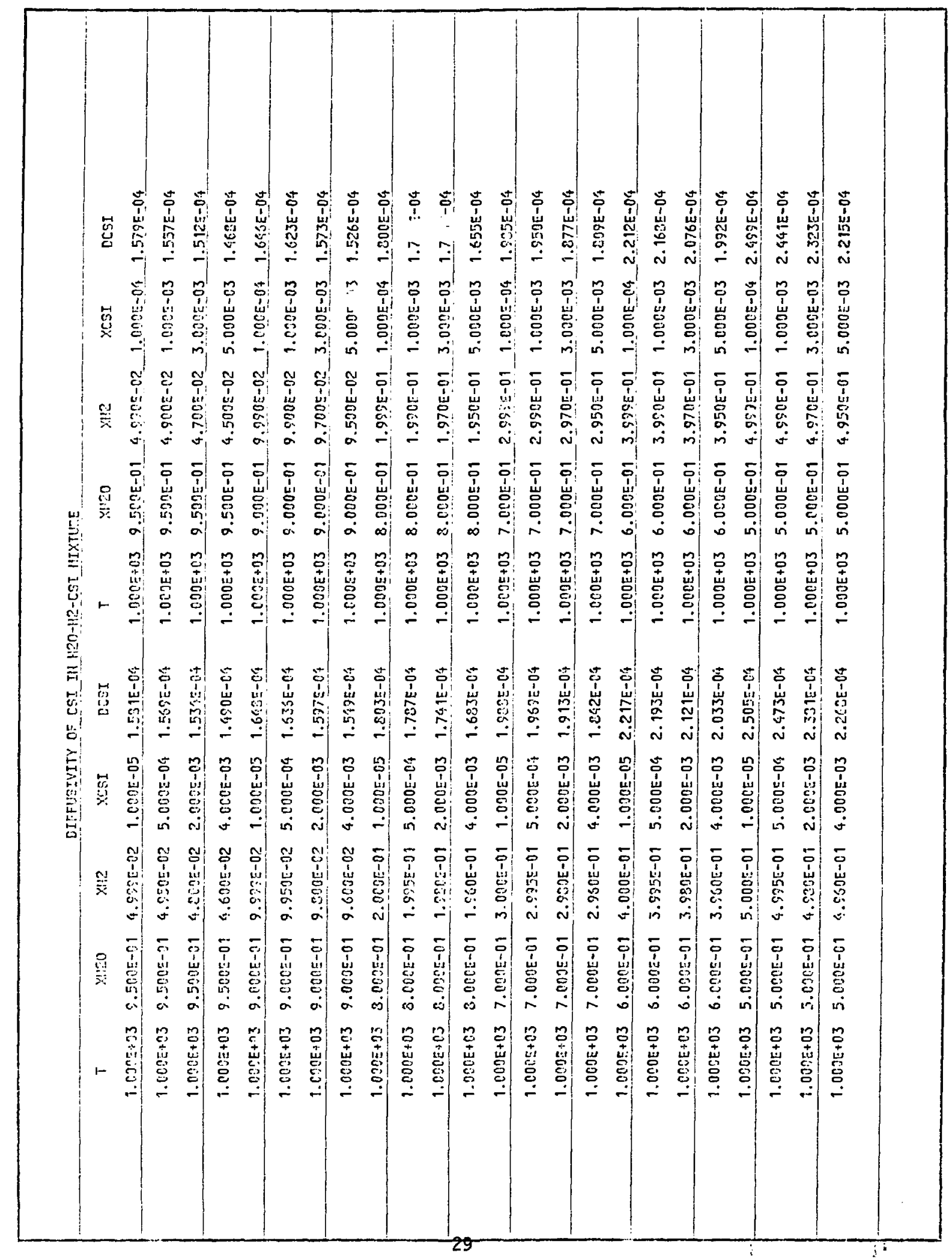




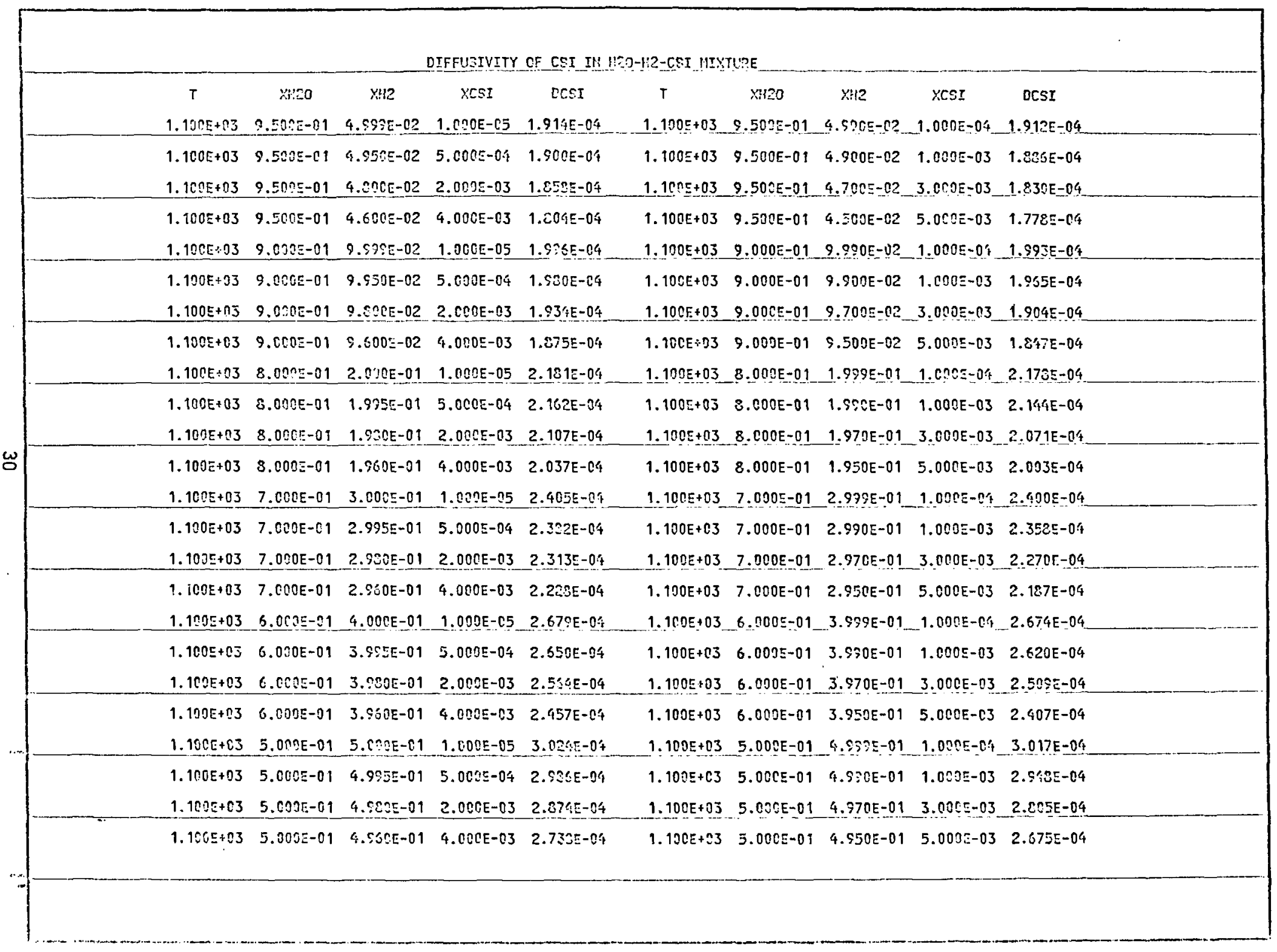




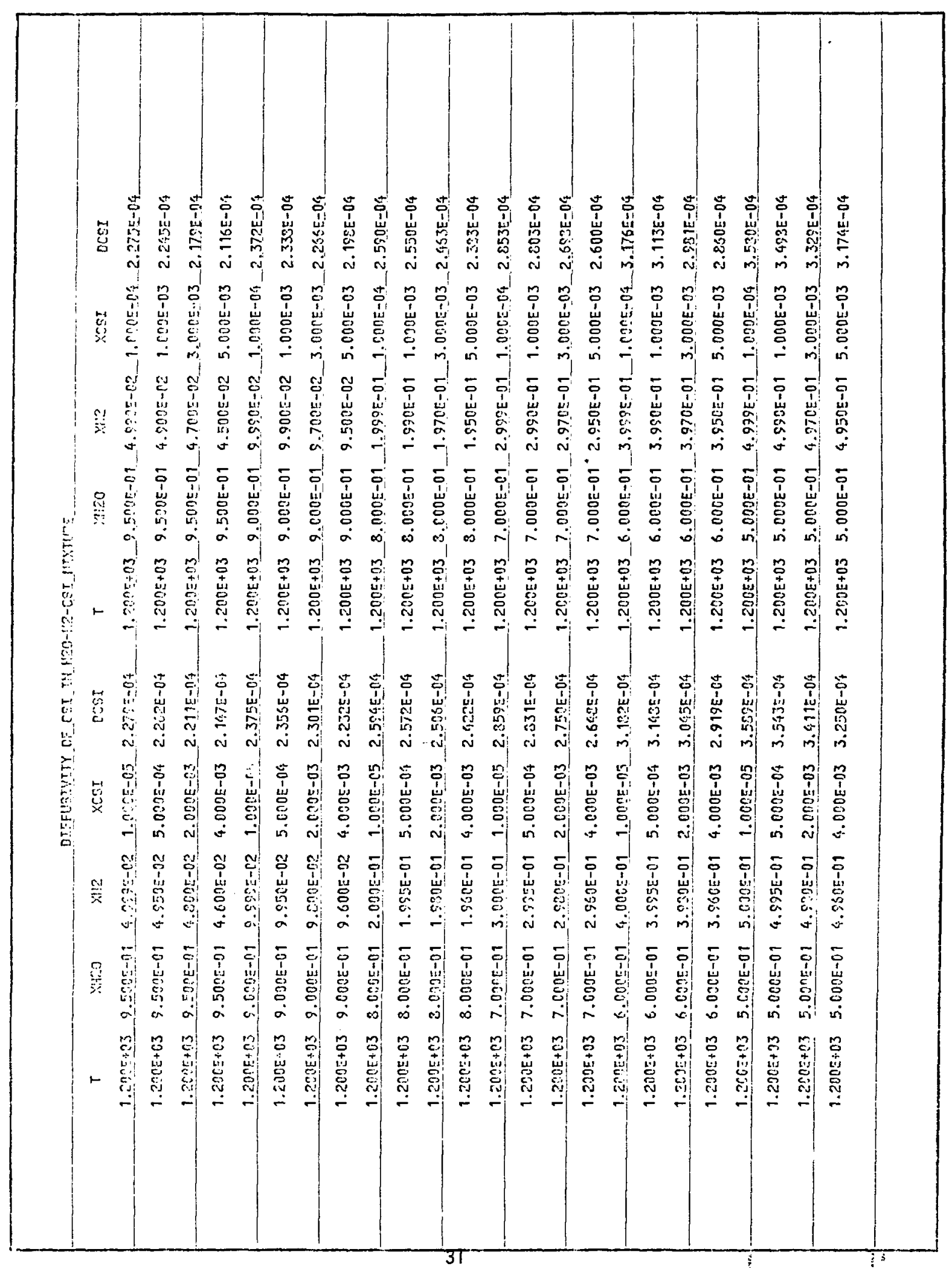




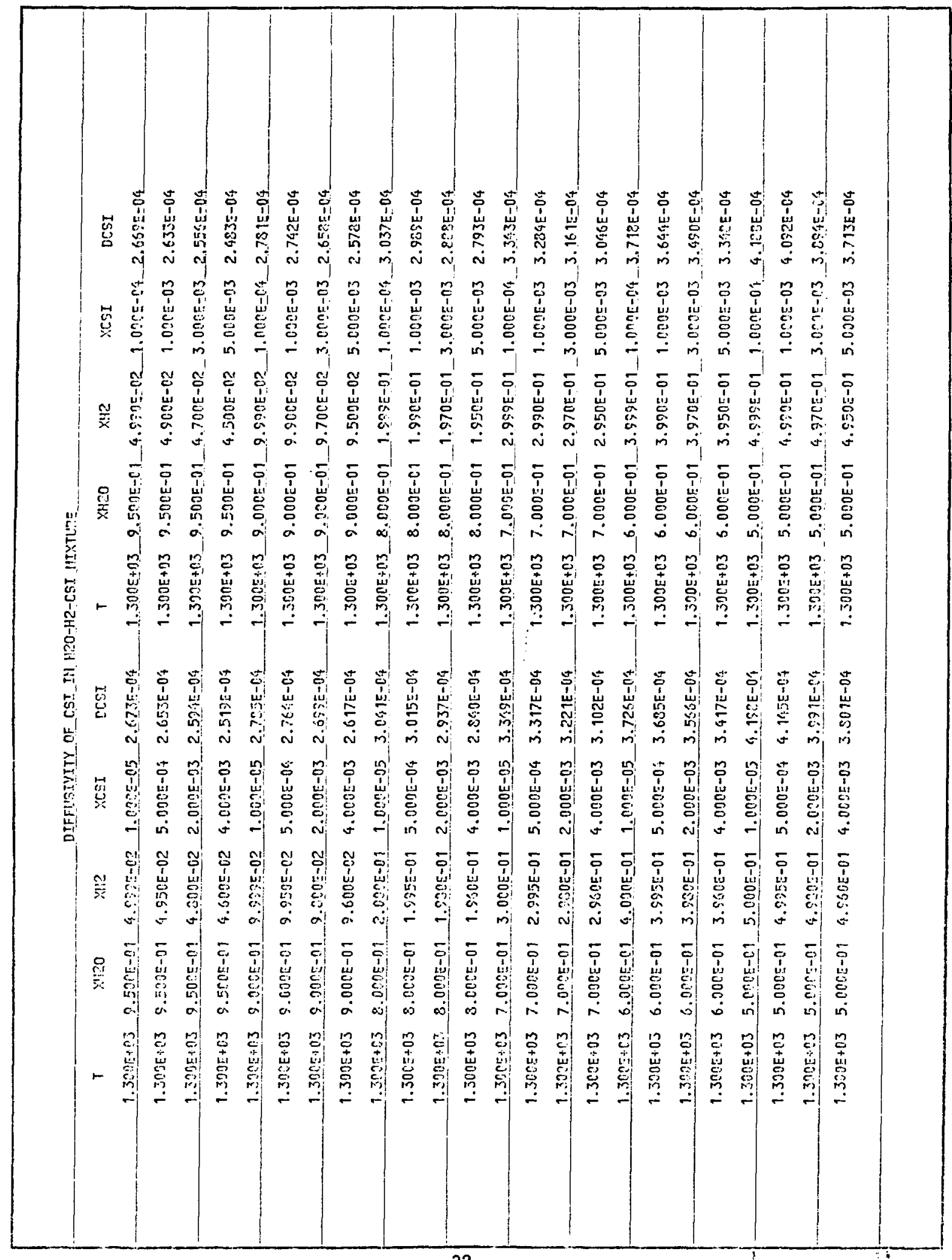




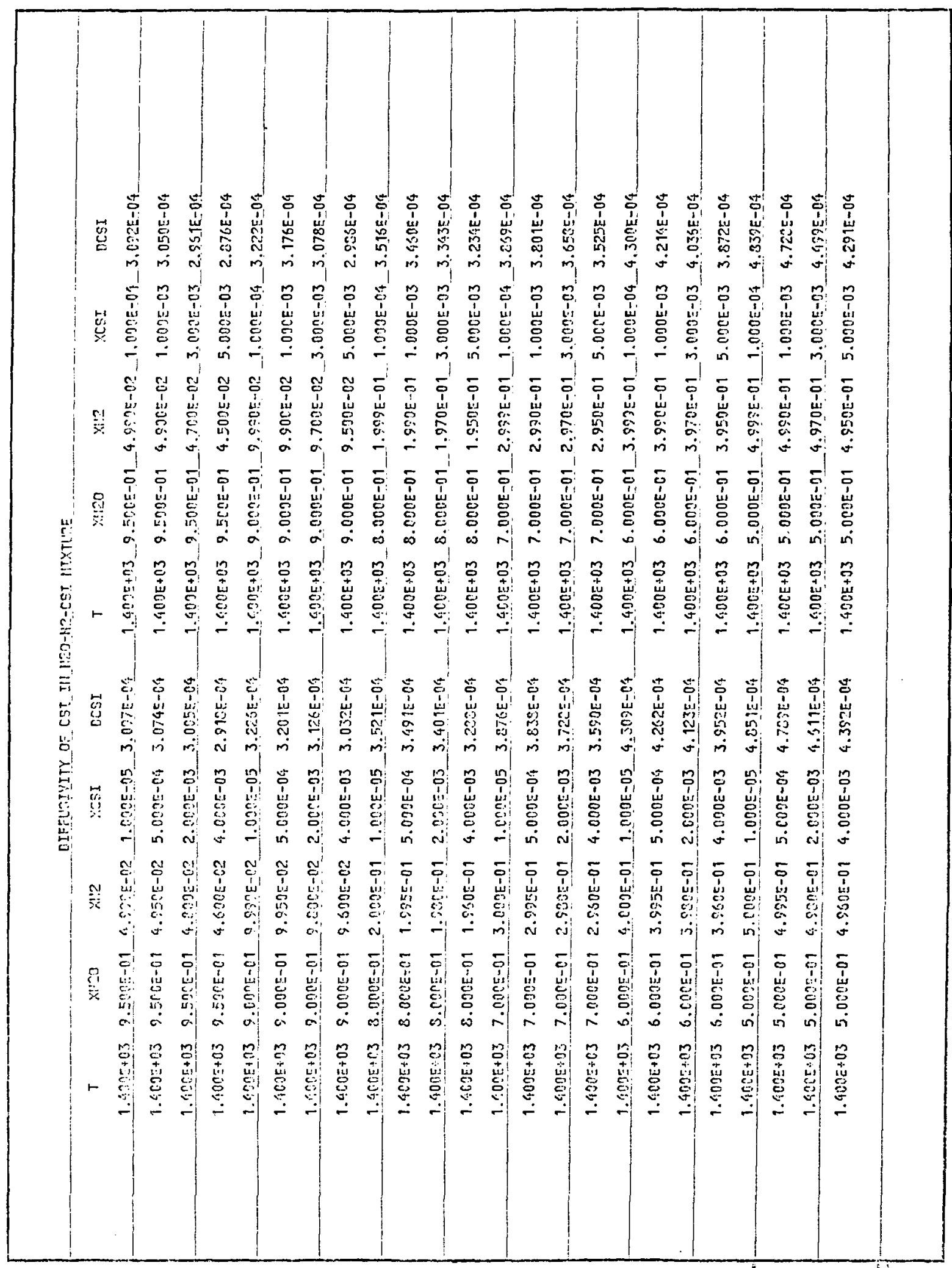




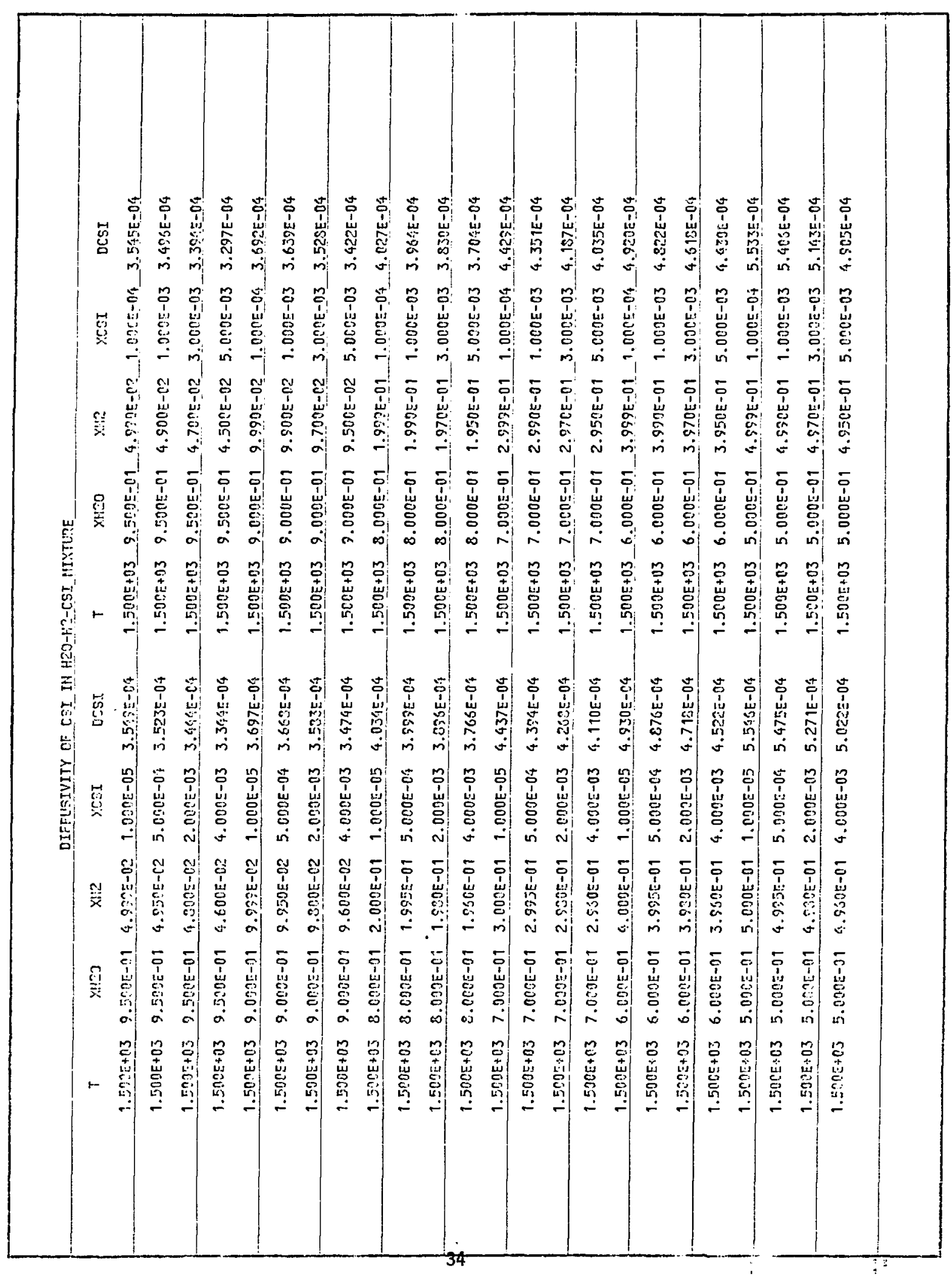




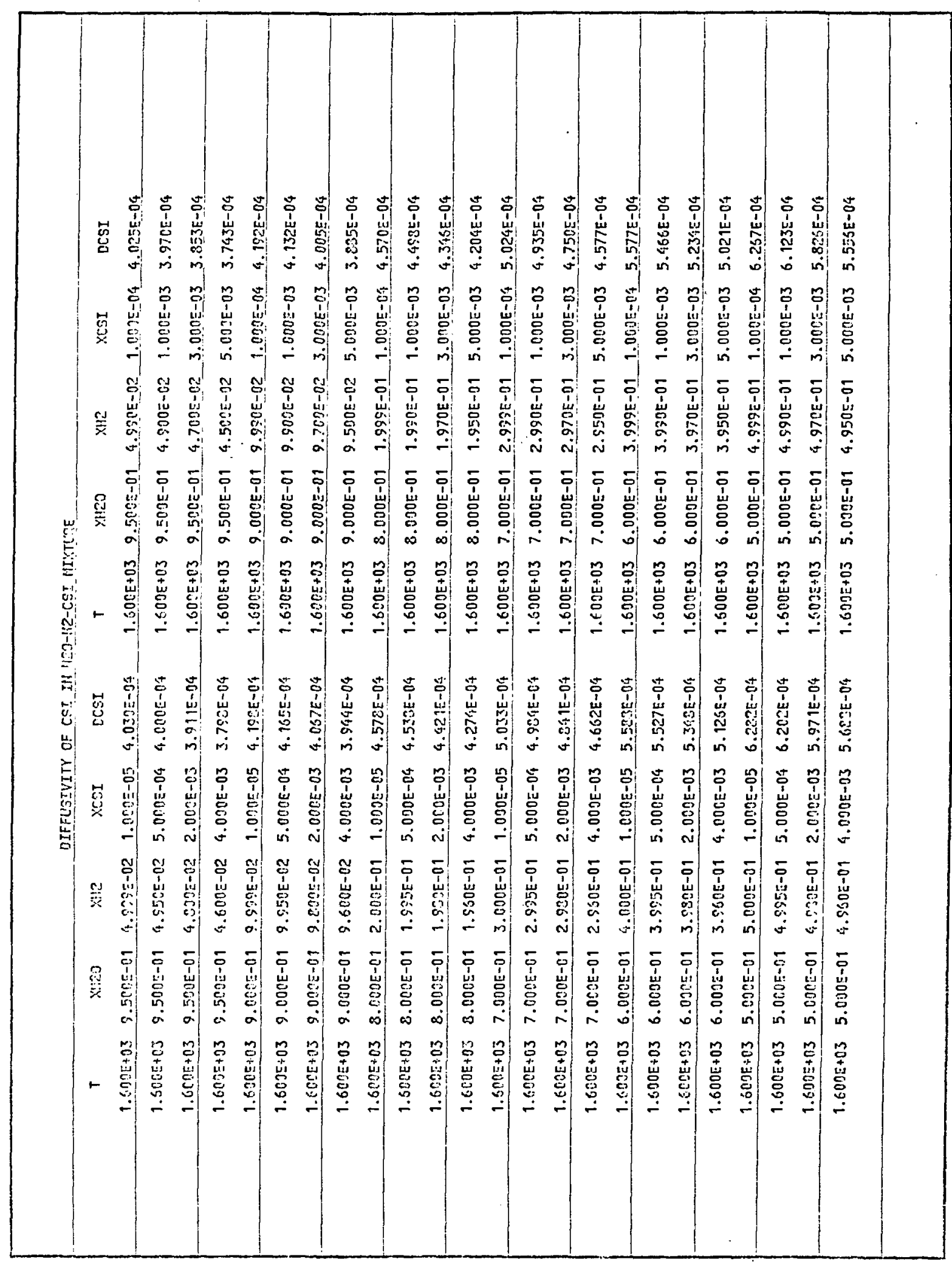




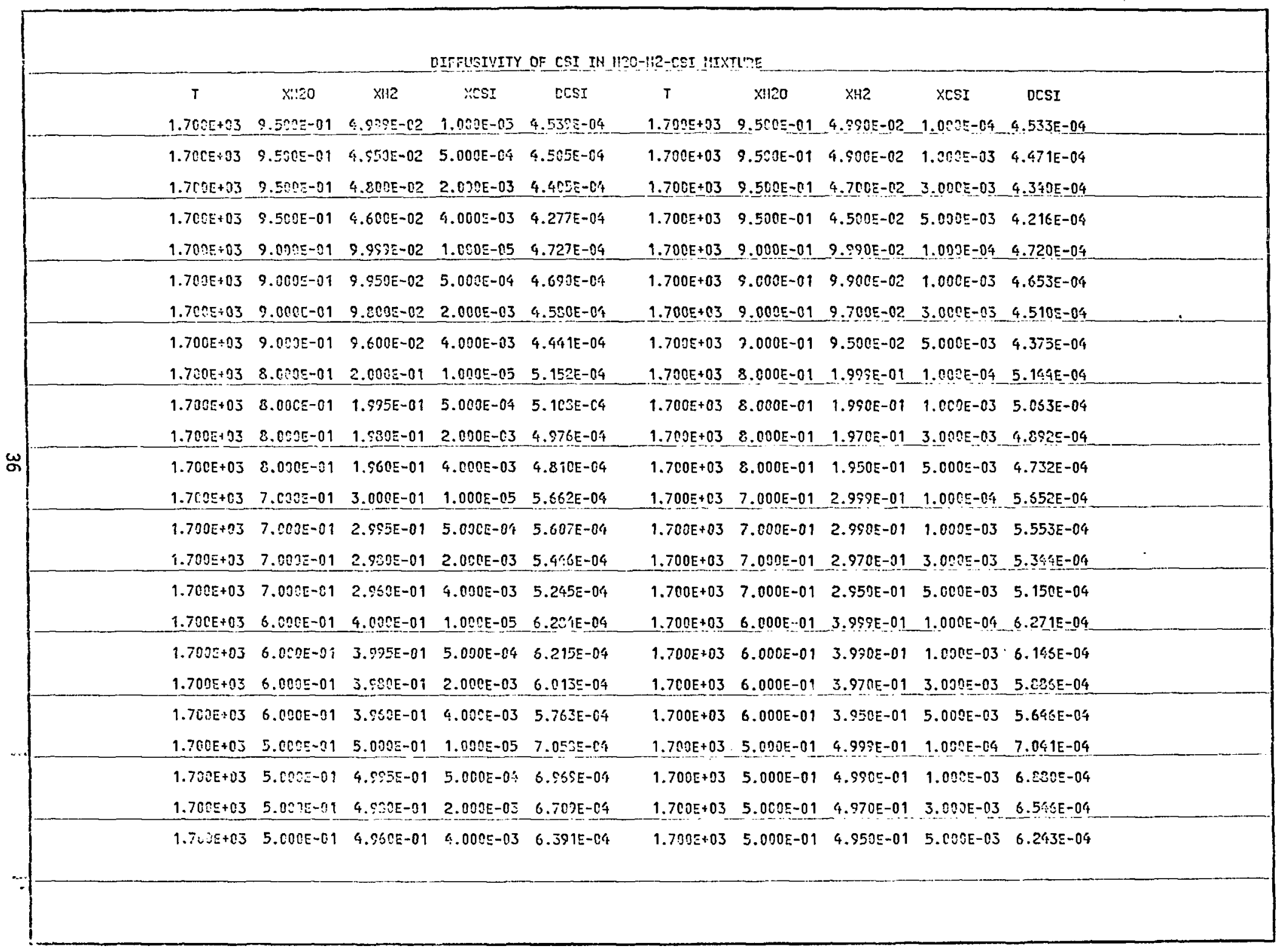




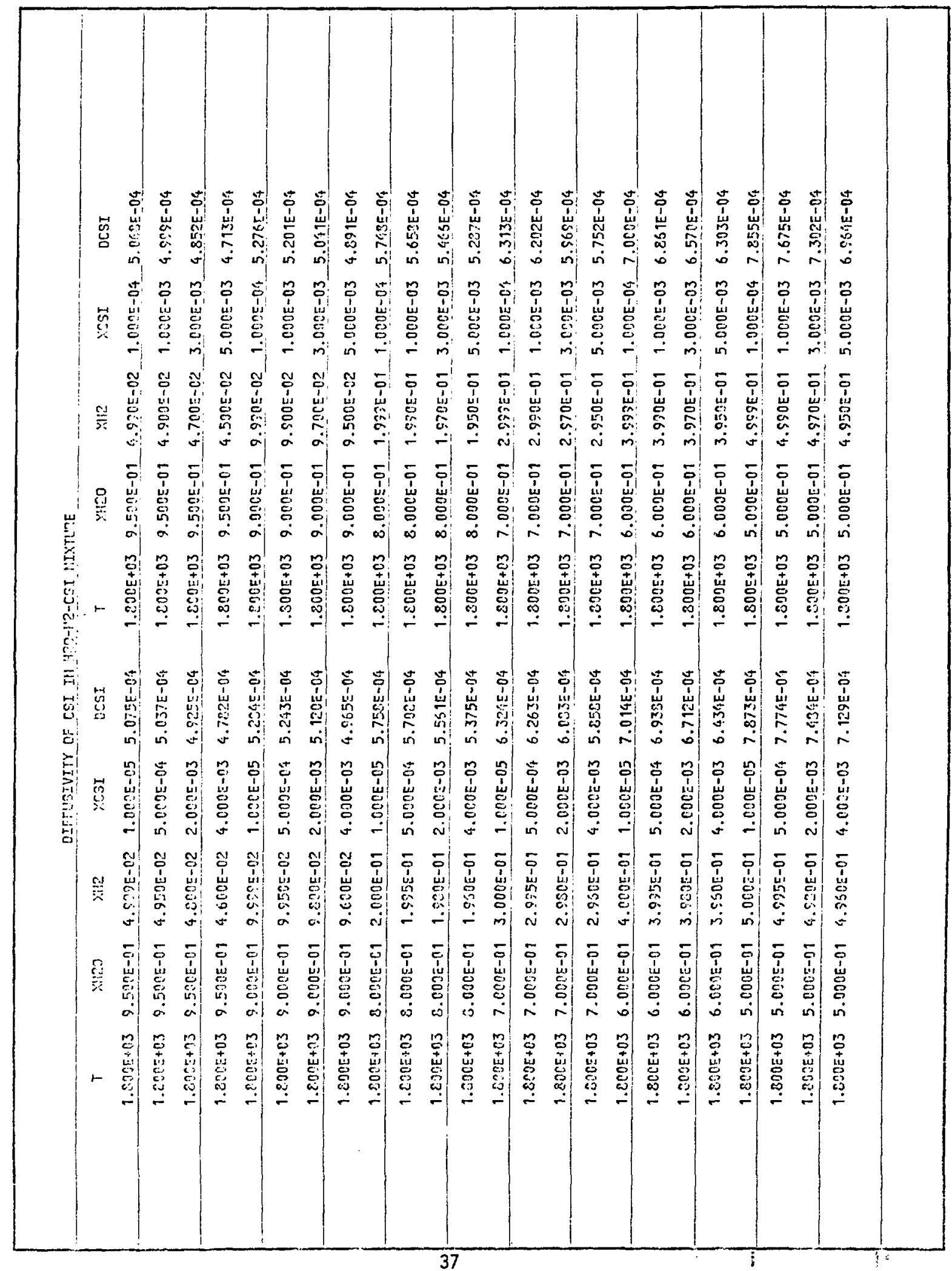




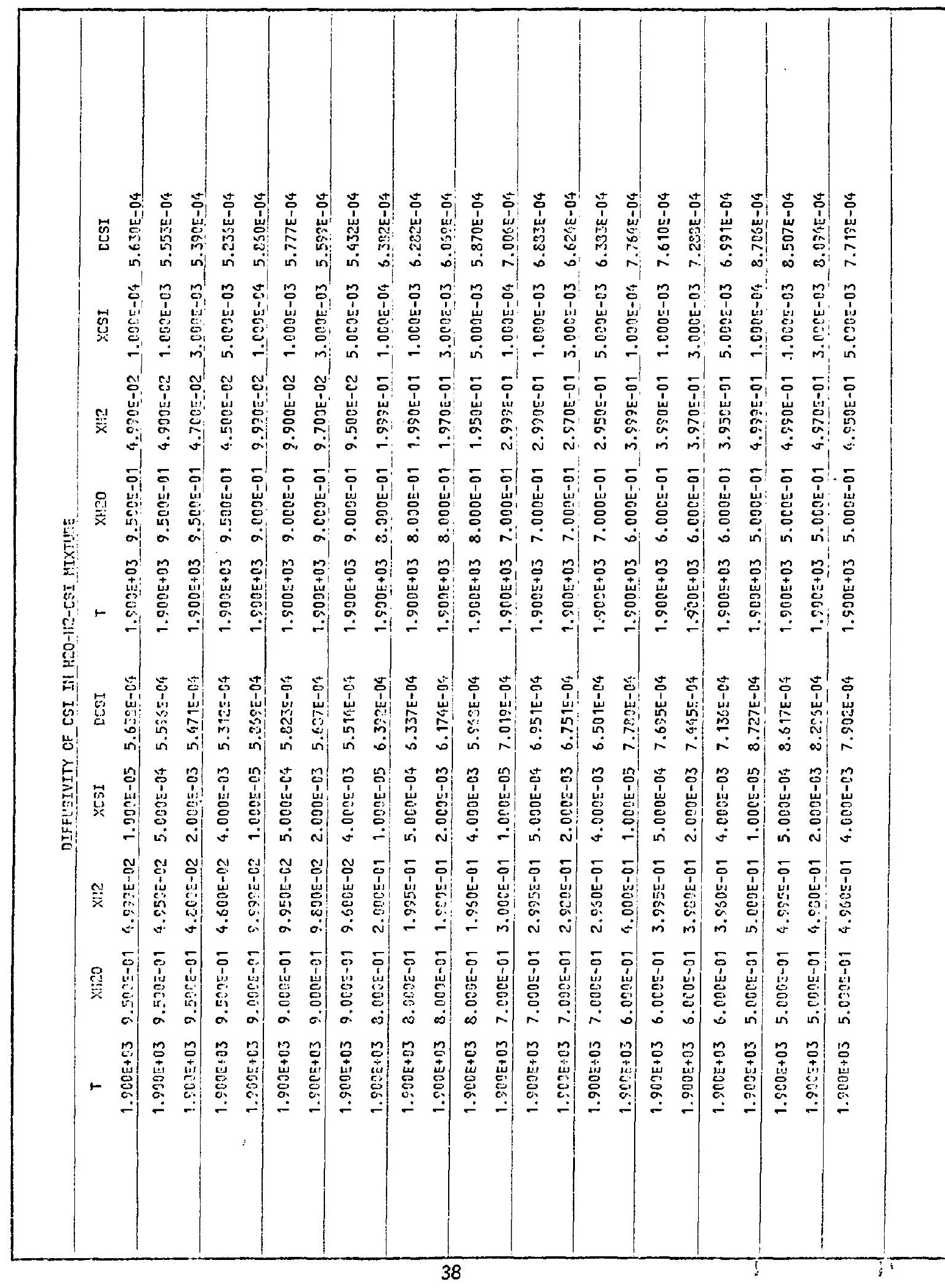




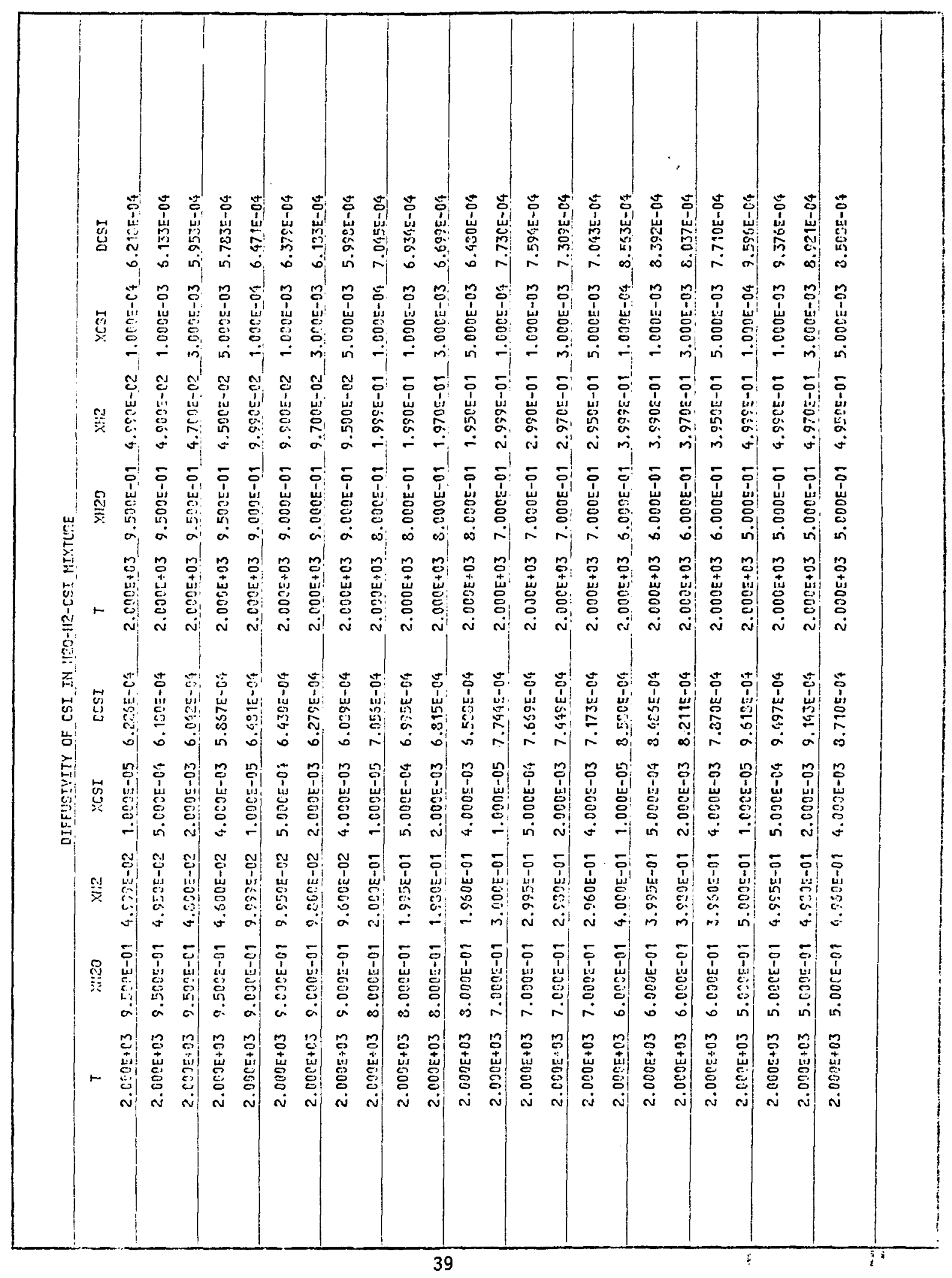




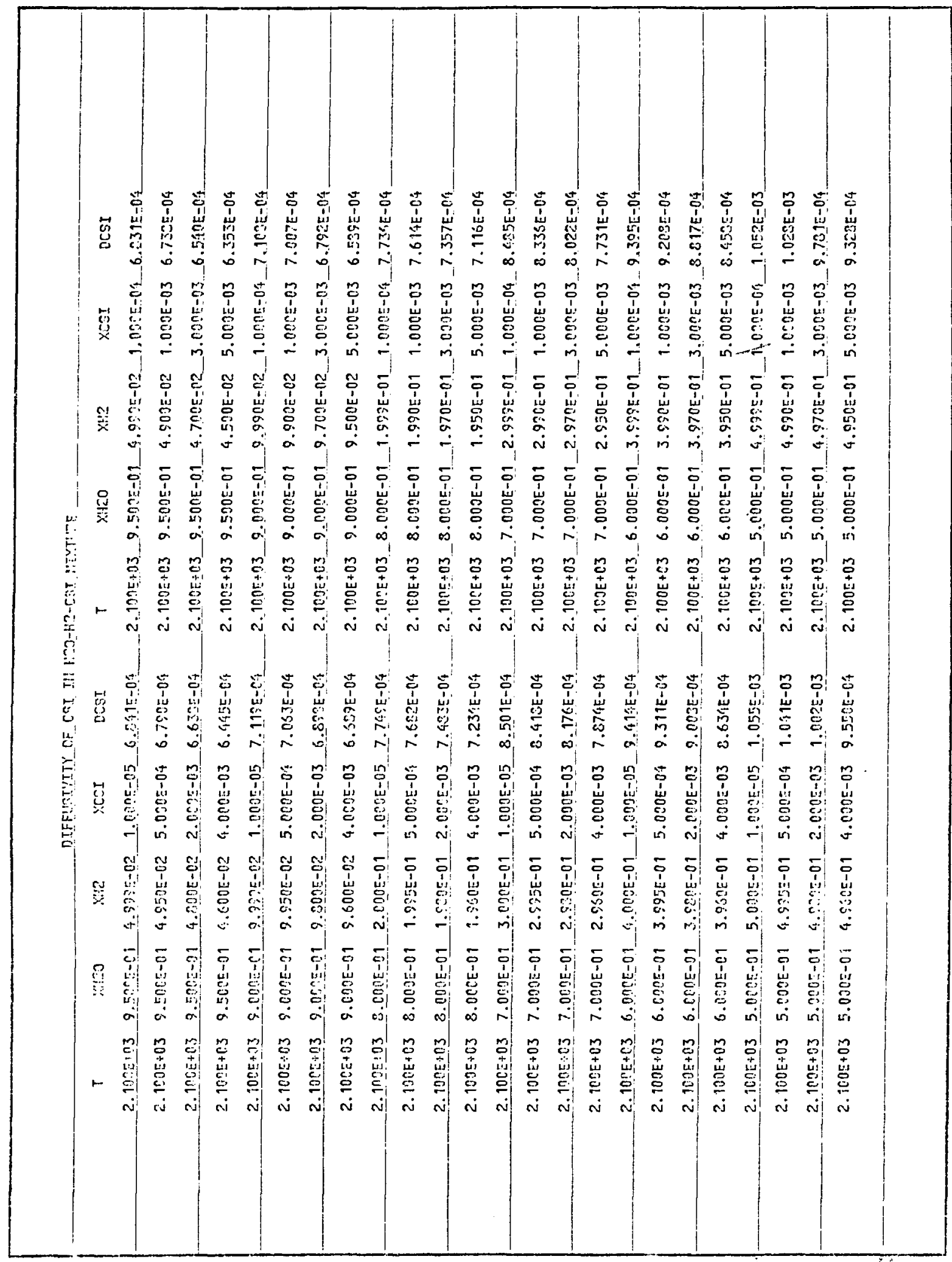




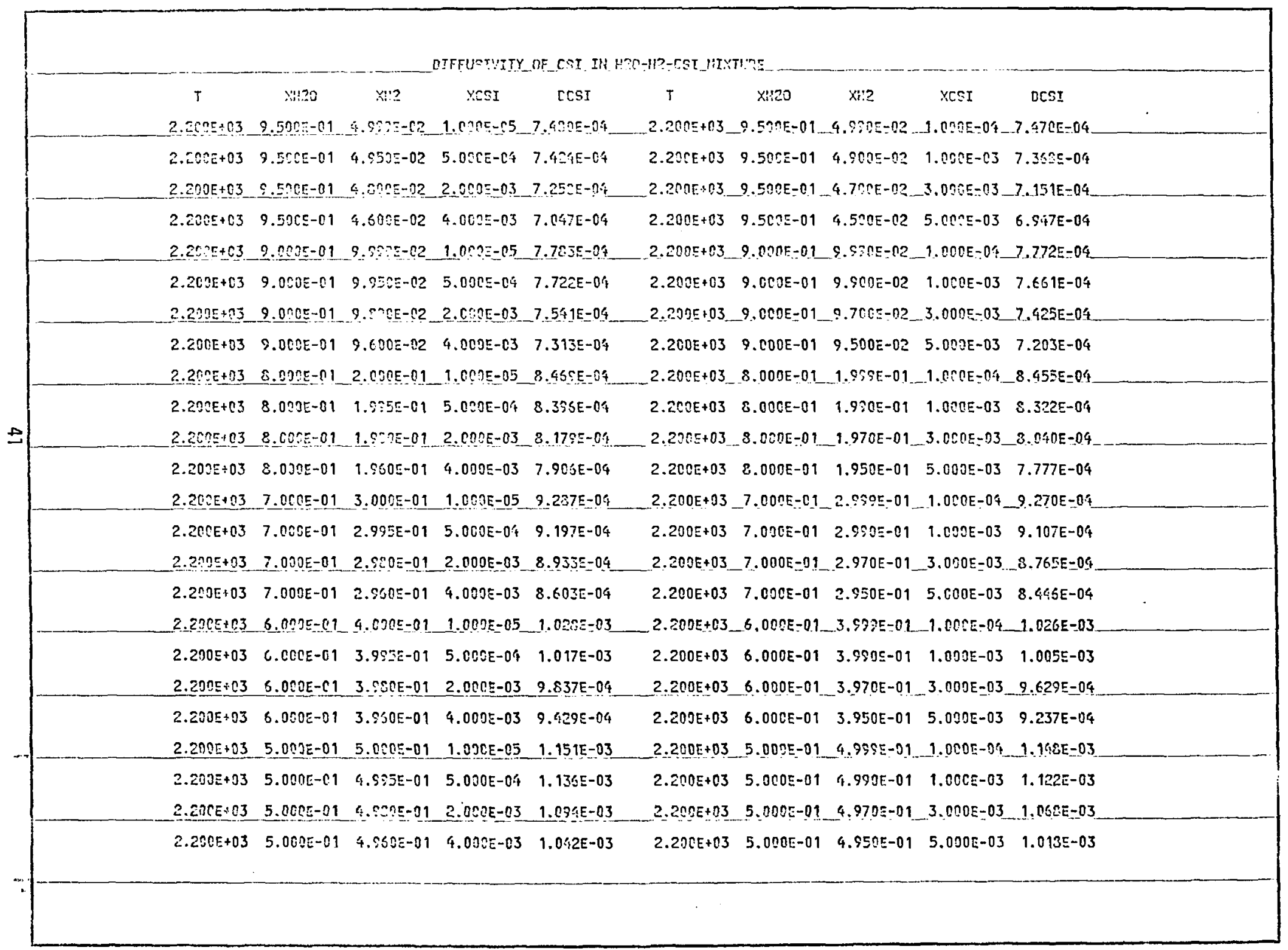




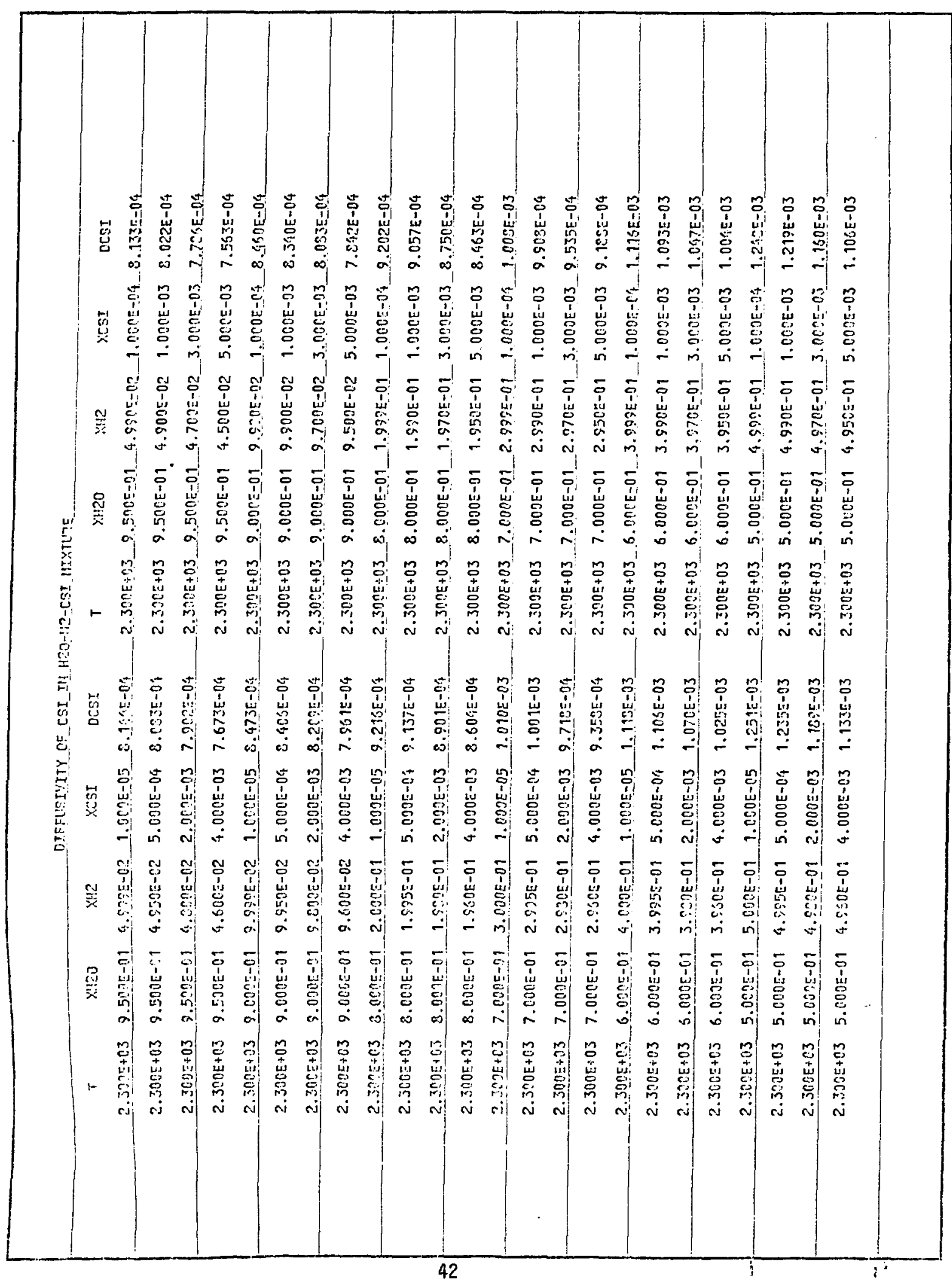




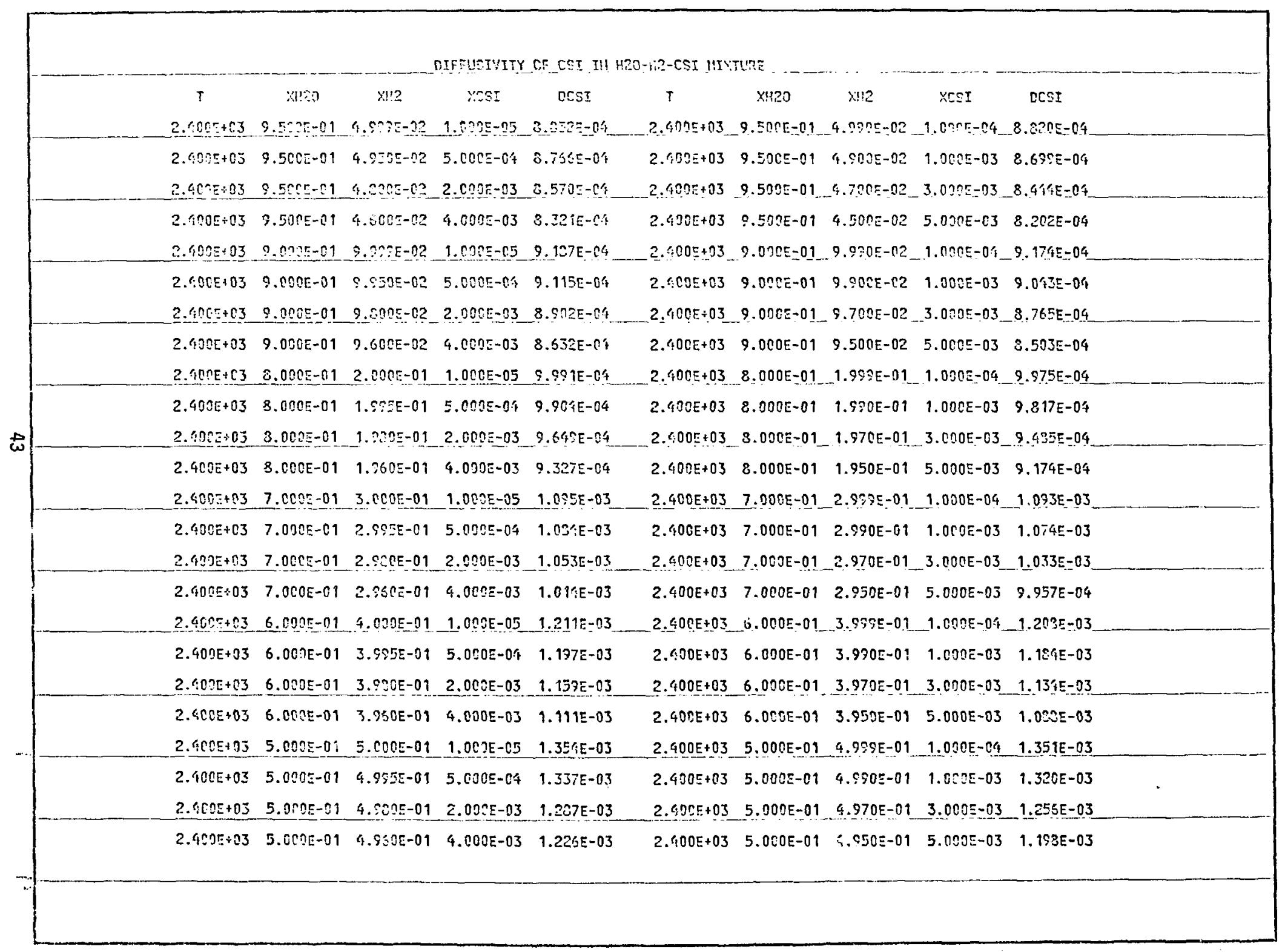




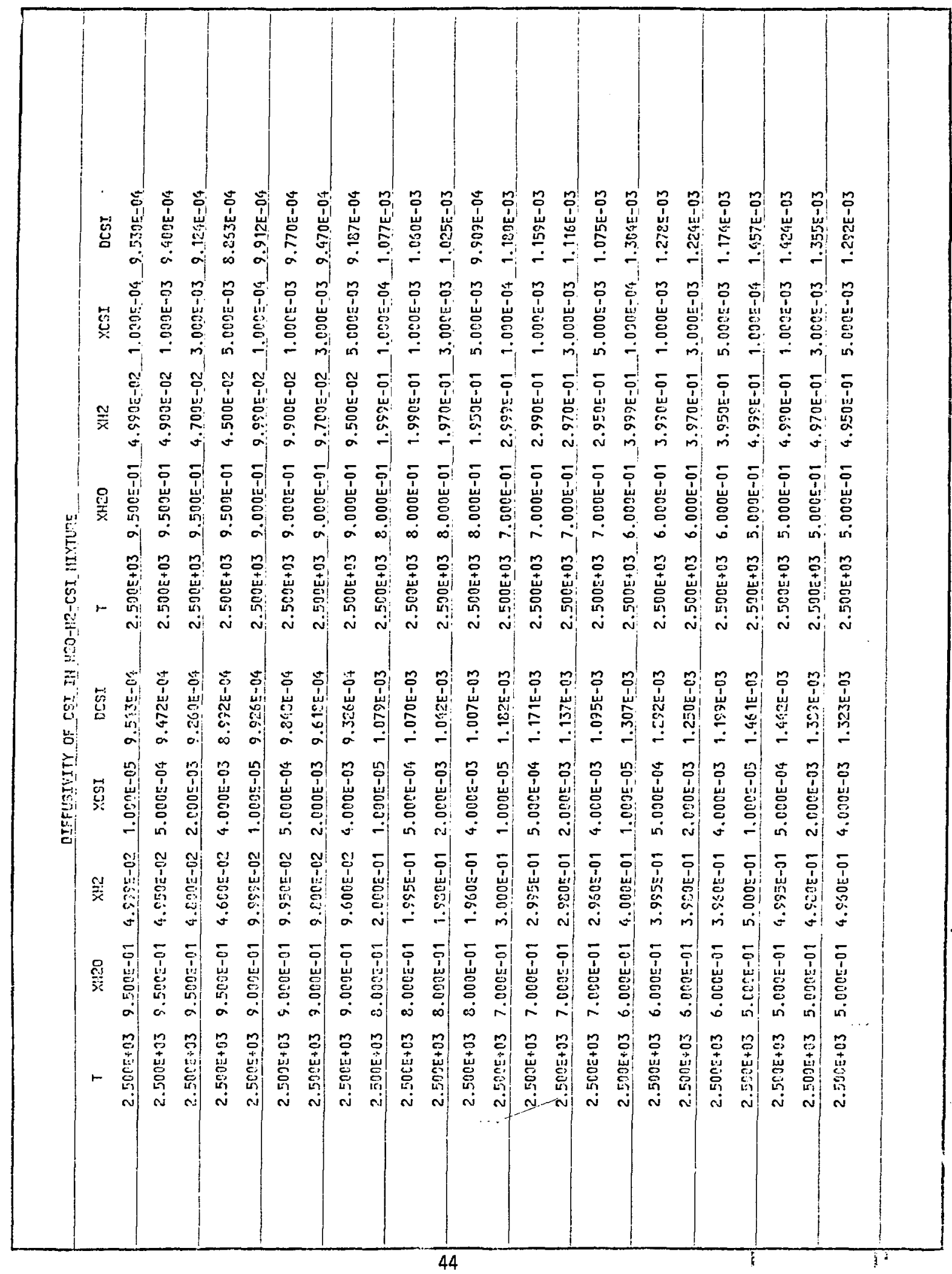




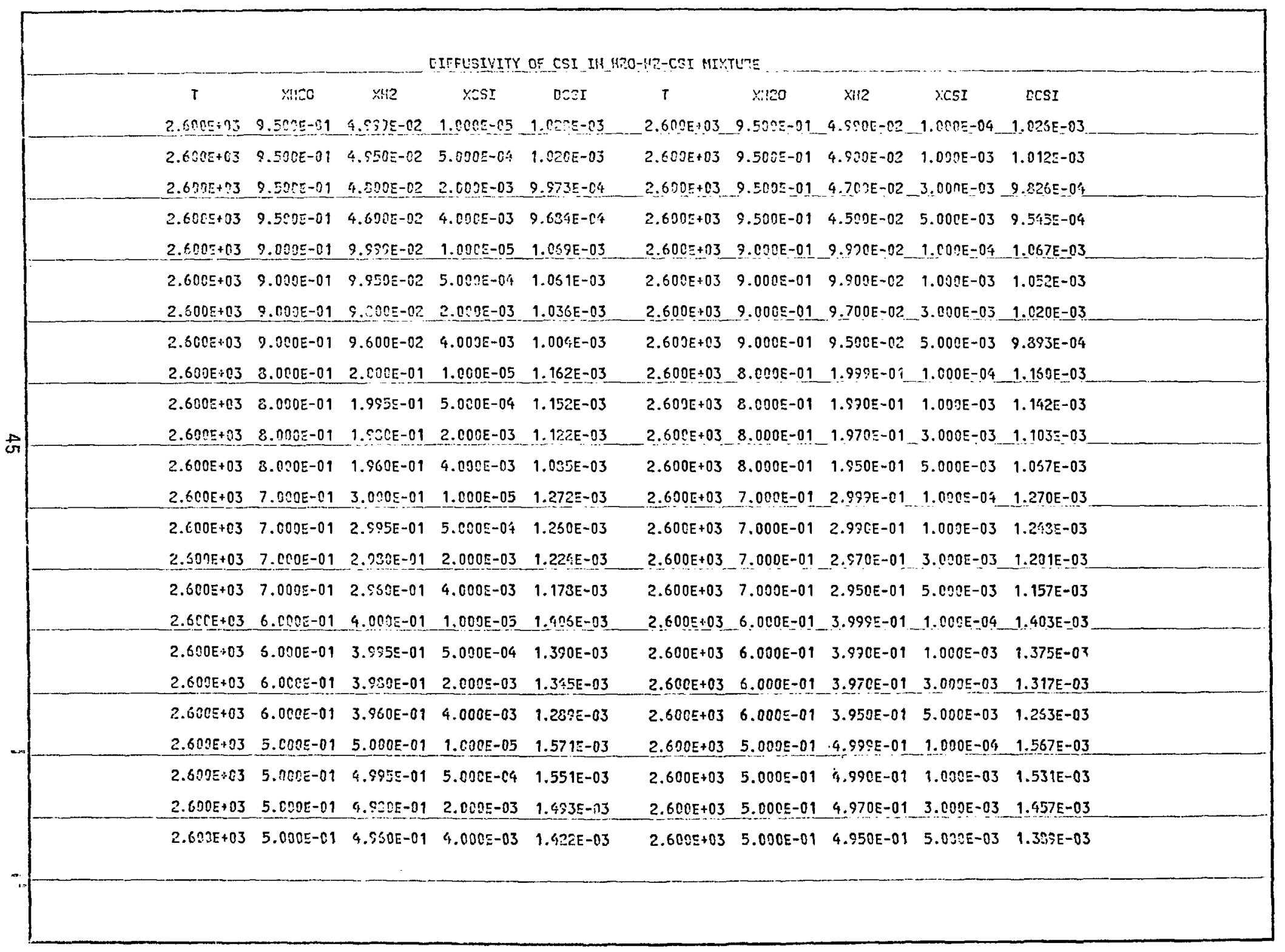




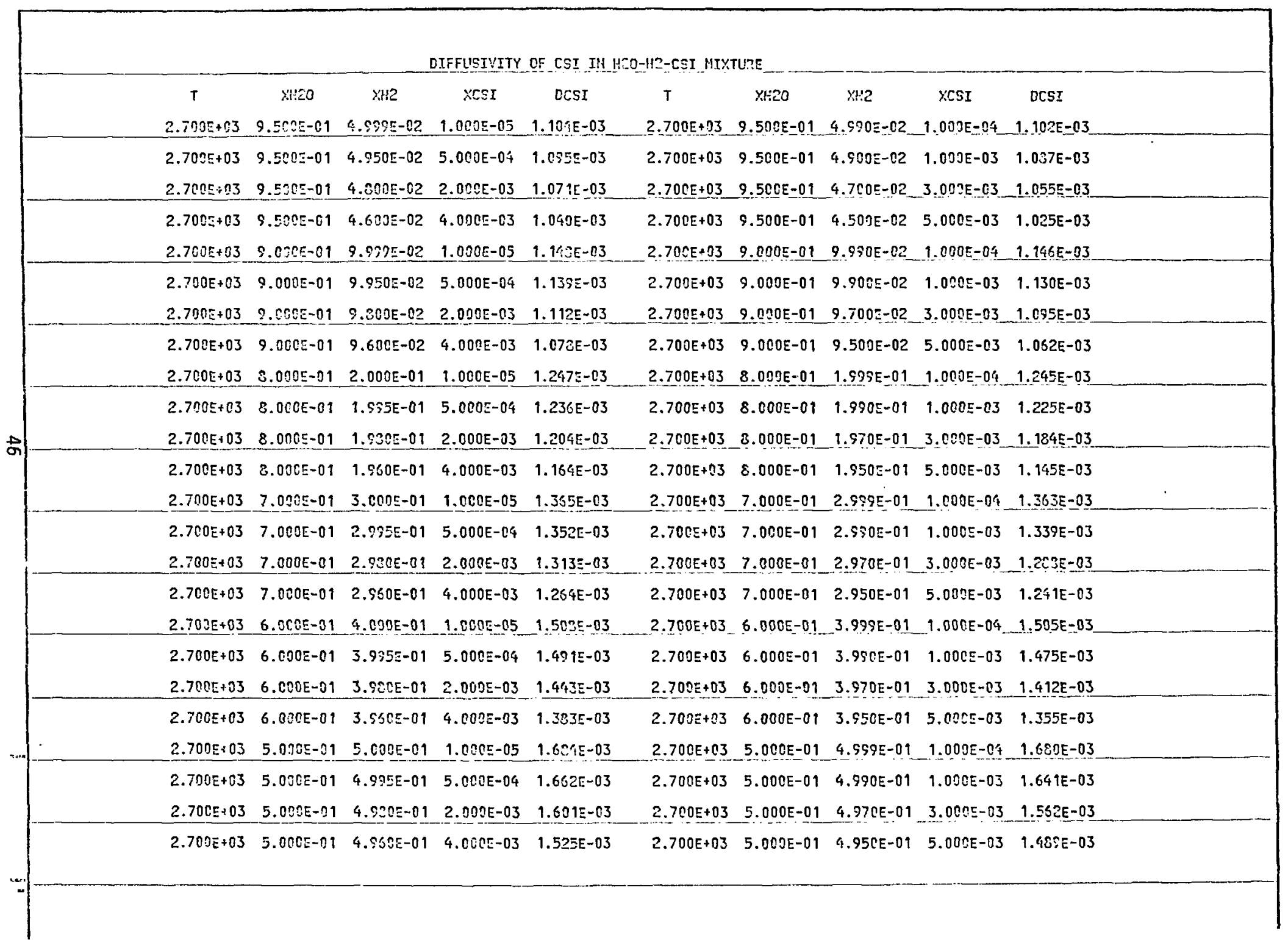




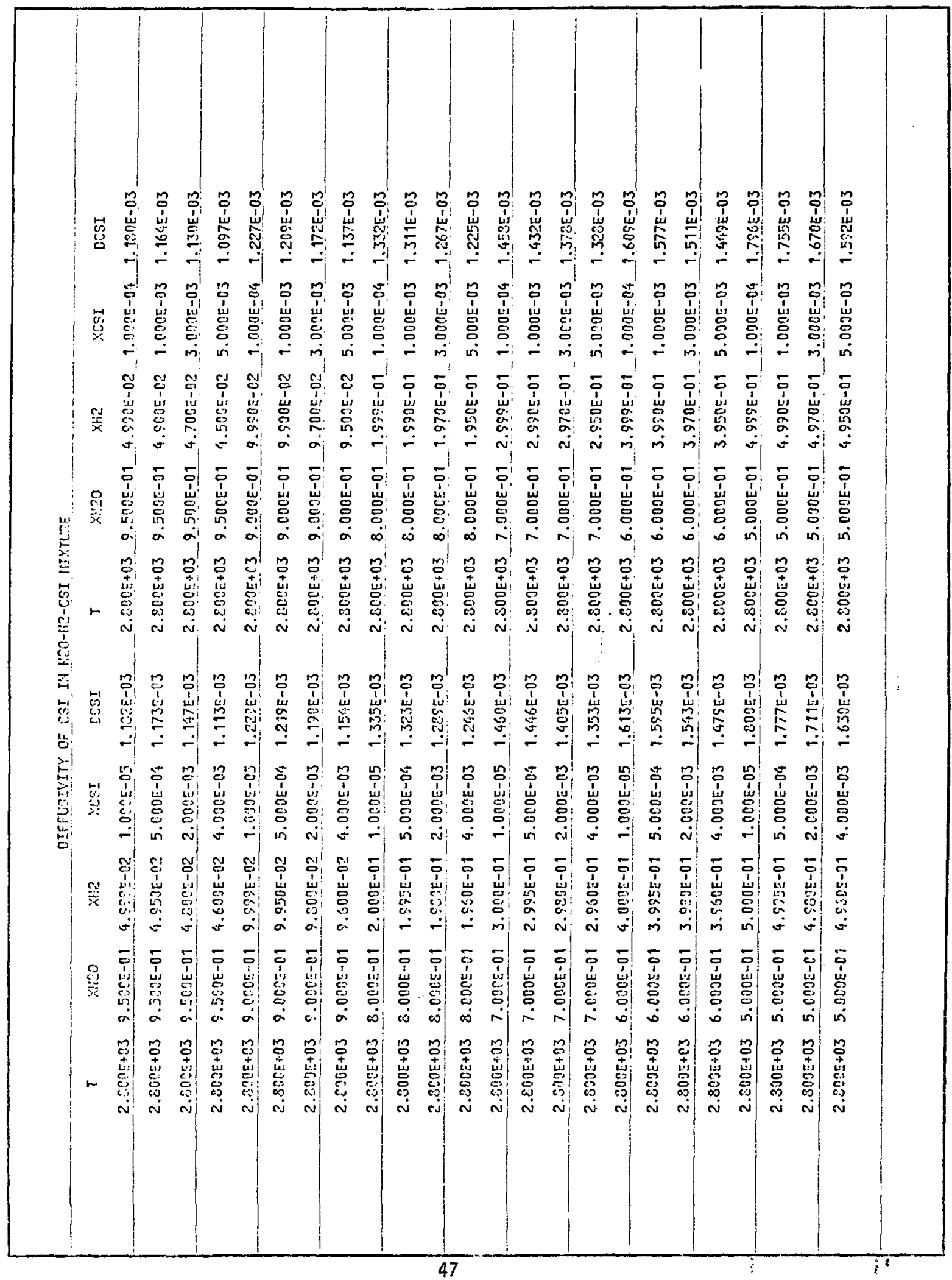




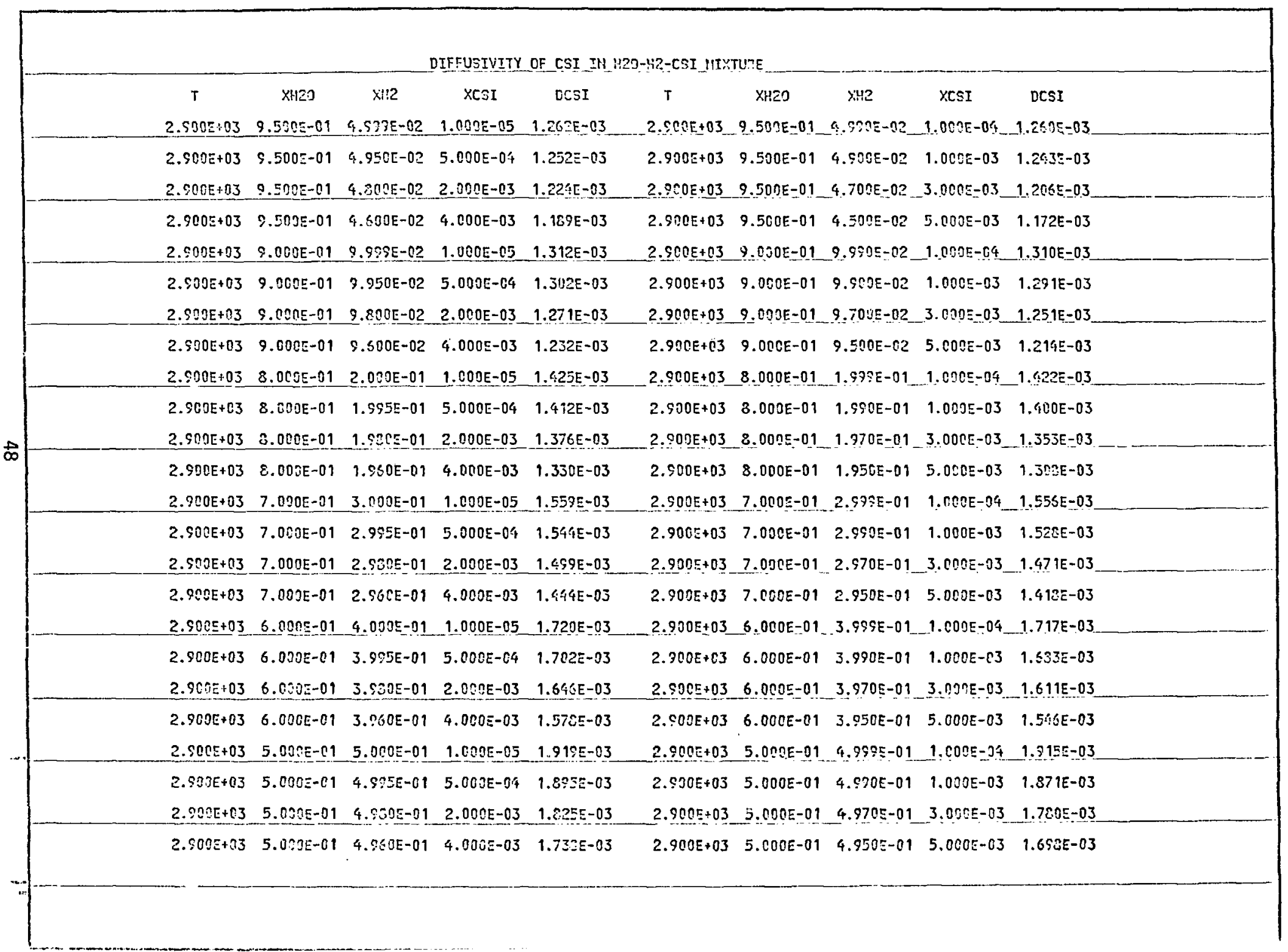




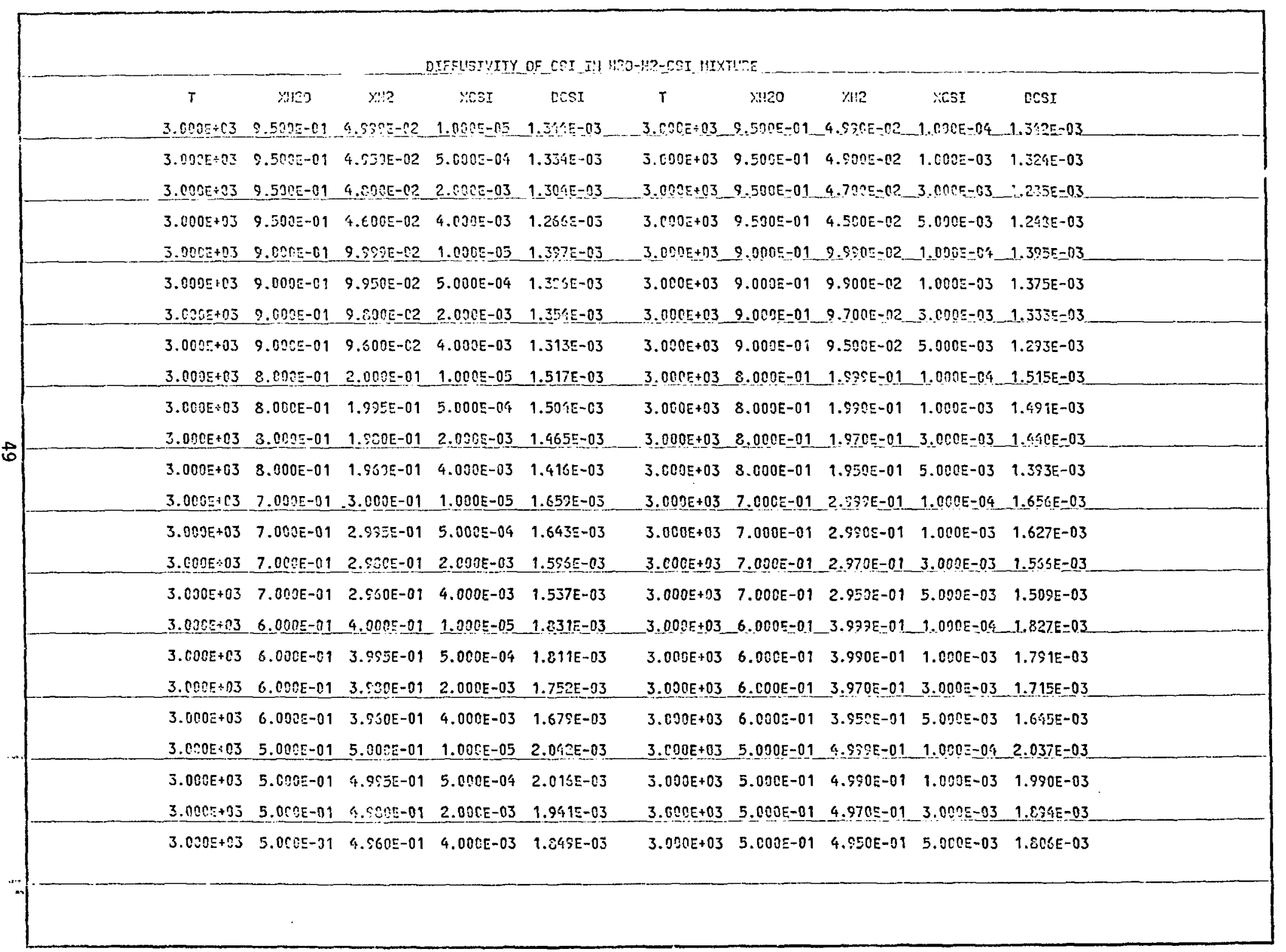




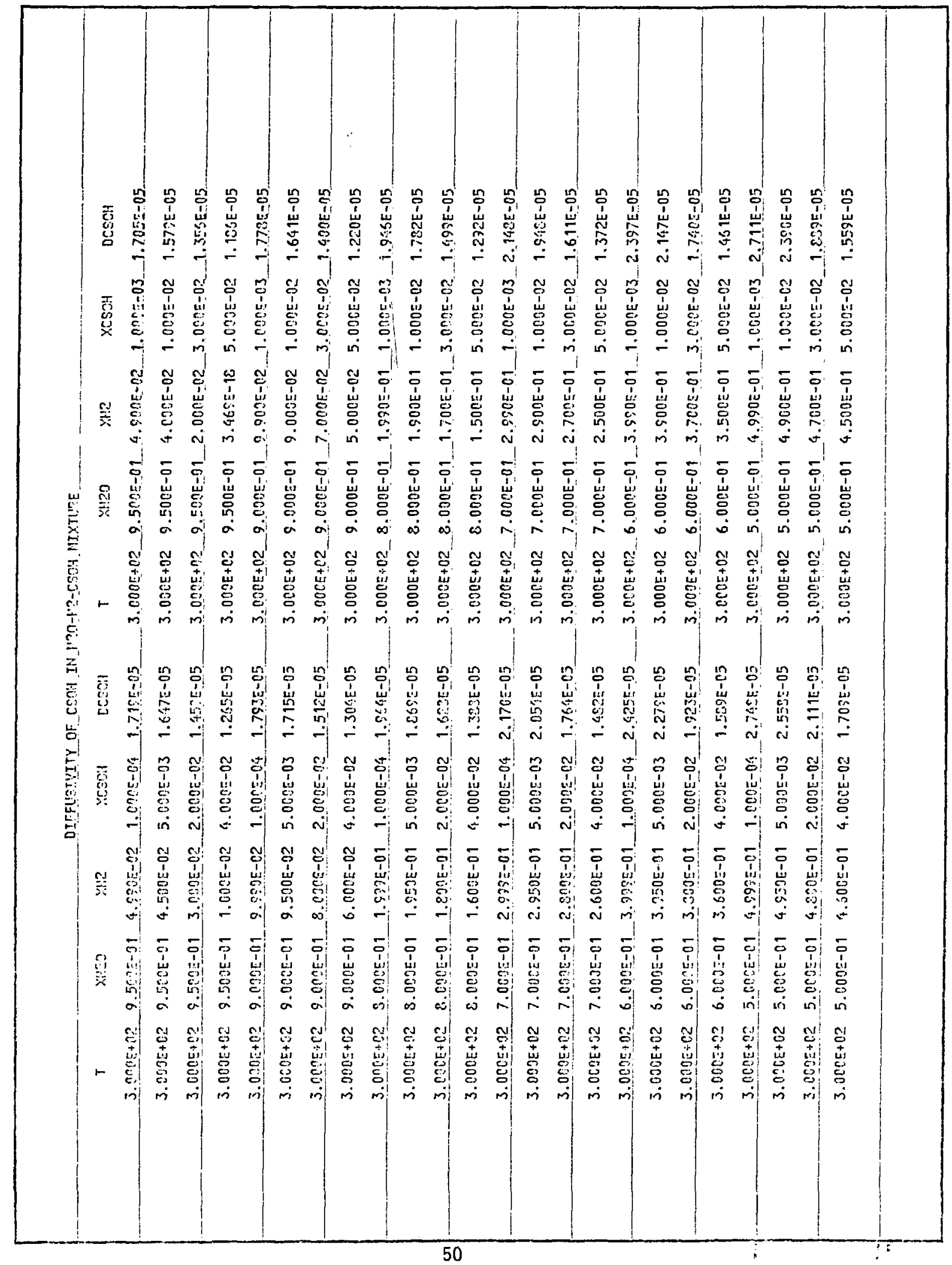




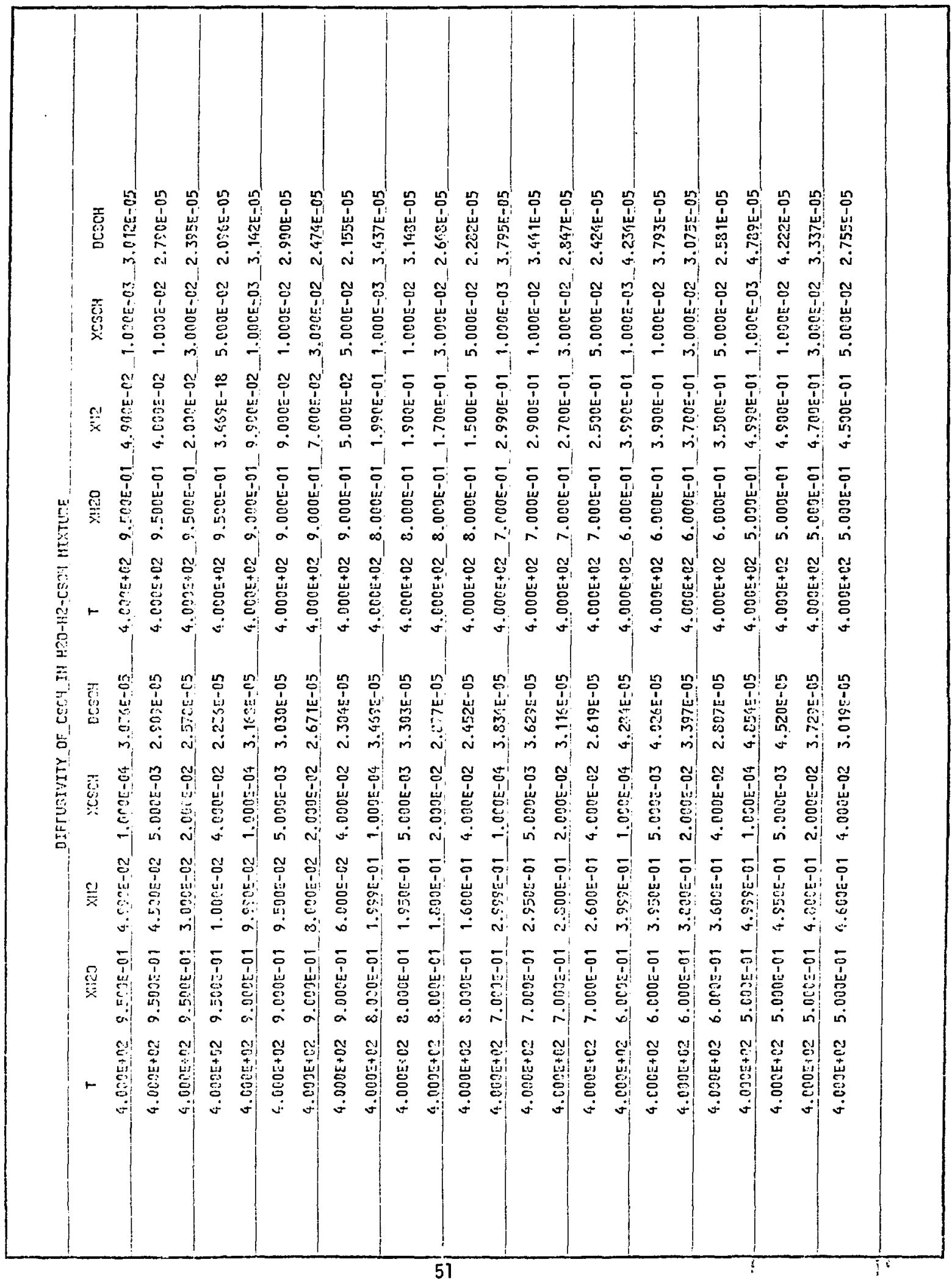




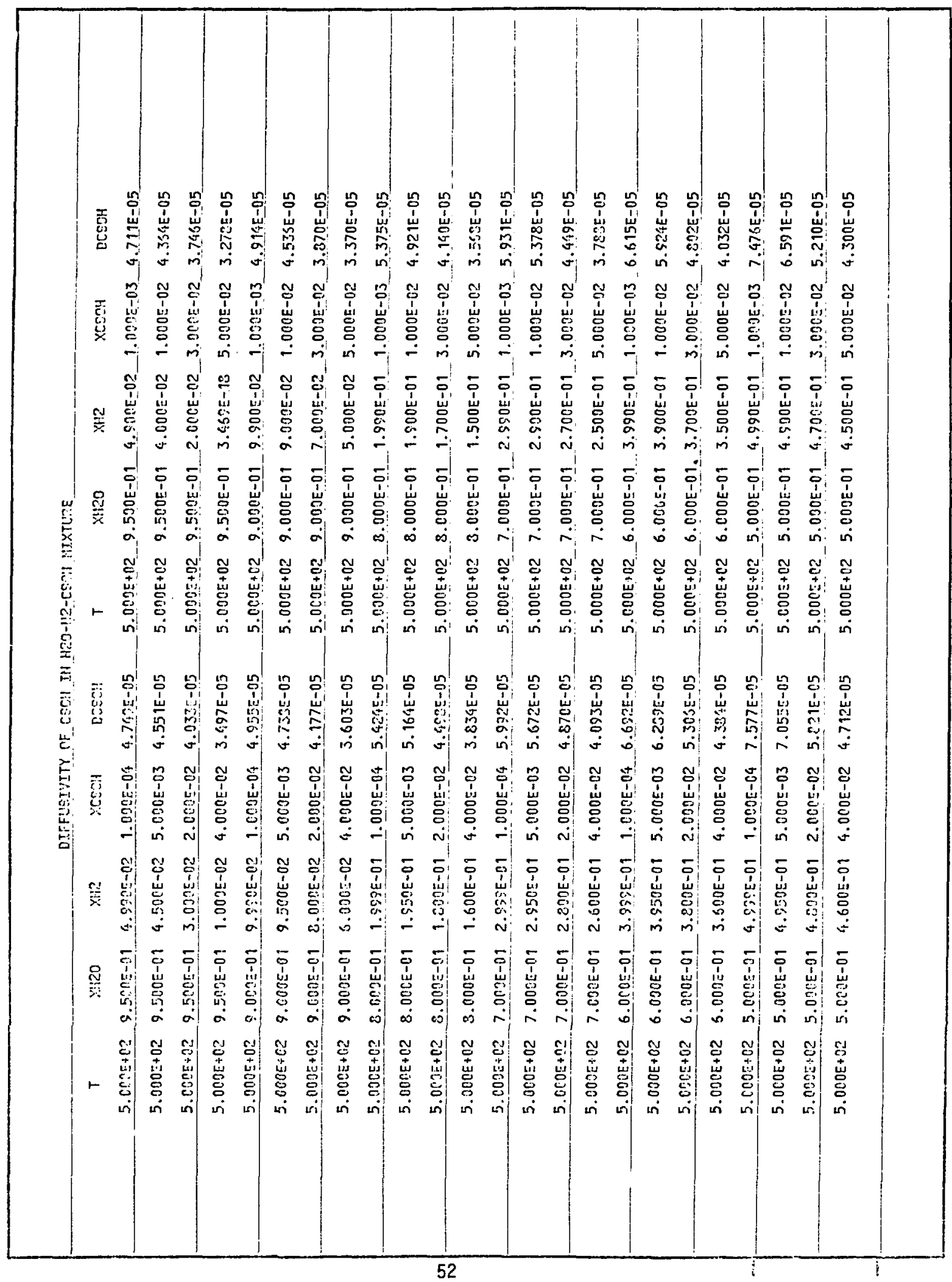




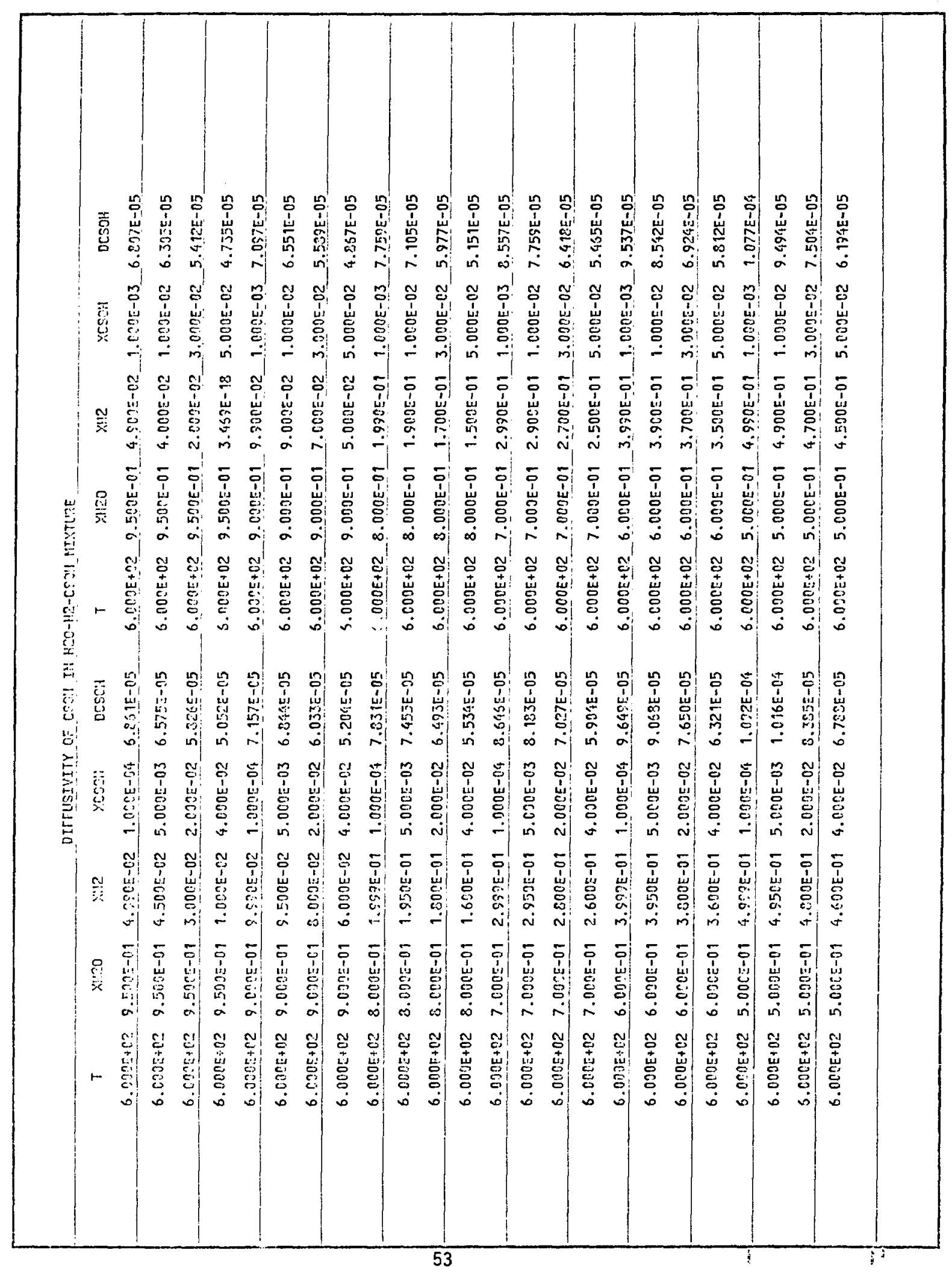




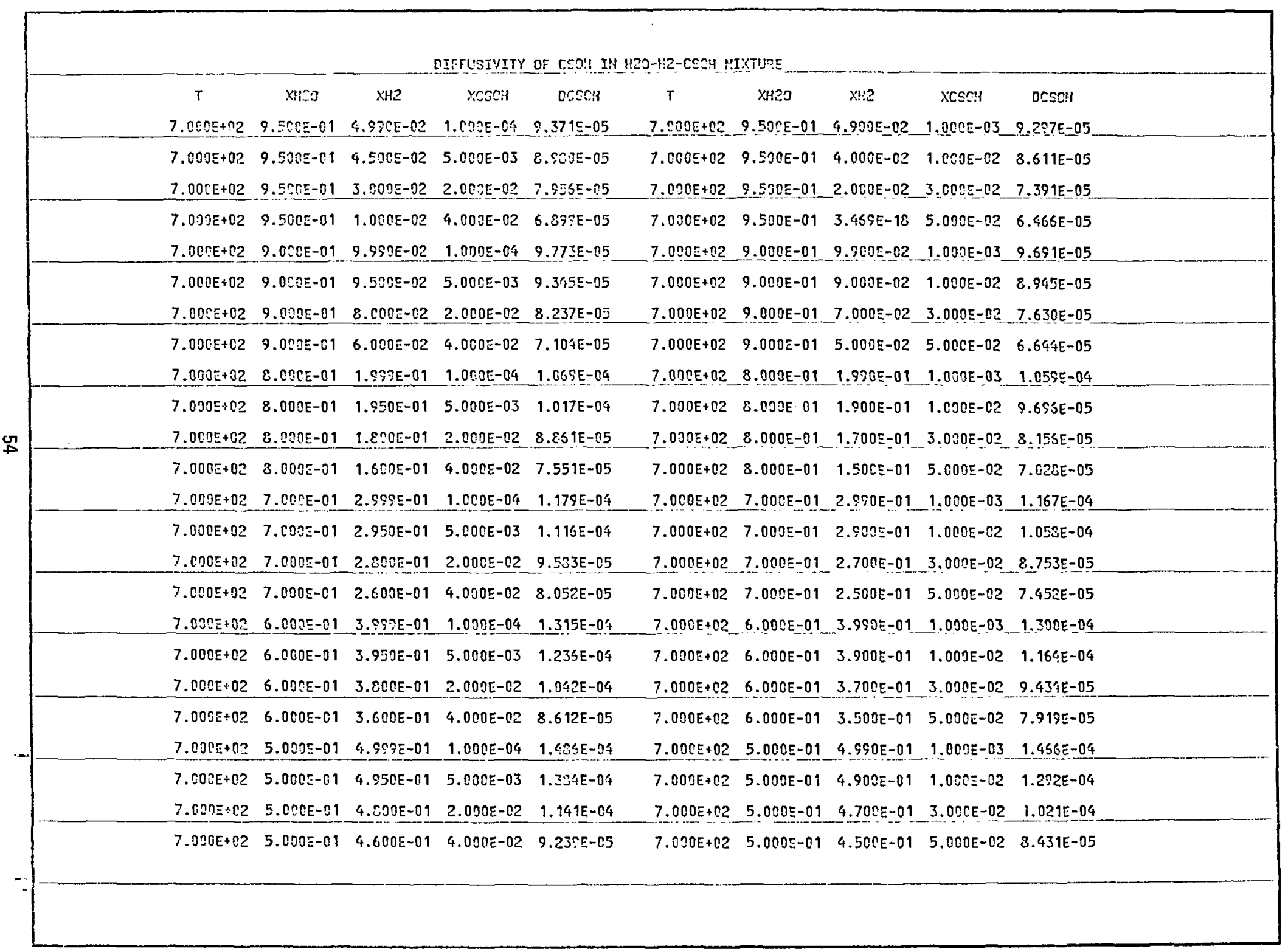




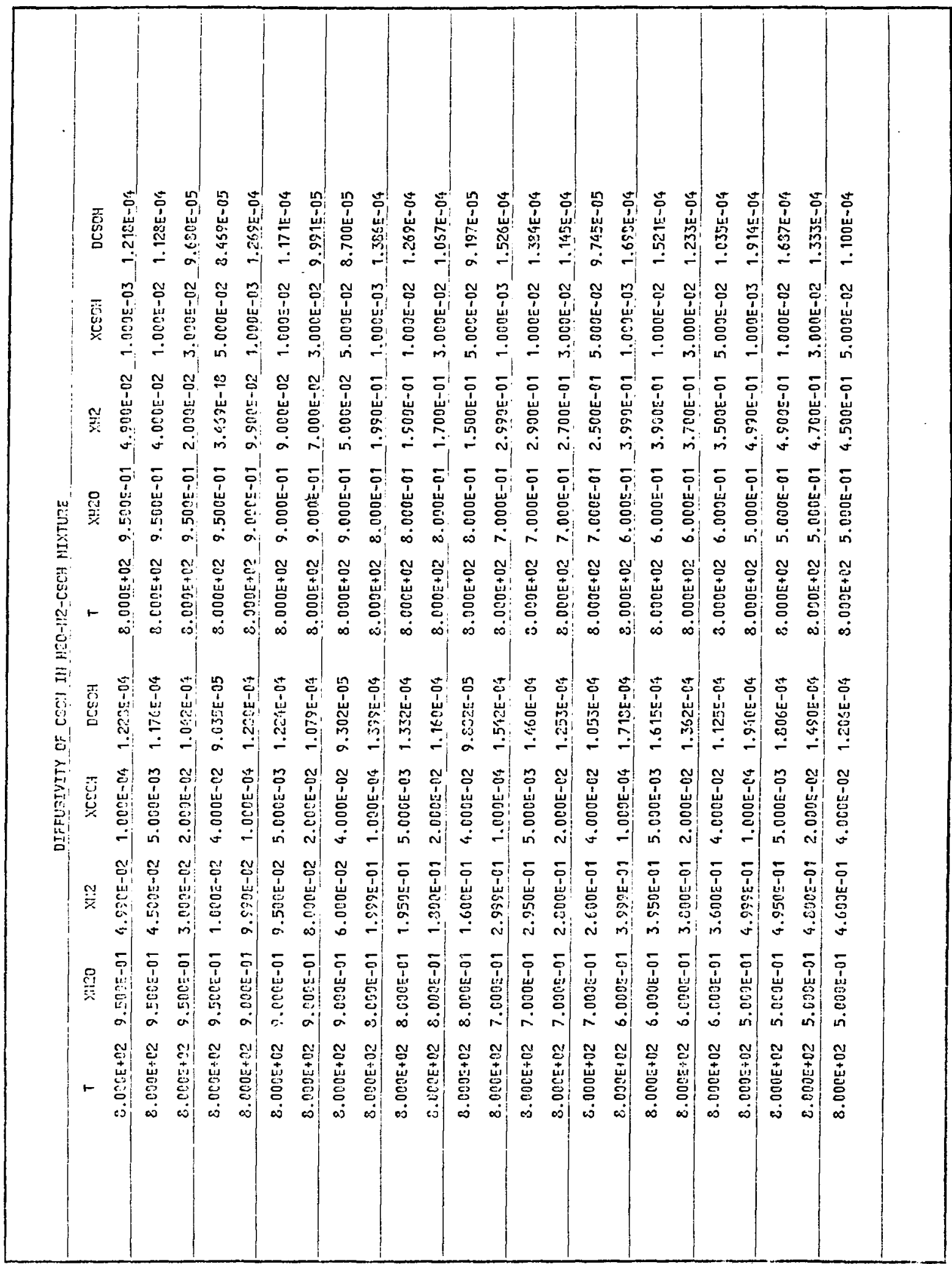




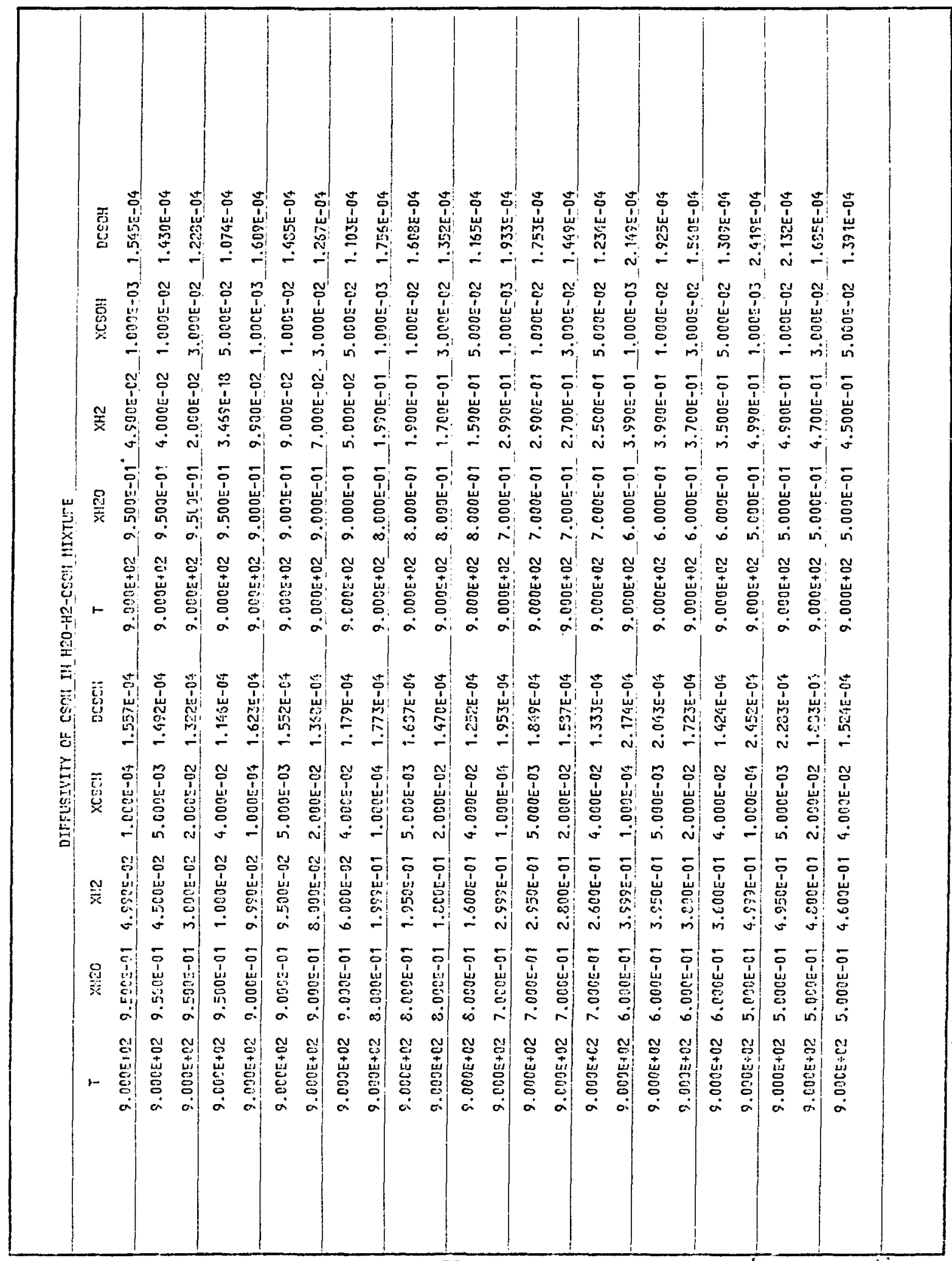




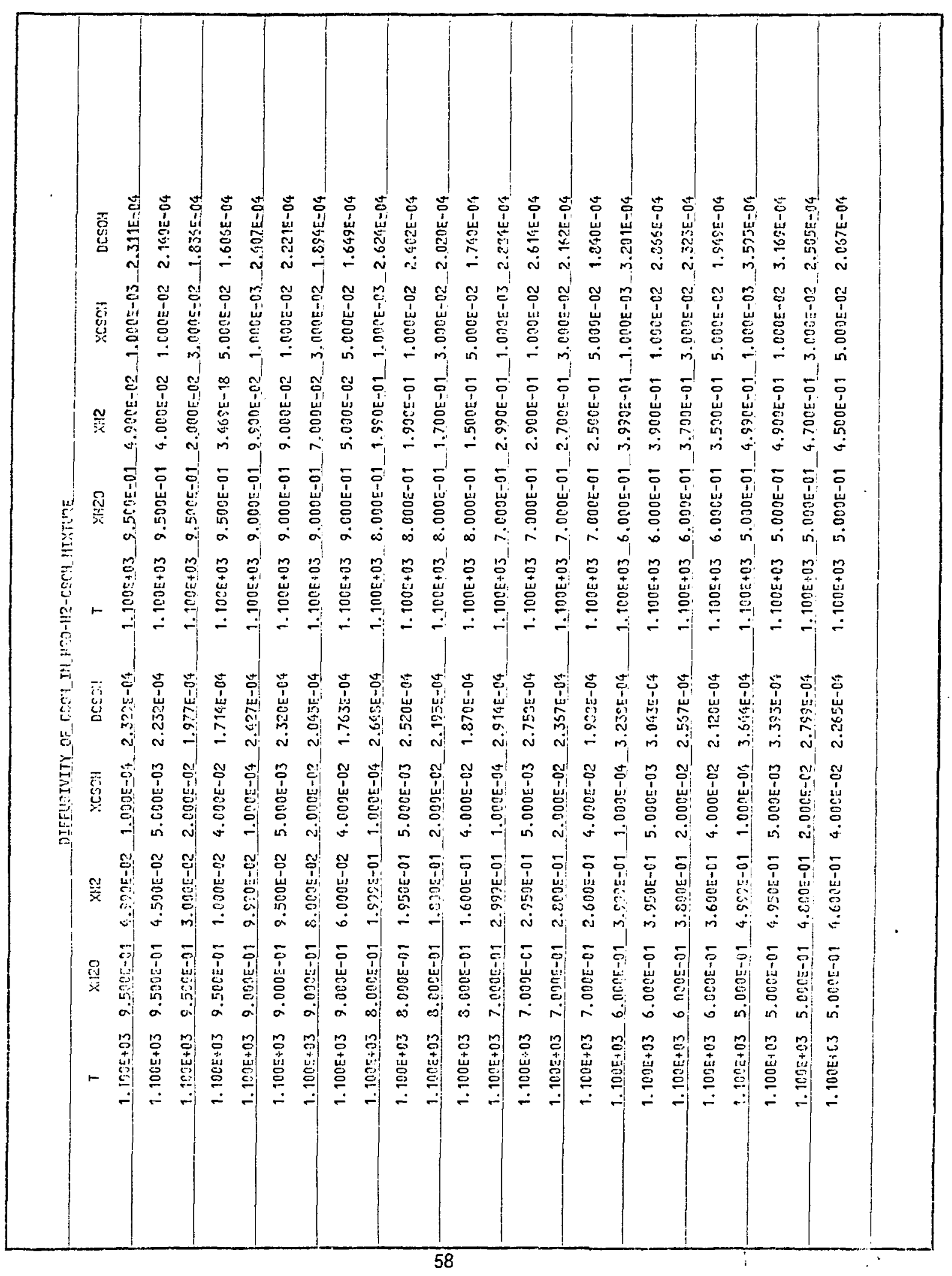




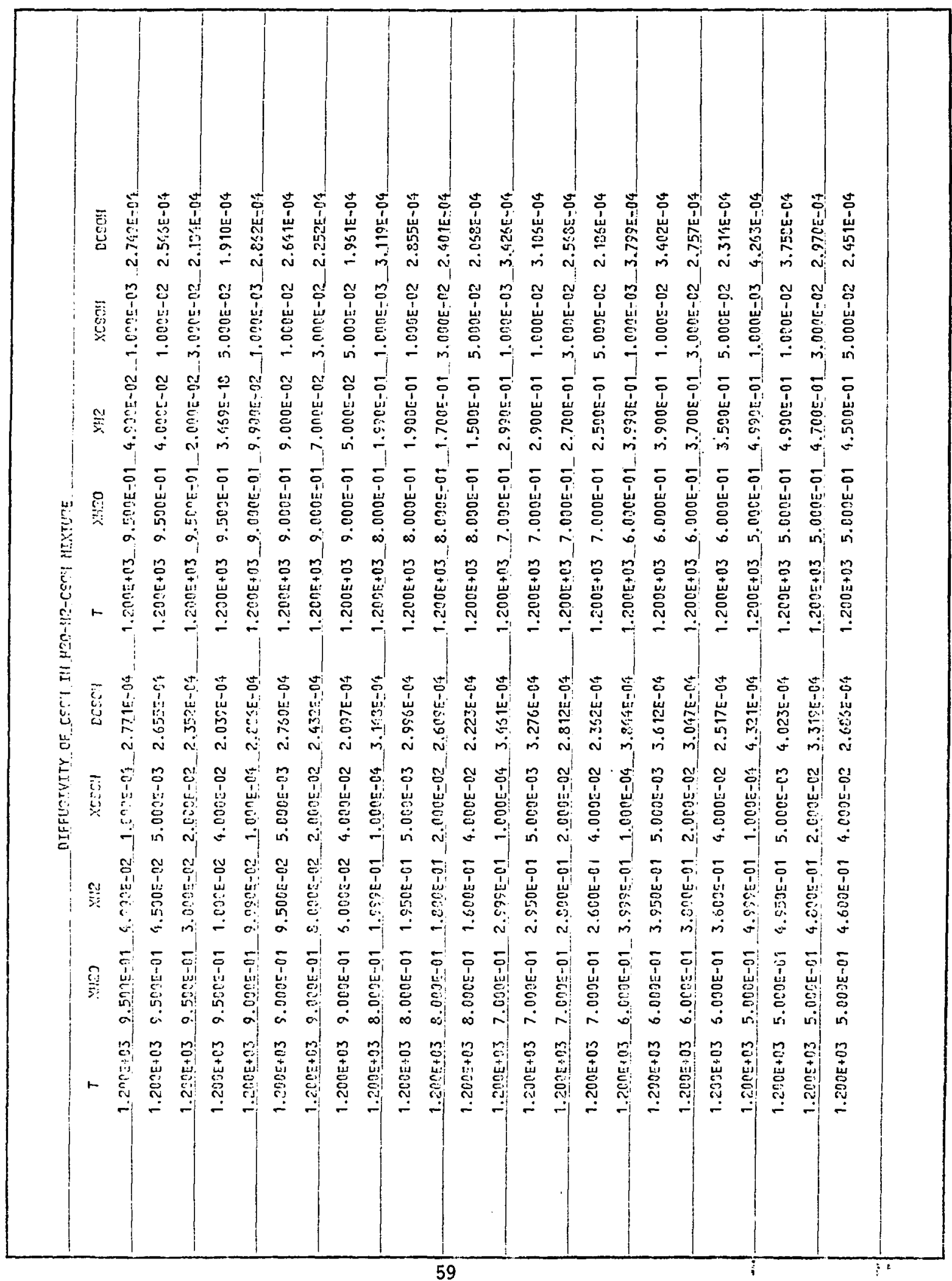




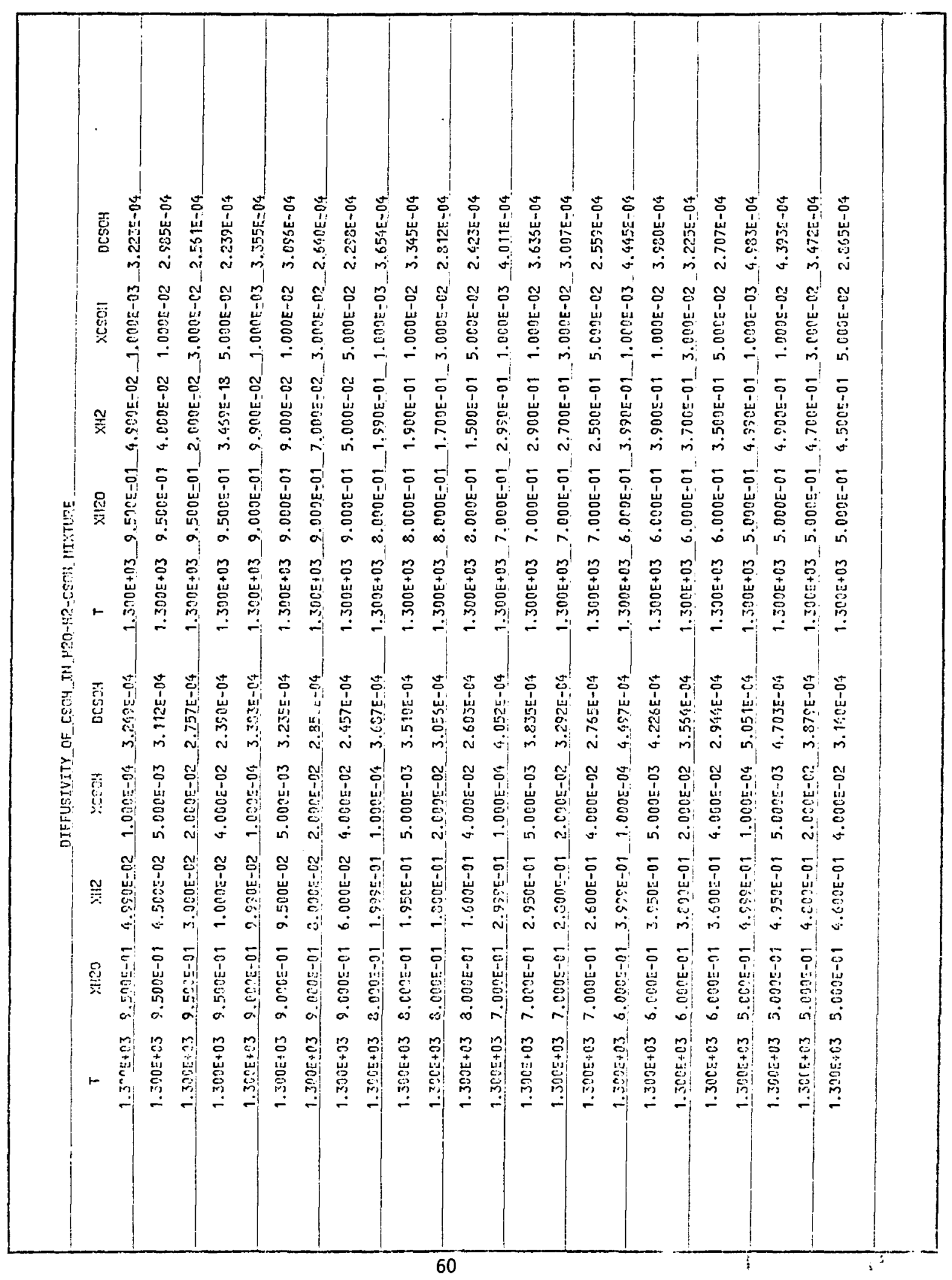




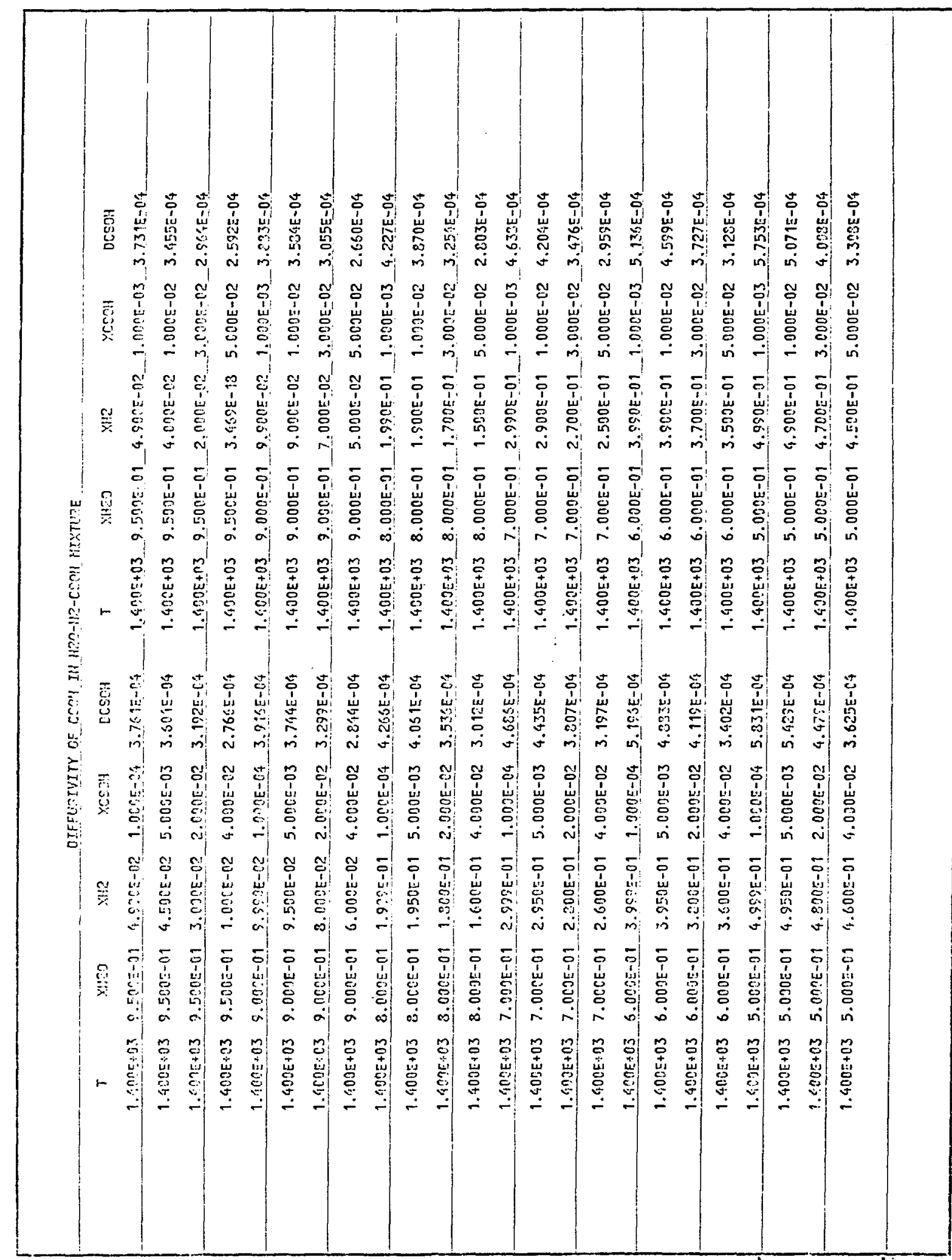




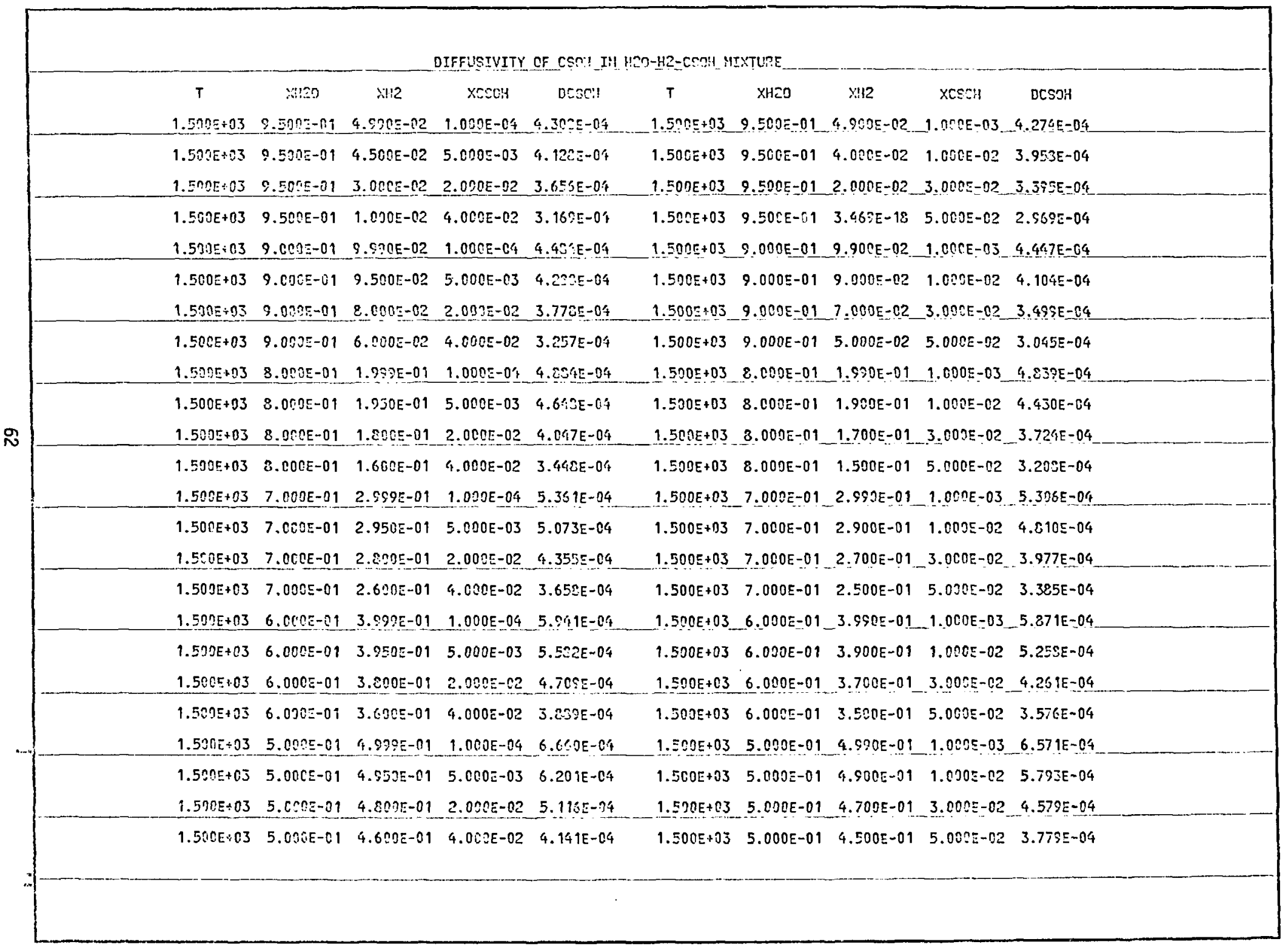




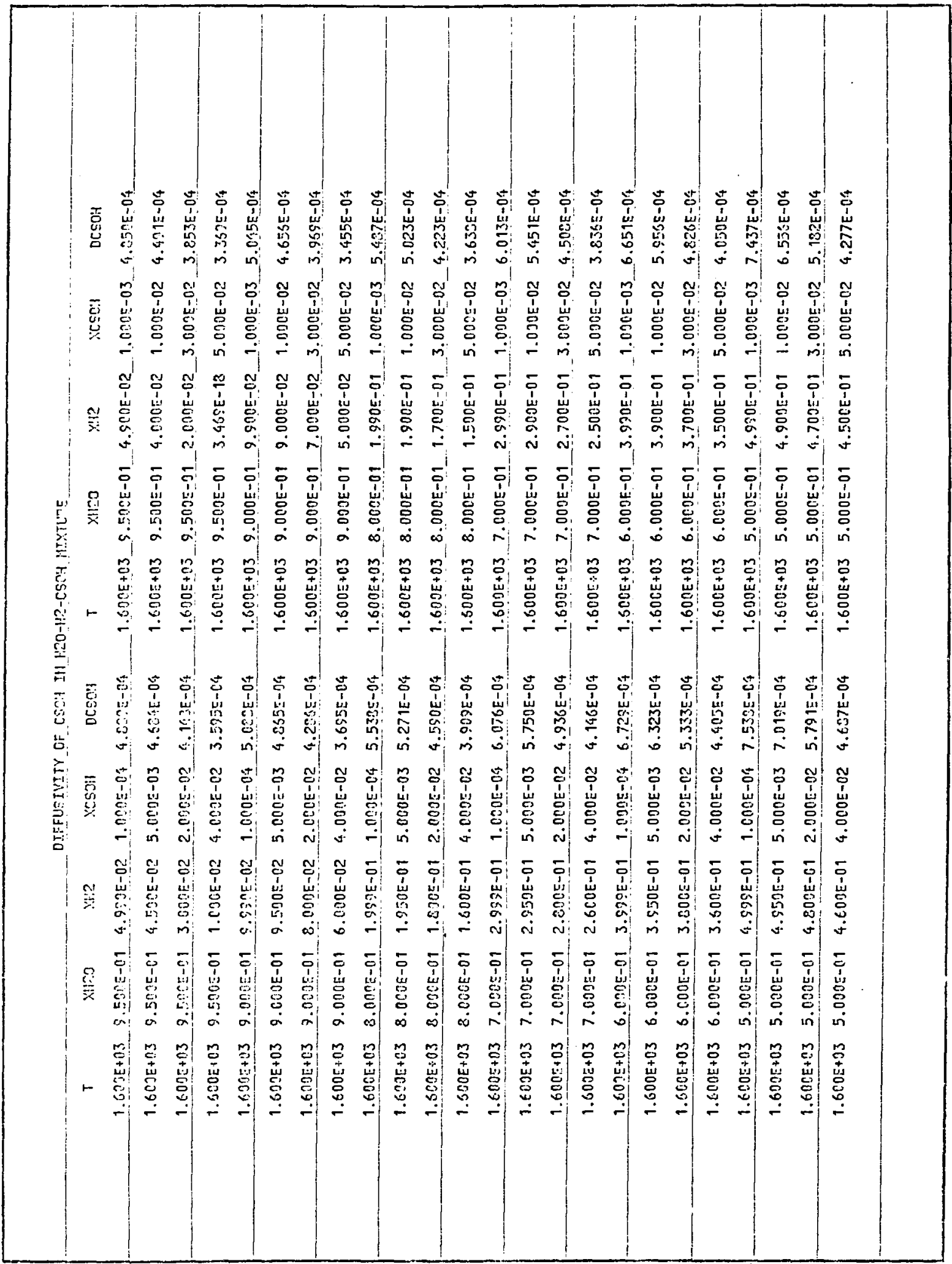




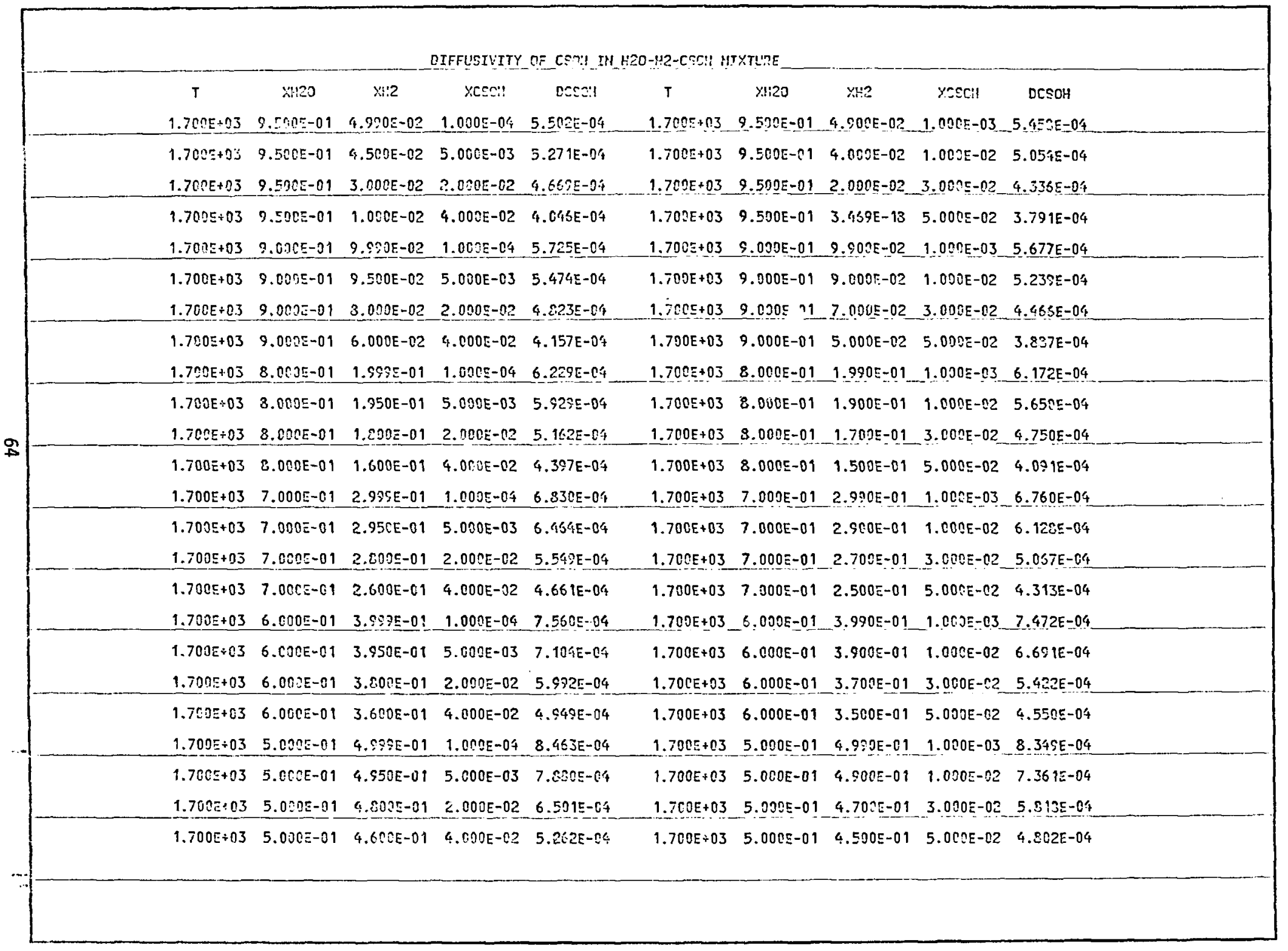




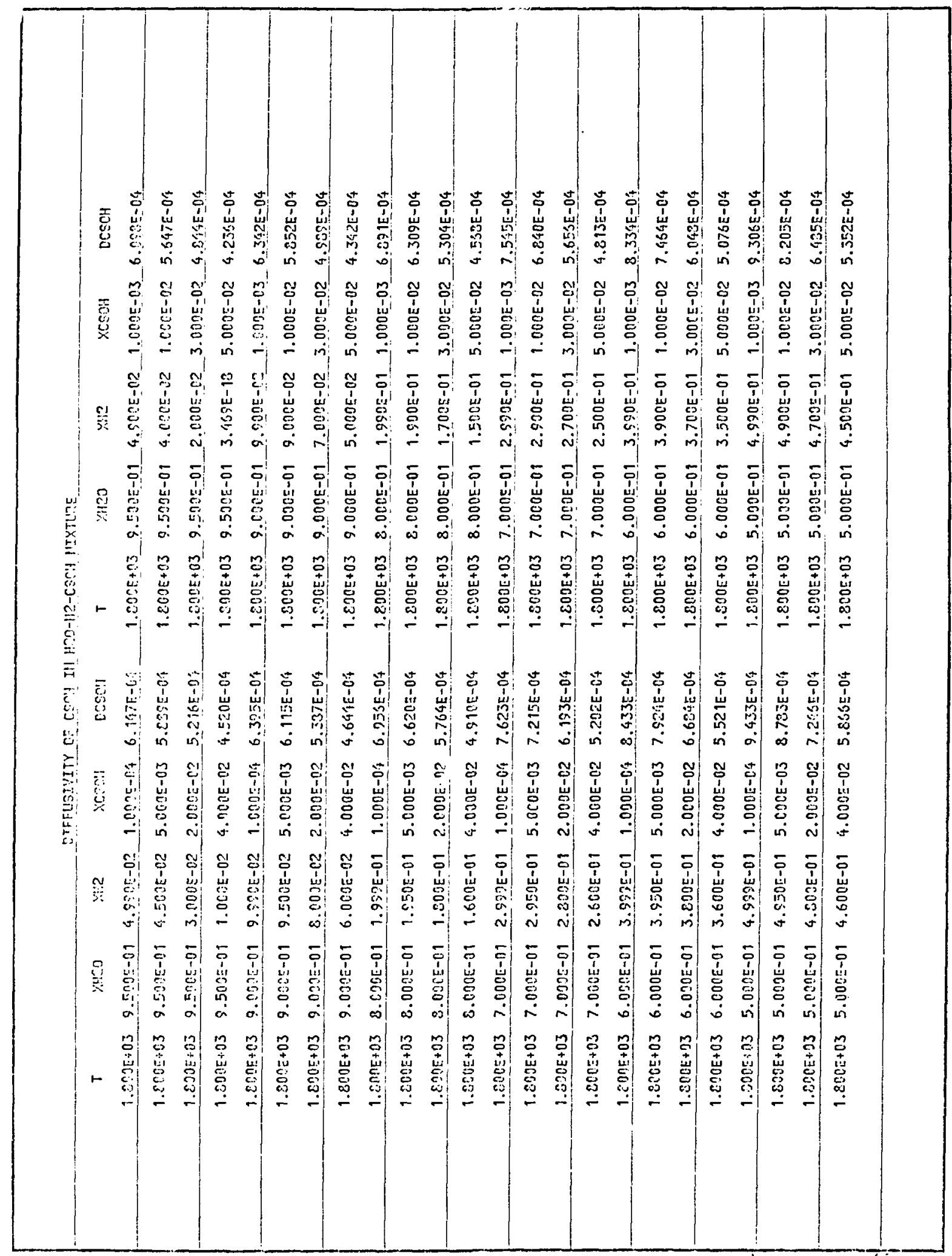




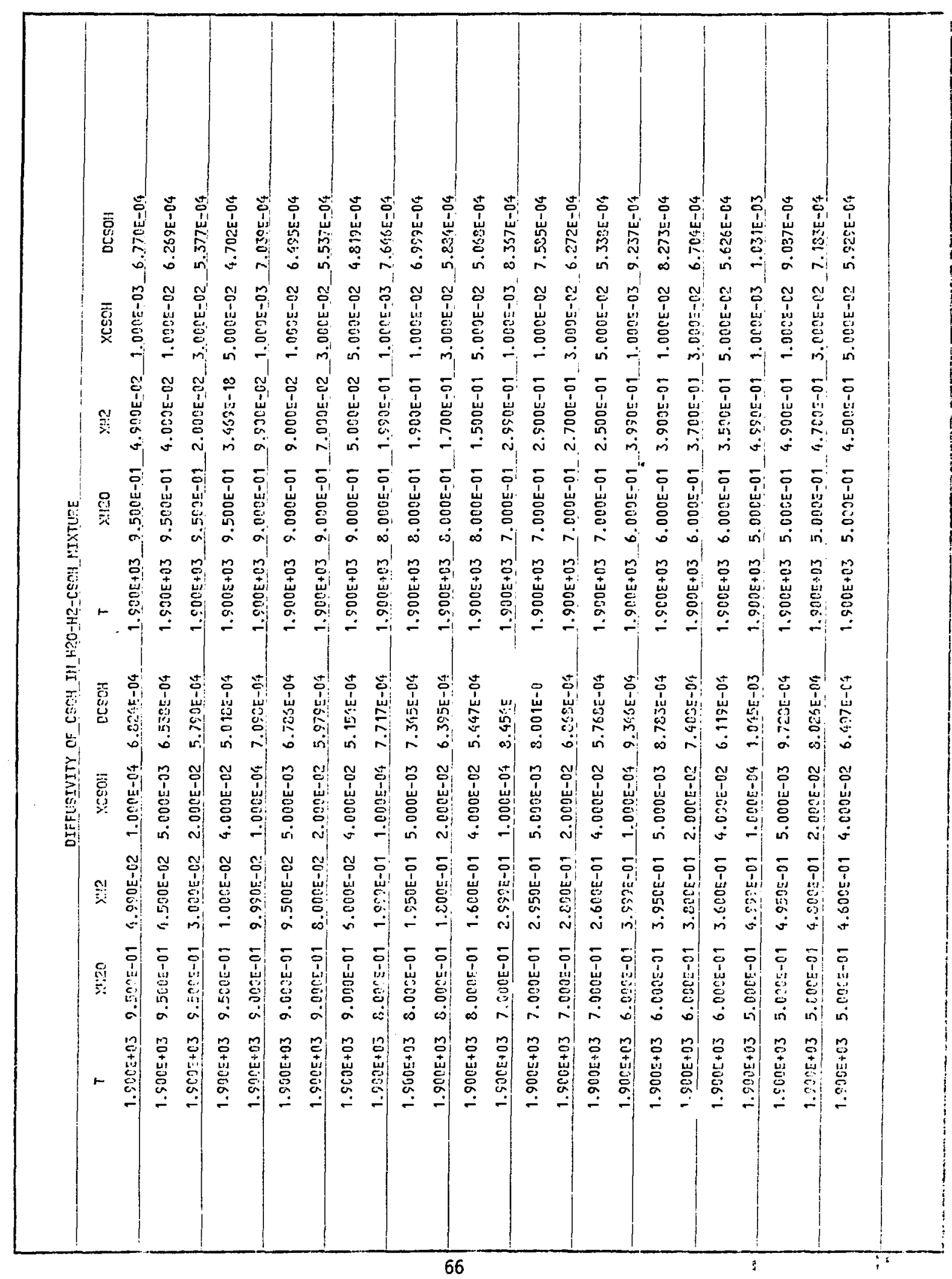




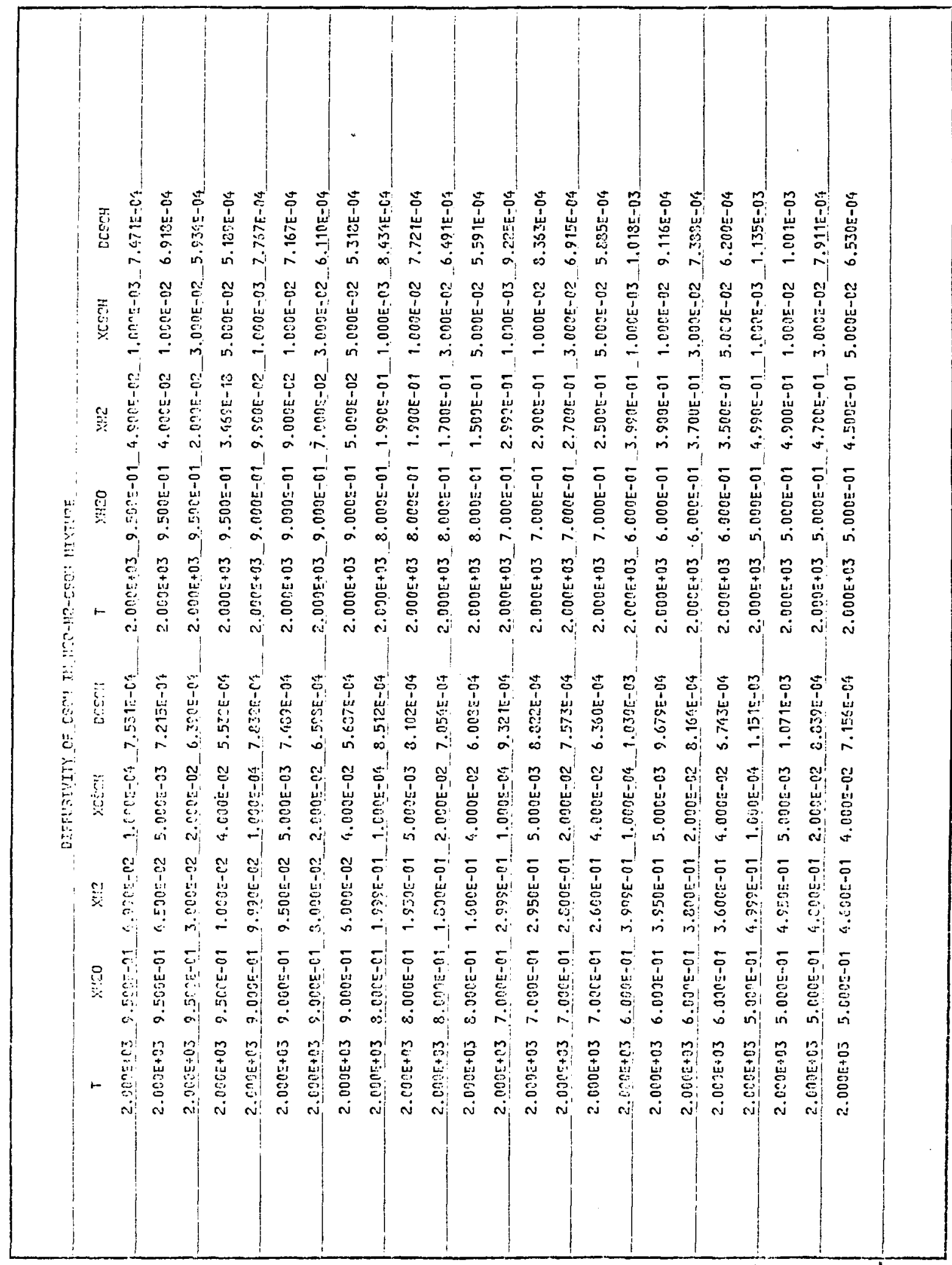




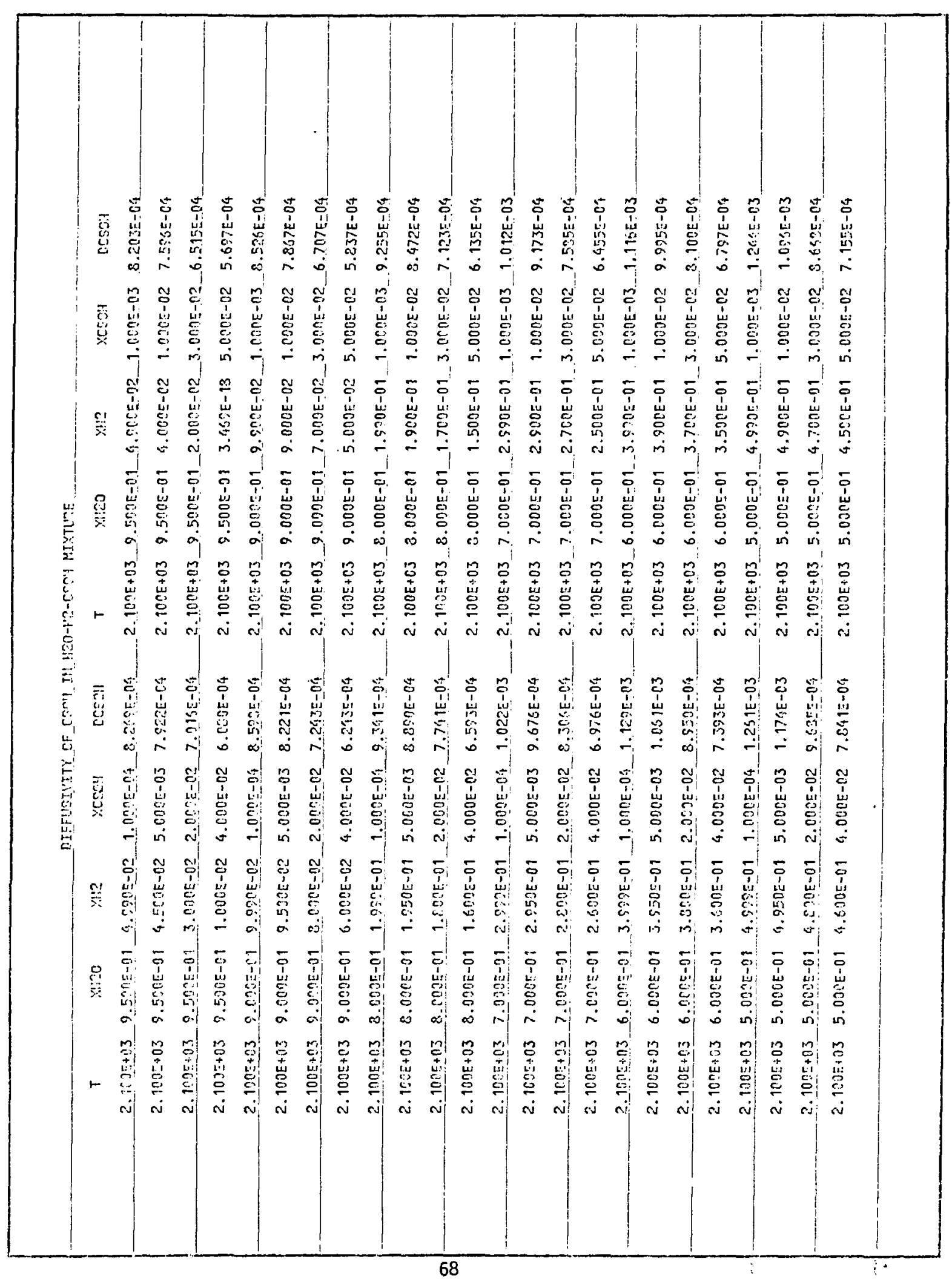




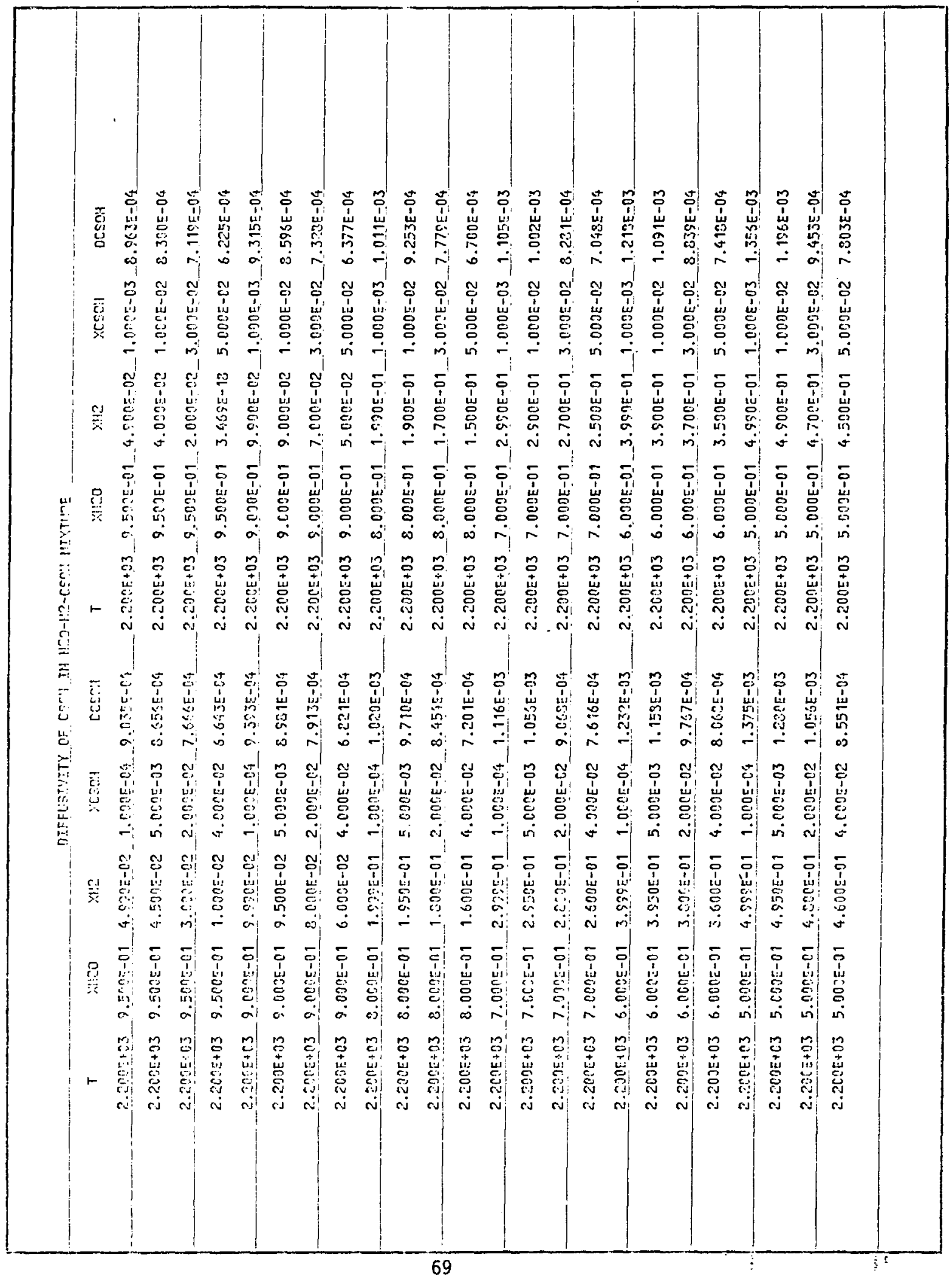




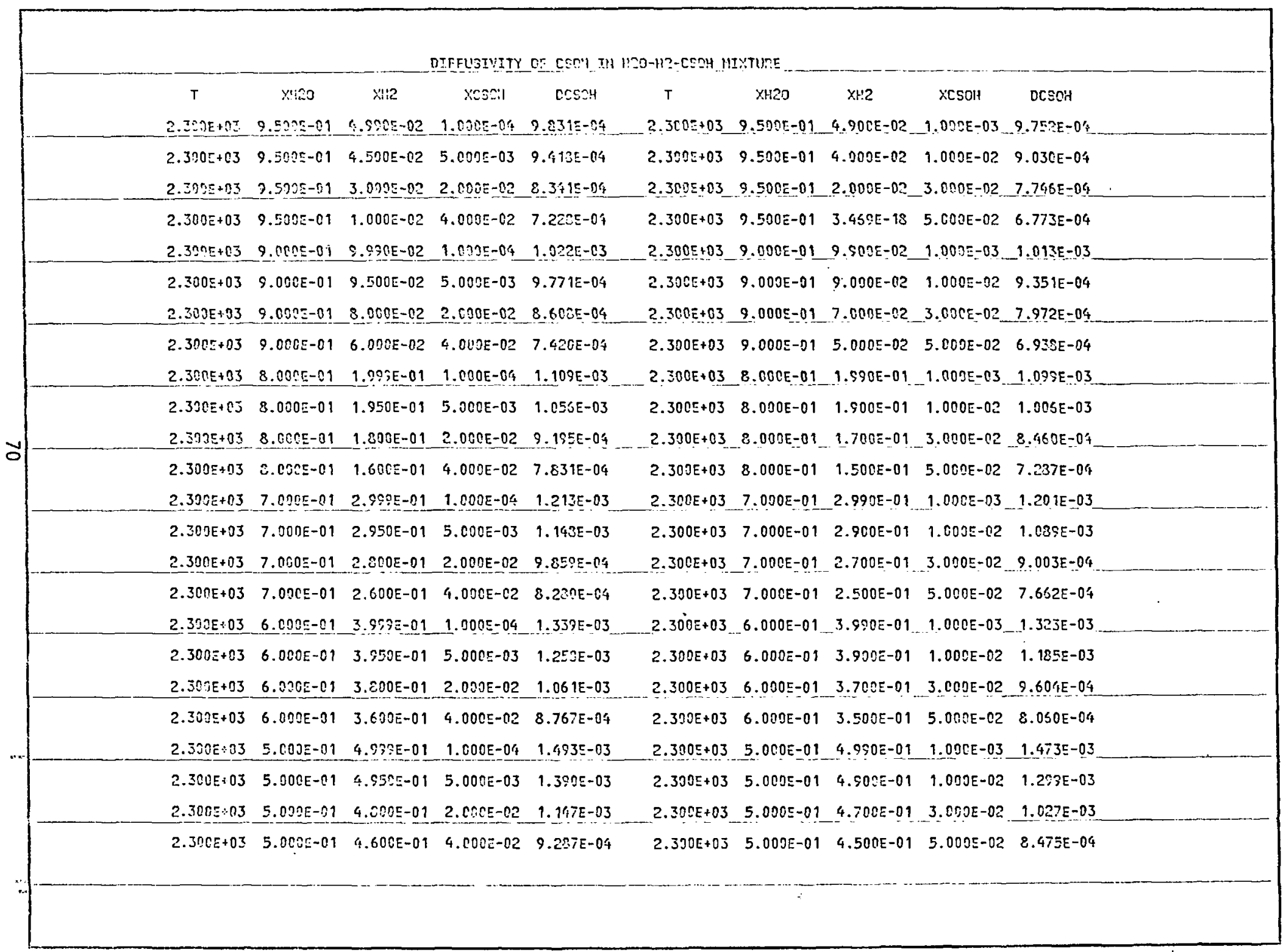




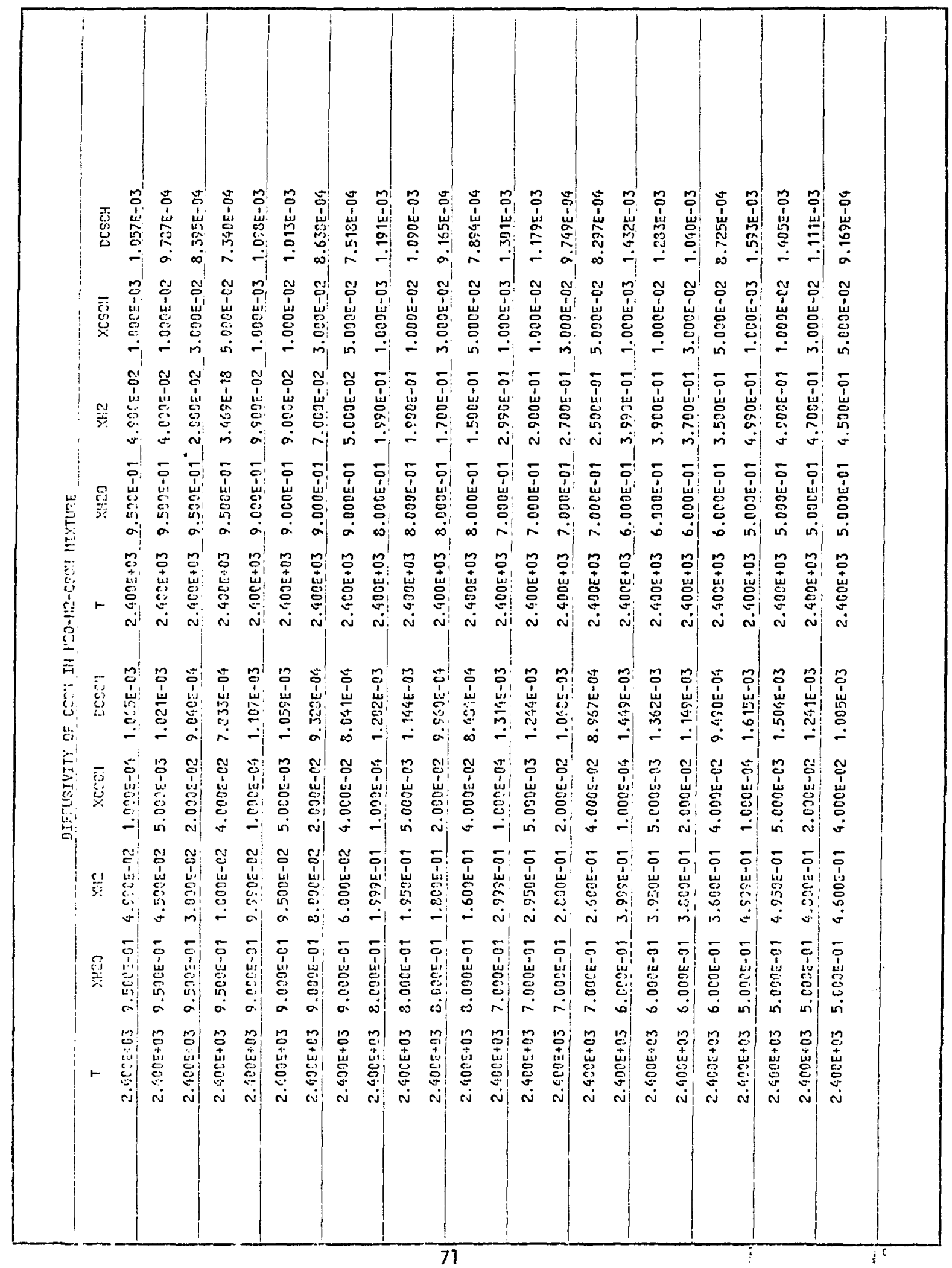




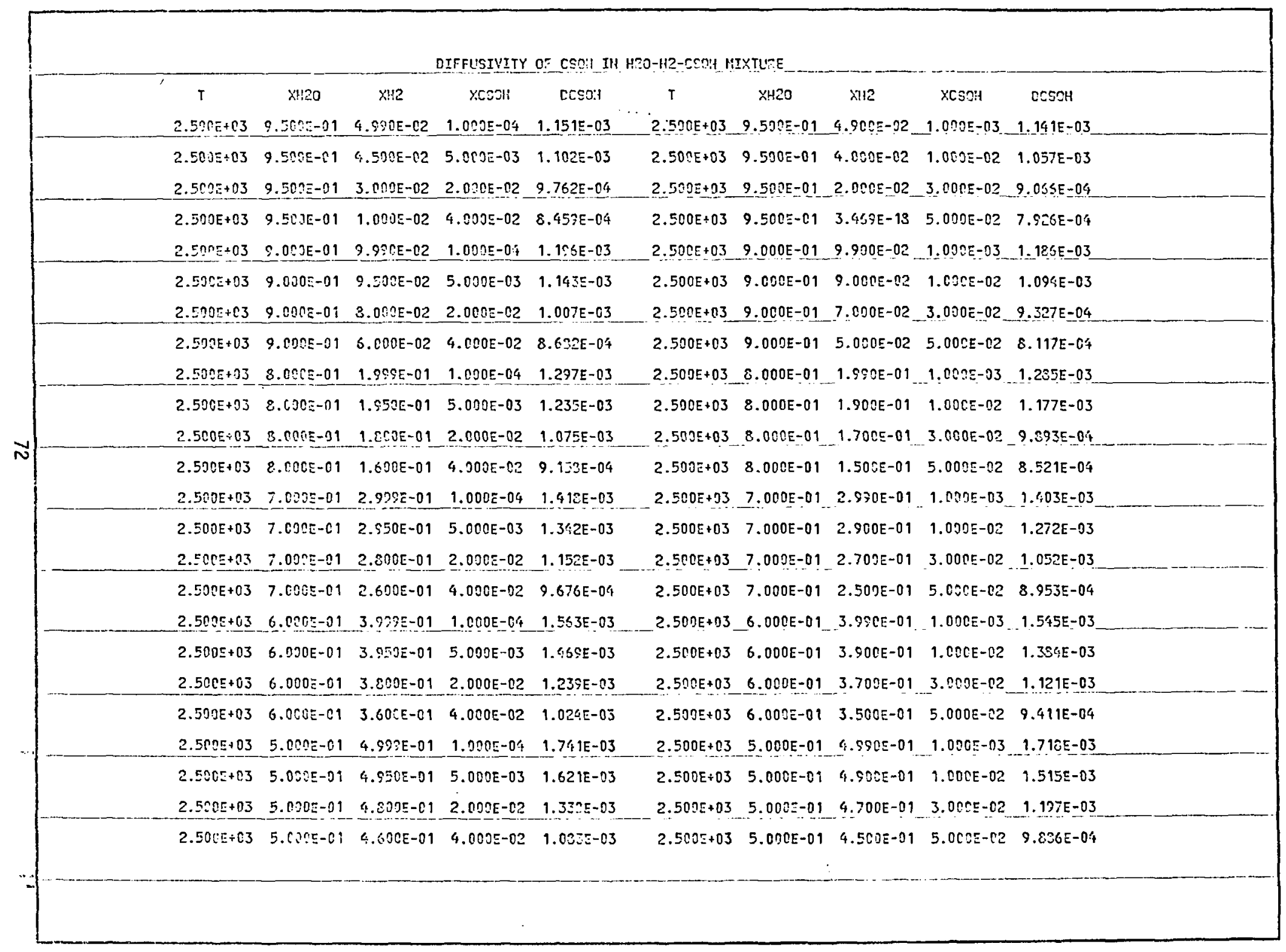




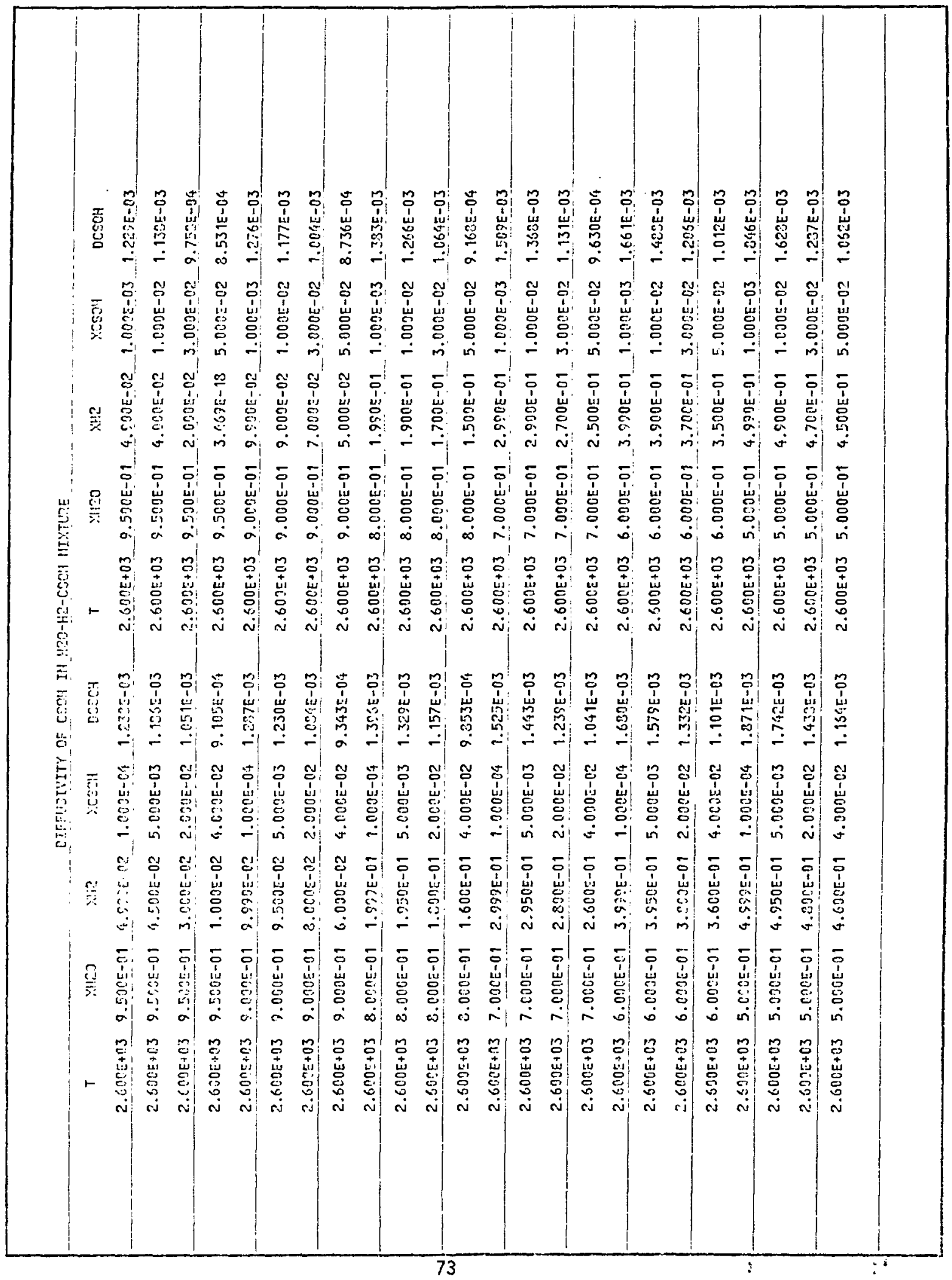




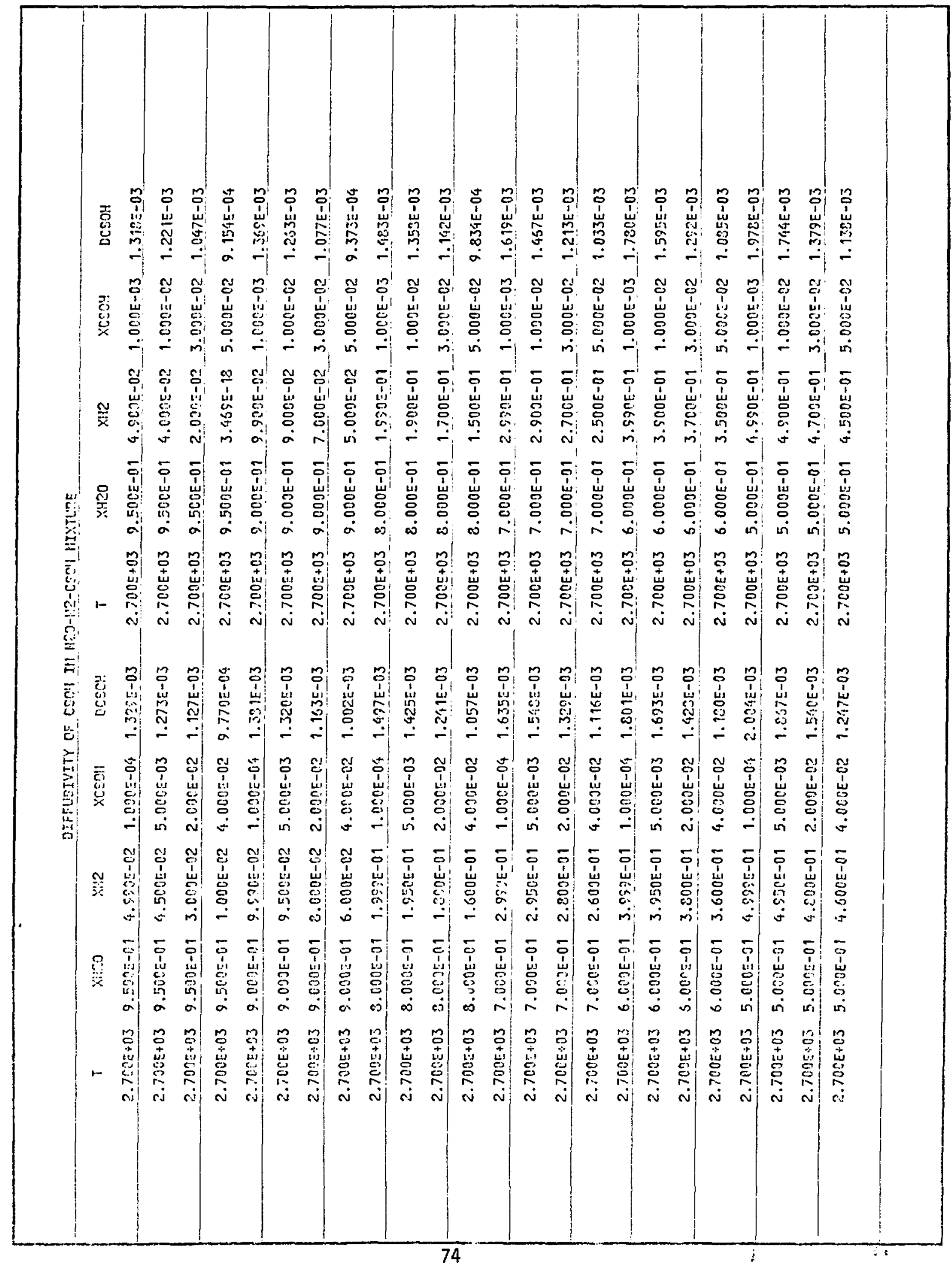




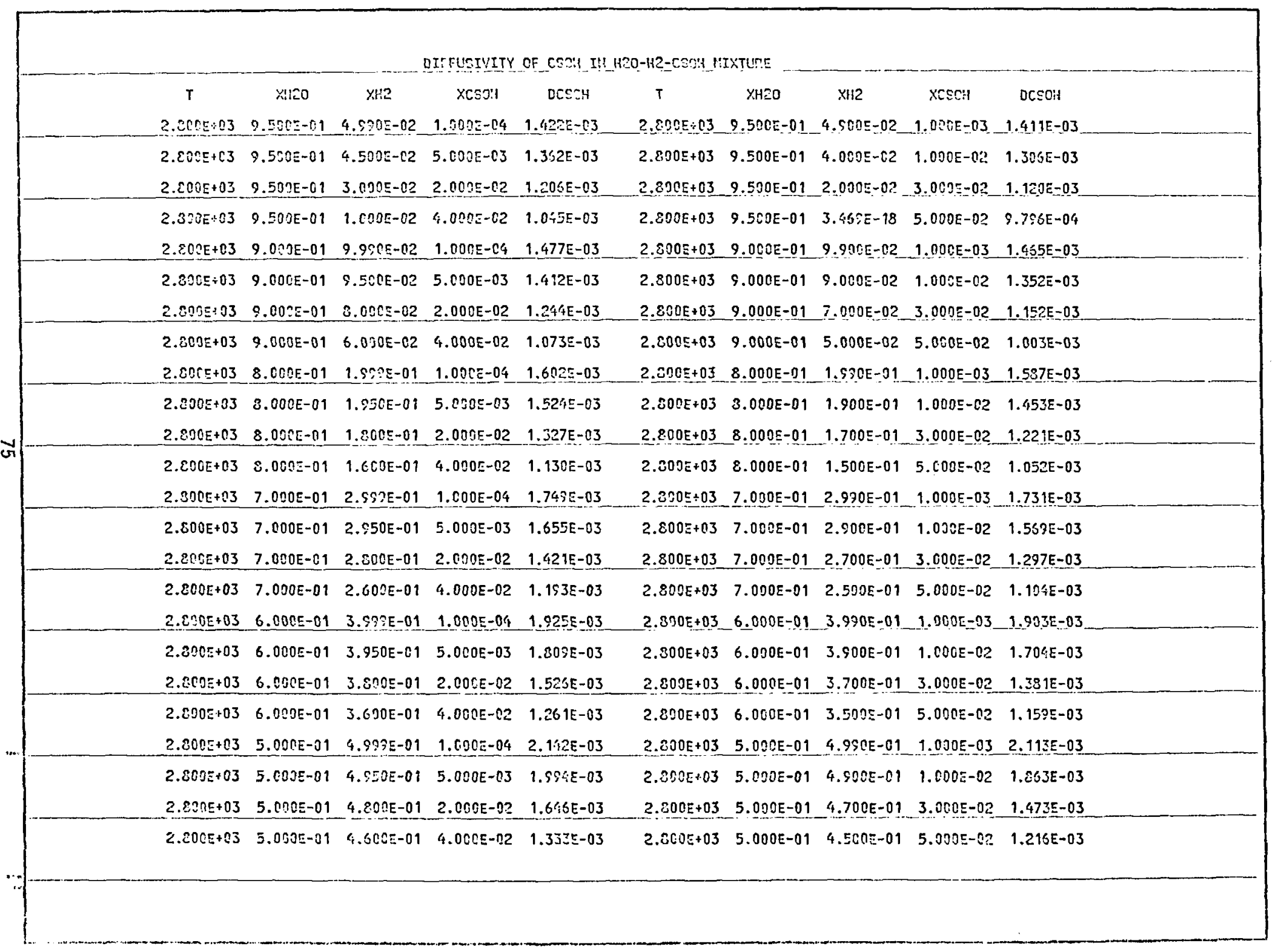




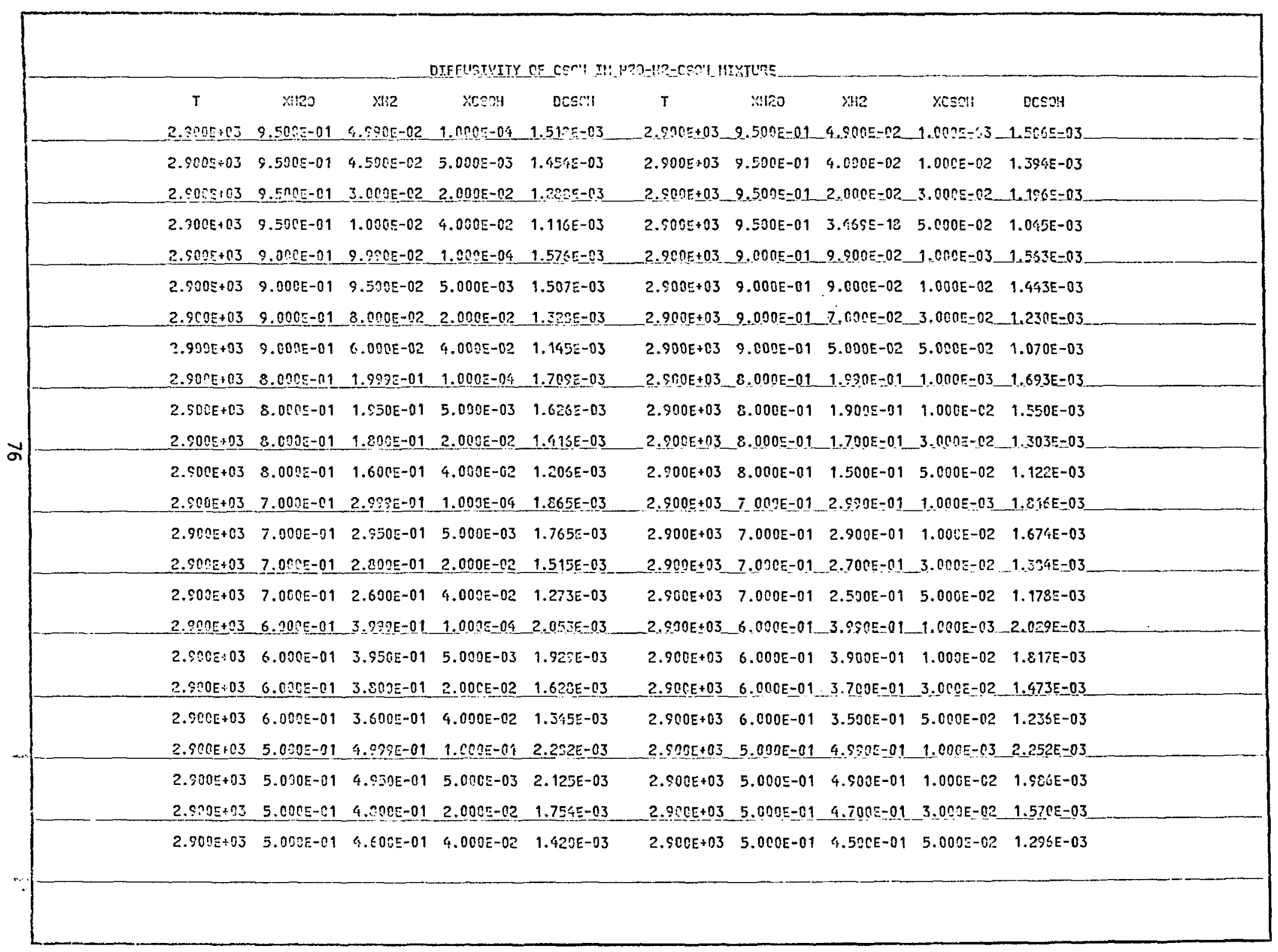




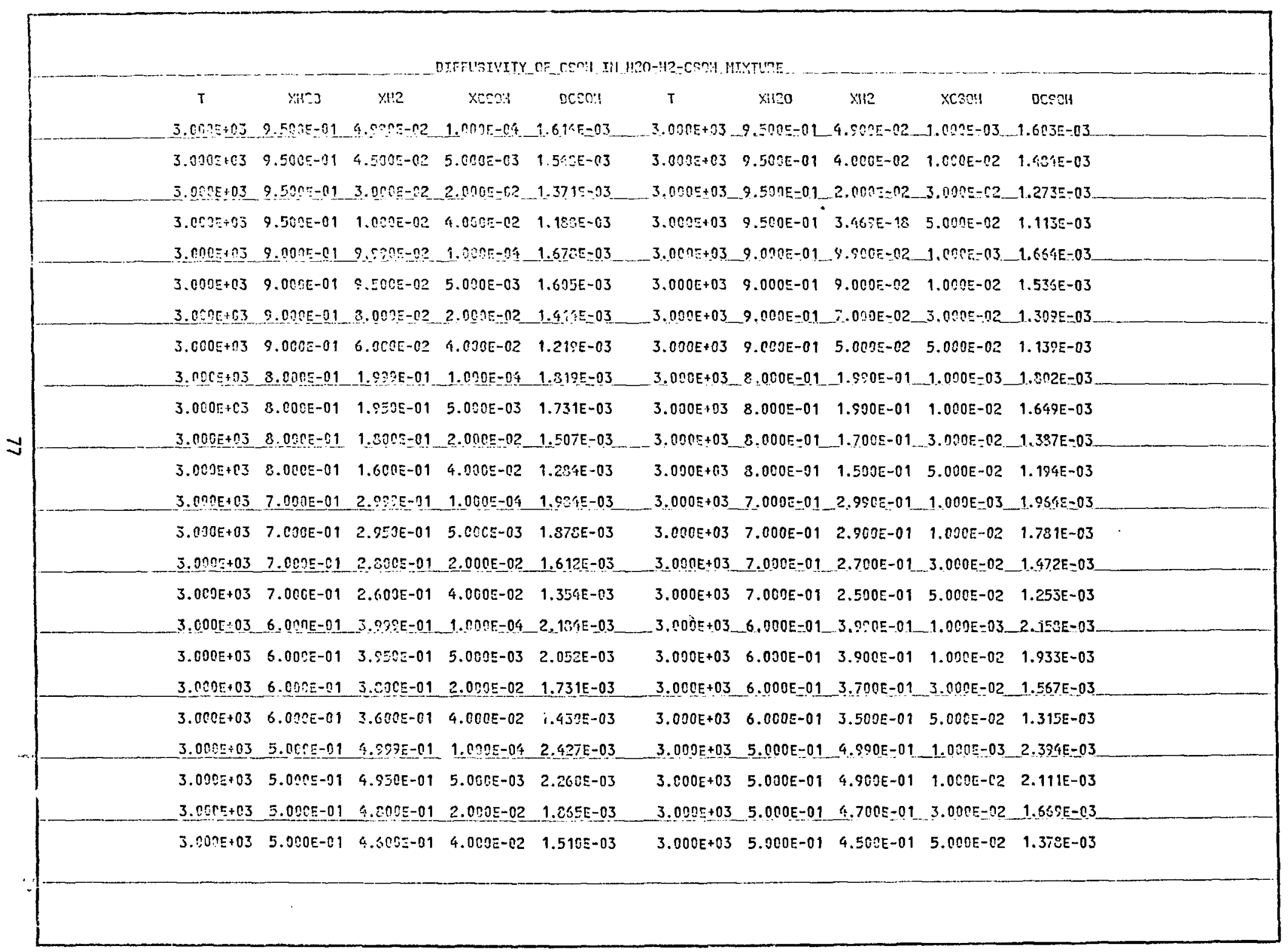




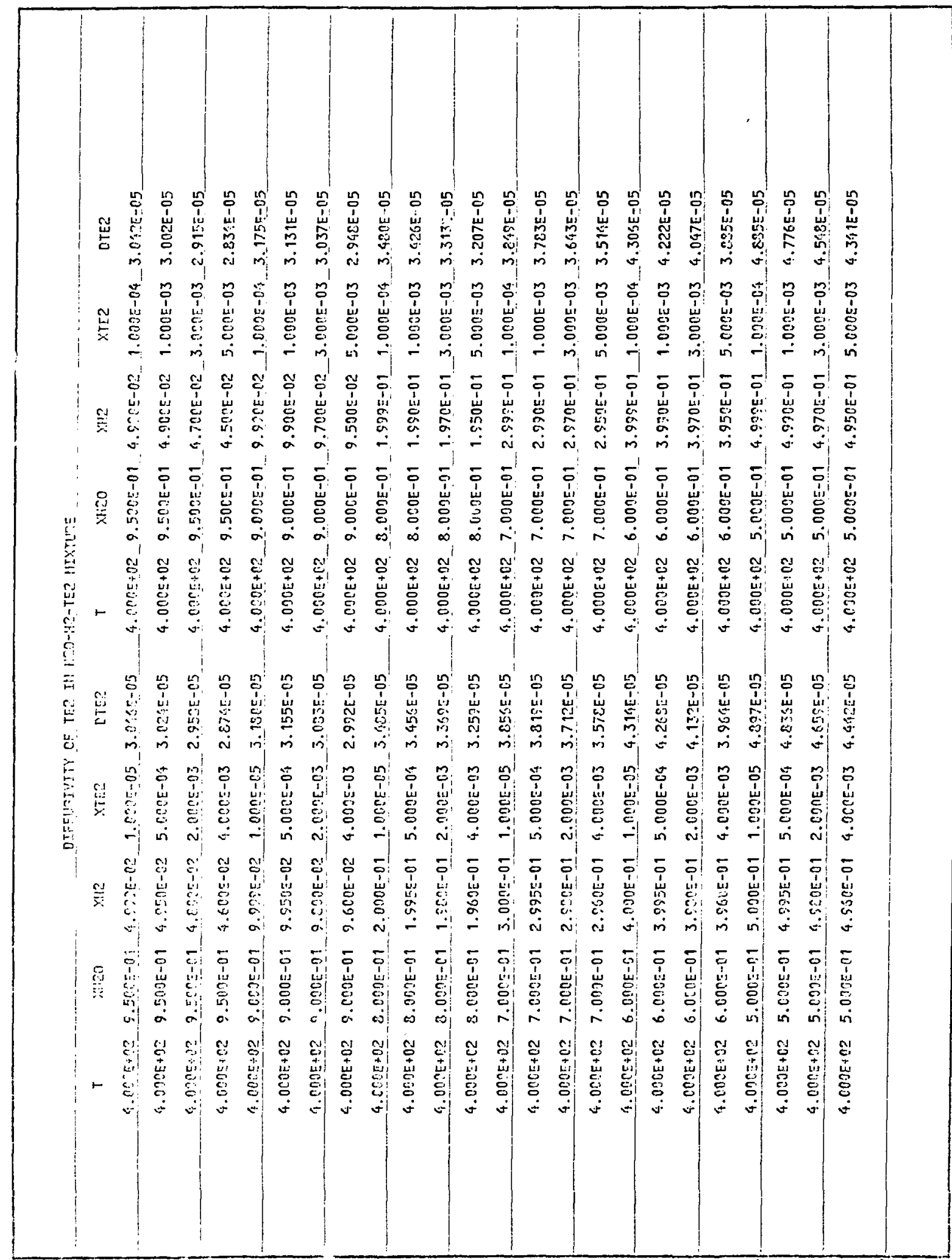




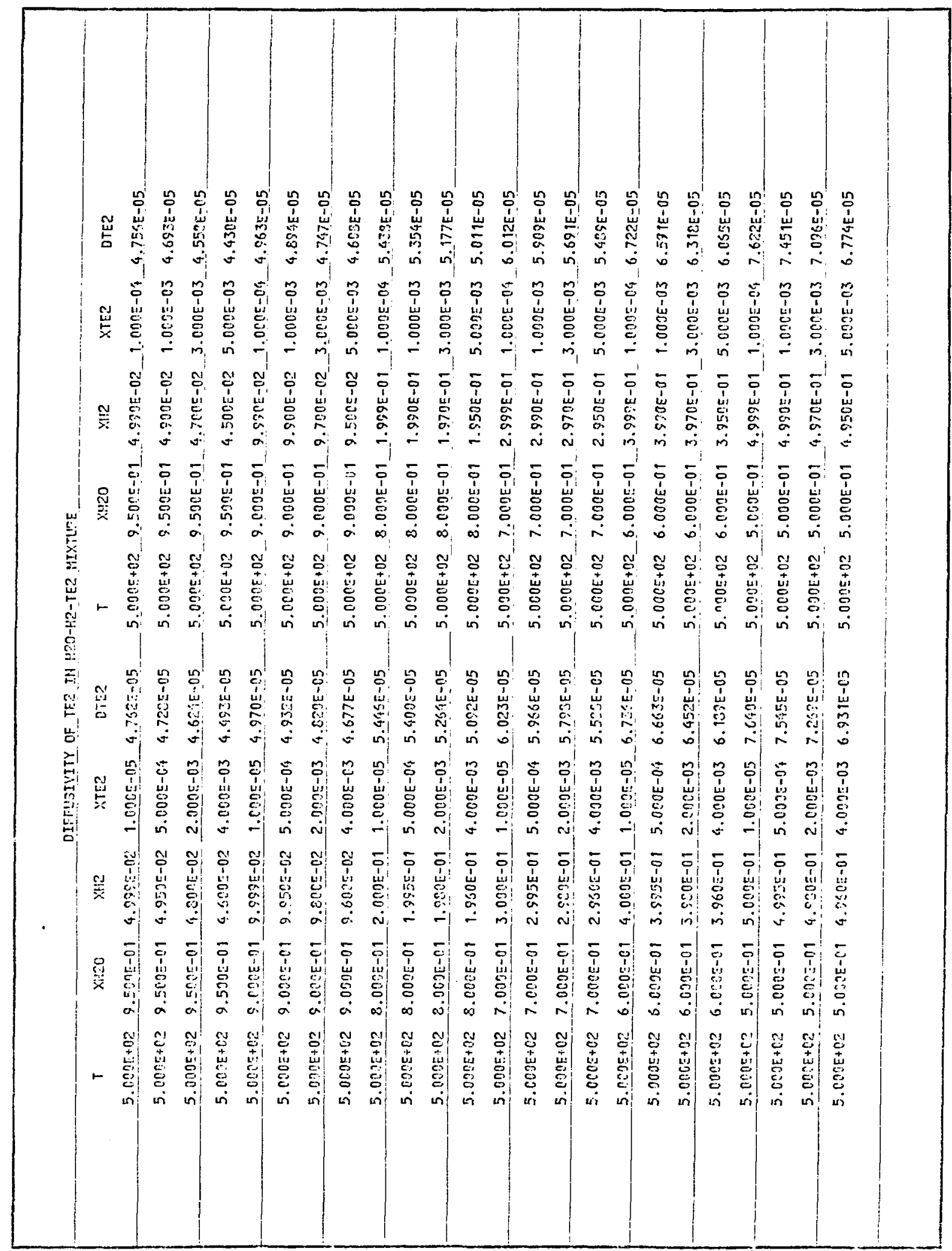




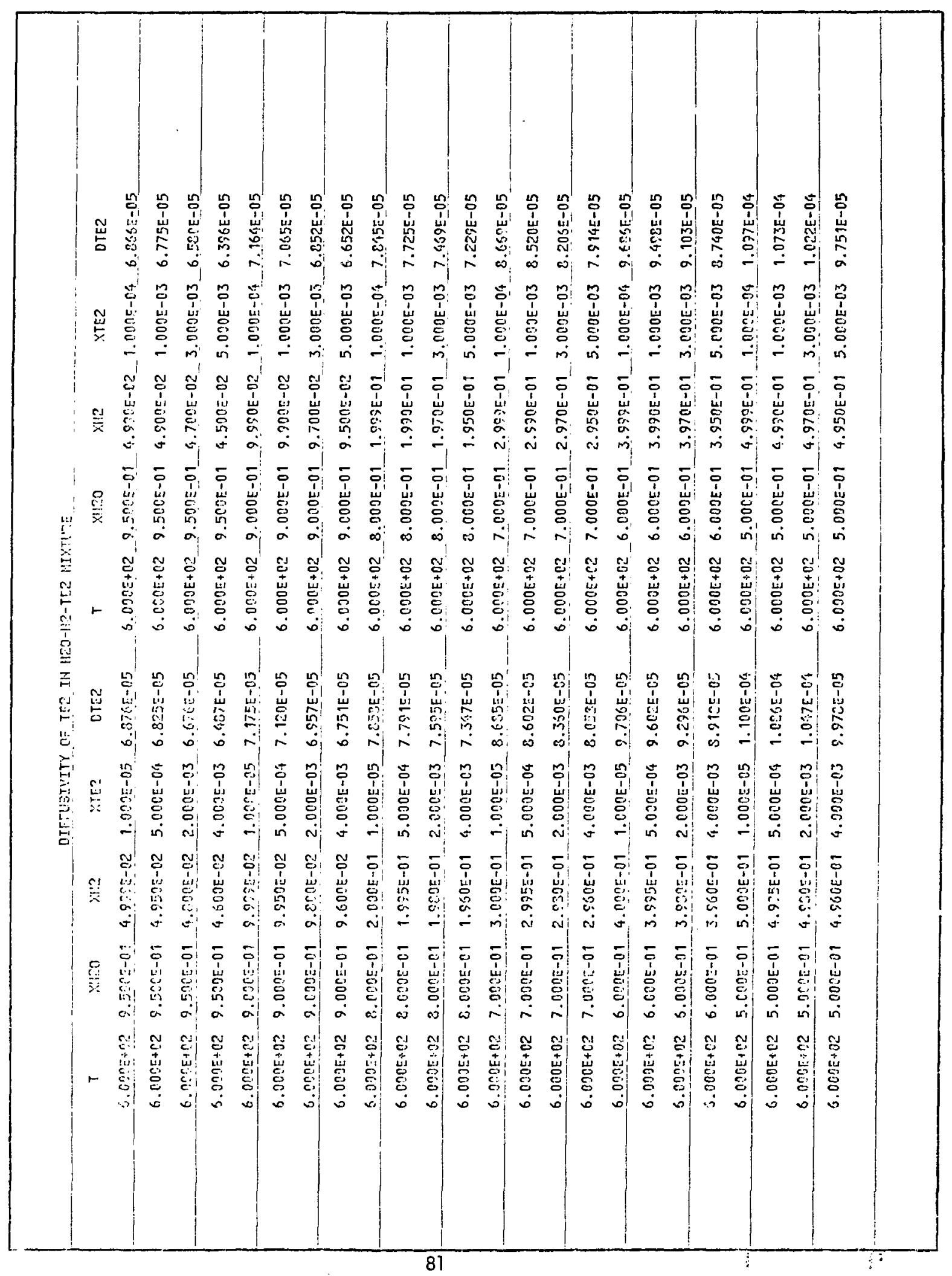




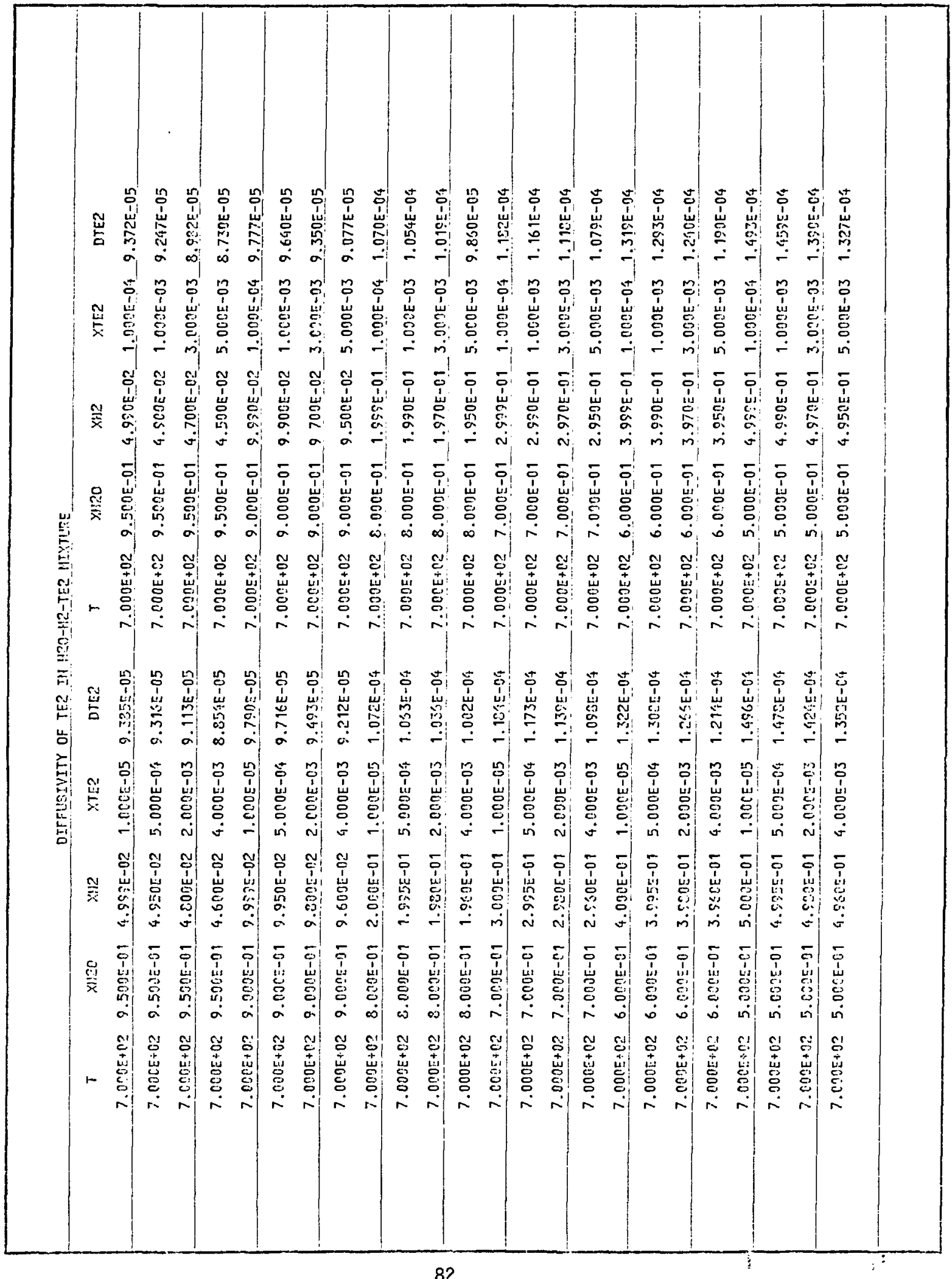




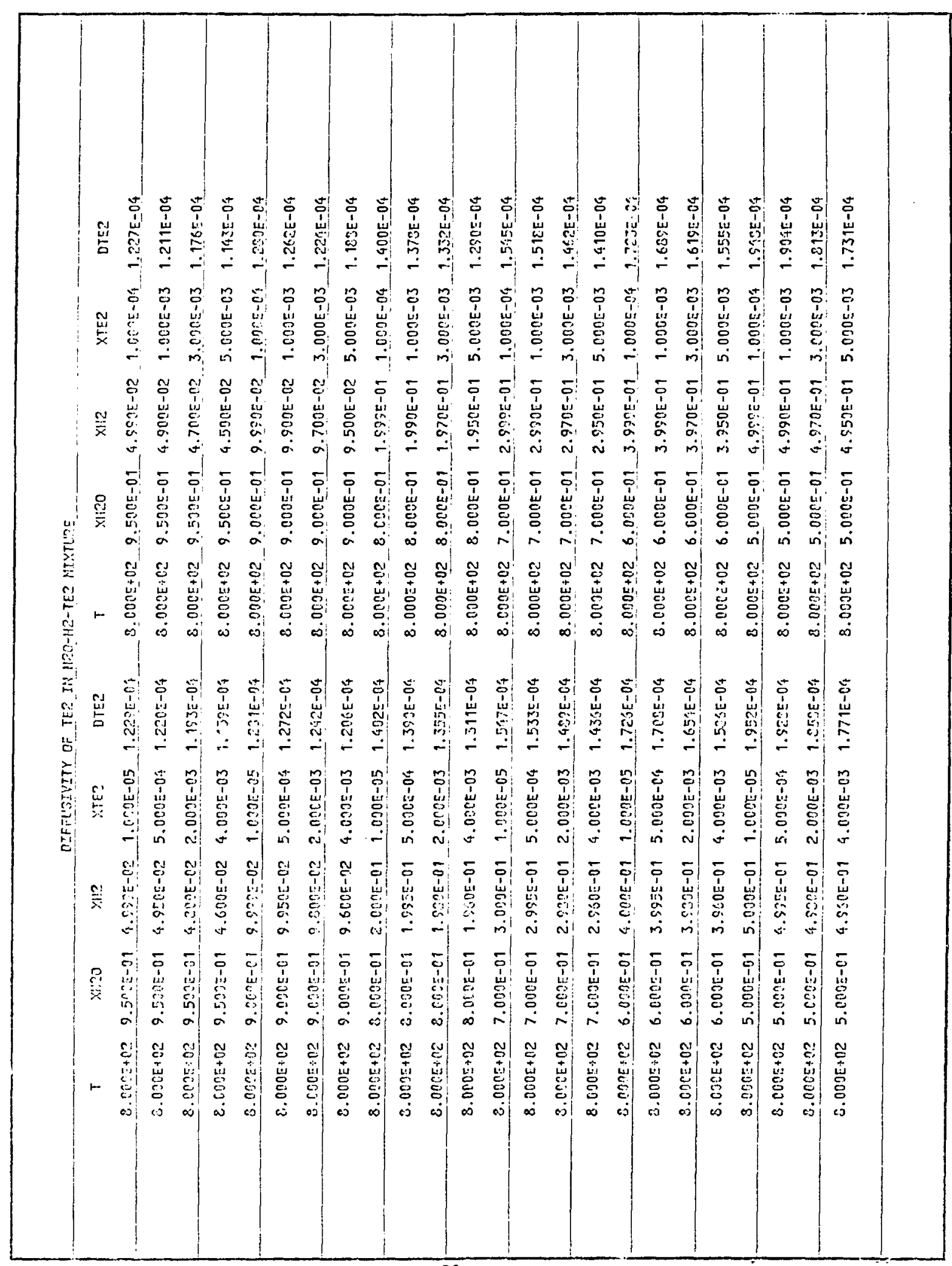




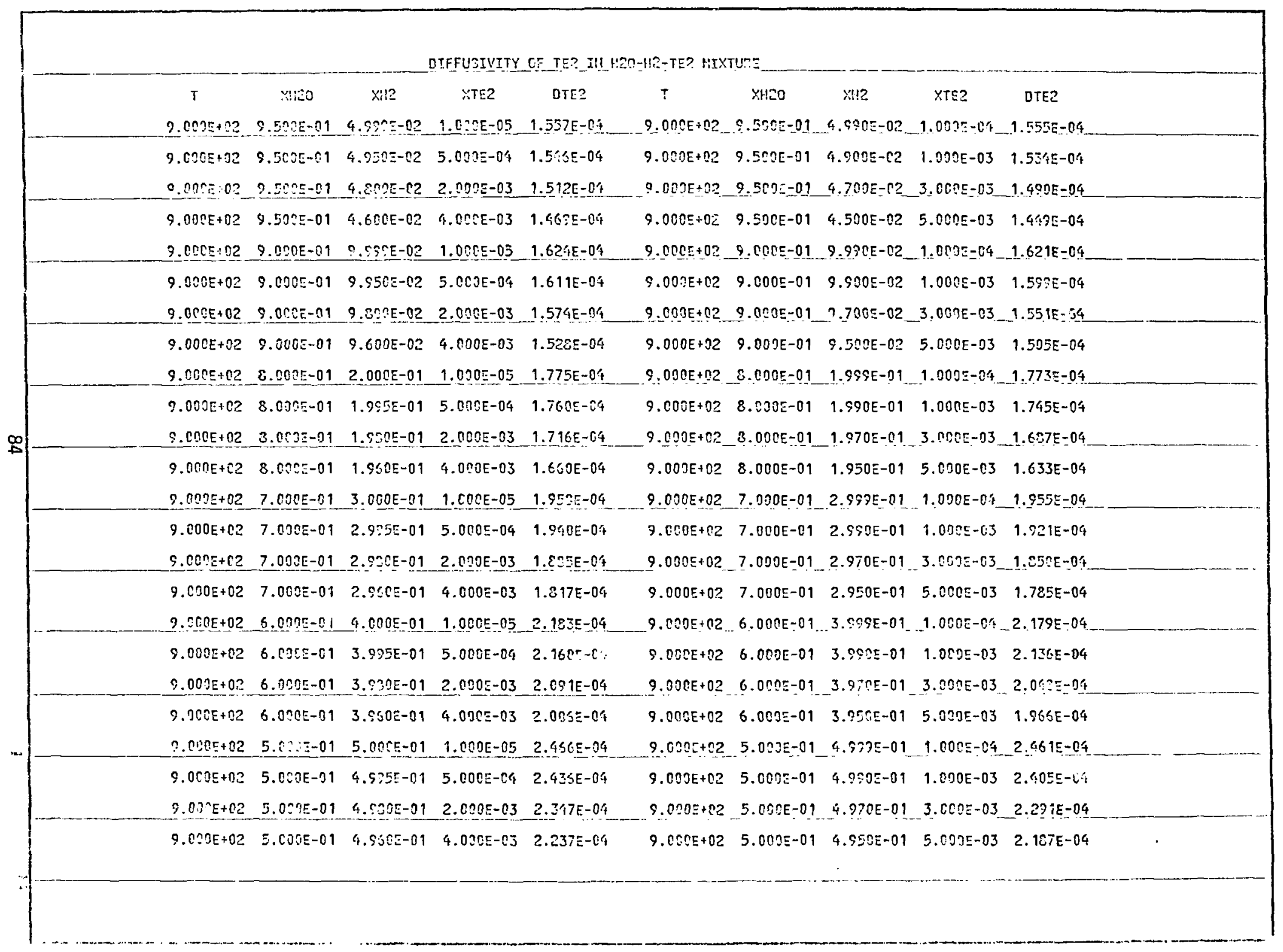




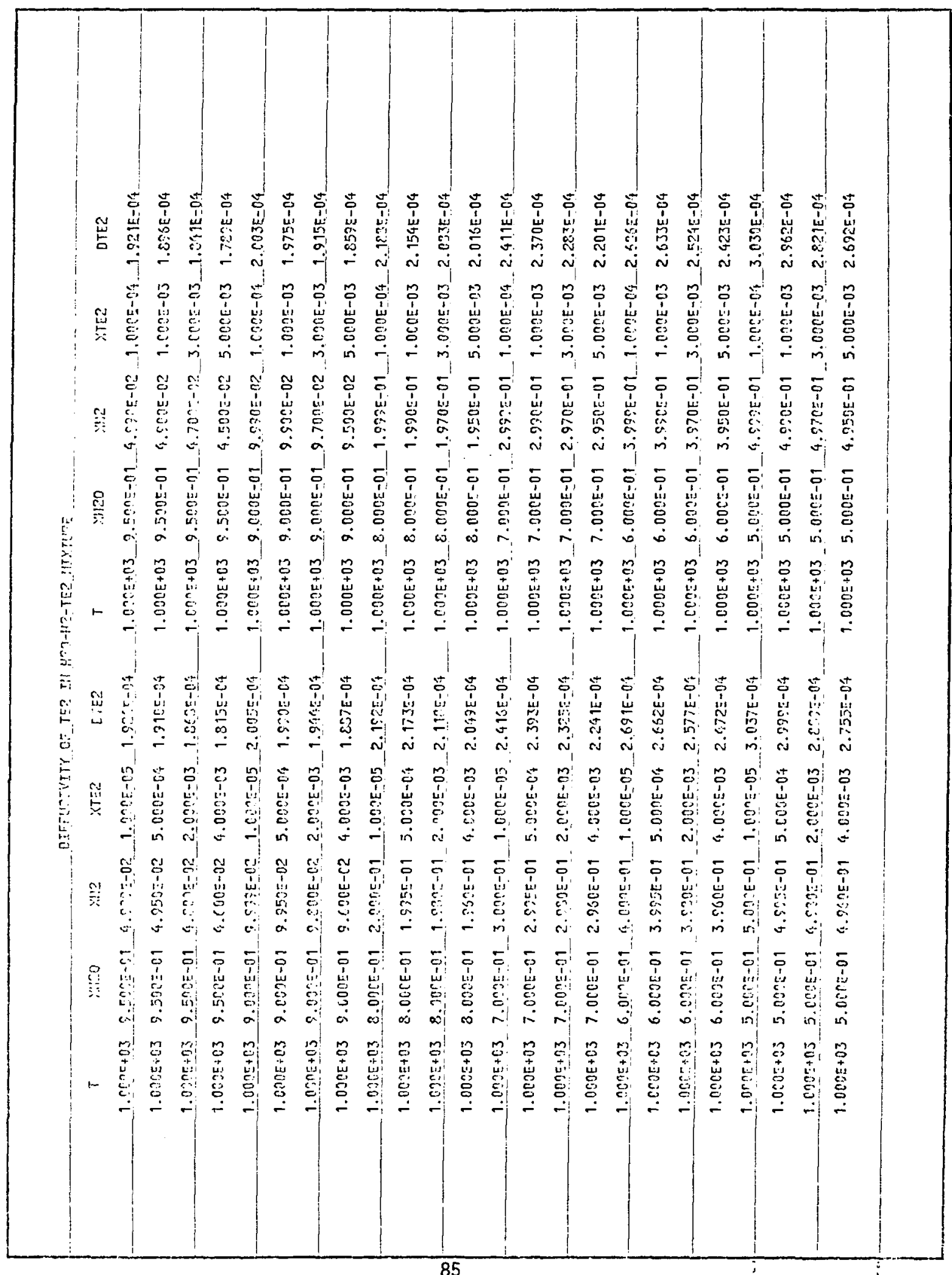




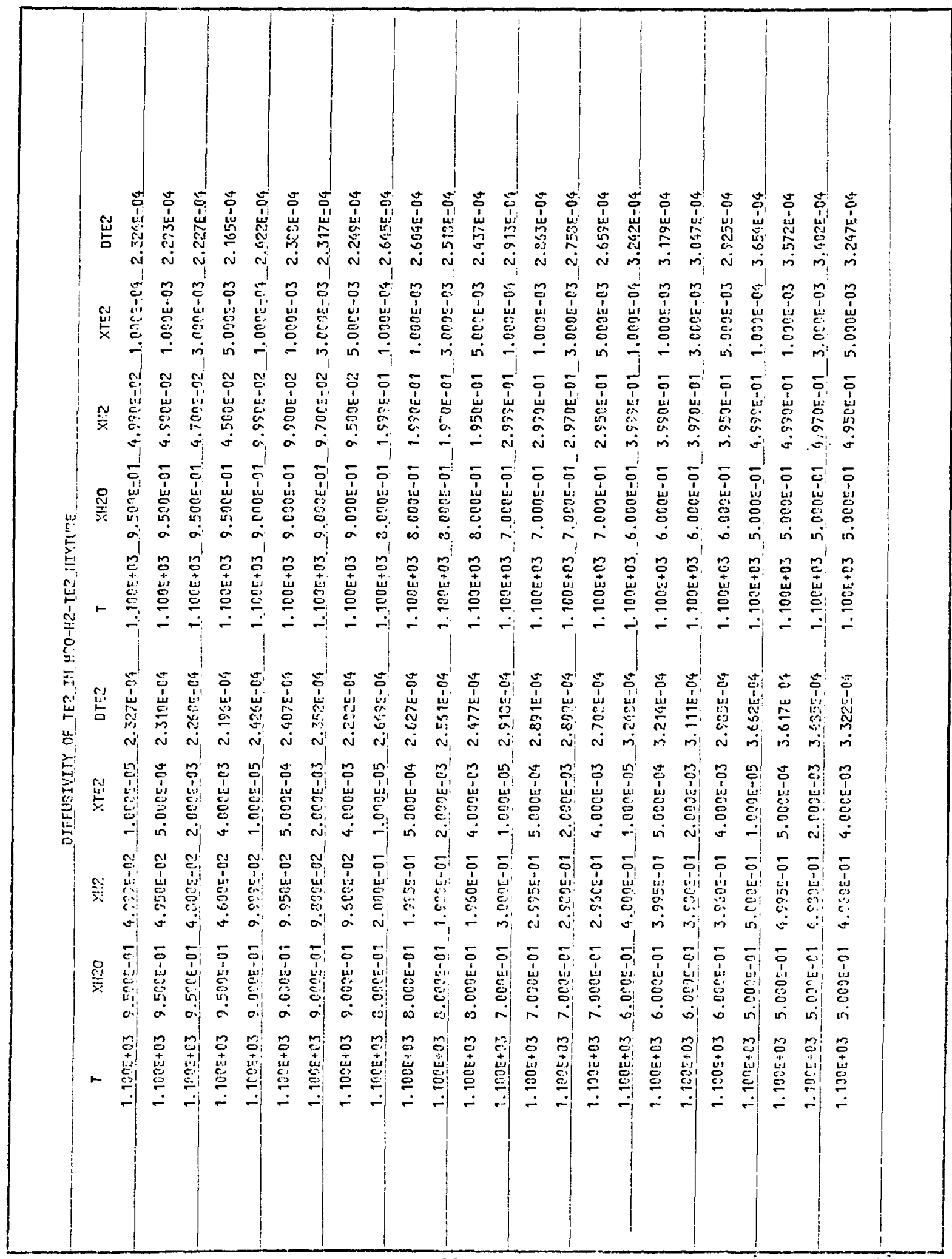




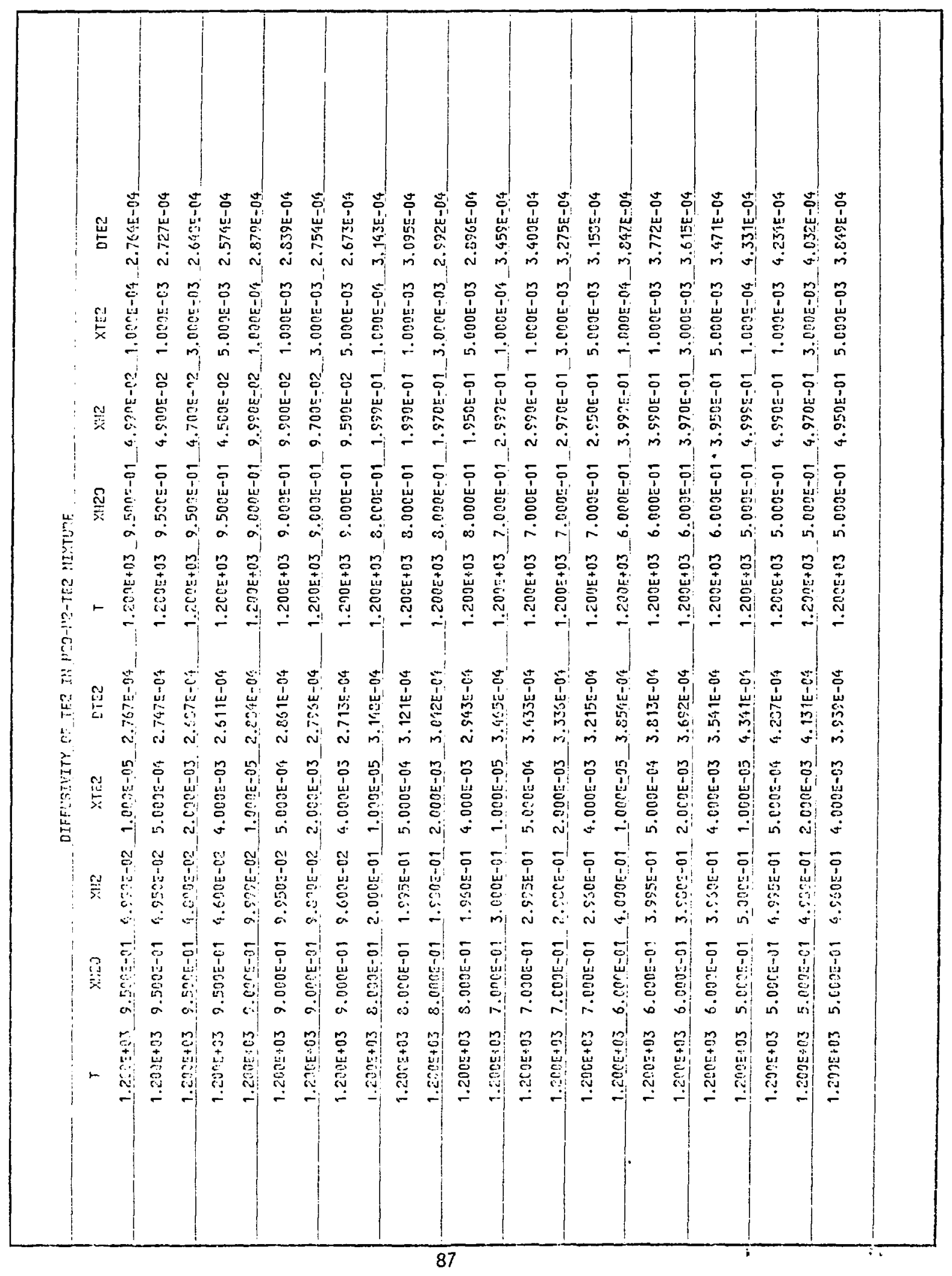




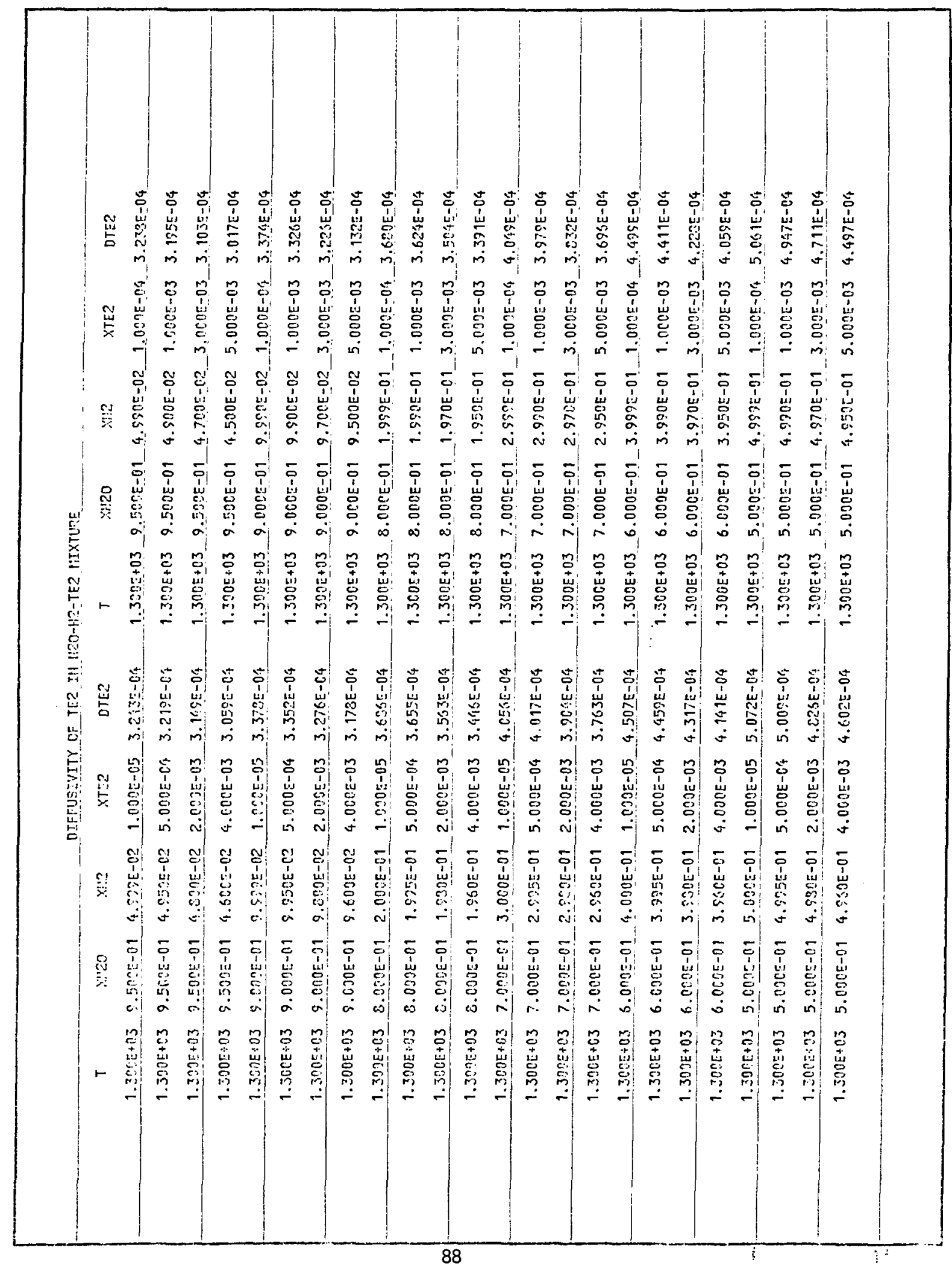




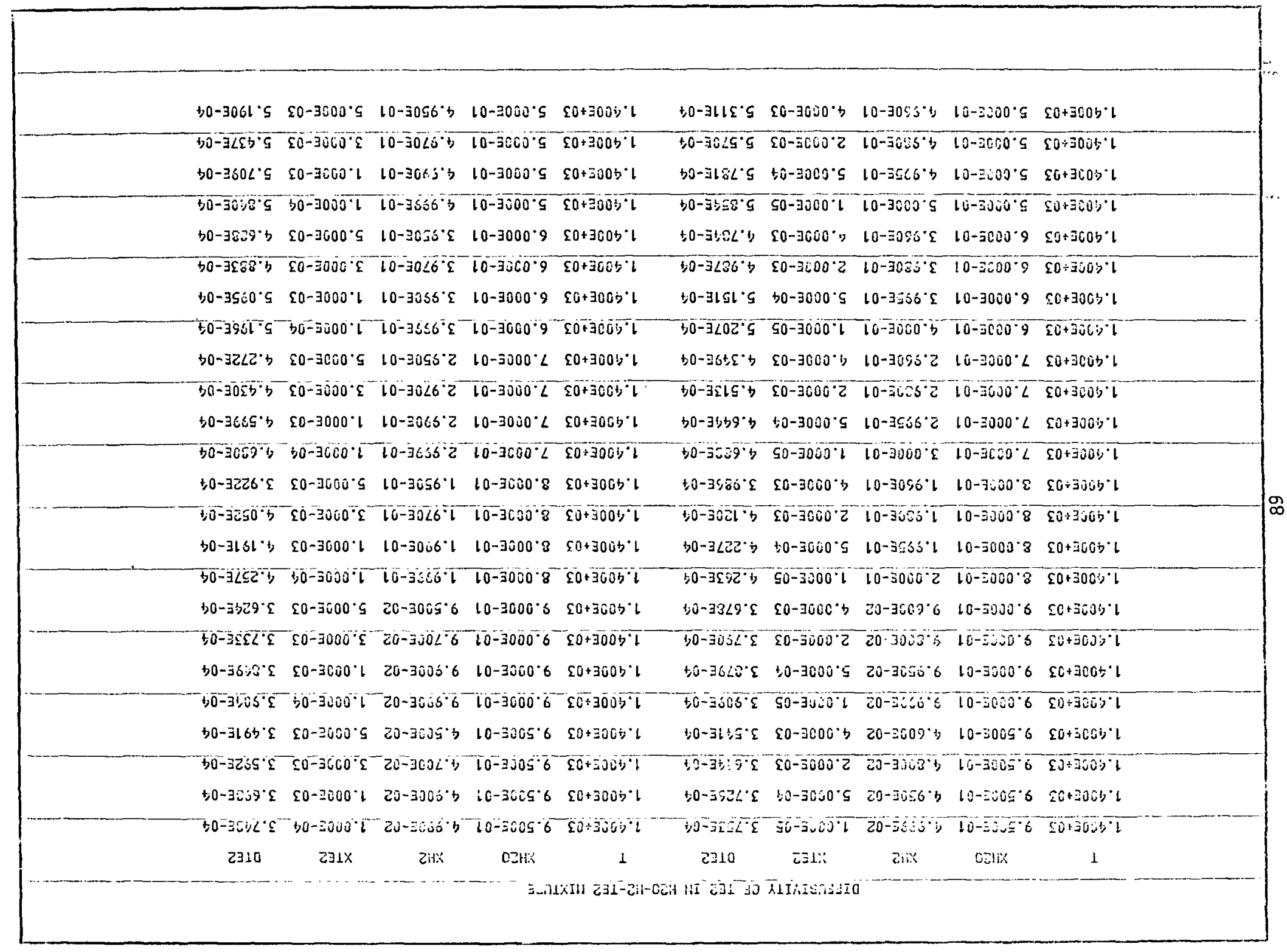




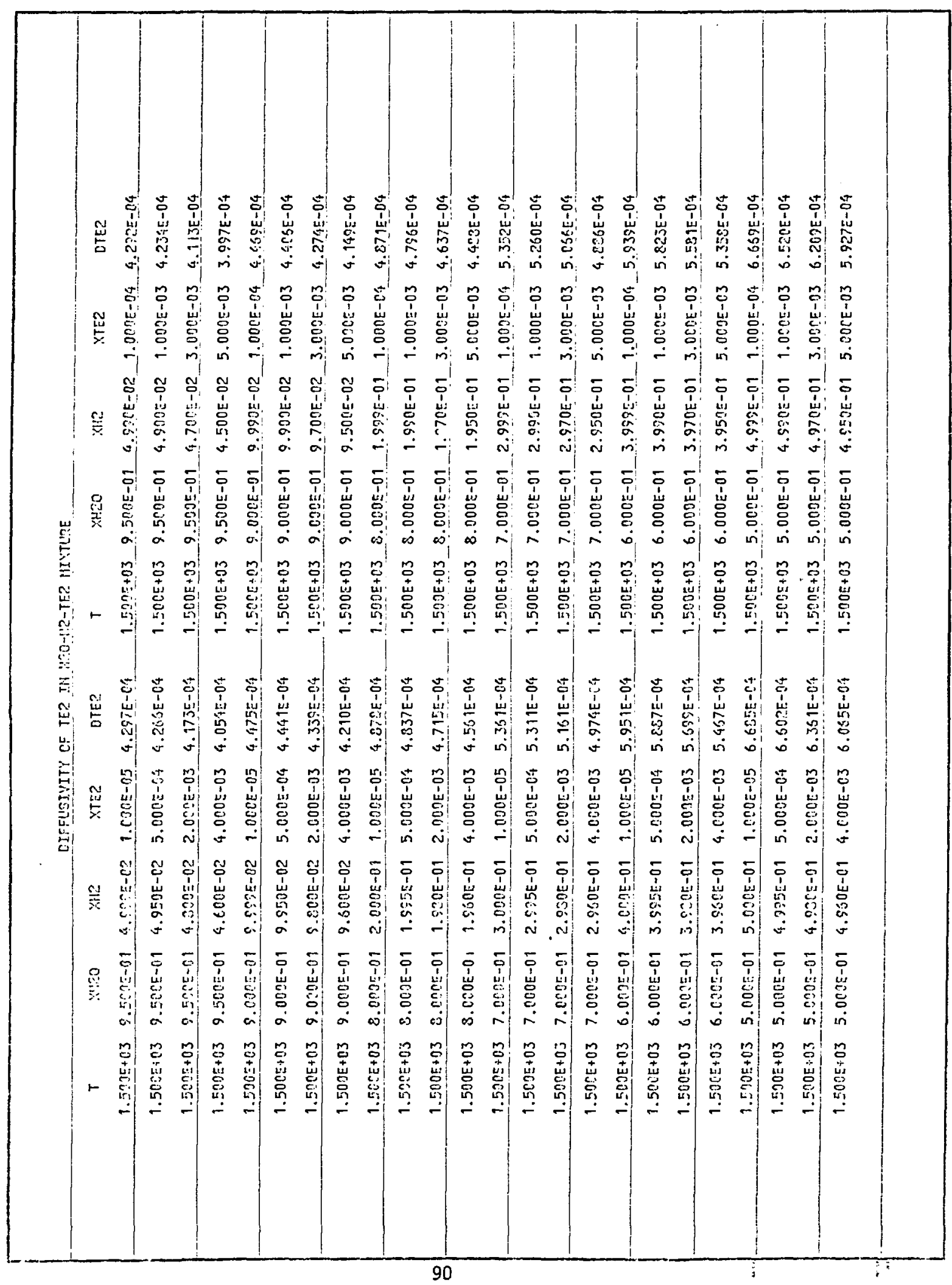




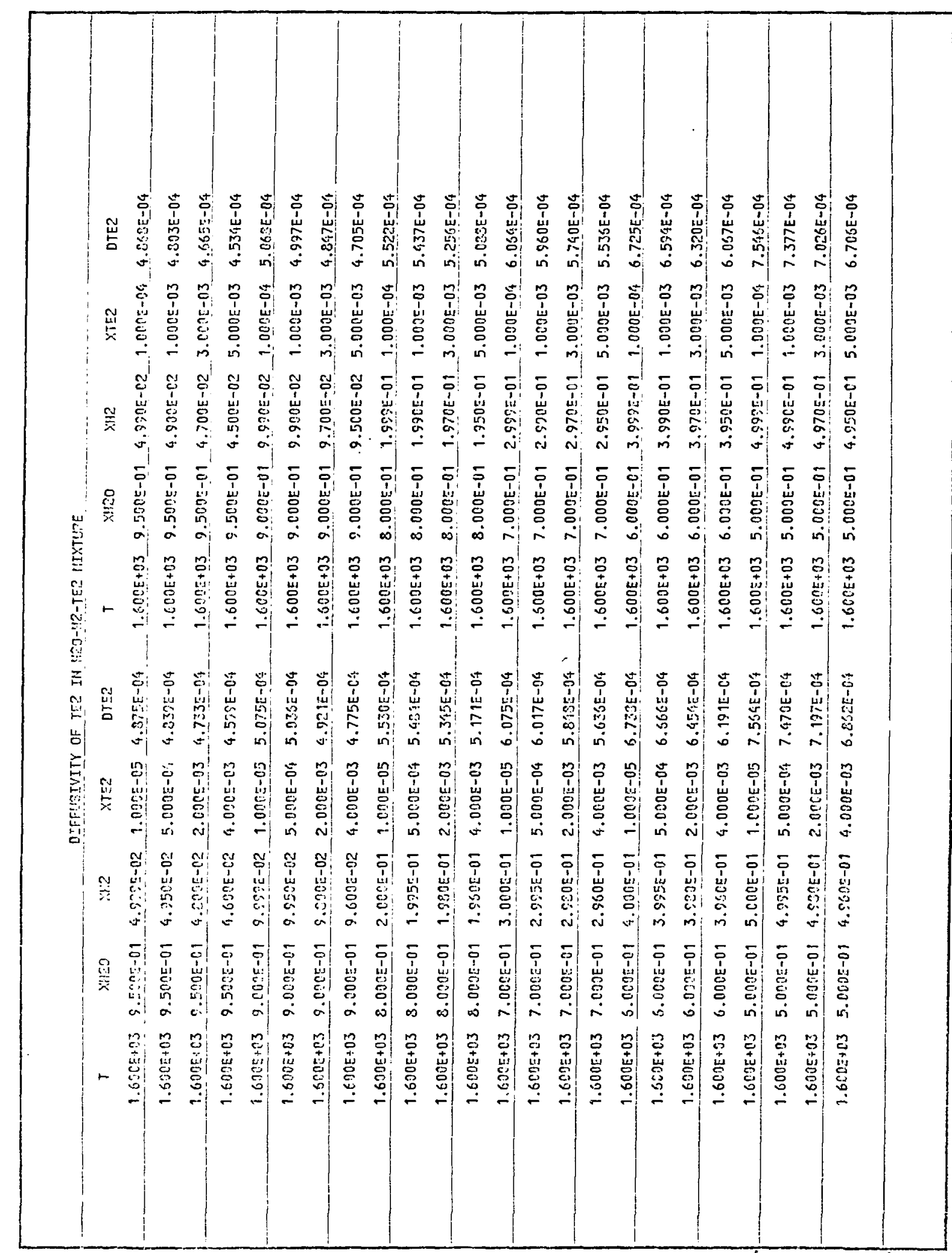


DIFEUSTVITY OF TEP III H?C-HP-TE2 HIXTU?E

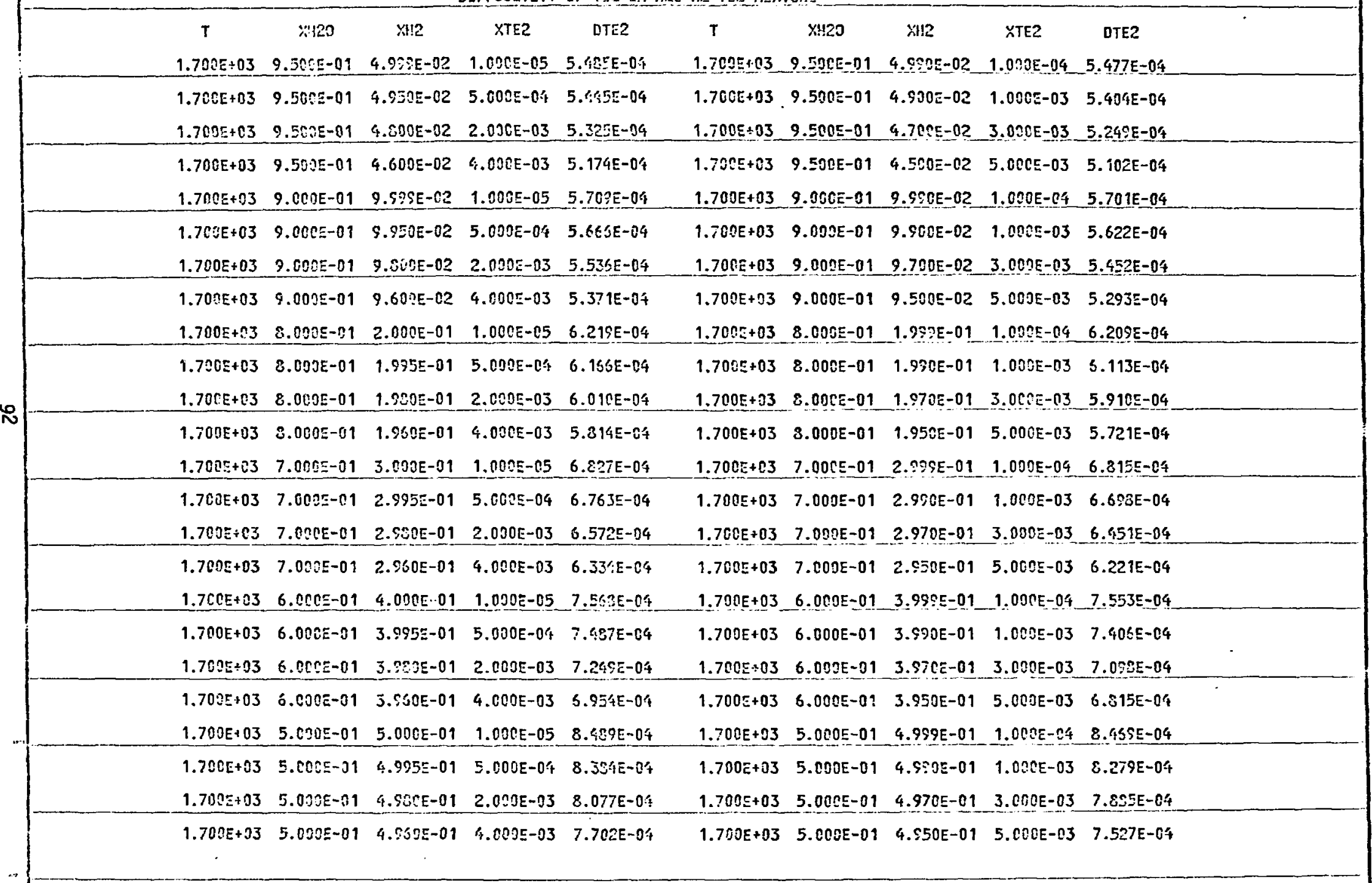




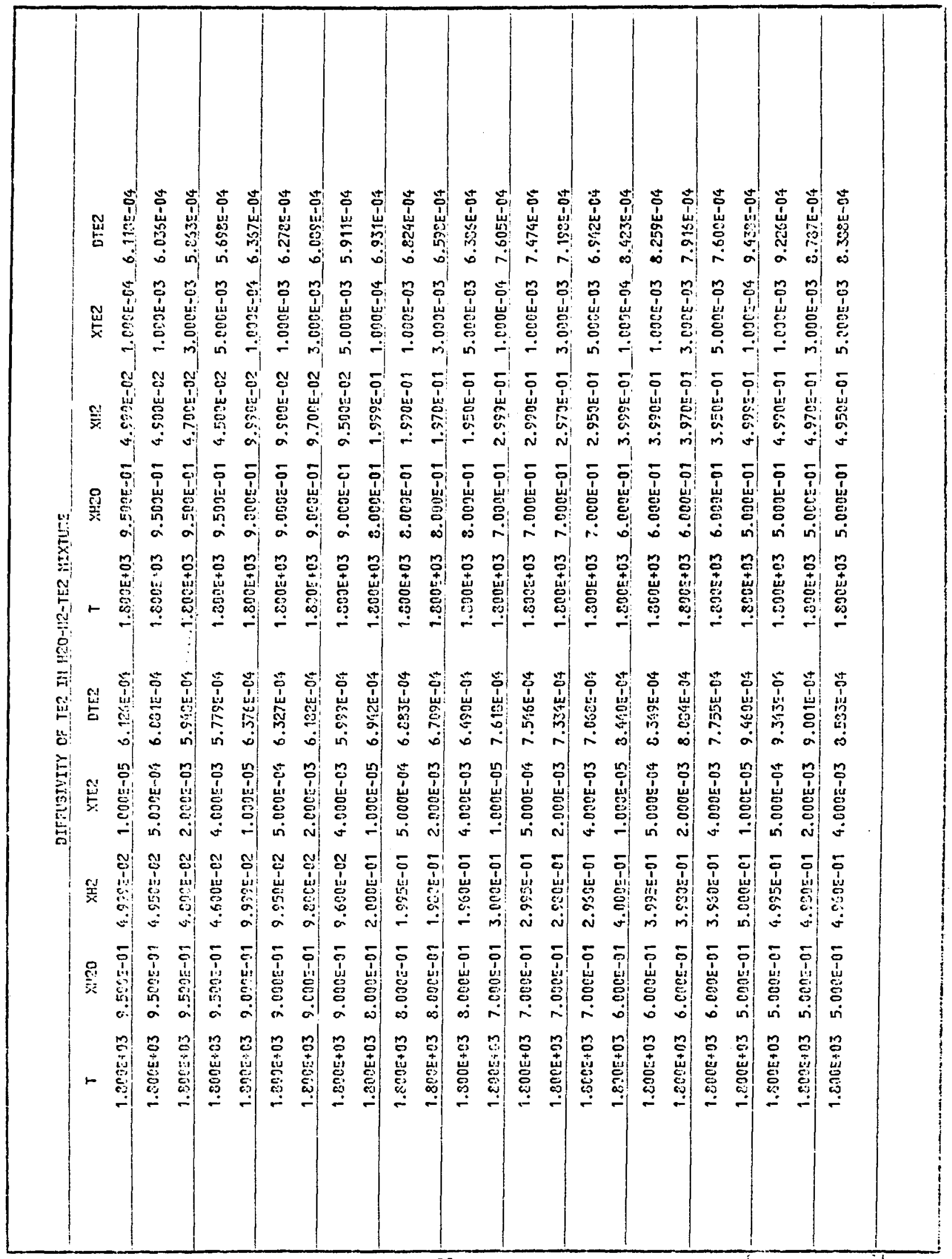




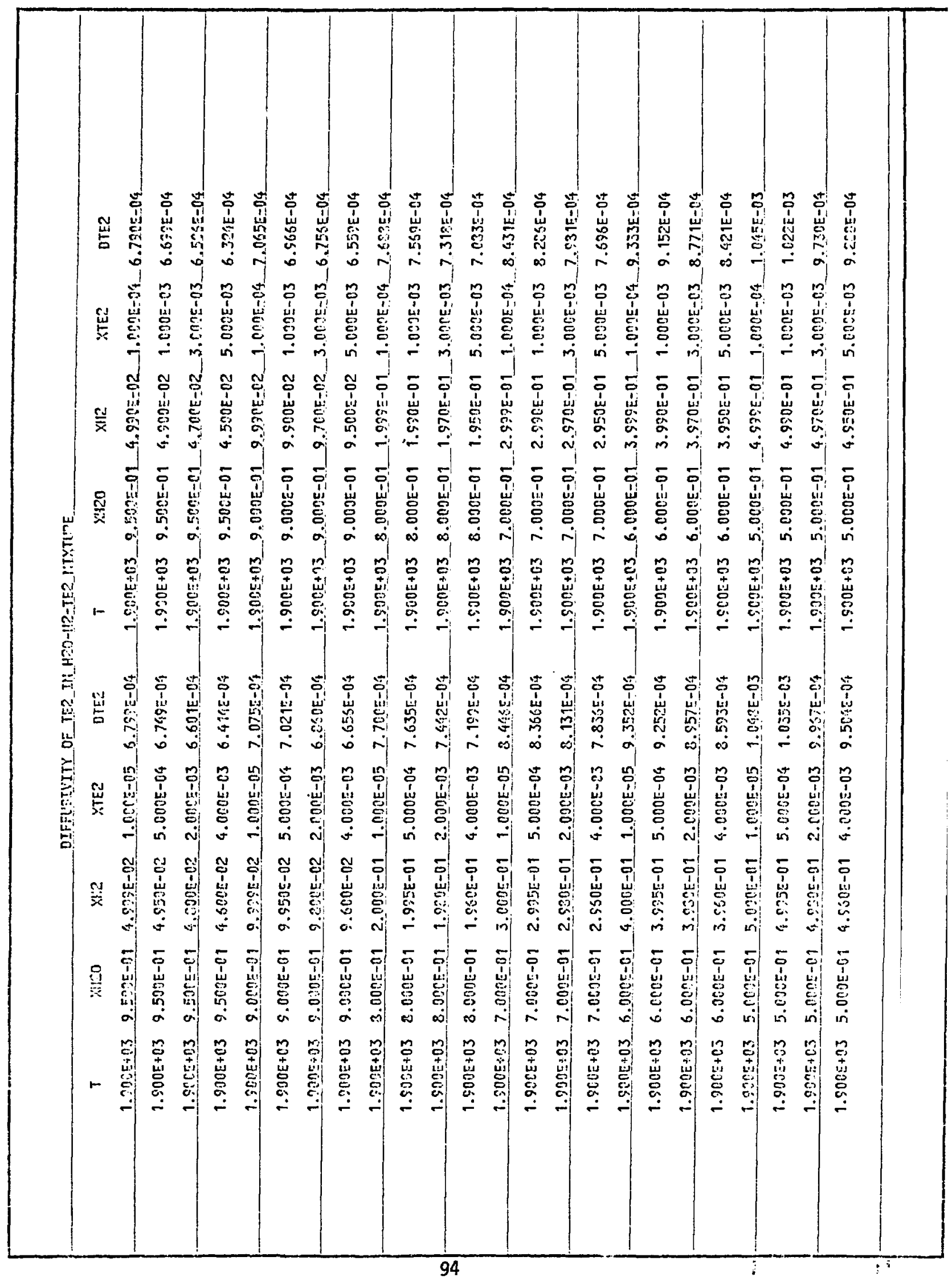





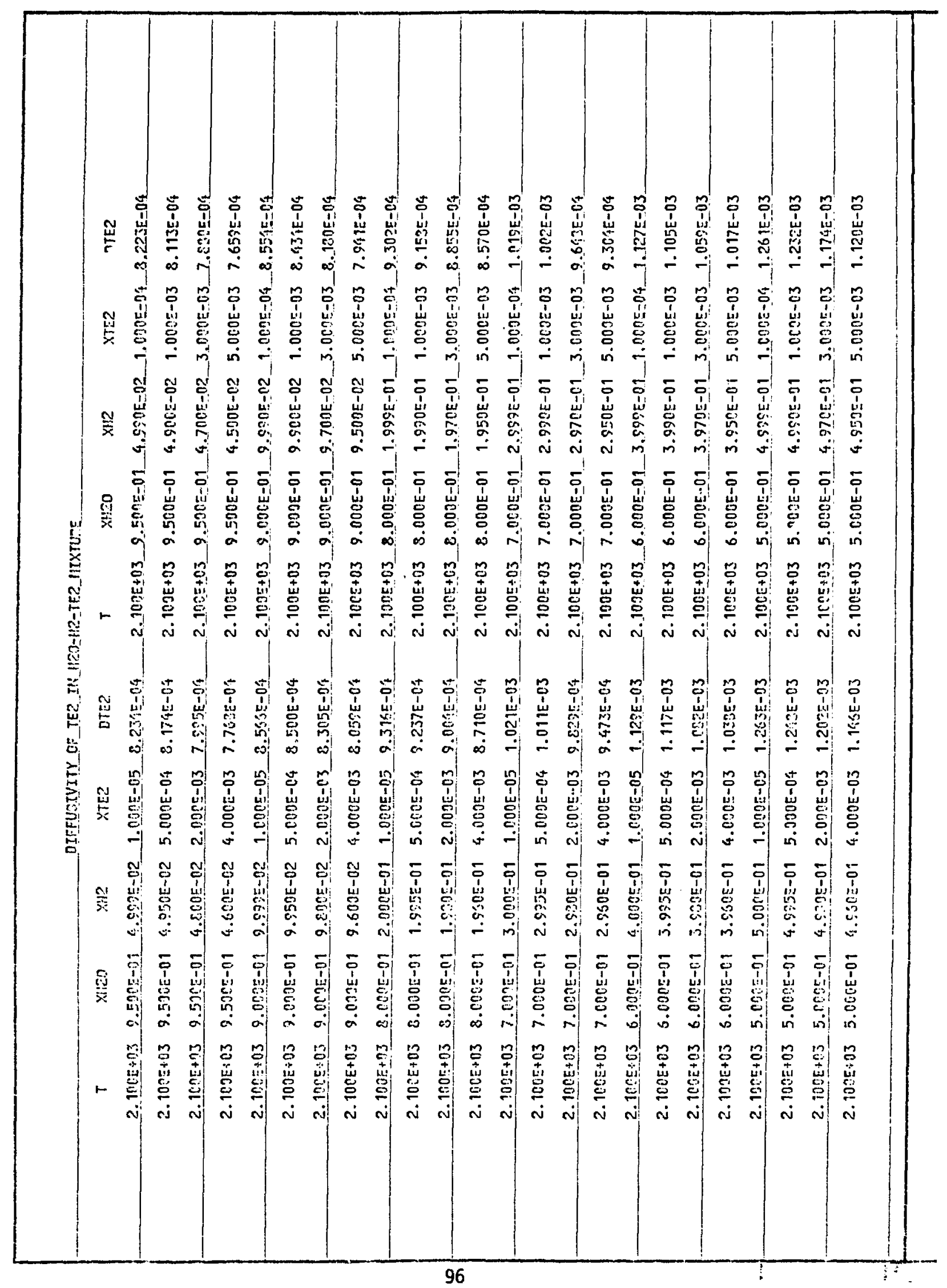




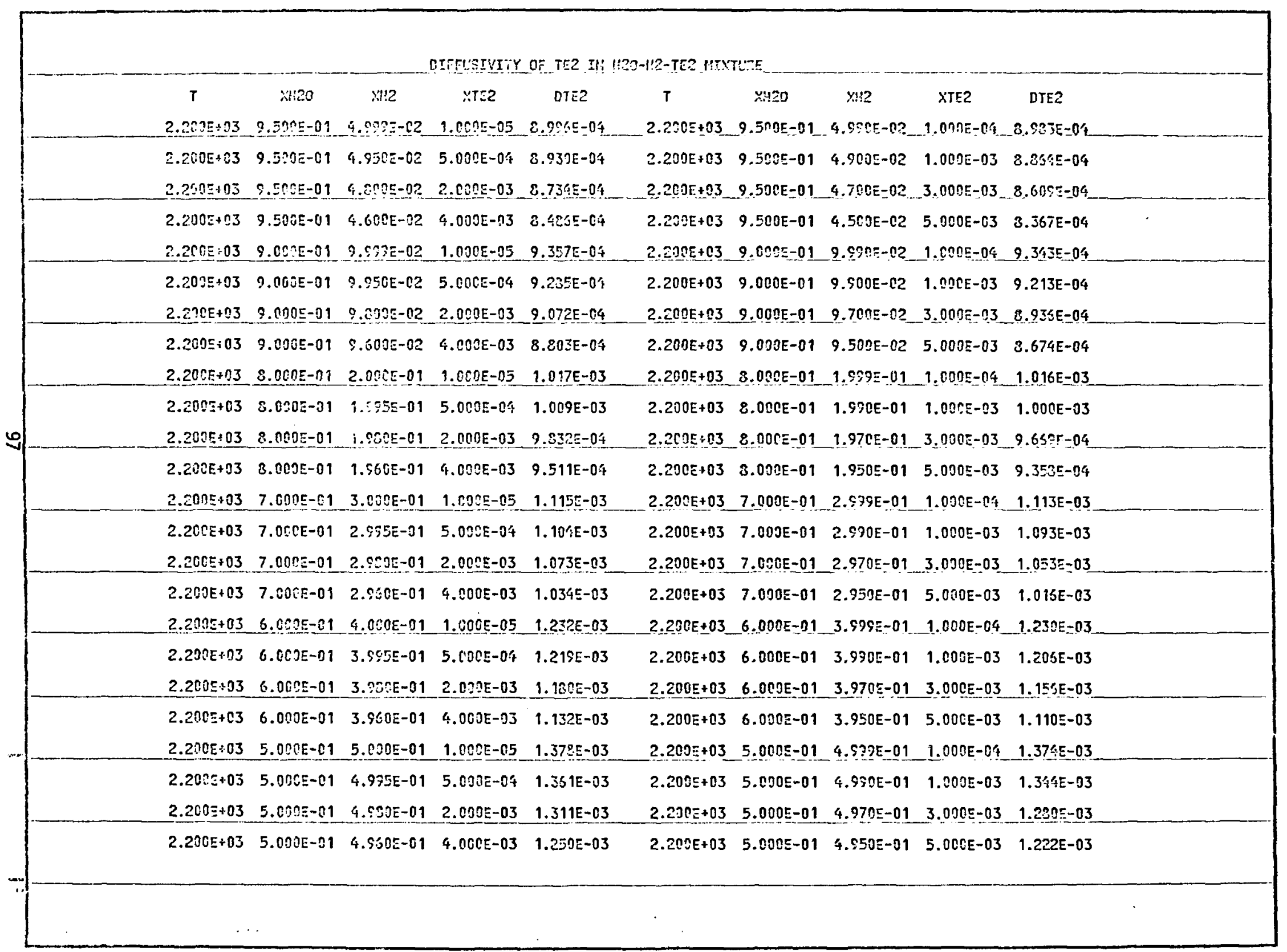




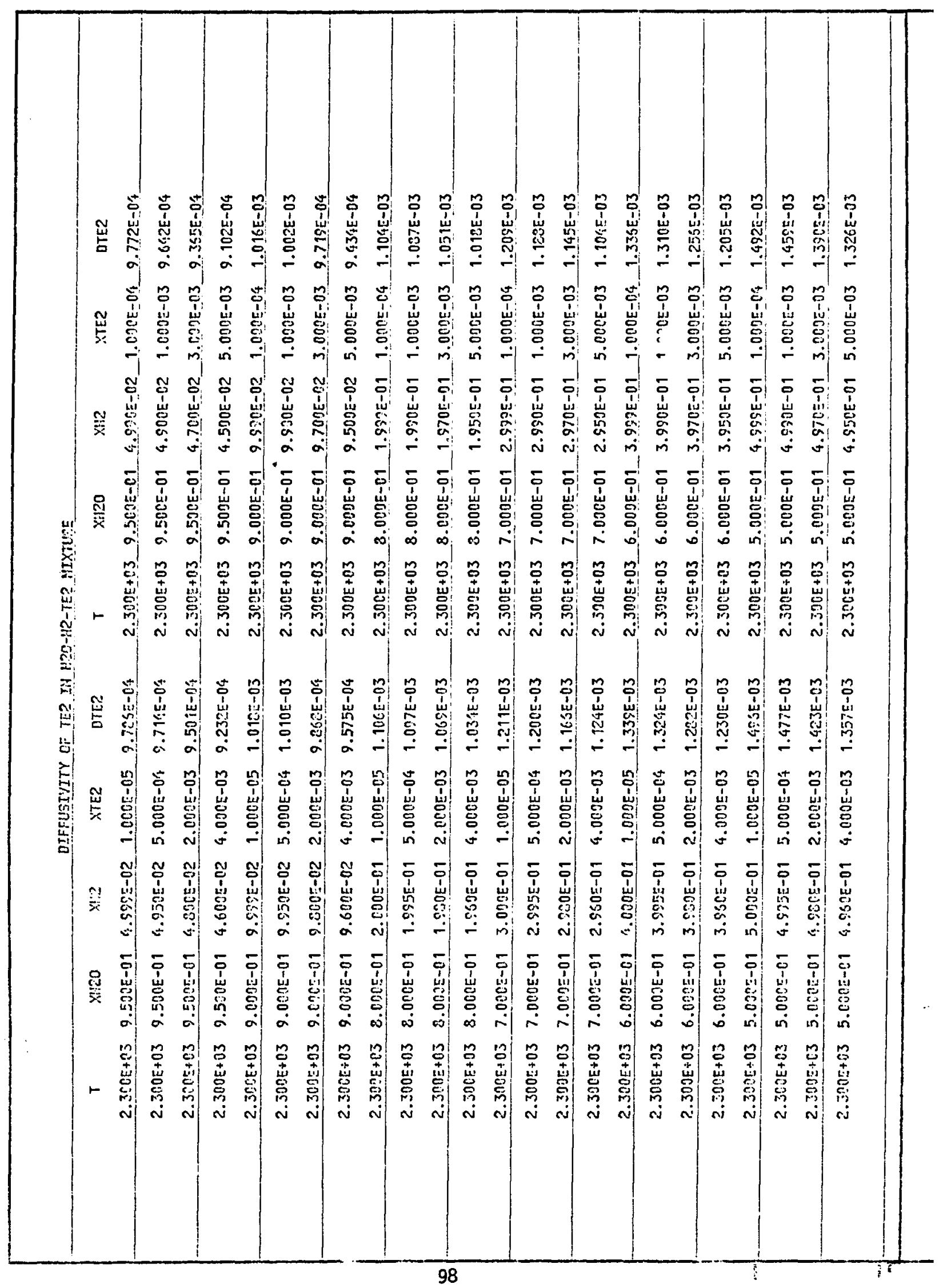




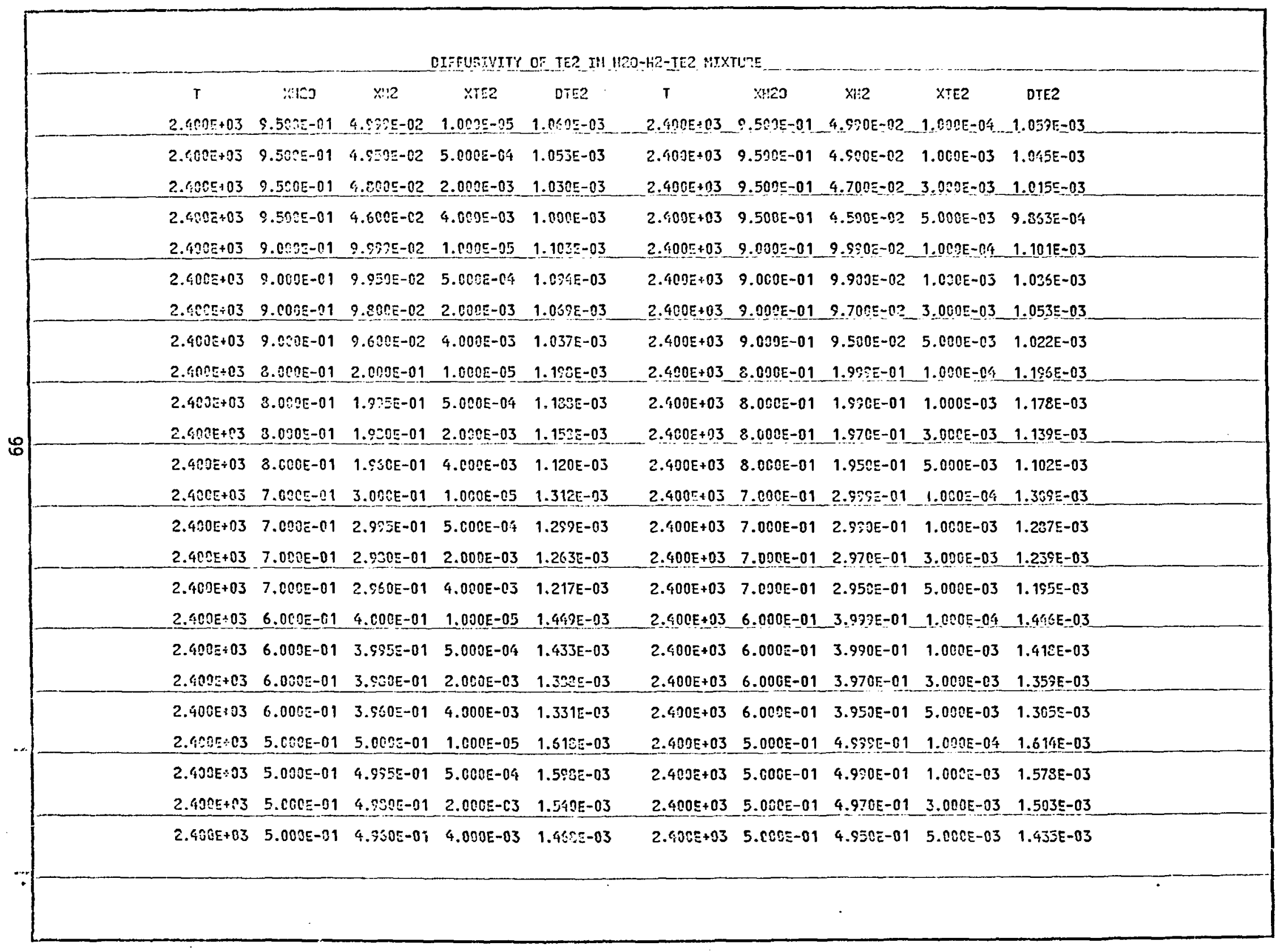




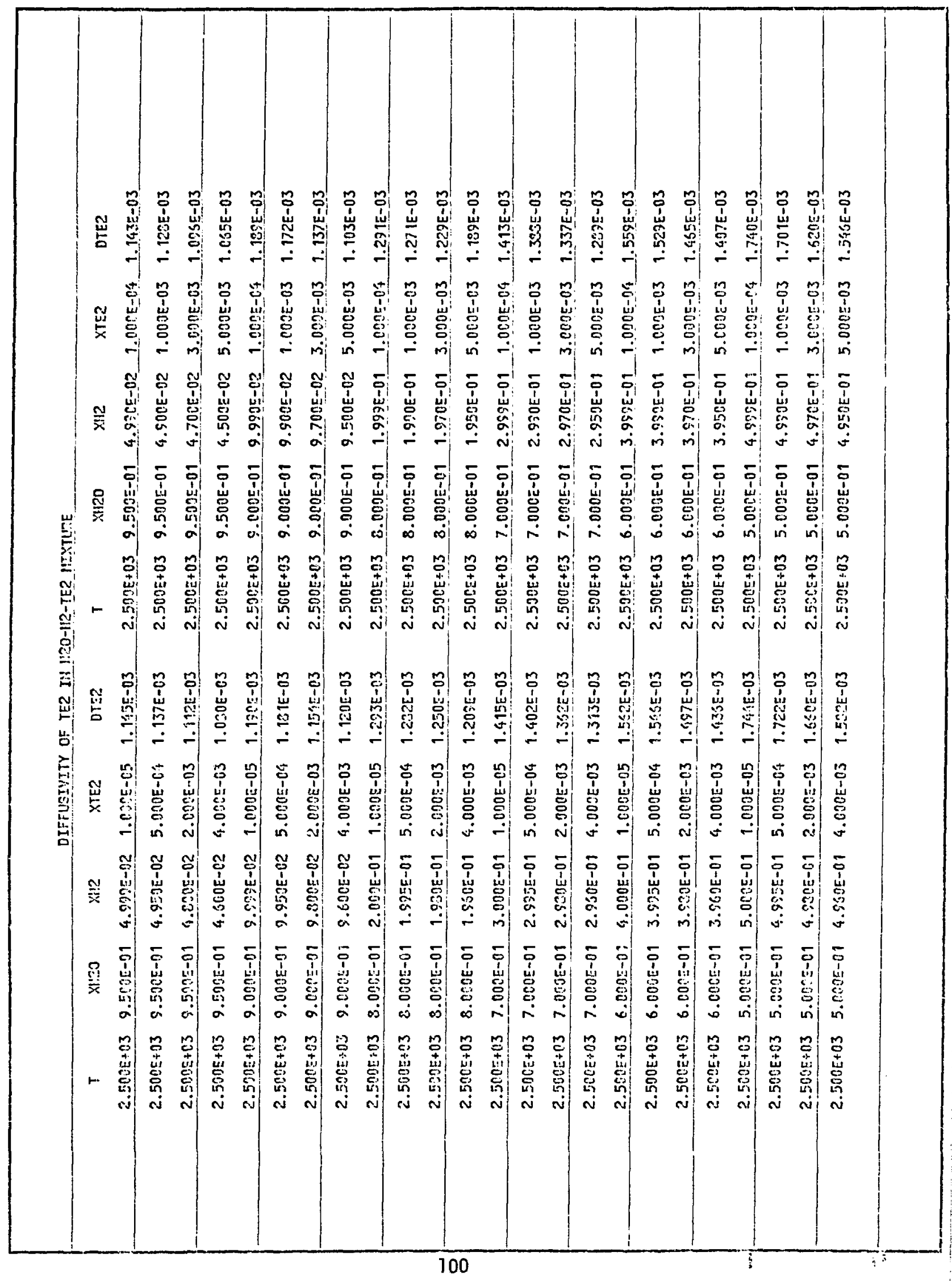




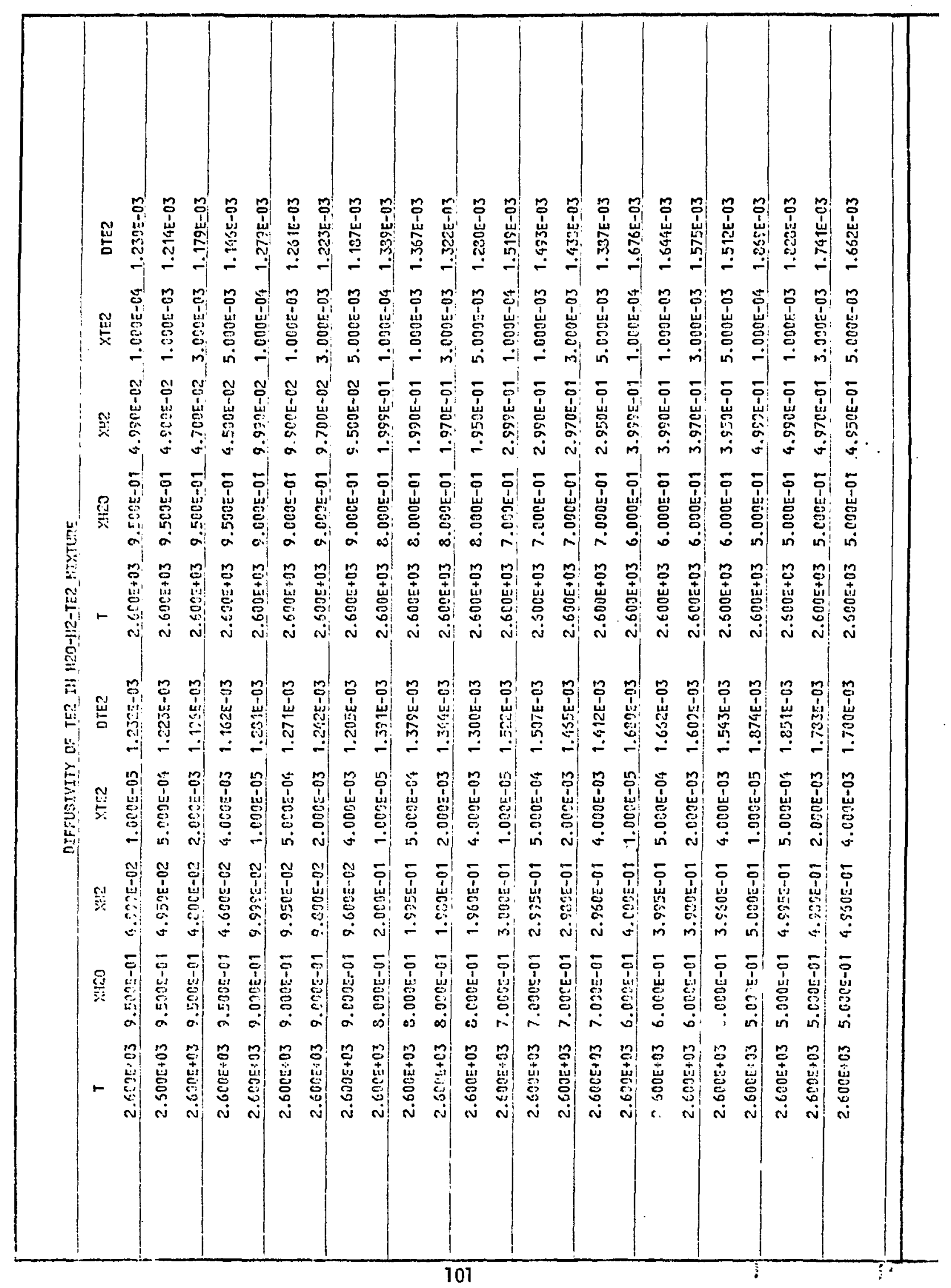




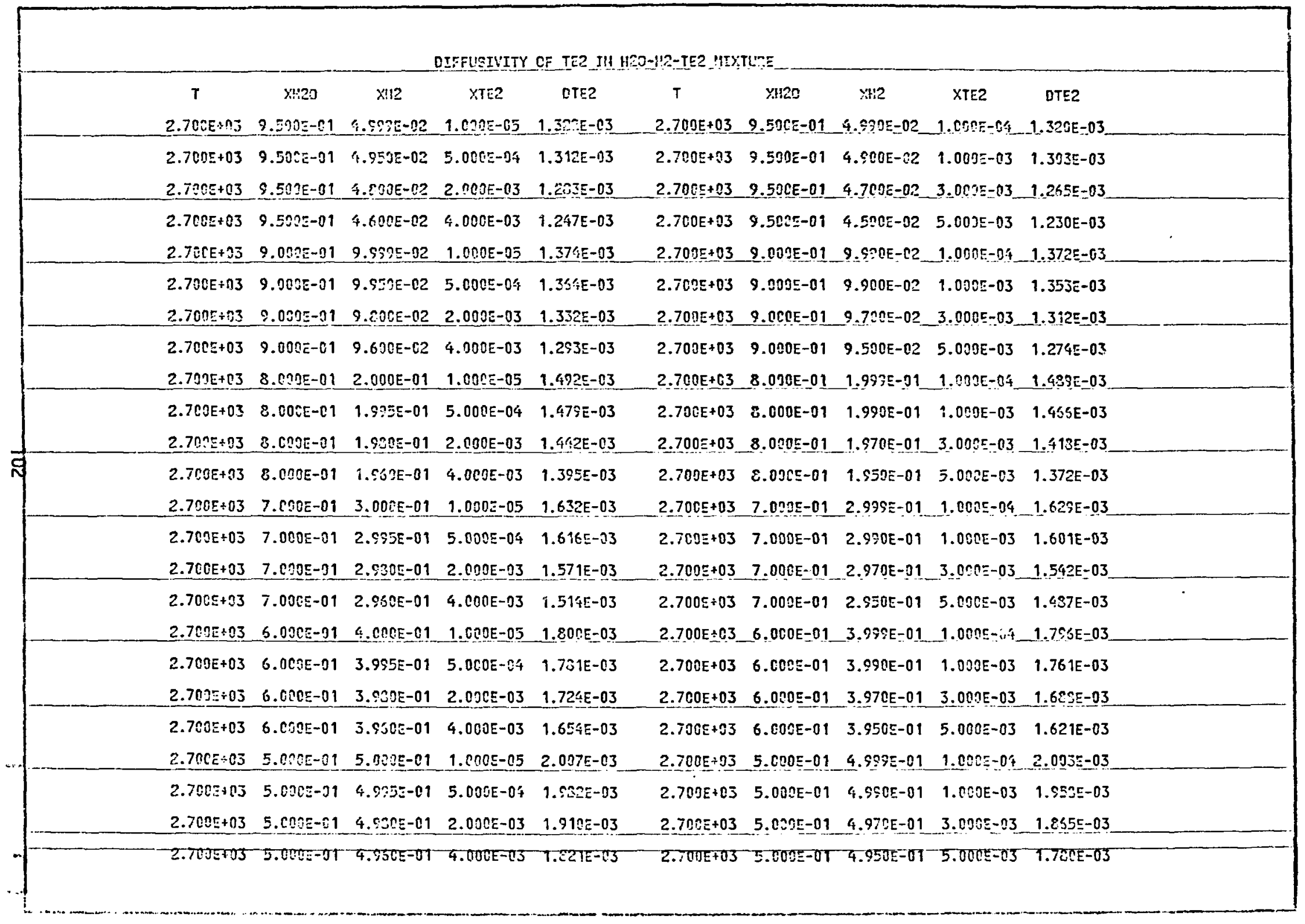




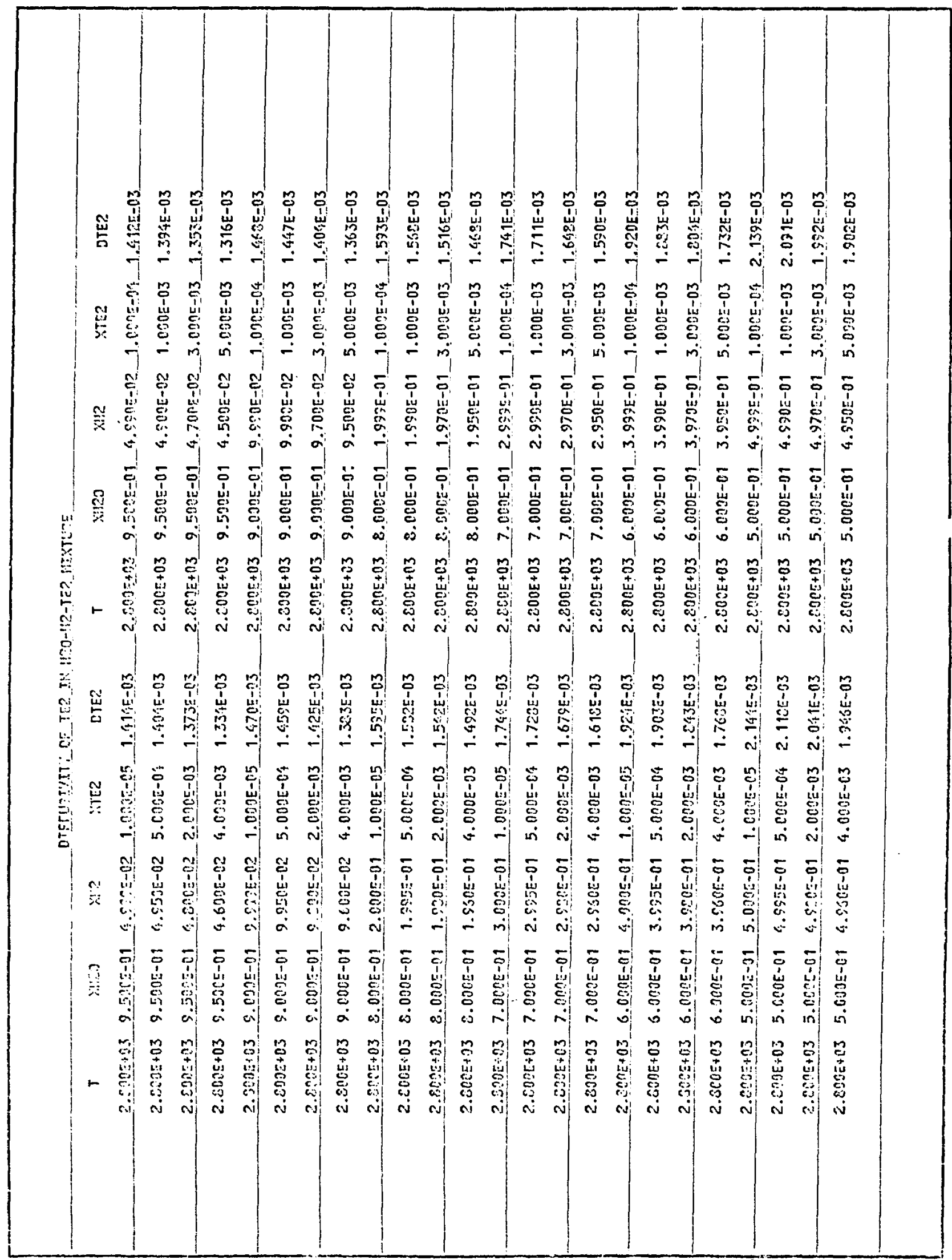




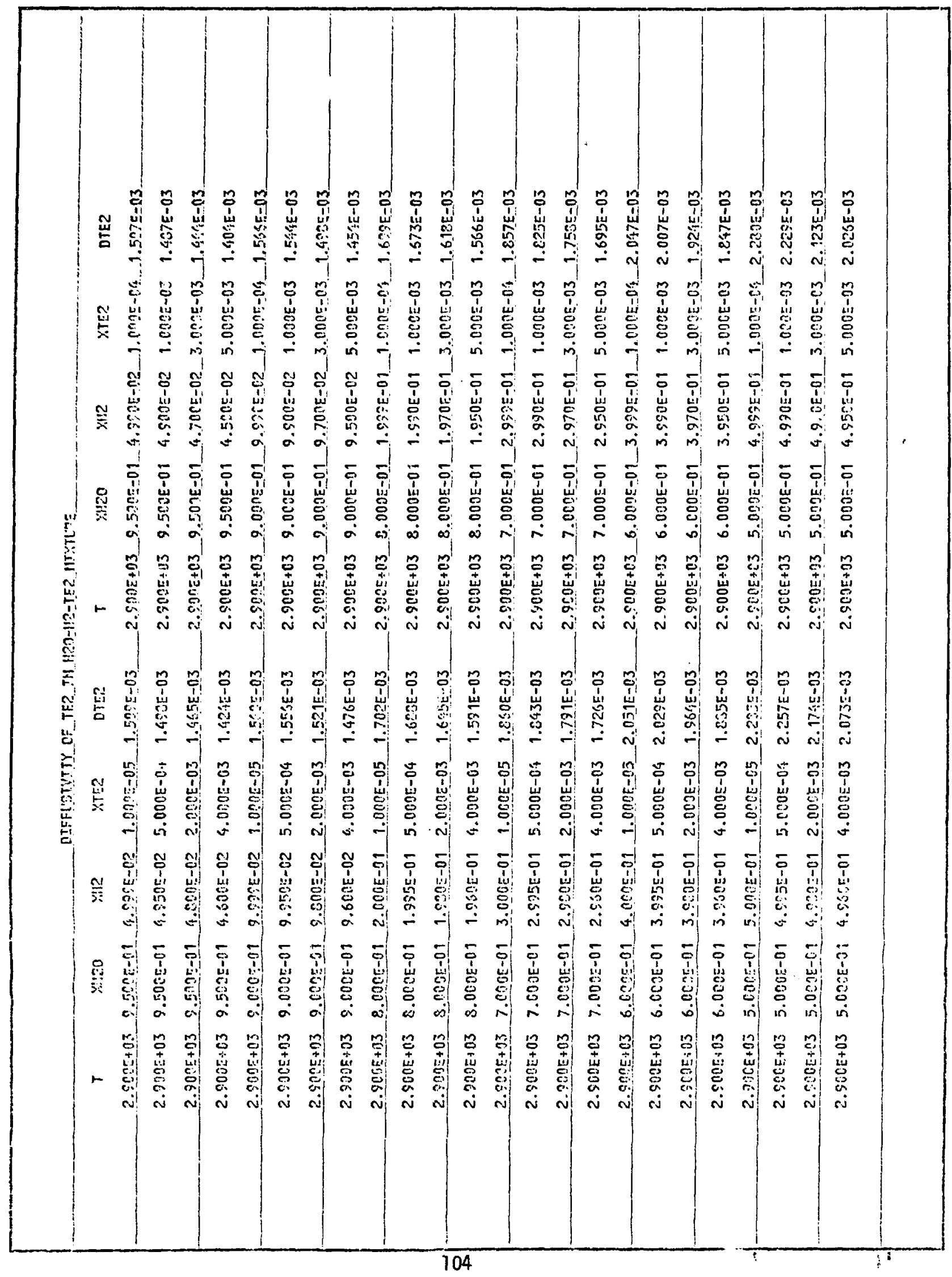




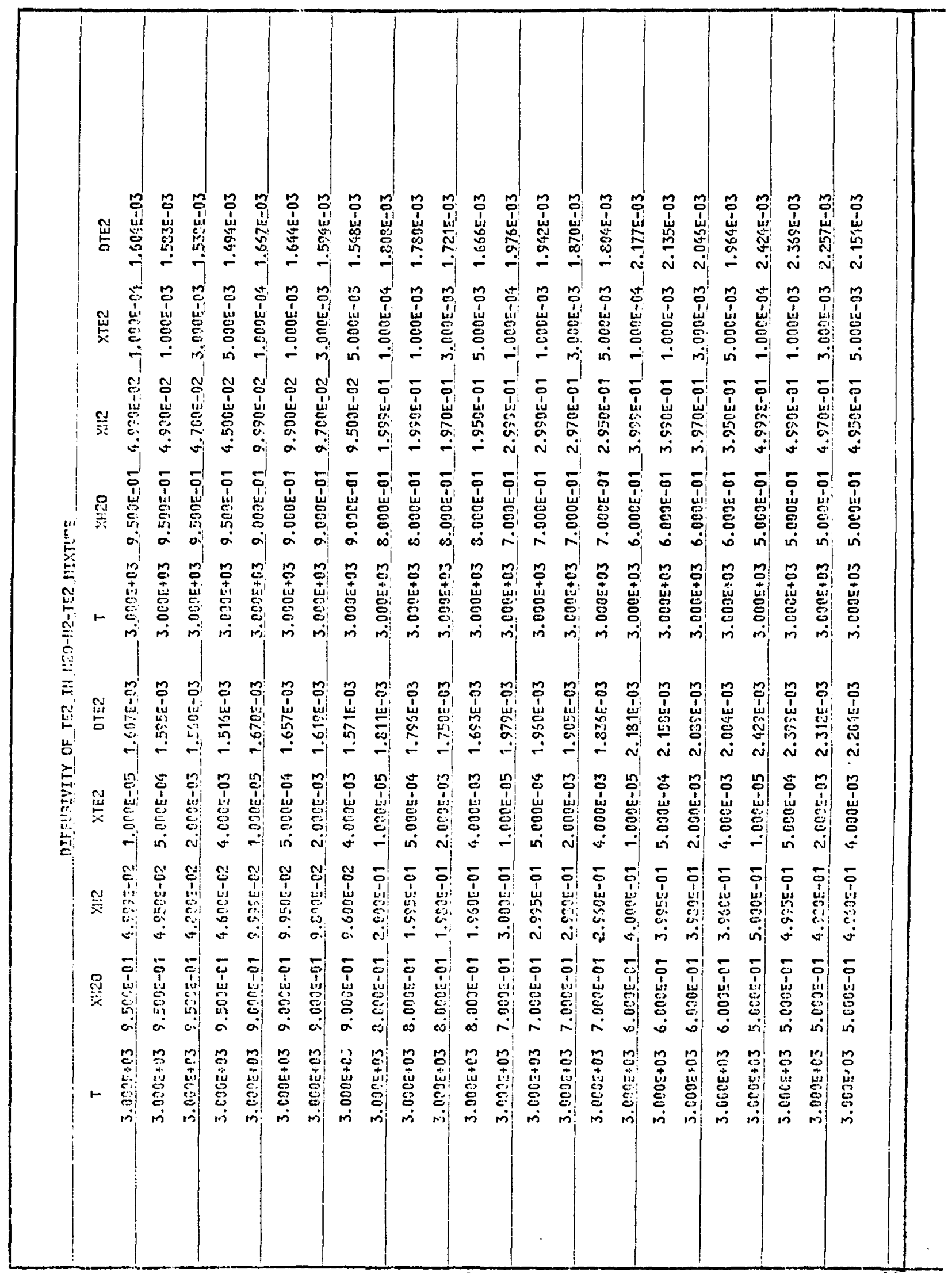




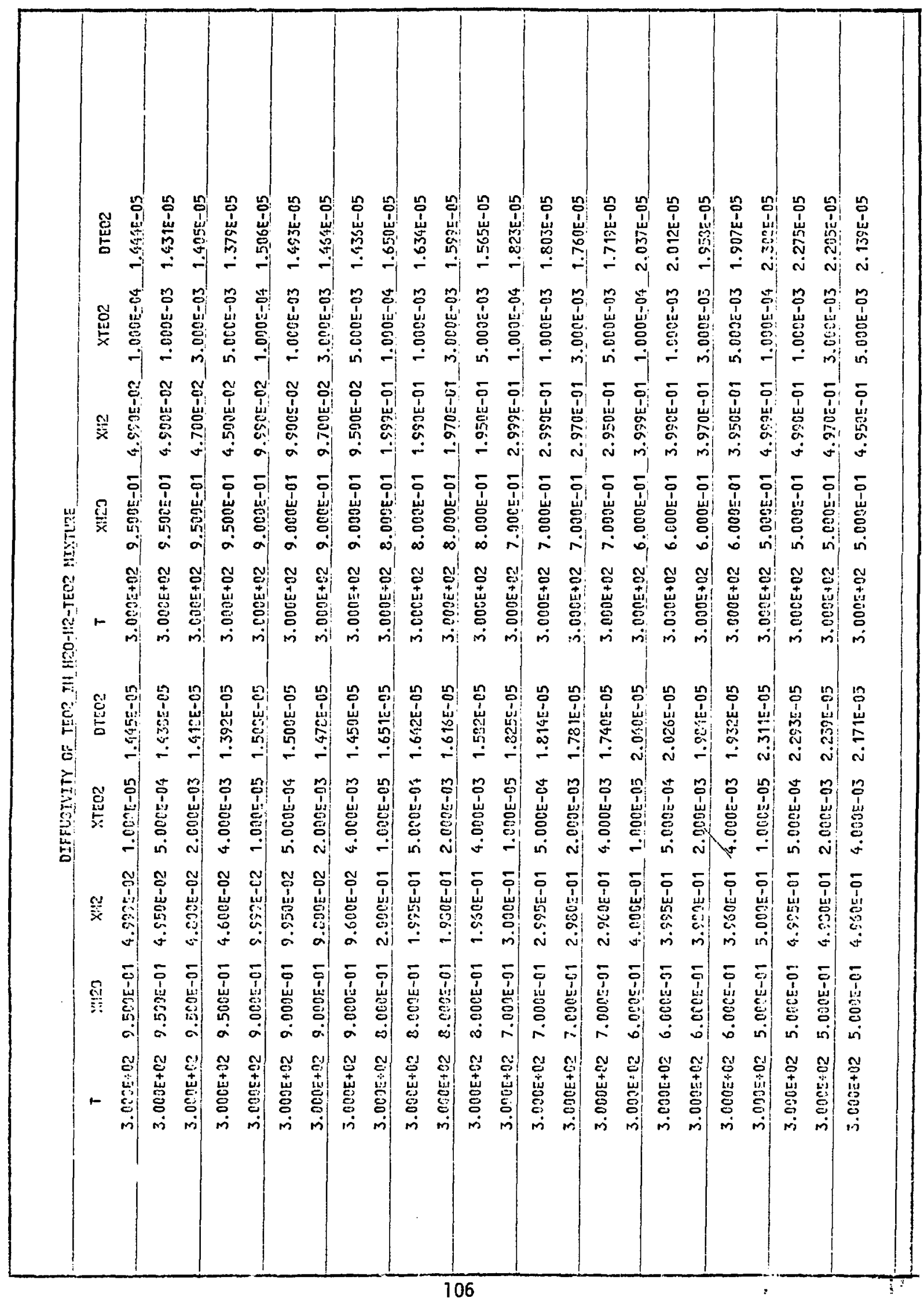




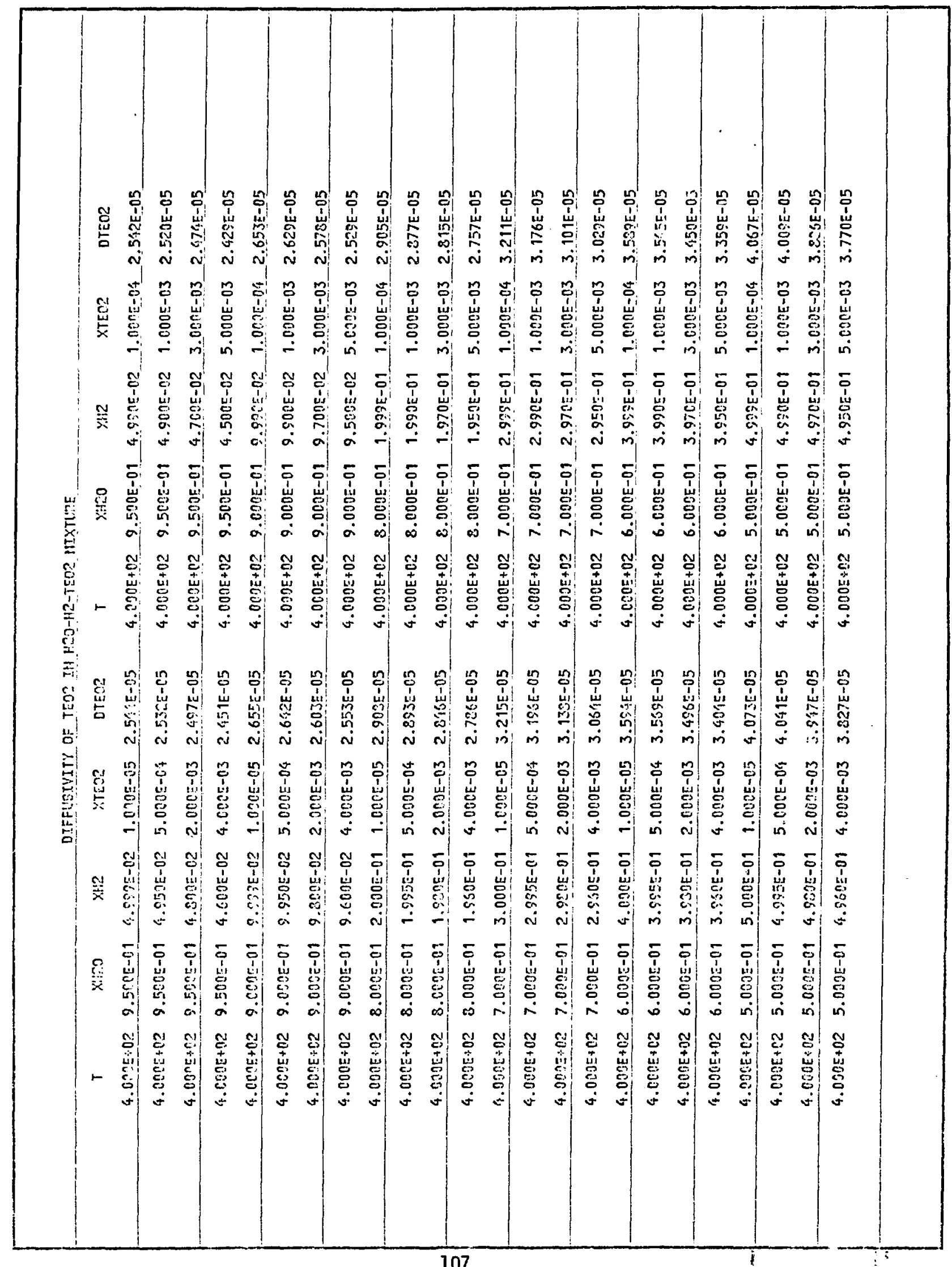




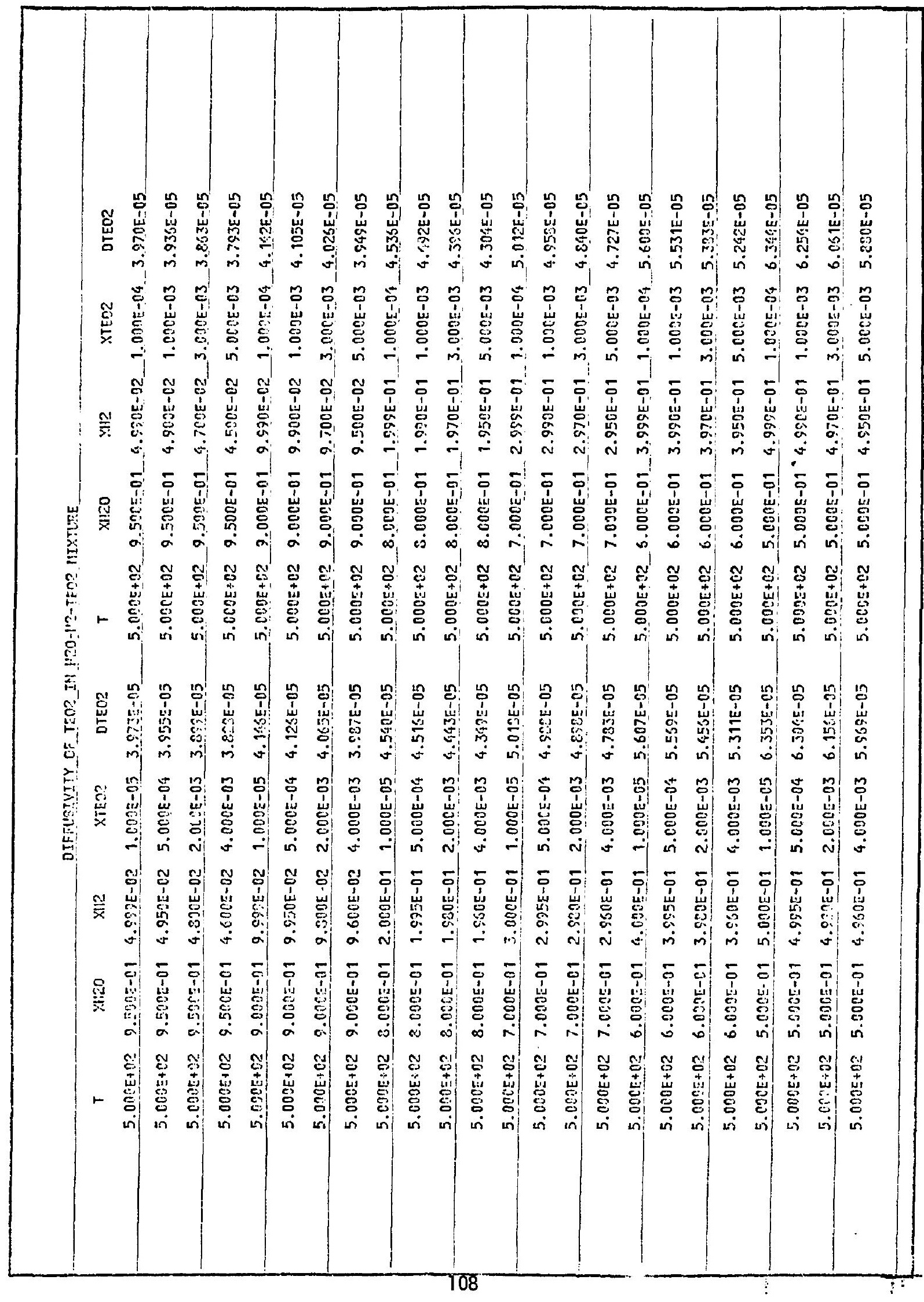




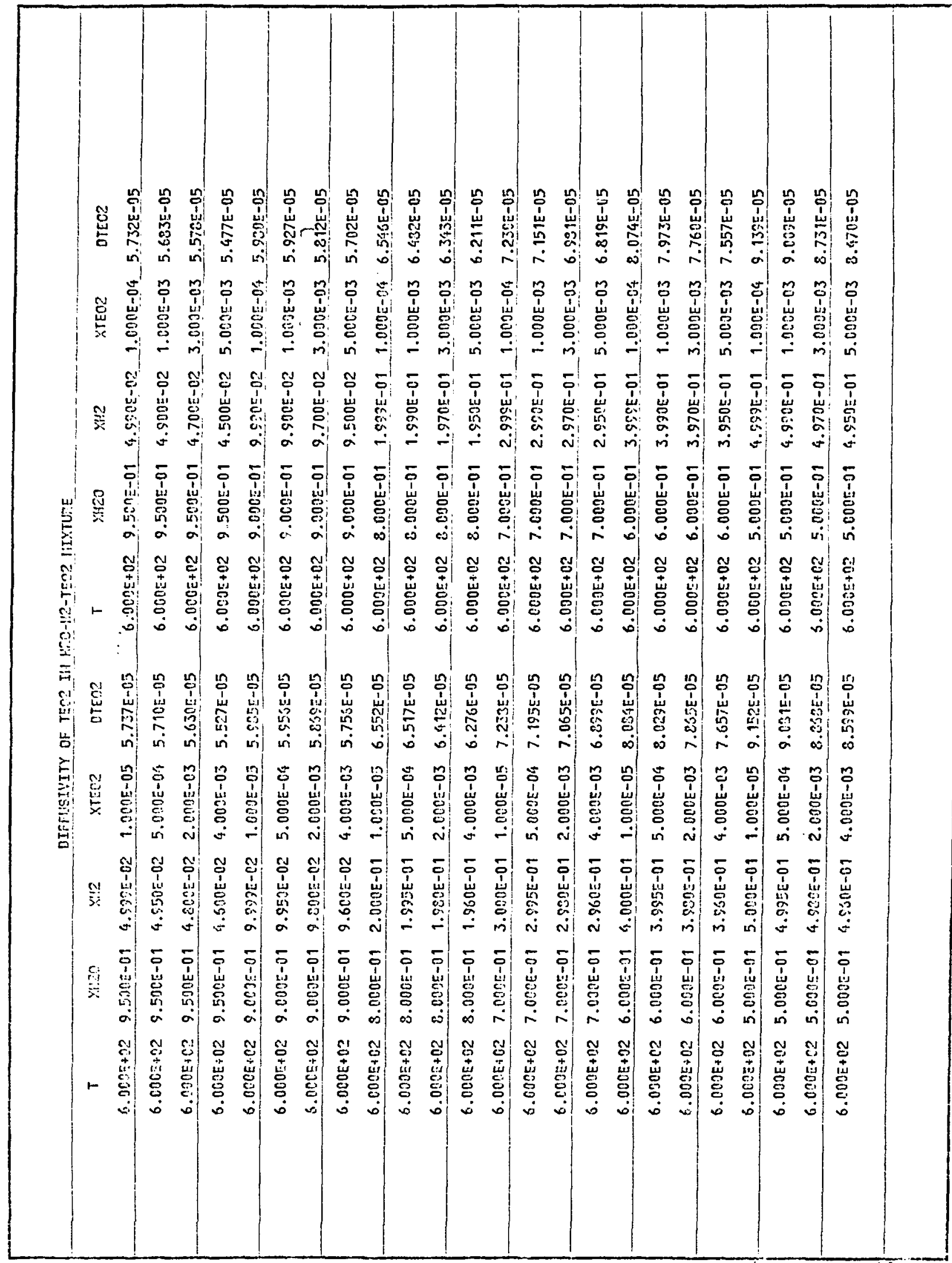




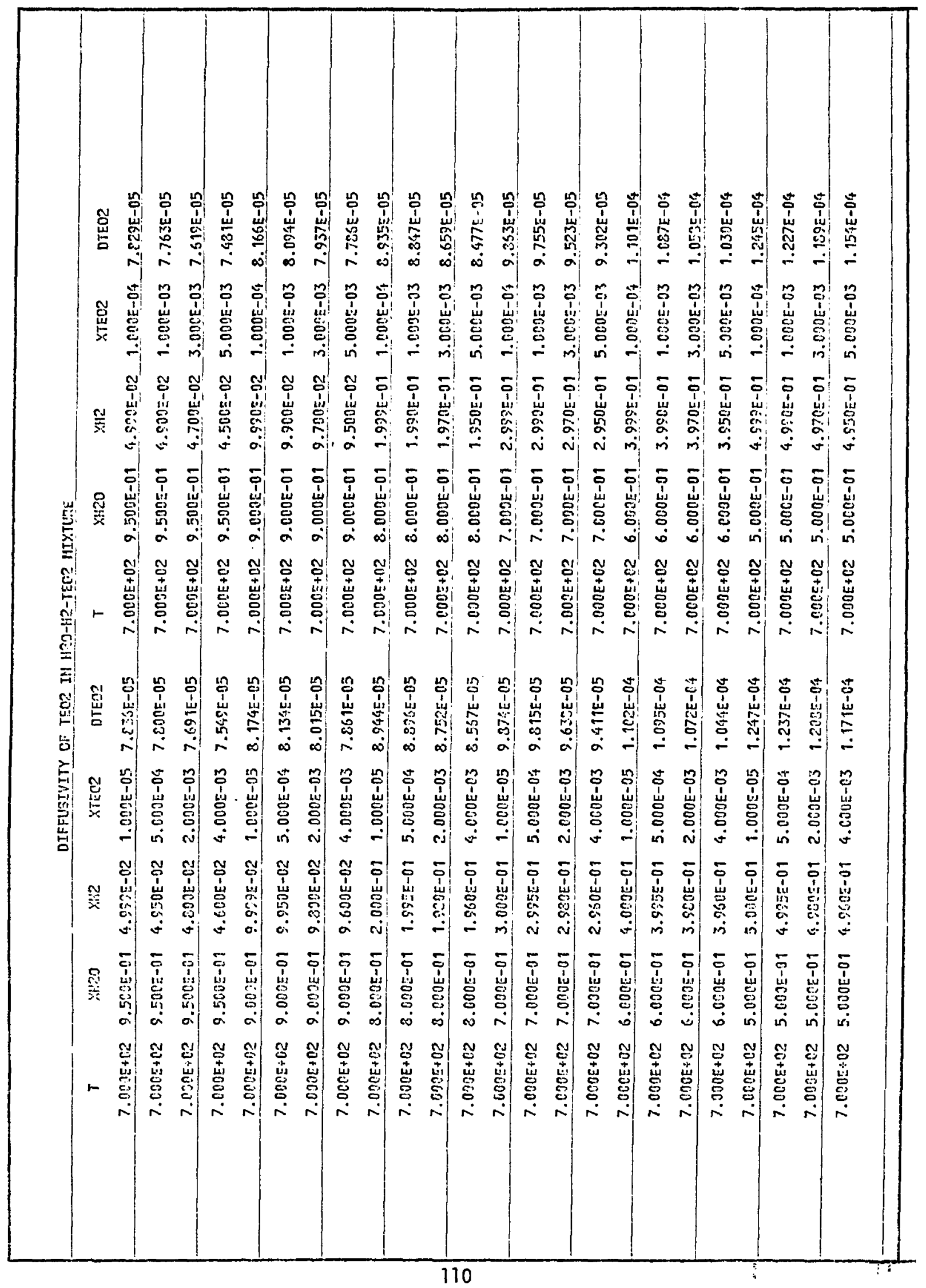




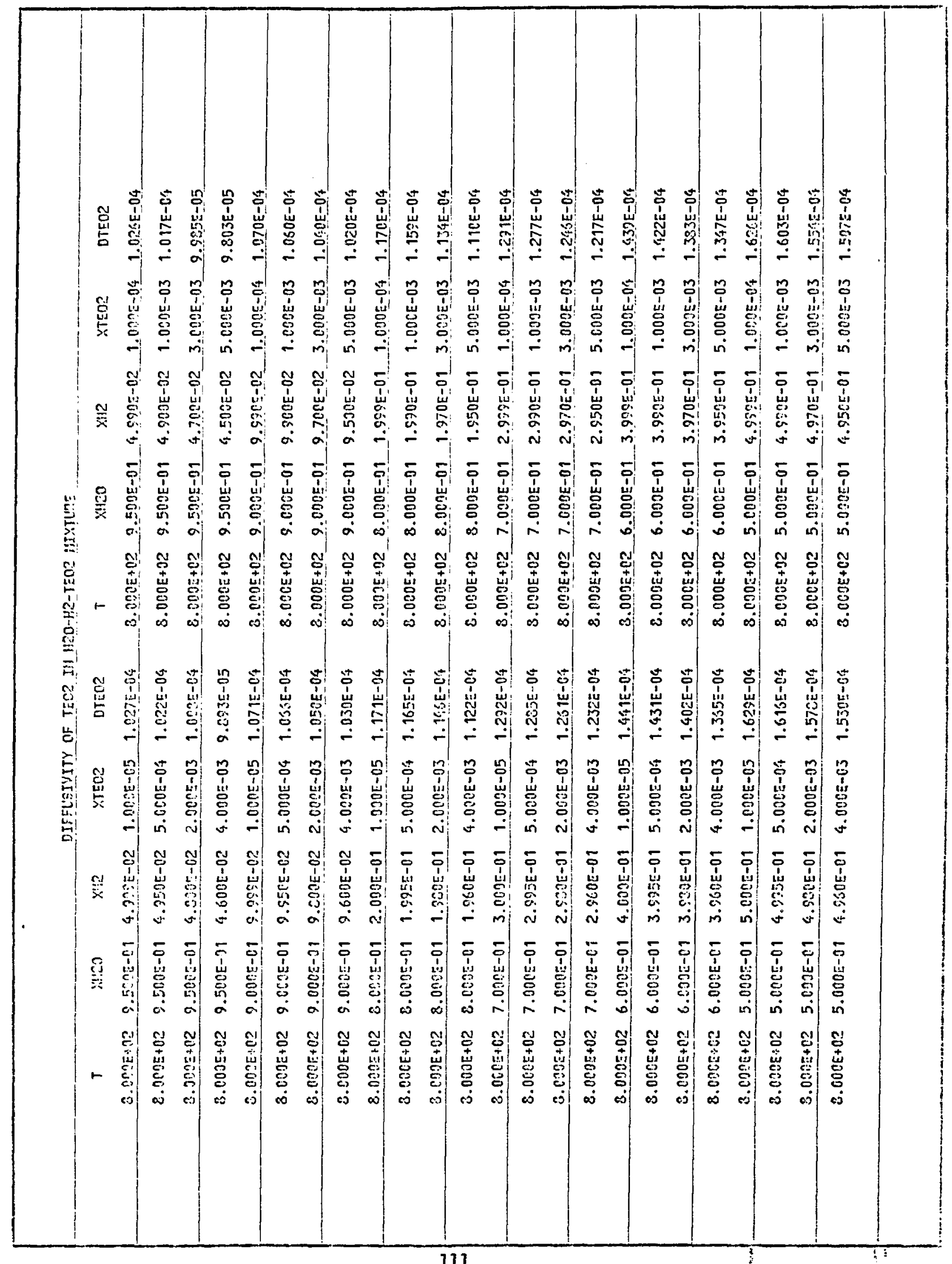




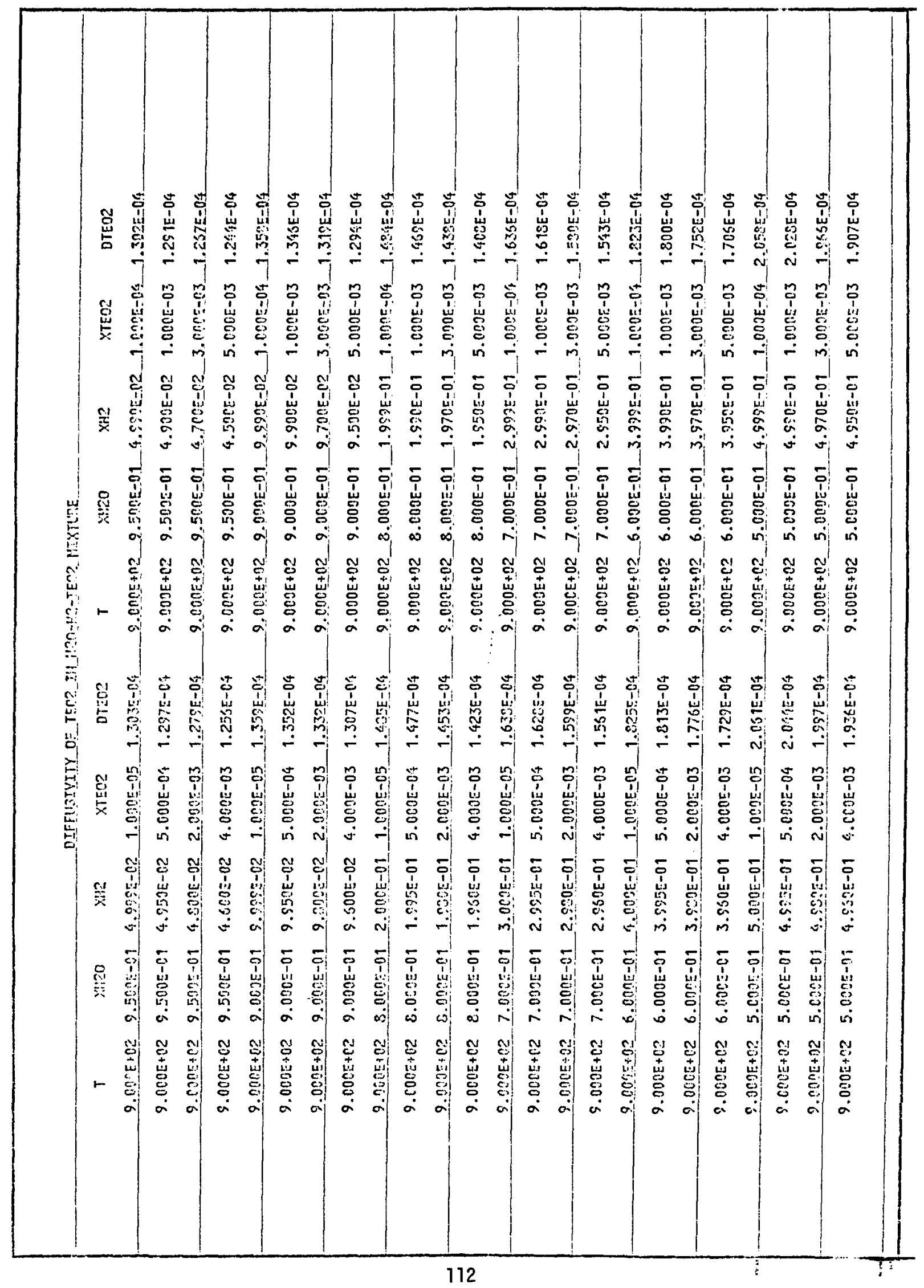




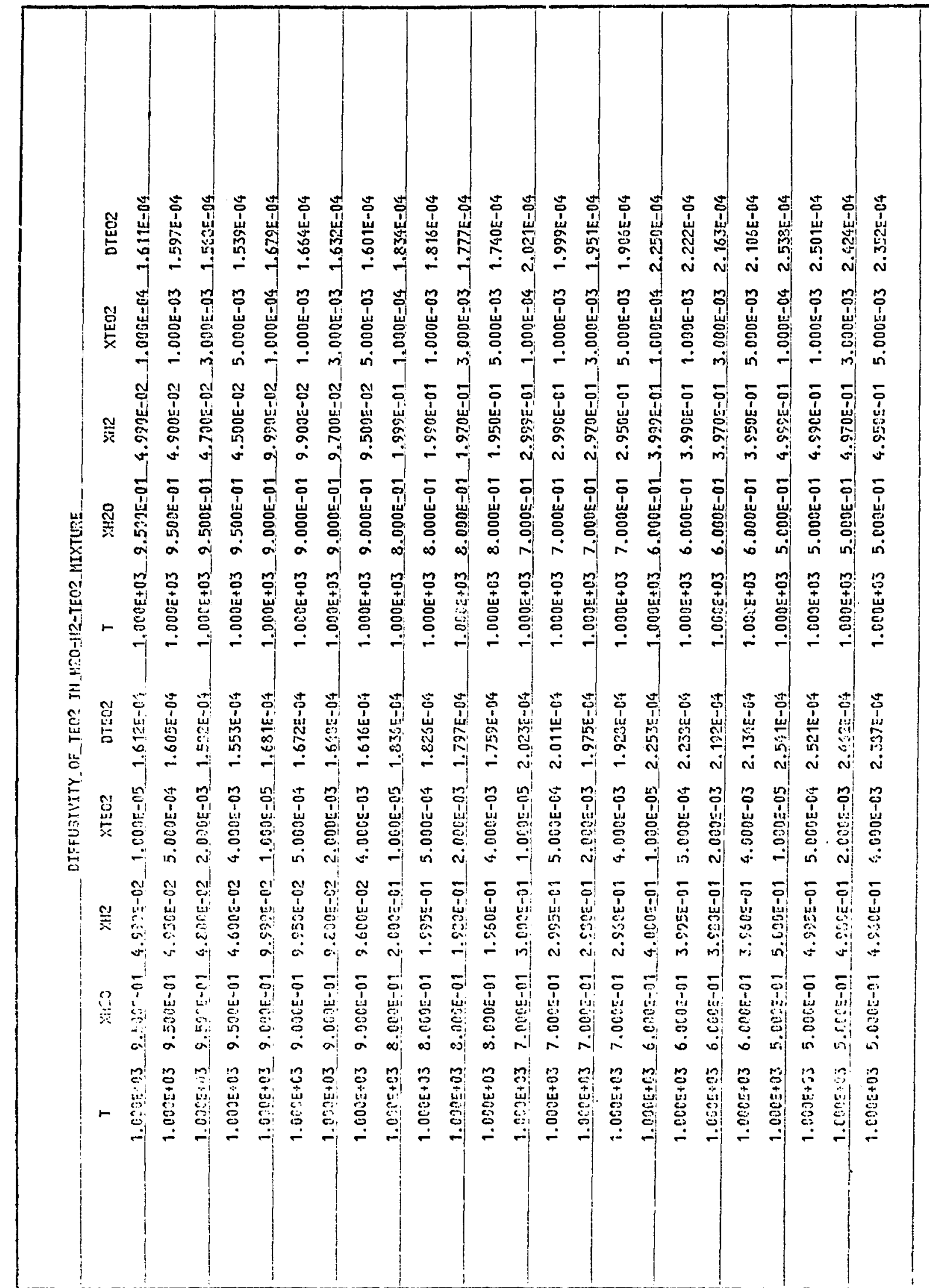


OIFFUSIVITY NE TER? IH H?O-? 2-TEO2 HIXTUTE

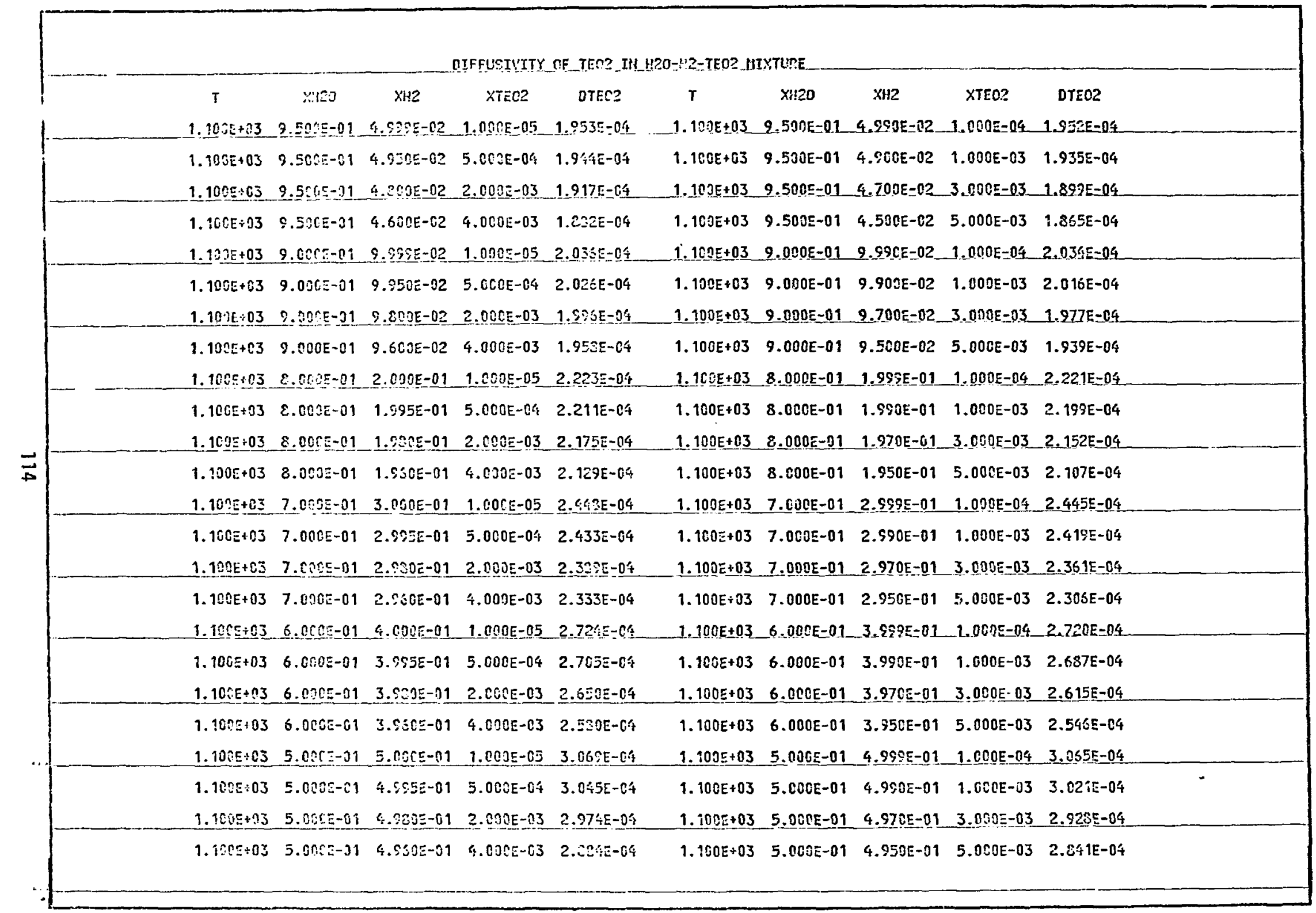




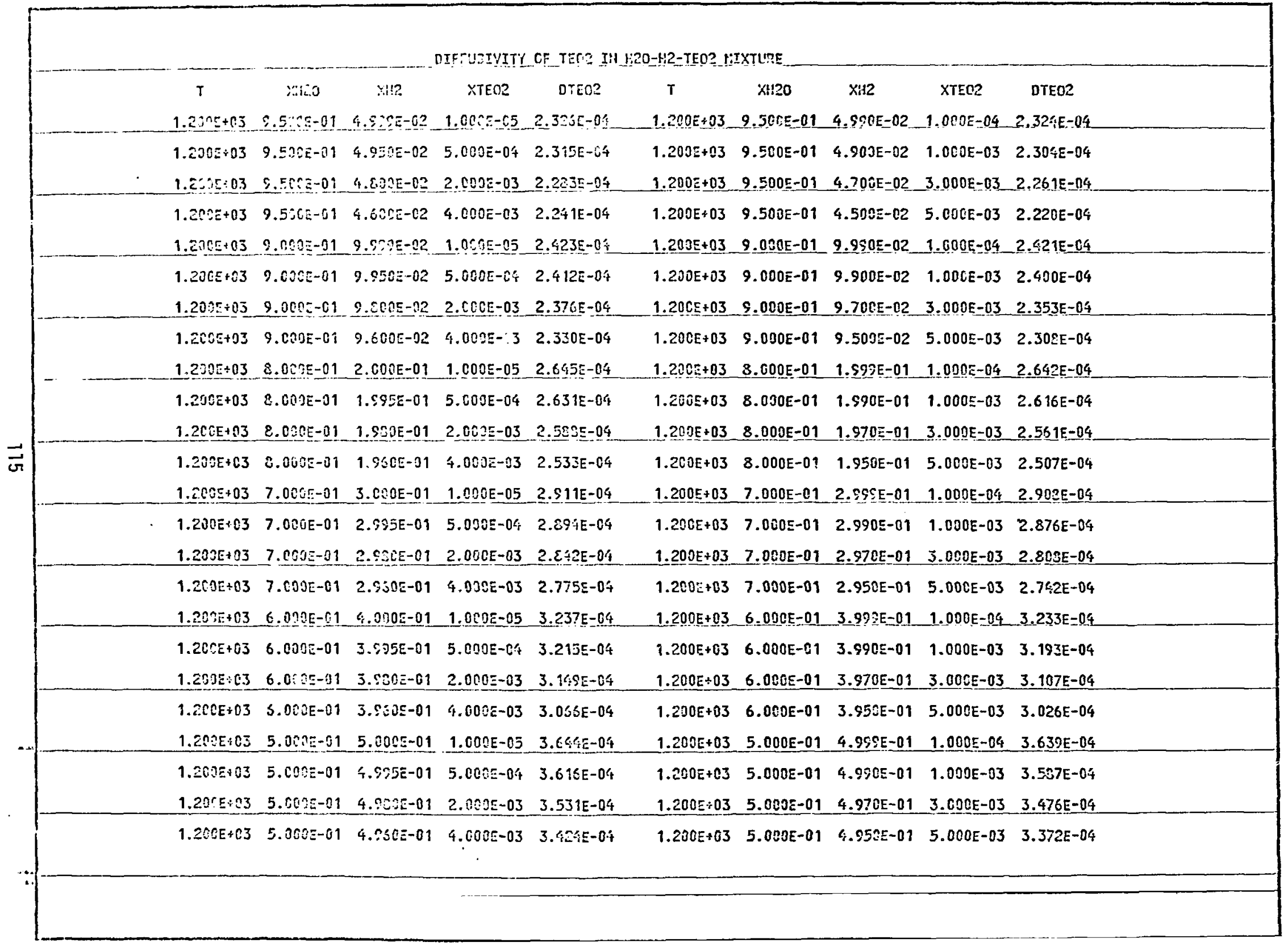




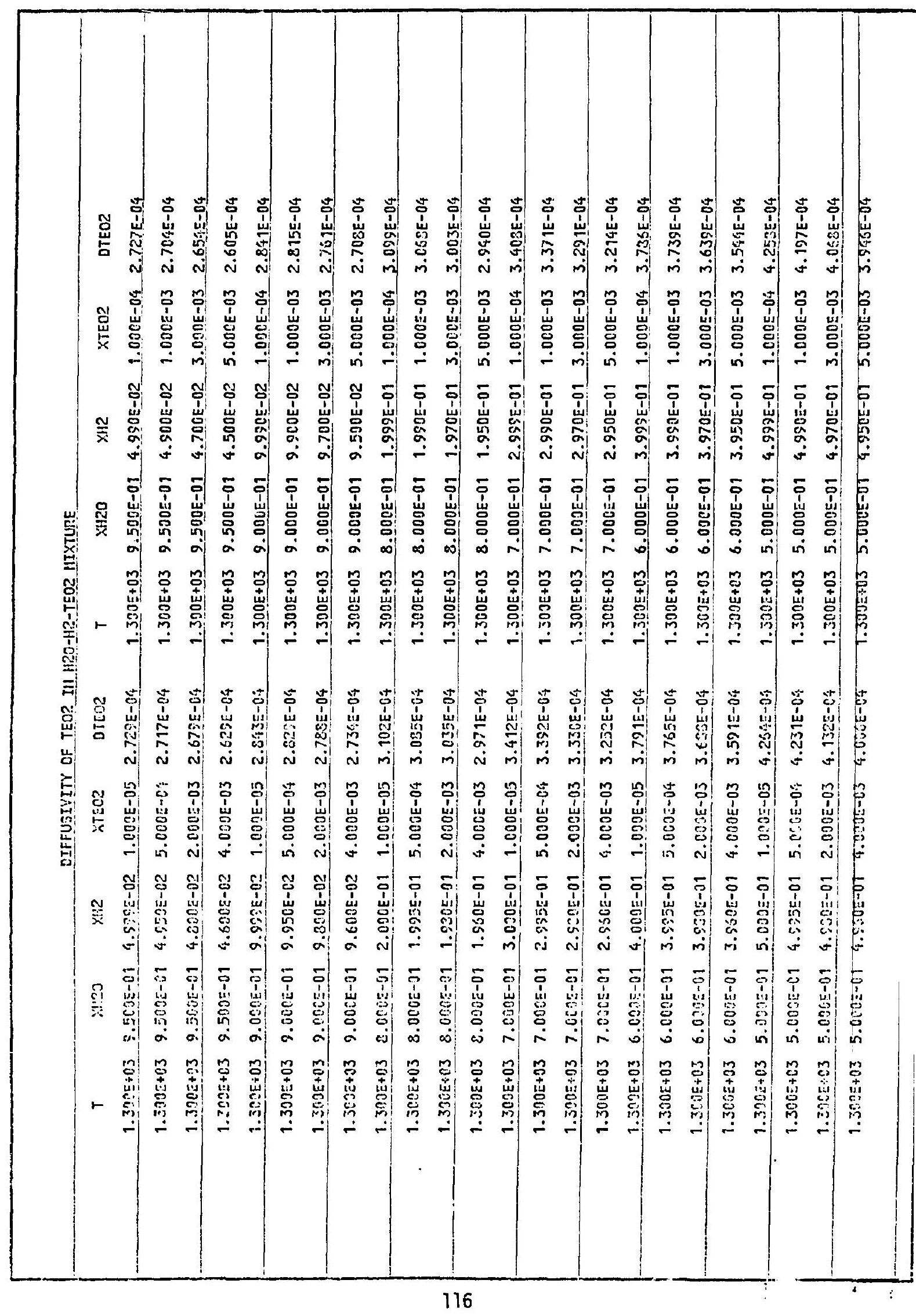




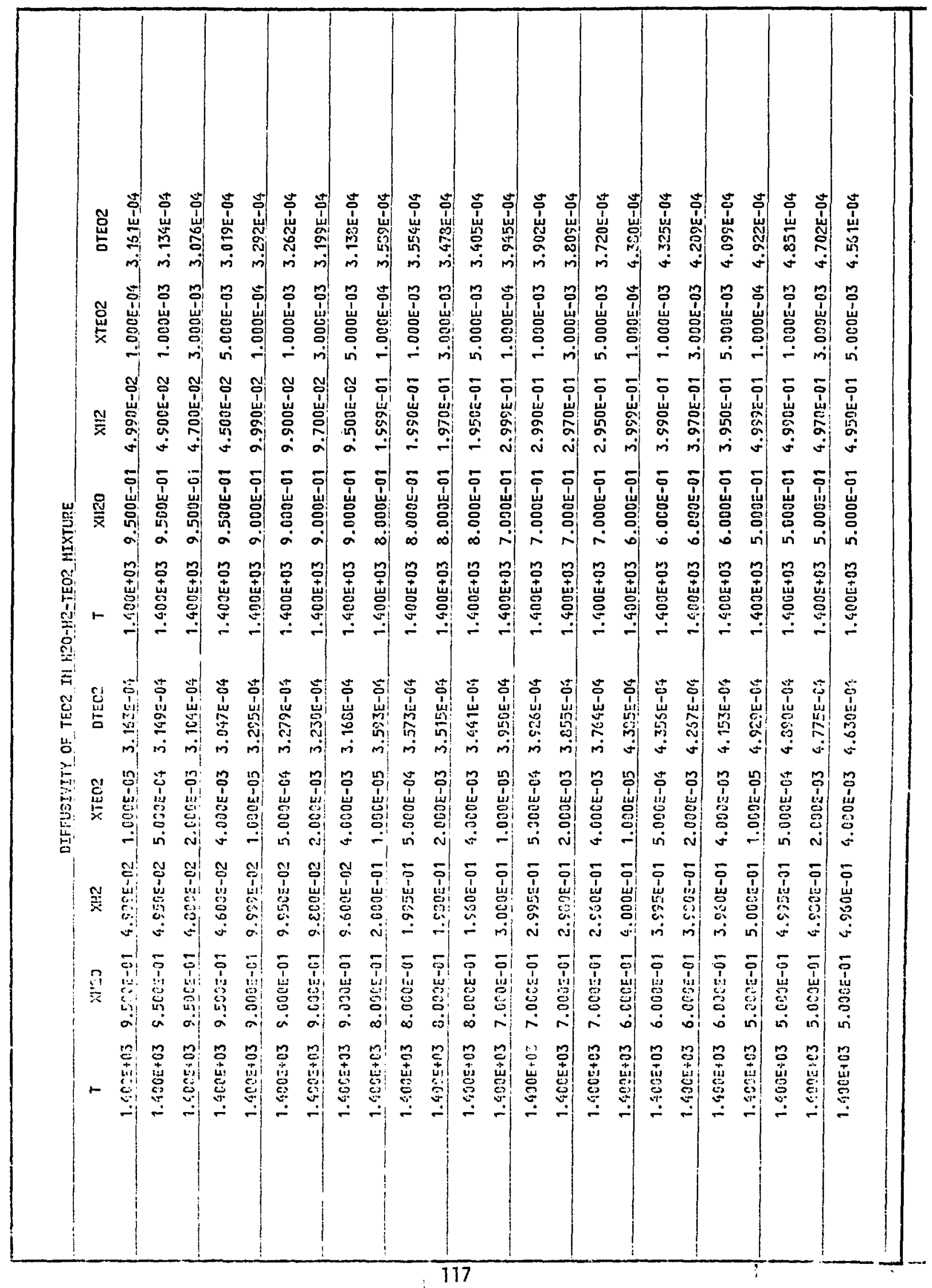




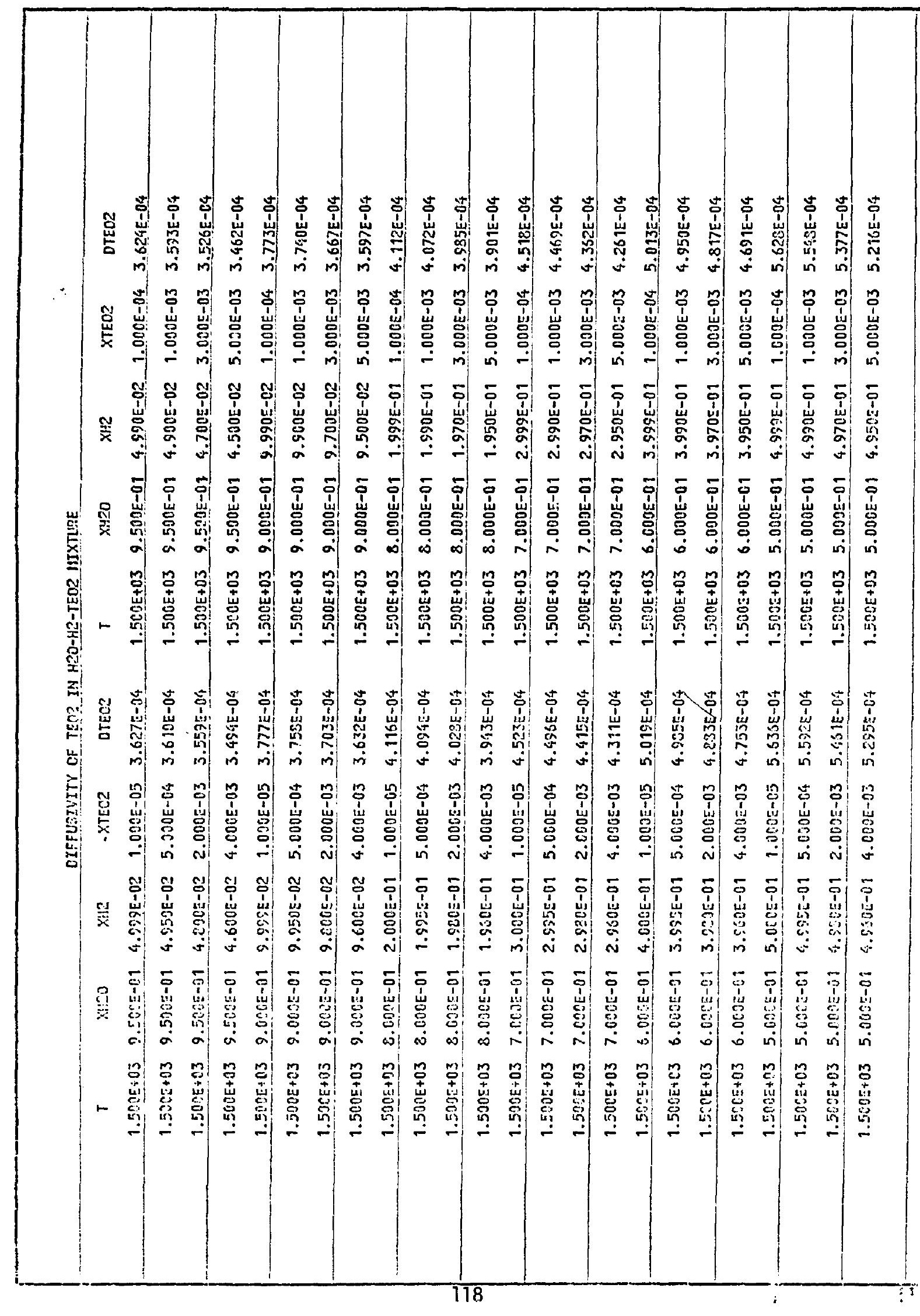




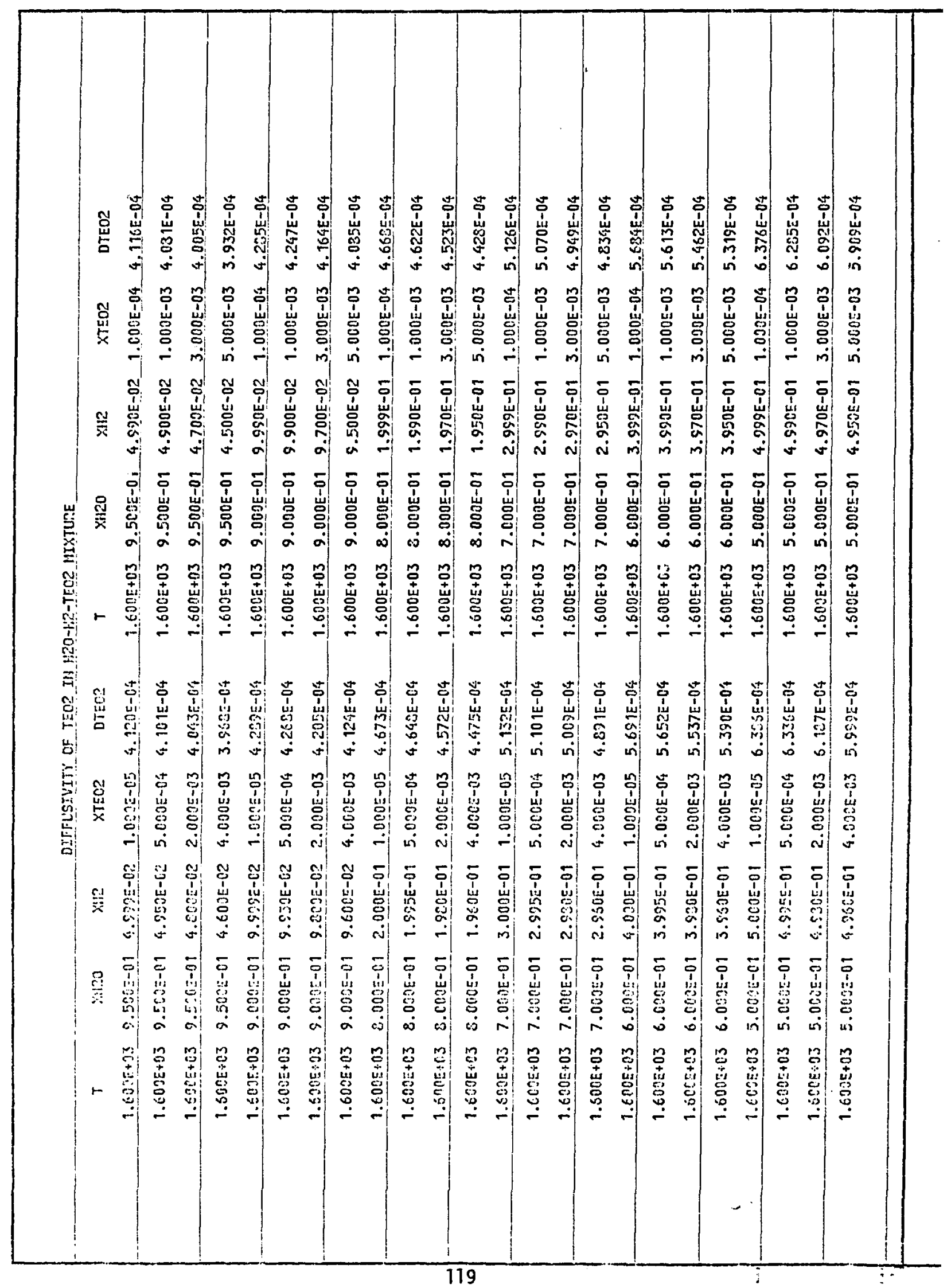




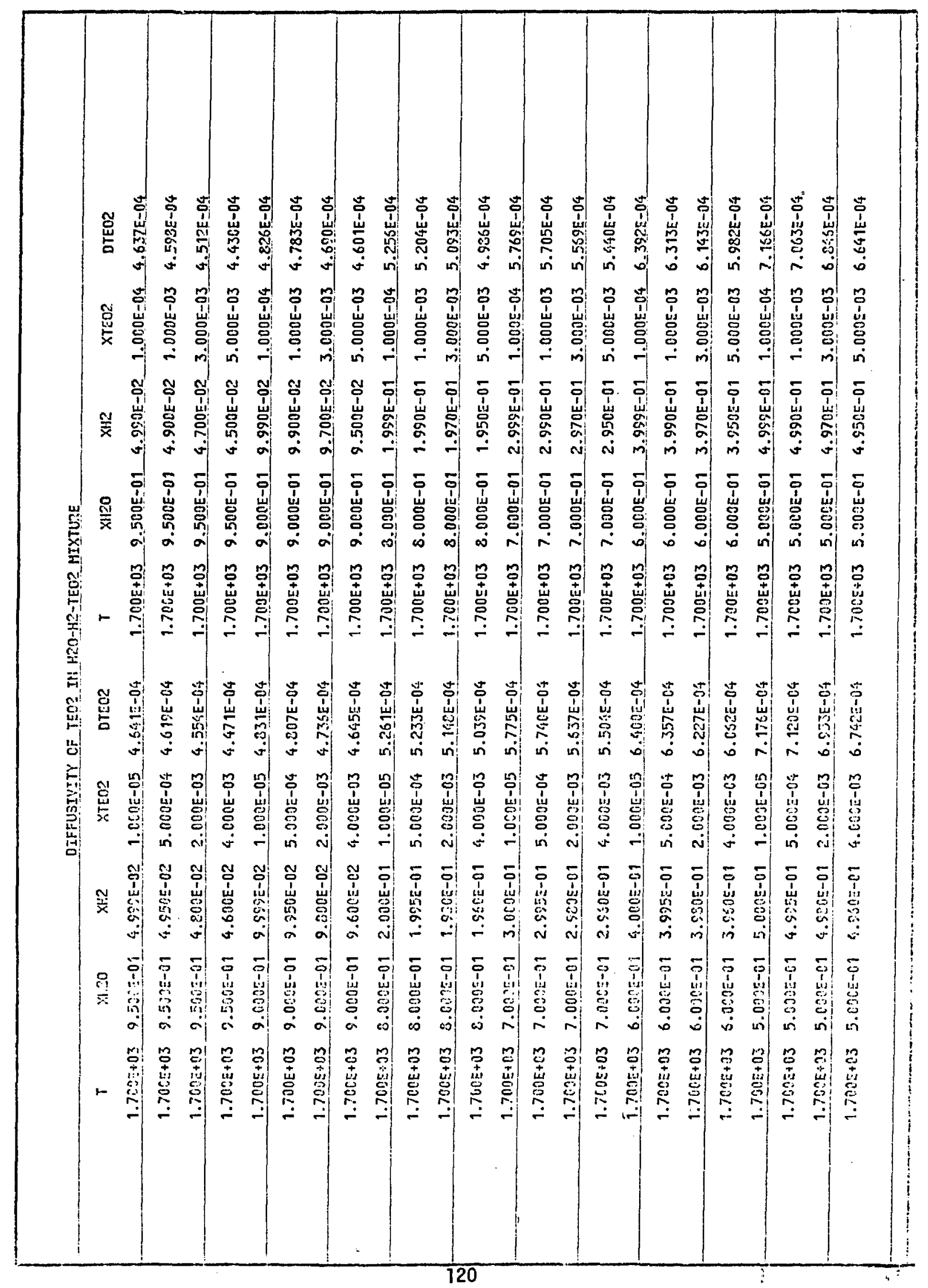




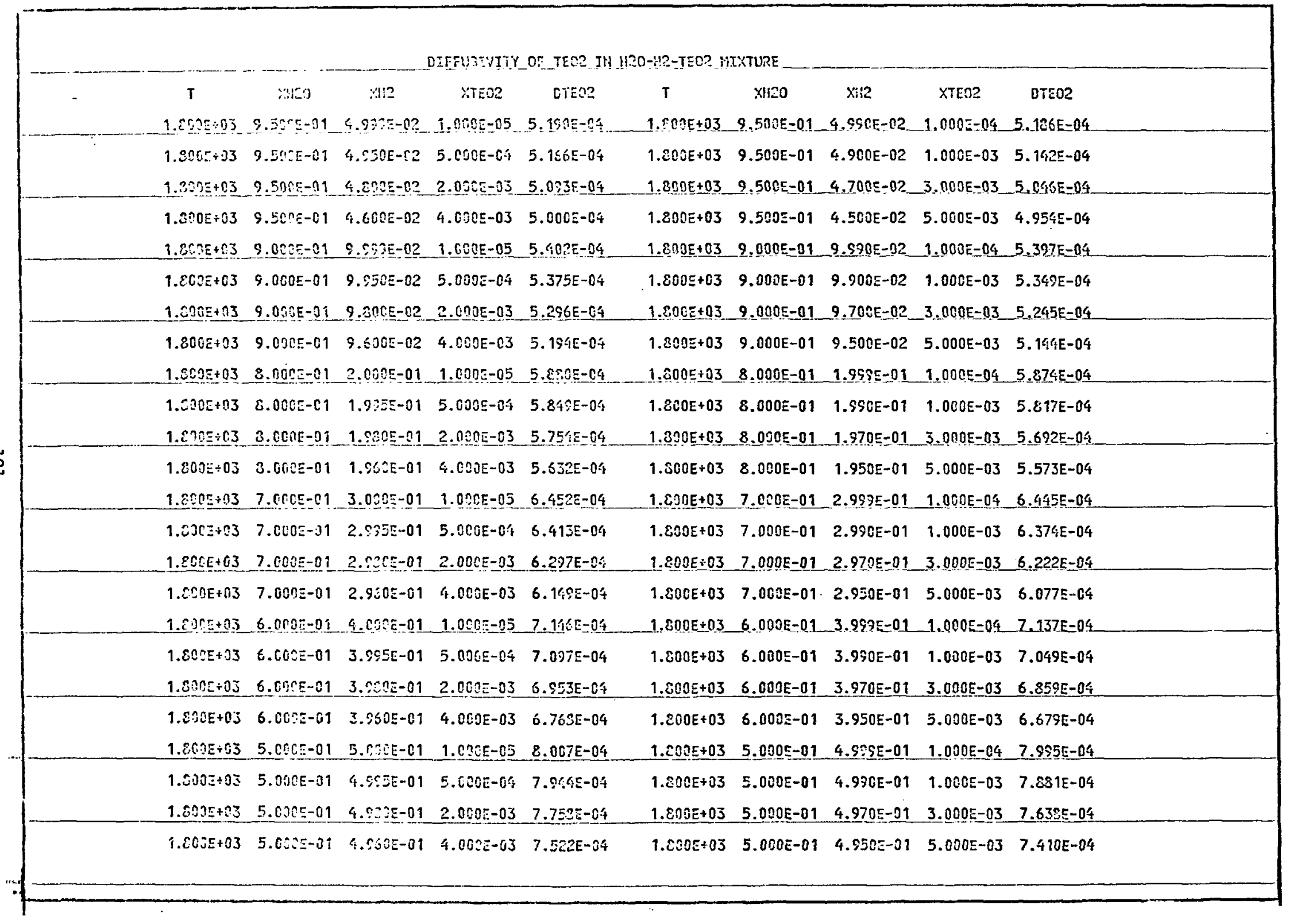




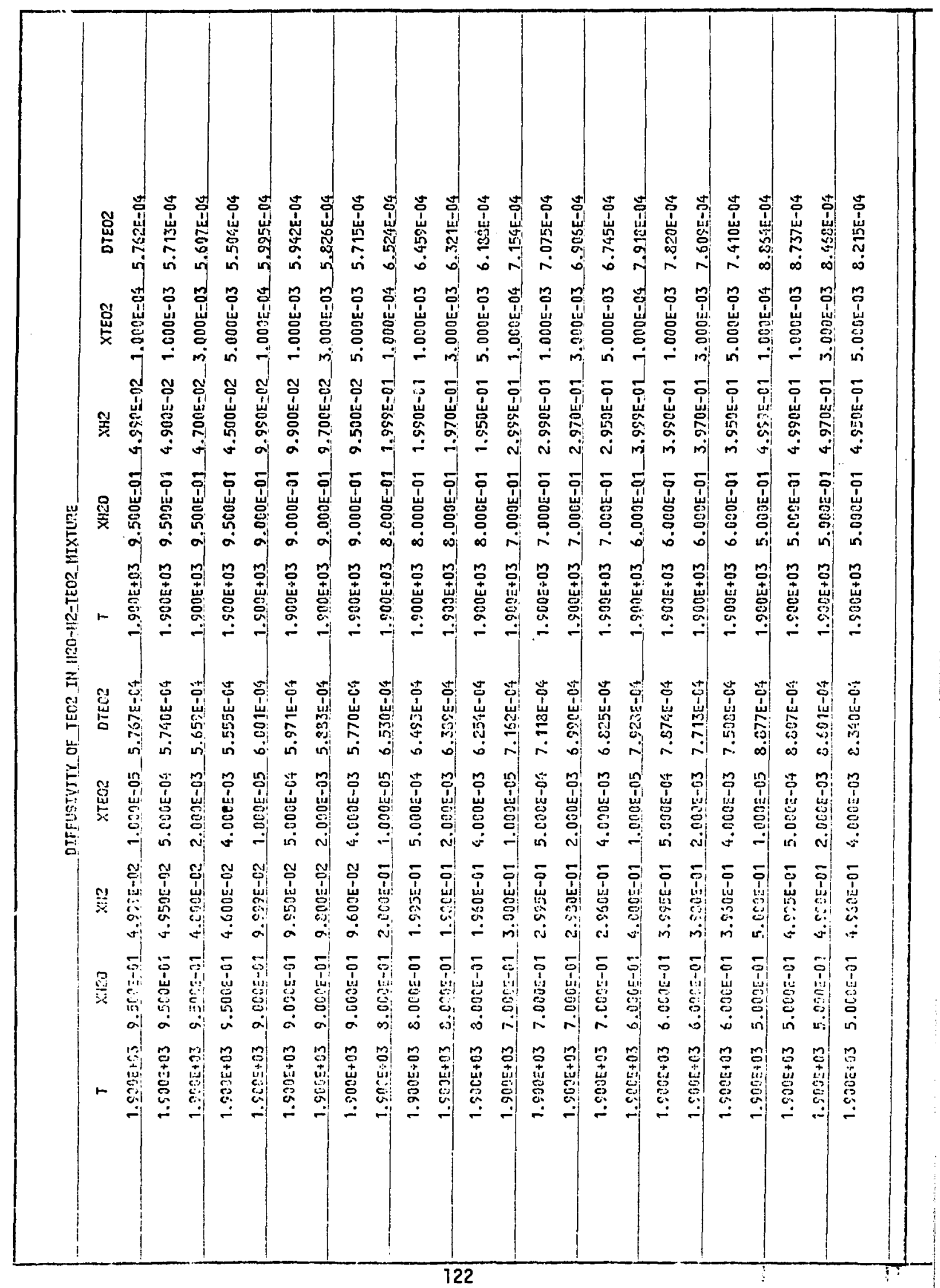




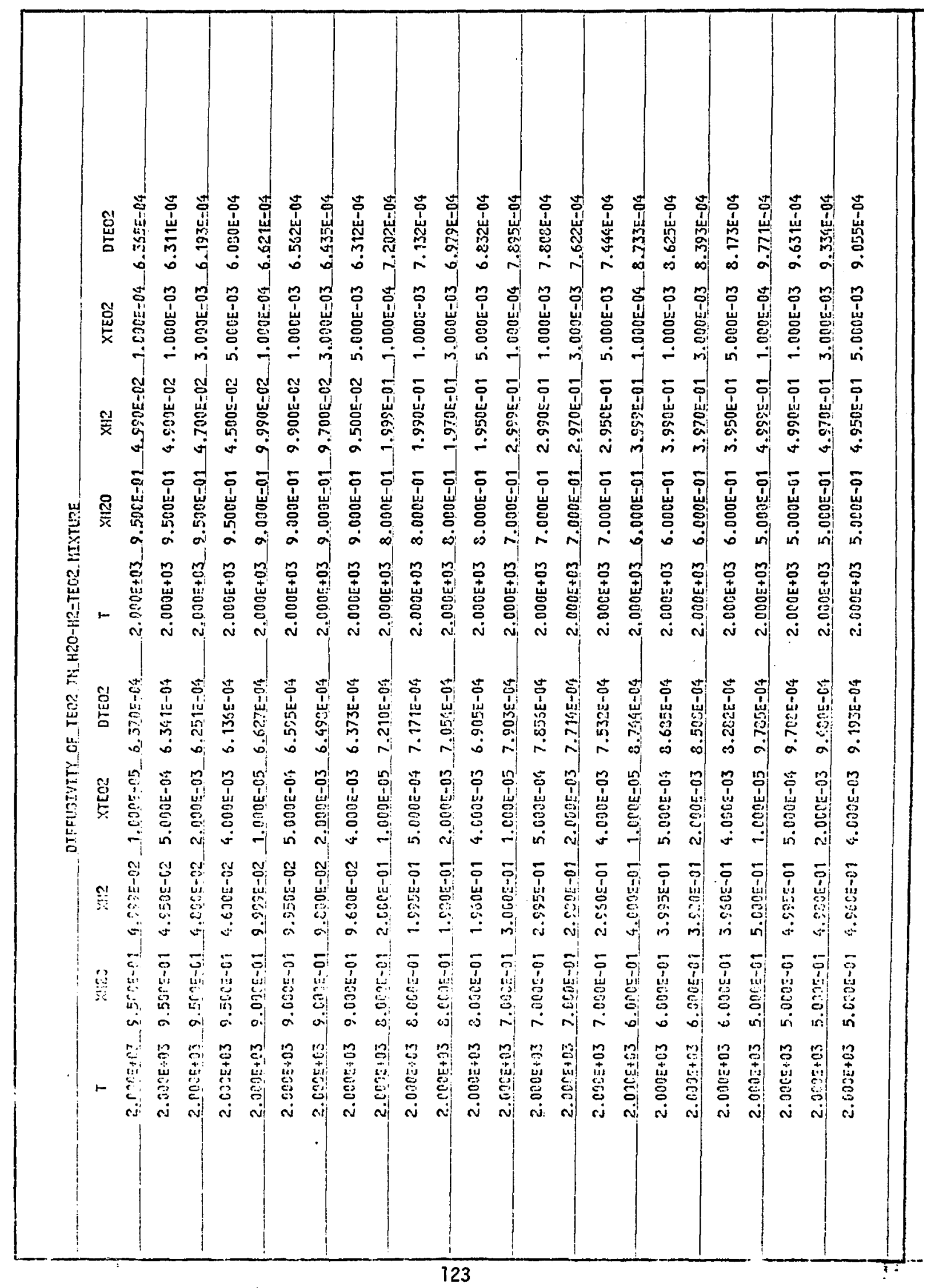




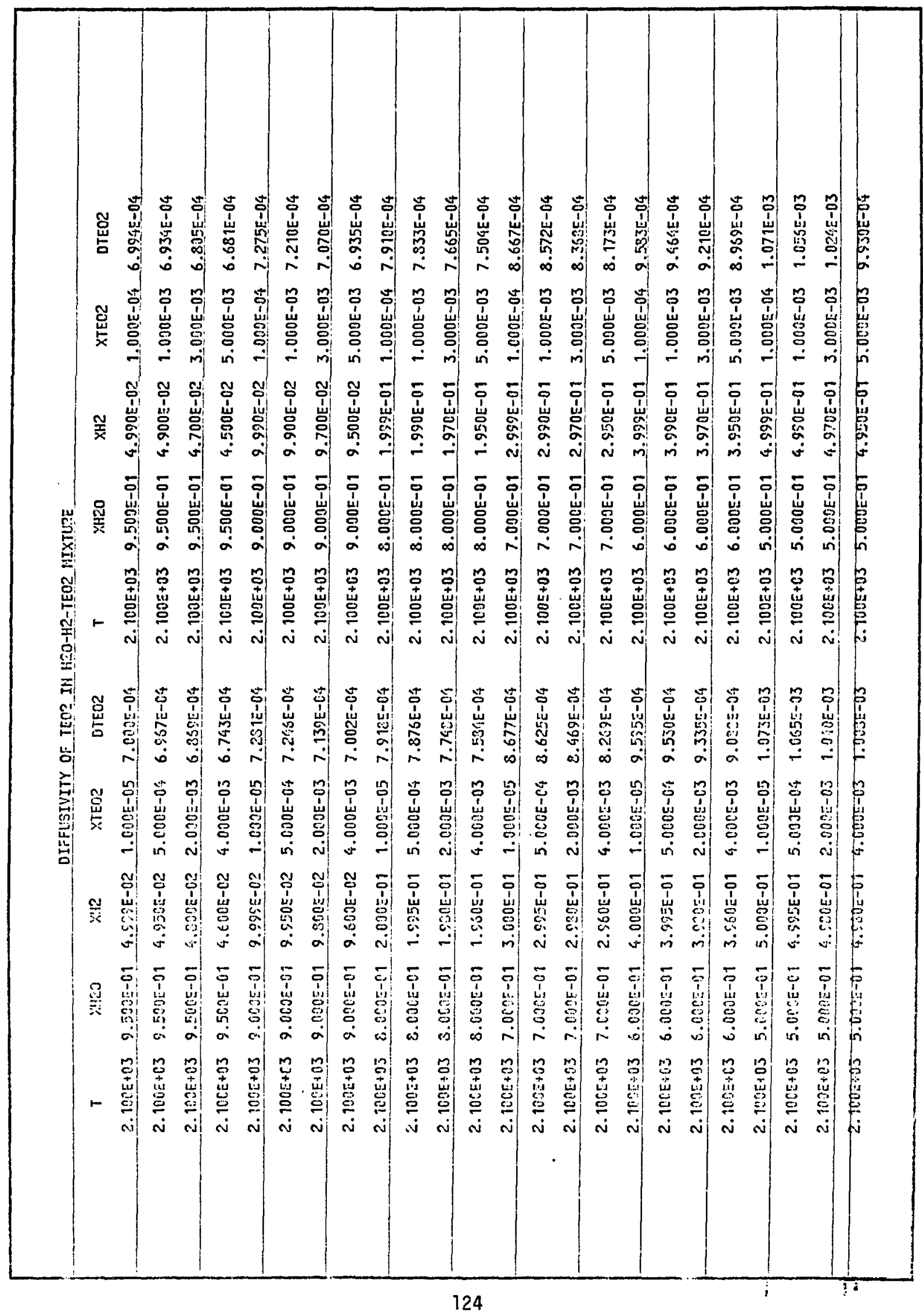




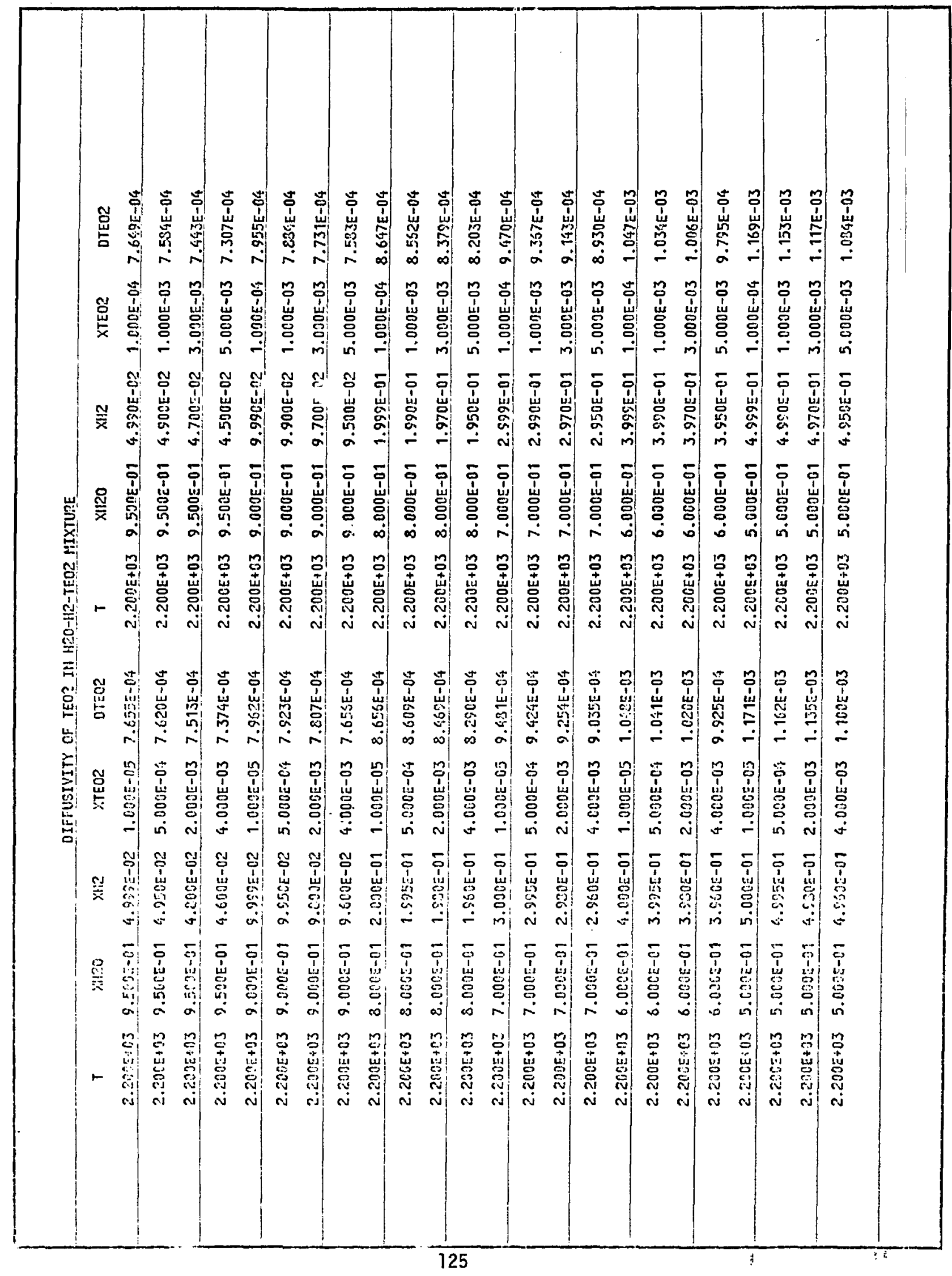




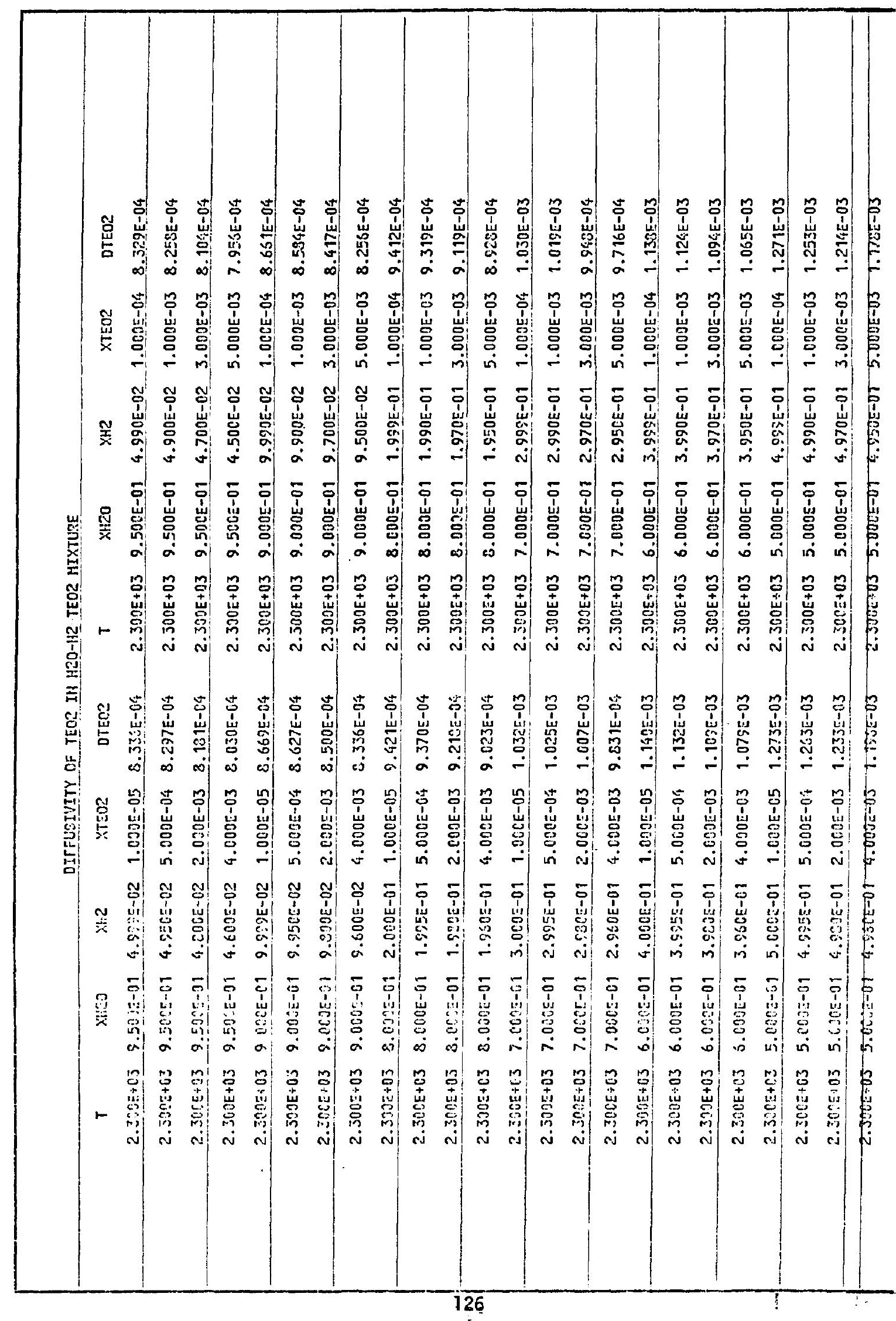




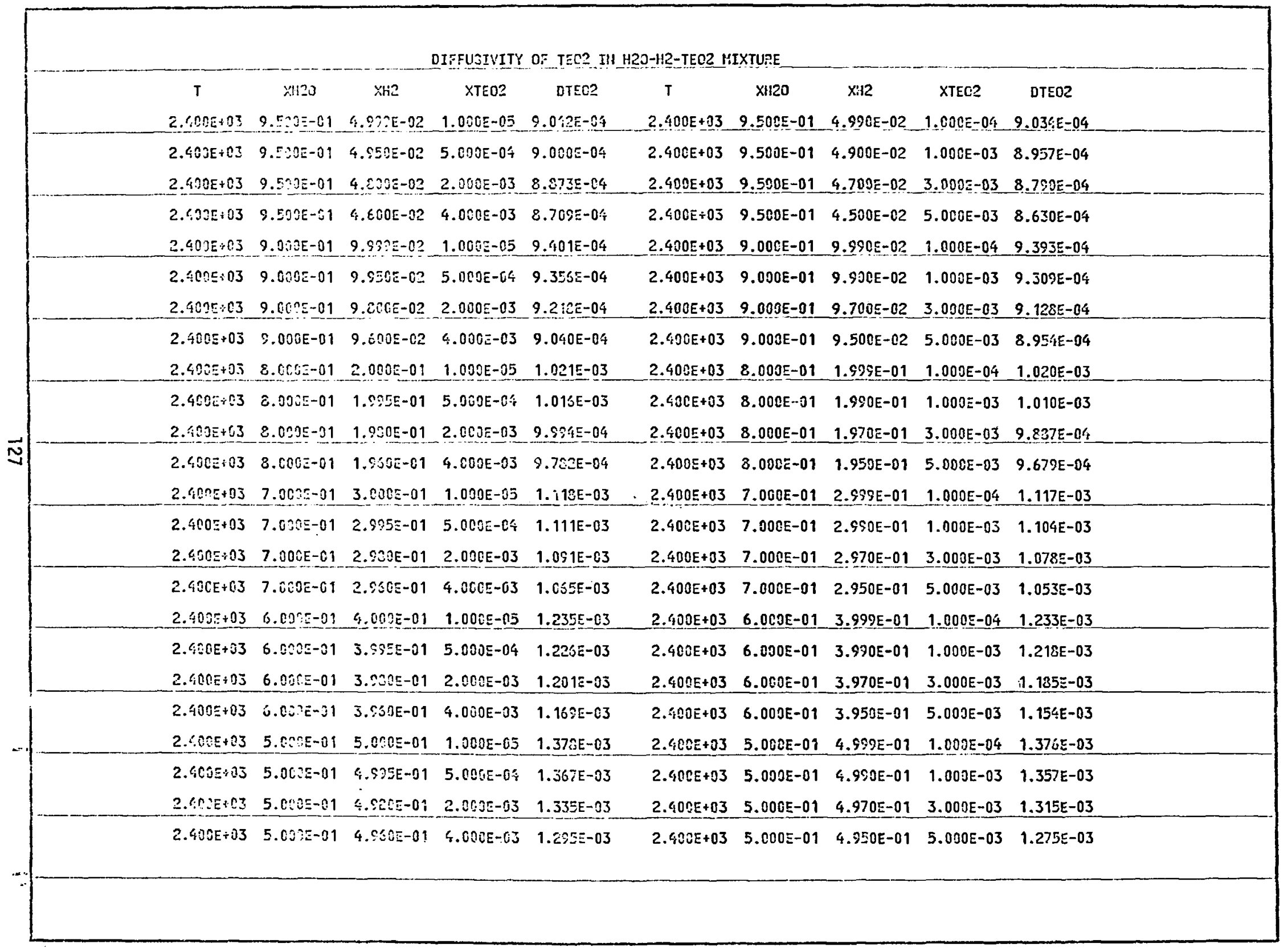




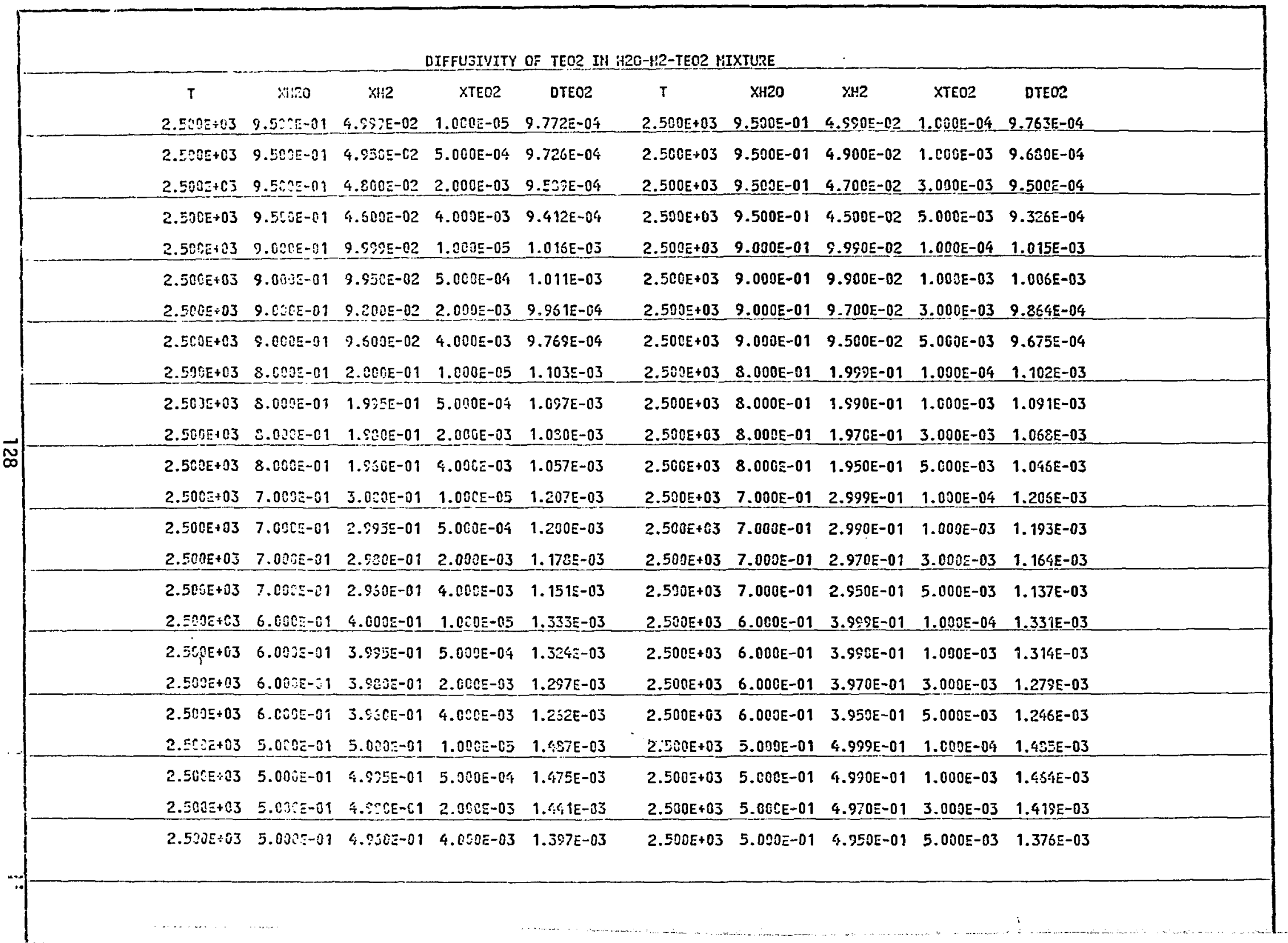




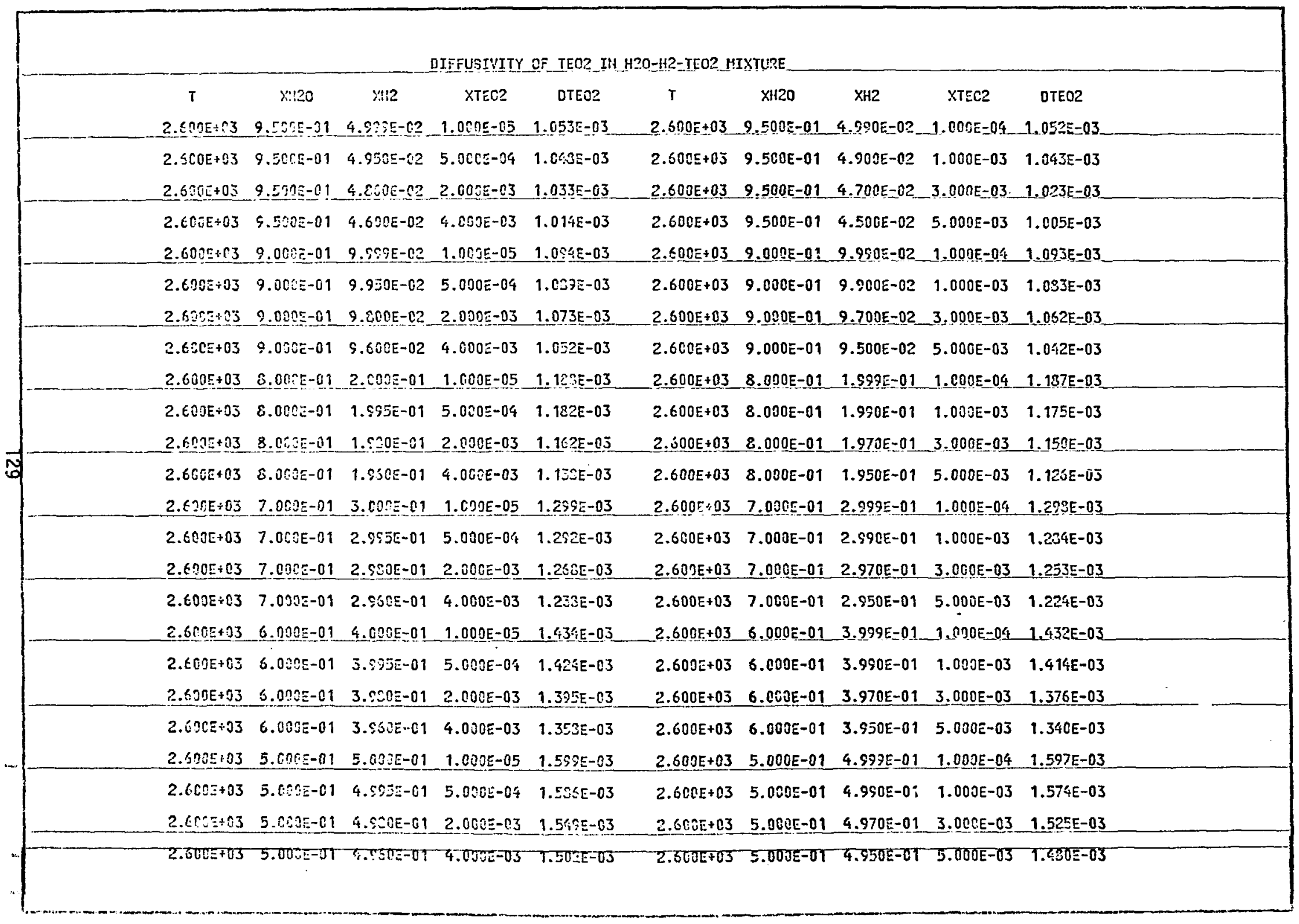




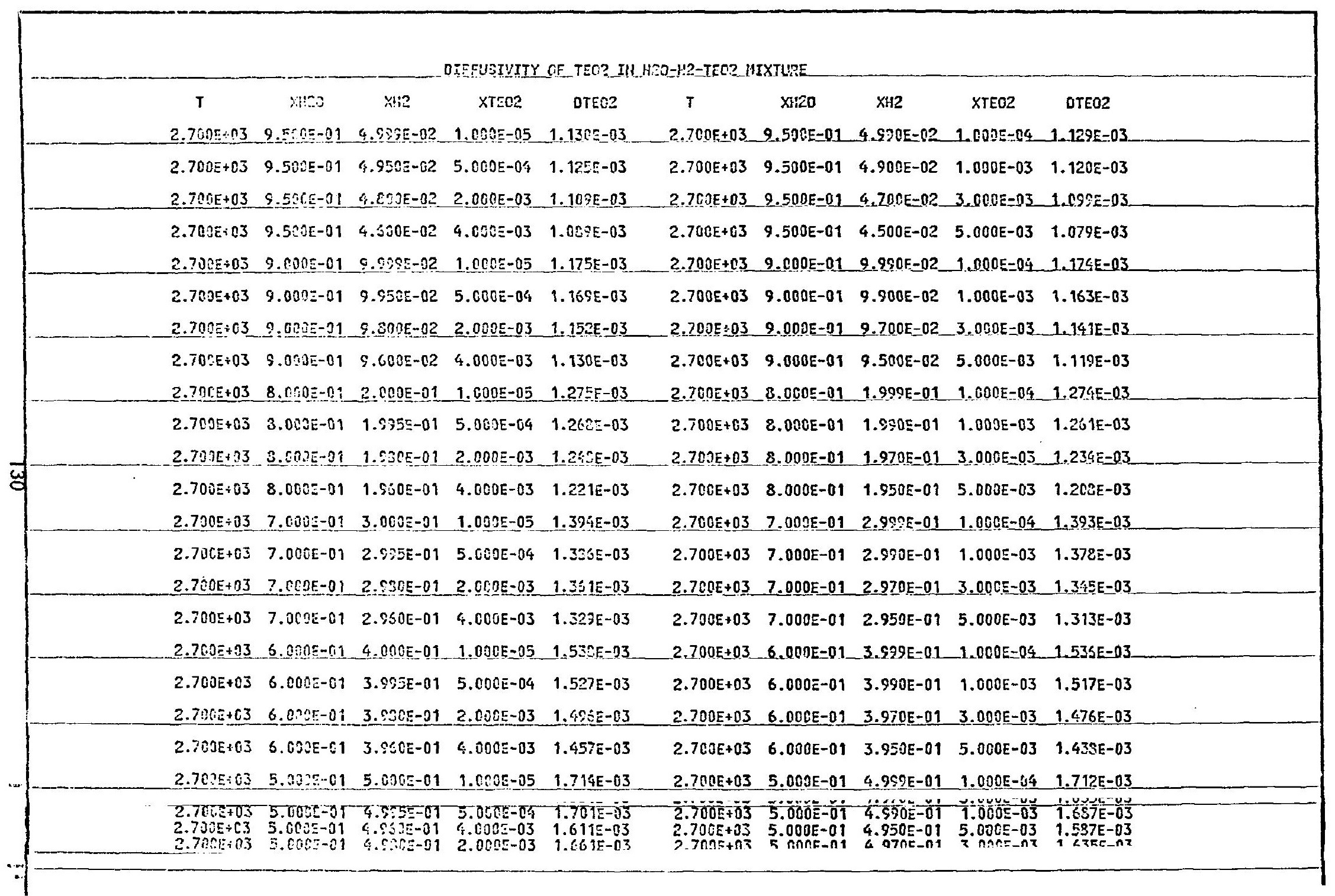




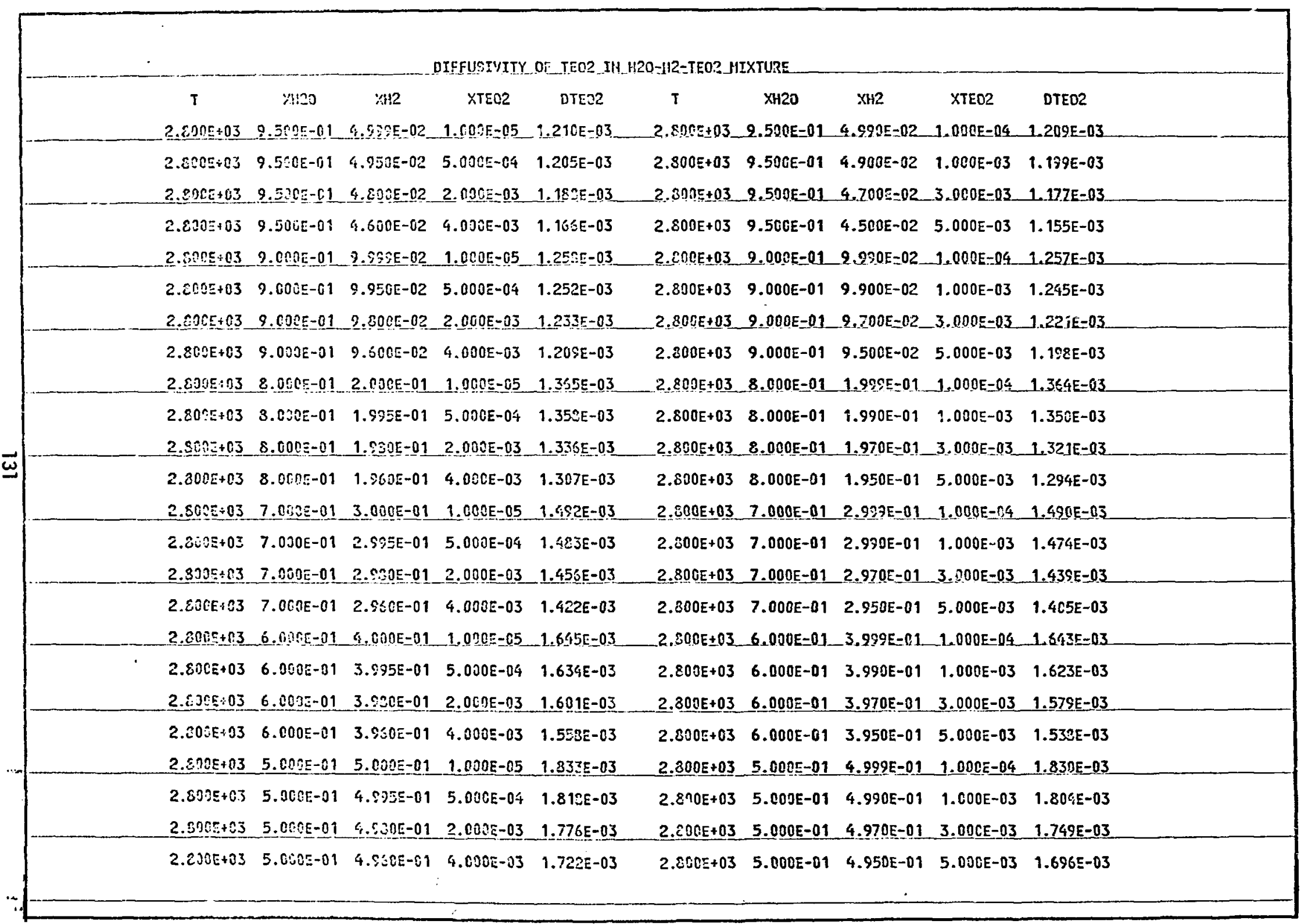




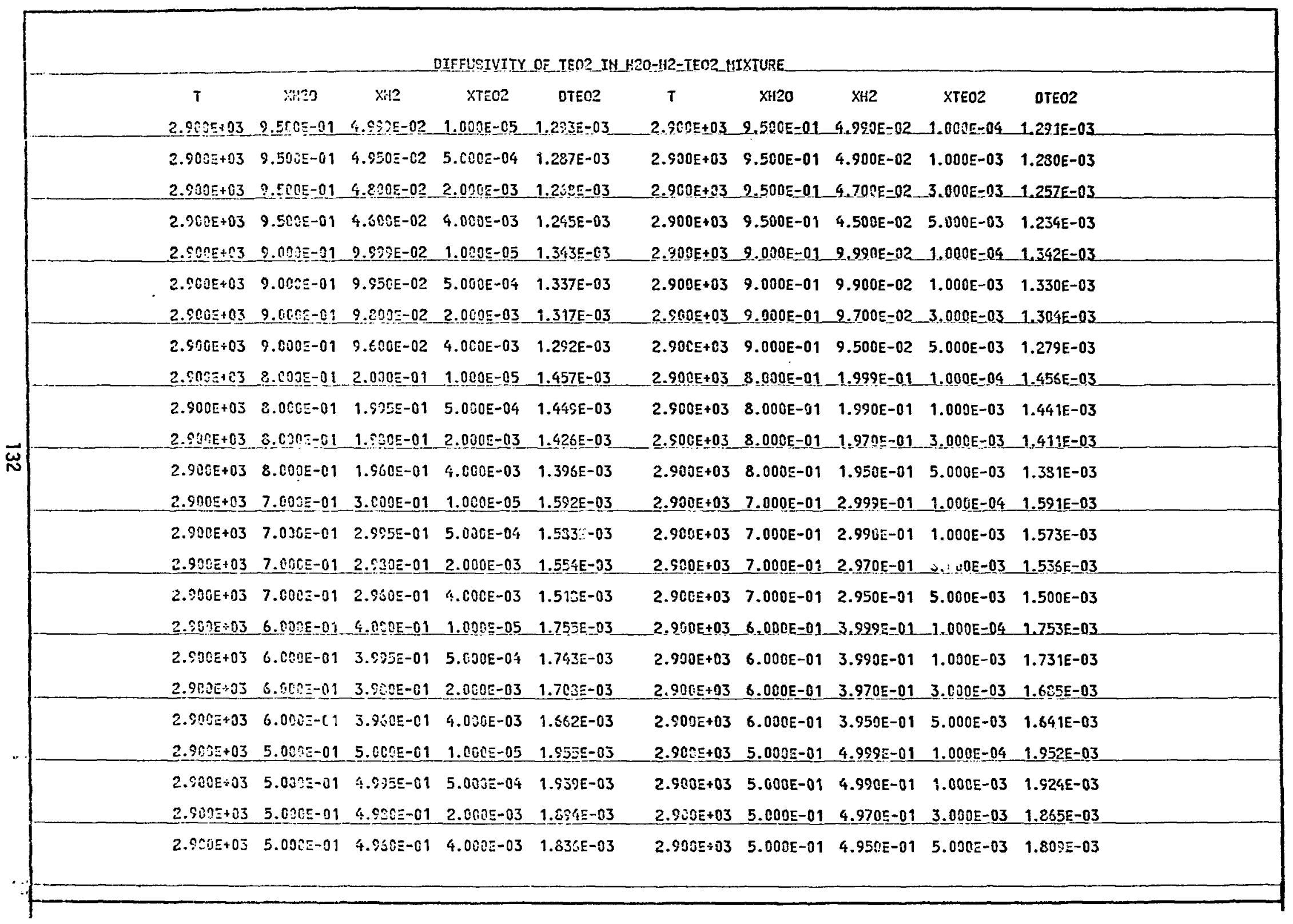




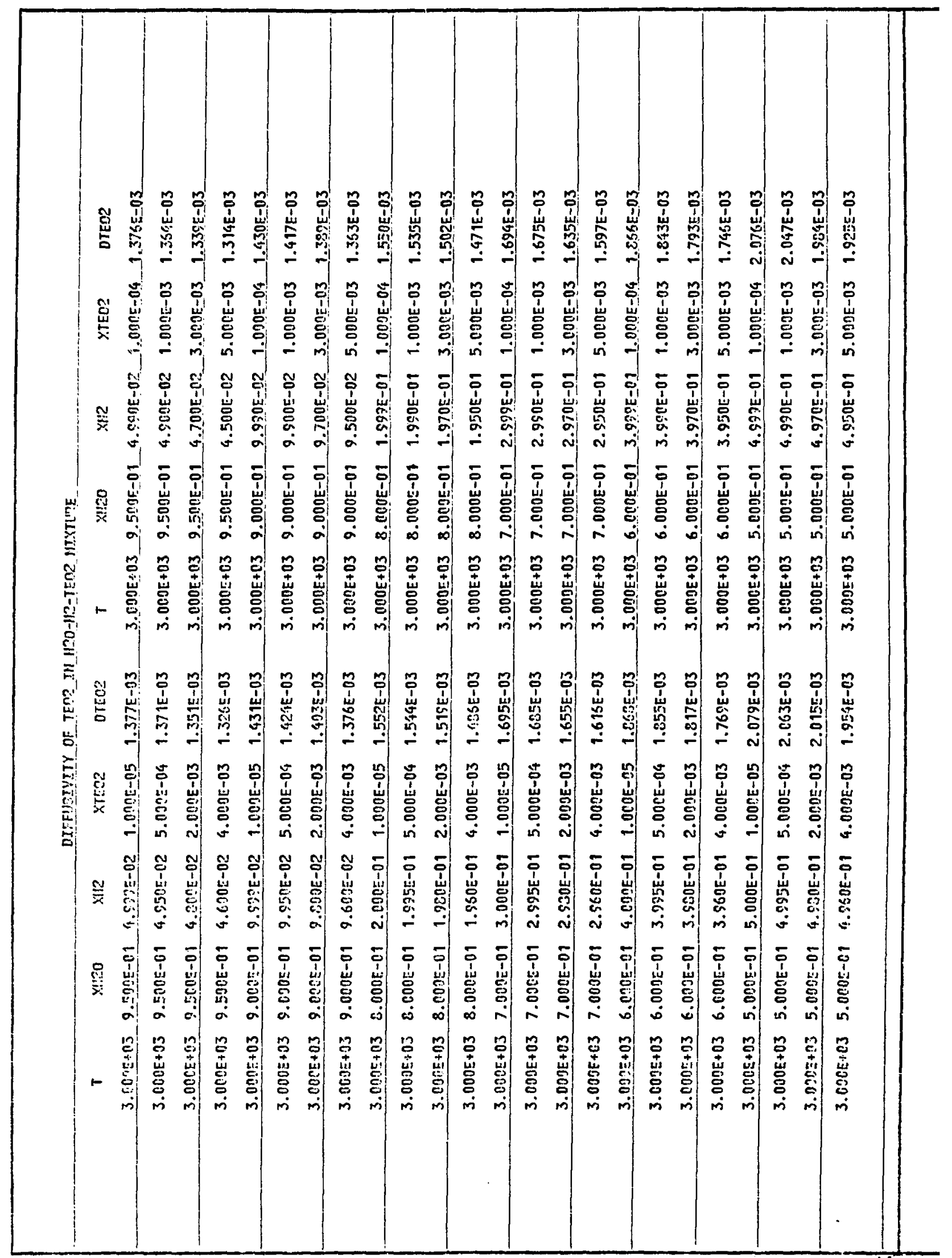




\section{Distribution for ANL/ENG/TM-01}

Internal:
P. B. Abramson
C. E. Dickerman
W. A. Ragland
R. K. Ahluwalia (10)
P. F. Dunn
C. B. Reed
R. Avery
J. B. van Erp
J. Rest
E. S. Beckjord
D. R. Ferguson
B. J. Schdeng
W. A. Bezella
J. Fink
C. A. Blomquist
A. J. Goldman
D. H. Shaftma
T. H. Braid
J. E. Herceg
L. Burris
K. H. Im (20)
R. Simms
M. G. Chasanov
K. D. Kuczen
D. H. Cho
C. E. Johnson
C. F. Chuang
L. Leibowitz
H. M. Chung
R. A. Lewis
K. S. Chung
J. F. Marchaterre
B. W. Spencer
A. M. Tentner
D. H. Thompso
C. E. Till
C. S. Wang
L. W. Deitrich
ANL Patentt De
ANL :-ibraries
$\mathrm{TT}, \mathrm{iles}(2)$

\section{External:}

DOE-TIC (2)

Manager, Chicago Operations office, DOE

T. M. Anderson, Westinghouse Electric Corporation

R. H. Buchholz, General Electric Co.

D. Cubiciotti, Electric Power Research Institute

J. A. Gieseke, Battelle Columbus Laboratories

R. K. Hilliard, Hanford Engineering Development Laboratory

T. S. Kress, Oak Ridge National Laboratory

J. T. Larkins, U. S. Nuclear Regulatory Commission

M. Levenson, Bechtel Power Corporation

S. Levine, NUS Corporation

P. F. MacDonald, Idaho National Engineering Laboratory

A. R. Millunzi, U. S. Department of Energy

H. A. Morewitz, Electric Power Research Institute

R. N. Oehlberg, Electric Power Research Institute

R. Peak, Hanford Engineering Development Laboratory

F. J. Rahn, Electric Power Research Institute

R. L. Ritzman, Science Applications Incorporated

R. A. Sallach, Sandia National Laboratories

W. R. Stratton, Los Al amos National Laboratory

R. C. Vogel, Electric Power Research Institute 